\title{
Paleontological discoveries in the Chorrillo Formation (upper Campanian-lower Maastrichtian, Upper Cretaceous), Santa Cruz Province, Patagonia, Argentina
}

\author{
Fernando. E. NOVAS ${ }^{1,2}$, Federico. L. AGNOLIN ${ }^{1,2,3}$, Sebastián ROZADILLA ${ }^{1,2}$, Alexis M. \\ ARANCIAGA-ROLANDO ${ }^{1,2}$, Federico BRISSON-EGLI', ${ }^{1,2}$, Matias J. MOTTA ${ }^{1,2}$, Mauricio \\ CERRONI ${ }^{1,2}$, Martín D. EZCURRA ${ }^{2,5}$, Agustín G. MARTINELLI' ${ }^{2,5}$, Julia S. D`ANGELO ${ }^{1,2}$, Gerardo \\ ALVAREZ-HERRERA ${ }^{1}$, Adriel R. GENTIL ${ }^{1,2}$, Sergio BOGAN ${ }^{3}$, Nicolás R. CHIMENTO ${ }^{1,2}$, Jordi \\ A. GARCÍA-MARSÀ ${ }^{1,2}$, Gastón LO COCO ${ }^{1,2}$, Sergio E. MIQUEL ${ }^{2,4}$, Fátima F. BRITO ${ }^{4}$, Ezequiel I. \\ VERA $^{2,6,7}$, Valeria S. PEREZ LOINAZE ${ }^{2,6}$, Mariela S. FERNÁNDEZ ${ }^{8}$ \& Leonardo SALGADO ${ }^{2,9}$ \\ ${ }^{1}$ Laboratorio de Anatomía Comparada y Evolución de los Vertebrados. Museo Argentino de Ciencias Naturales \\ "Bernardino Rivadavia”, Avenida Ángel Gallardo 470, Buenos Aires C1405DJR, Argentina - fernovas@yahoo. \\ com.ar. ${ }^{2}$ Consejo Nacional de Investigaciones Científicas y Técnicas, Argentina. ${ }^{3}$ Fundación de Historia Natural \\ "Felix de Azara", Universidad Maimonides, Hidalgo 775, C1405BDB Buenos Aires, Argentina. ${ }^{4}$ Laboratorio de \\ Malacología terrestre. División Invertebrados Museo Argentino de Ciencias Naturales "Bernardino Rivadavia", \\ Avenida Ángel Gallardo 470, Buenos Aires C1405DJR, Argentina. ${ }^{5}$ Sección Paleontología de Vertebrados. \\ Museo Argentino de Ciencias Naturales "Bernardino Rivadavia”, Avenida Ángel Gallardo 470, Buenos \\ Aires C1405DJR, Argentina. ${ }^{6}$ División Paleobotánica. Museo Argentino de Ciencias Naturales "Bernardino \\ Rivadavia”, Avenida Ángel Gallardo 470, Buenos Aires C1405DJR, Argentina. ${ }^{7}$ Área de Paleontología. \\ Departamento de Geología, Universidad de Buenos Aires, Pabellón 2, Ciudad Universitaria (C1428EGA) Buenos \\ Aires, Argentina. ${ }^{8}$ Instituto de Investigaciones en Biodiversidad y Medioambiente (CONICET-INIBIOMA), \\ Quintral 1250, 8400 San Carlos de Bariloche, Río Negro, Argentina. ${ }^{9}$ Instituto de Investigación en Paleobiología \\ y Geología de la Universidad Nacional de Río Negro, General Roca, Río Negro, Argentina
}

\begin{abstract}
The first fossil remains of vertebrates, invertebrates, plants and palynomorphs of the Chorrillo Formation (Austral Basin), about 30km to the SW of the town of El Calafate (Province of Santa Cruz), are described. Fossils include the elasmarian (basal Iguanodontia) Isasicursor santacrucensis gen. et sp. nov., the large titanosaur Nullotitan glaciaris gen. et sp. nov., both large and small Megaraptoridae indet., and fragments of sauropod and theropod eggshells. The list of vertebrates is also composed by the Neognathae Kookne yeutensis gen. et sp. nov., two isolated caudal vertebrae of Mammalia indet., and isolated teeth of a large mosasaur. Remains of fishes, anurans, turtles, and snakes are represented by fragmentary material of low taxonomical value, with the exception of remains belonging to Calyptocephalellidae. On the other hand, a remarkable diversity of terrestrial and freshwater gastropods has been documented, as well as fossil woods and palinological assemblages. The Chorrillo Formation continues south, in the Las Chinas River valley, southern Chile, where it is called Dorotea Formation. Both units share in their lower two thirds abundant materials of titanosaurs, whose remains cease to appear in the upper third, registering only elasmarians (Chorrillo Formation) and hadrosaurs (Dorotea Formation). Above both units there are levels with remains of invertebrates and marine reptiles. It is striking that the dinosaurs of the lower two thirds of the Chorrillo and Dorotea formations are represented by large basal titanosaurs and Megaraptoridae coelurosaurs, being the Saltasaurinae and Aeolosaurinae sauropods and Abelisauridae theropods totally absent. In contrast, these taxa are dominant components in sedimentary units of central and northern Patagonia (e.g., Allen, Los Alamitos, La Colonia formations). Such differences could reflect, in part, a greater antiquity (i.e., late Campanian-early Maastrichtian) for the Chorrillo fossils, or, more probably, different environmental conditions. Thus, knowledge of the biota of the southern tip of Patagonia is expanded, particularly those temporarily close to the K-Pg boundary.
\end{abstract}

Key words: Chorrillo Formation, Southern Patagonia, Late Cretaceous, fossils

Resumen: Hallazgos Paleontológicos en la Formación Chorrillo (Campaniano-Maastrichtiano, Cretácico Superior), Provincia de Santa Cruz, Patagonia, Argentina. Se describen los primeros restos fósiles de vertebrados, invertebrados, plantas y palinomorfos de la Formación Chorrillo (Cuenca Austral), aflorante unos $30 \mathrm{~km}$ al SW de la localidad de El Calafate (Provincia de Santa Cruz). Los fósiles de dinosaurios no avianos incluyen el elasmariano (Iguanodontia basal) Isasicursor santacrucensis gen. et sp. nov., el titanosaurio 
gigante Nullotitan glaciaris gen. et sp. nov., Megaraptoridae indet. de tamaños pequeño y grande, y fragmentos de cáscaras de huevo pertenecientes a saurópodos y terópodos. La lista de vertebrados se compone también del Neognathae Kookne yeutensis gen. et sp. nov., dos vértebras caudales aisladas de Mammalia indet., y dientes aislados de un mosasaurio de gran tamaño. Han sido colectados también restos de peces, anuros, tortugas y serpientes los cuales están representados por material fragmentario de escaso valor taxonómico, con la excepción de restos pertenecientes a Calyptocephalellidae. Por otra parte, ha sido documentada una notable diversidad de gasterópodos terrestres y dulceacuícolas, así como leños fósiles y asociaciones palinológicas. La Formación Chorrillo se continúa hacia el sur, en el valle del río Las Chinas, Chile, en donde es denominada Formación Dorotea. Ambas unidades comparten en sus dos tercios inferiores abundante material de titanosaurios, cuyos restos dejan de aparecer en el tercio superior, registrándose solo elasmarianos (Fm Chorrillo) y hadrosaurios (Fm Dorotea). Por encima de ambas unidades existen niveles con restos de invertebrados y reptiles marinos. Llama la atención que los dinosaurios de los dos tercios inferiores de las formaciones Chorrillo y Dorotea estén representados por titanosaurios basales de gran tamaño y celurosaurios Megaraptoridae, estando ausentes los Saltasaurinae, Aeolosaurinae y Abelisauridae, los cuales son componentes dominantes en las unidades sedimentarias del Maastrichtiano de la provincia de Chubut y del norte patagónico (p.ej., formaciones Allen, Los Alamitos y La Colonia, por ejemplo). Estas diferencias podrían reflejar, en parte, una mayor antigüedad (i.e., Campaniano tardío -Maastrichtiano temprano) para los fósiles de Chorrillo. Se amplía así el conocimiento de las biotas del extremo sur de Patagonia, en particular de aquellas temporalmente cercanas al límite K-Pg.

Palabras clave: Formación Chorrillo, Patagonia austral, Cretácico Tardío, fósiles.

\section{INTRODUCTION}

The Chorrillo Formation (Upper Cretaceous, Campanian-Maastrichtian; Arbe, 2002; Nullo et al., 2006) extensively crops out to the south of Centinela River, Santa Cruz Province, southern Patagonia, Argentina (Figure 1). The Chorrillo Formation extends NE to $\mathrm{SW}$ as a narrow band with a maximum E-W width of $2 \mathrm{kms}$. The Chorrillo Formation continues southward on the Chilean side, being partially equivalent to the Dorotea Formation (Upper Cretaceous, Campanian-Maastrichtian; Macellari et al., 1989; Vogt et al., 2014; González Abarca, 2015; Manriquez et al., 2019).

Feruglio (in Fossa Mancini et al., 1938) was the first to call "Estratos de Chorrillo" (i.e., "Chorrillo Beds") to these rocks cropping out to the south of the Argentino Lake, indicating the presence of fossil logs and dinosaur bones (Feruglio, 1944-45). Aside from these citations concerning the presence of unspecified dinosaur remains, the first to discover a partial sauropod skeleton was Francisco Nullo in 1980, then geologist of Argentine Geological Survey, while exploring the top of the hills of the Alta Vista farm ("estancia"). Nullo informed on the discovery to the renowned paleontologist José Bonaparte, who collected a partial cervical vertebra of such titanosaur specimen (see description below). Bonaparte illustrated the titanosaur bones -still yielding on the ground- in a popular book about South American dinosaurs (Bonaparte, 1996). From the same locality, Bonaparte also collected (but did not describe) some isolated theropod re- mains, including a partial ulna and a shed tooth, forming part of the Paleontological Collection of the Museo Argentino de Ciencias Naturales, in Buenos Aires.

Recent explorations carried out in La Anita and Alta Vista farms, approximately $30 \mathrm{~km} \mathrm{SW}$ from El Calafate city, allowed relocation of the titanosaur specimen discovered by Nullo, but also resulted in the discovery of novel vertebrate remains, which are described below. The explorations were carried out on from January $13^{\text {th }}-17^{\text {th }}$ and March $14^{\text {th }}-19^{\text {th }}, 2019$.

The complex topography of the region made the access somewhat difficult, even for $4 \mathrm{x} 4$ vehicles, thus long and exhausting walks were required to reach the fossil sites. Notwithstanding such circumstantial inconveniences, a rich collection of fossils made up by large titanosaur bone fragments, theropod remains, medium-sized ornithopods, tiny vertebrate bones, gastropods, and plant remains, starts to be amassed from this southern region of the Argentine Patagonia.

The fossil remains studied below, the first to be formally described from the Chorrillo Formation, shed valuable information on a wide variety of Late Cretaceous organisms in the southern cone, complementing the fossil record that has been obtained from equivalent stratigraphic levels in the geographically close Las Chinas River Valley, in southern Chile (Leppe et. al., 2014; González Abarca, 2015; Manriquez et al., 2019).

\section{GEOLOGICAL SETTING}

We follow the stratigraphic interpretations 
expressed by Nullo et al. (2006) in recognizing in the study area the following stratigraphic succession (from bottom to top): Alta Vista, La Anita, La Irene, Chorrillo, and Calafate formations. Both Alta Vista and La Anita bedrocks form the high cliffs of the homonymous farms. The dinosaur-bearing beds of the Chorrillo Formation form continuous outcrops on the high plateaus on the top of these hills (Figure 1). In Argentina these beds extend to the international border with Chile, close to the "Hito Baguales 2" (Figure 1; Nullo et al., 2006). The top of the Chorrillo Formation laterally inter-fingers and is overlaid by the marine Calafate Formation (Marensi et al. 2004; Odino Barreto et al., 2018). The rock succession comprehended by La Anita, La Irene and Chorrillo formations conforms an upper Campanian-early Maastrichtian regressive episode, started with the deltaic deposits of the La Anita Formation, and followed upwards by braided and meandering fluvial deposits of the La Irene and Chorrillo formations (Arbe \& Hechem, 1984; Macellari et al., 1989; Nullo et al., 2006; Moyano Paz et al., 2018; Tettamanti et al., 2018).

Tettamanti et al., (2018) synonymized Cerro Fortaleza, La Anita, La Irene, and Chorrillo formations under the name of "Upper Cretaceous Continental Deposits". We concur with these authors in interpreting these lithologically similar beds as part of a same diachronic episode of Campanian through Maastrichtian continental sedimentation. However, we prefer to keep the original lithostratigraphic names for these units, waiting for more paleovertebradological information from both Chorrillo and Cerro Fortaleza beds, eventually offering more confident age determinations for these beds.

Regarding the age of the Chorrillo Formation, it has to be no older than the underlying Early Campanian Alta Vista beds (the age of which is based on abundant marine invertebrates; Blasco et al., 1980; Nullo et al., 2006) and the Maastrichtian La Irene Formation (the age of which is based on palynological assemblages; Povilauskas et al., 2008). Moreover, the Chorrillo Formation inter-fingers to the SE with the shallow marine deposits of the Cerro Cazador Formation (Macellari, 1988), which yielded the associated presence of Eubaculites and Maorites, interpreted as early Maastrichtian in age (Nullo et al., 2006). The Chorrillo Formation is overlaid by the marine Calafate Formation, considered to be late Maastrichtian based on dinoflagelate cysts association (Marenssi et al., 2004; Guler et al.,
2005; Nullo et al., 2006). In sum, the dinosaurbearing, continental deposits of the Chorrillo Formation exposed at the top of the high plateaus of the La Anita and Alta Vista ranges, may be early Maastrichtian in age. Evidence from the equivalent Dorotea beds supports, however, that the lower thirds of the Chorrillo Formation be late Campanian, at least (see below).

The Argentine sequence formed by both the continental Chorrillo and the marine Calafate formations resembles the sedimentary unit that in southern Chile is named as Dorotea Formation (F. Nullo, pers. comm.). As Cecioni (1957) and Katz (1963) have noted, rock units cropping out on both sides of the international border are inseparable from a formational point of view. This observation also applies for Chorrillo plus Calafate (on the Argentine side) and Dorotea (in Chile), which exhibit almost the same lithological characteristics and fossil content. The Dorotea Formation includes basal and middle sections equivalent to Chorrillo, and an upper section resembling, both lithologically and in fossil content, to the Calafate Formation.

The stratigraphic succession of the Chorrillo Formation is made up by intercalated levels of greenish and reddish sandstones, intercalated by some conglomeratic banks. Important is to say that the following description is tentative, requiring for more detailed stratigraphic and sedimentological surveys. Immediately above the La Anita beds, the base of the Chorrillo Formation is characterized by green mudstones with fragmentary plant remains. Following upwards there is a bank of conglomerates and coarse sandstones containing abundant fossil wood and badly preserved leaves. These stratigraphic levels with abundant plant remains are replaced upwards by the already mentioned greenish and reddish sandstone levels, with an approximate thickness of $250 \mathrm{~m}$ (Nullo et al., 2006), containing dinosaur and other vertebrate remains. Such succession is capped by a meter thick sandstone bank, green in color, bearing abundant specimens of tiny bivalves (approximately 2-3 cm long), including ostreids, mytilids and pectinids (see below for taxonomic identification). The sequence of greenish and reddish sandstones is cyclic and monotonous, thus being difficult to recognize discrete members.

We informally separate the Chorrillo beds into three "levels", but this arbitrary subdivision pends on future sedimentological studies. The titanosaur bones originally discovered by F. Nullo come from the lower third of the formation, but 
remains of titanosaurs of similar size also come from the middle portion of the unit. A thick bank of conglomerates exposes on the base of the upper third of the Chorrillo Formation, and above it repeats again the alternate sequence of greenish and reddish sandstones bearing dinosaur remains. The upper levels of the Chorrillo Formation yielded abundant remains of different individuals of a single species of a basal iguanodontian, mixed with several shed teeth of a large, indeterminate mosasaur. The sequence ends with a conglomeratic level (approximately one-meter-thick), overlaid by a bank (roughly one meter thick) made up by slender and elongate bivalves (Gryphaeostrea cf. G. callophyla Ihering, 1903 and Cubitostrea cf. C. ameghinoi Ihering, 1902, indeterminate Mytilidae and Pectinidae; D. Pérez, B.Santelli, and M.Álvarez, pers. comm.). This couple of banks (conglomerate plus bivalves) represents the base of the Calafate Formation.

For southern Chile, Manriquez et al., (2019) described the stratigraphic sequence of the Dorotea Formation and its fossil content. At the base of the formation, they identified leaf impressions of a variety of taxa; from the middle section (exposed in a fossil spot they name "Saurópodo") they described (in addition to plants) titanosaur, ornithischian, and bird bones, turtle and frog fragments, and mammal and theropod teeth. The paper by Manriquez et al. (2019) does not specify the taxonomic referral of the fossils collected, and no reference of the completeness of the collected materials is offered. However, such fossil assemblage from the "Saurópodo Member" looks similar to the lower and mid-sections of the Chorrillo Formation. Interesting is to say that the levels of "Saurópodo Member" are comprehended by radiometric datings below $(74.9 \mathrm{my})$ and above (71.7my), thus strongly suggesting these deposits correspond to the Campanian-Maastrichtian boundary (Manriquez et al., 2019).

In sum, general aspect of Chorrillo plus Calafate beds resembles the sequence of Dorotea beds, suggesting these units represent a same sedimentary sequence. However, precise correlation between these beds requires further stratigraphy survey of the entire region. Besides, future exploration and study also need to be done to elucidate if the Chorrillo Formation is equivalent or not with the dinosaur-bearing, continental deposits of the Cerro Fortaleza Formation (radimetrically dated as Campanian; Sickman et al., 2018), exposed north of Argentino Lake, on both margins of the La Leona River.

\section{MATERIALS AND METHODS}

\section{Study area}

The fossil remains come from different spots and stratigraphic levels, within an area of approximately $2000 \mathrm{~m}^{2}$ (Figure 1 ). The fossil spots are the following:

-Nullo site (locality 1): Yielded six titanosaur bone accumulations, which do not necessarily correspond with discrete individuals. Stratigraphically it corresponds to the lower third of the Chorrillo Formation.

-Titanosaur tibia site (locality 2): This place provided a single, well preserved titanosaur tibia, titanosaur eggshells, sauropod teeth, theropod eggshells, avian coracoid, snake vertebra, and fish teeth. This site yielded the woods described above. Stratigraphically it corresponds to the lower third of the Chorrillo Formation.

-Megaraptorid site (locality 3): This place provided fragments of a single large, indeterminate Megaraptoridae, represented by 2 vertebrae, proximal pubis and rib fragments. Invertebrate bioturbations were found in close proximity. Stratigraphically this locality corresponds with the middle portion of the Chorrillo Formation.

-Puma cave site (locality 4): 50 specimens of terrestrial molluscs have been collected from mid-levels of the Chorrillo beds, in close proximity to mammalian, turtle, snake, ornithopod and theropod bone remains, and sauropod teeth. Six articulated caudal vertebrae of a large titanosaur come from $10 \mathrm{~m}$ far from this fossil spot. All these specimens were produced by the same stratigraphic level, corresponding to the middle portion of the Chorrillo Formation.

-Ornithopod site (locality 5): Association of different sized specimens corresponding to a single, new species of an elasmarian ornithopod, represented by vertebrae, phalanges, a, and metatarsals. Found in close association with seven mosasaur teeth. Stratigraphically it corresponds to the upper third of the Chorrillo Formation, roughly 20 meters below the beds with marine molluscs (interpreted as the base of the Calafate Formation).

\section{Collected material}

The collected materials belong to the collection of the Museo Padre Molina, Río Gallegos, Santa Cruz province. Some specimens, coming from the same site and stratigraphic levels, were collected in 1981 by J.F. Bonaparte and are housed at the Vertebrate Paleontology Collection, Museo Argentino de Ciencias Naturales "Bernardino 


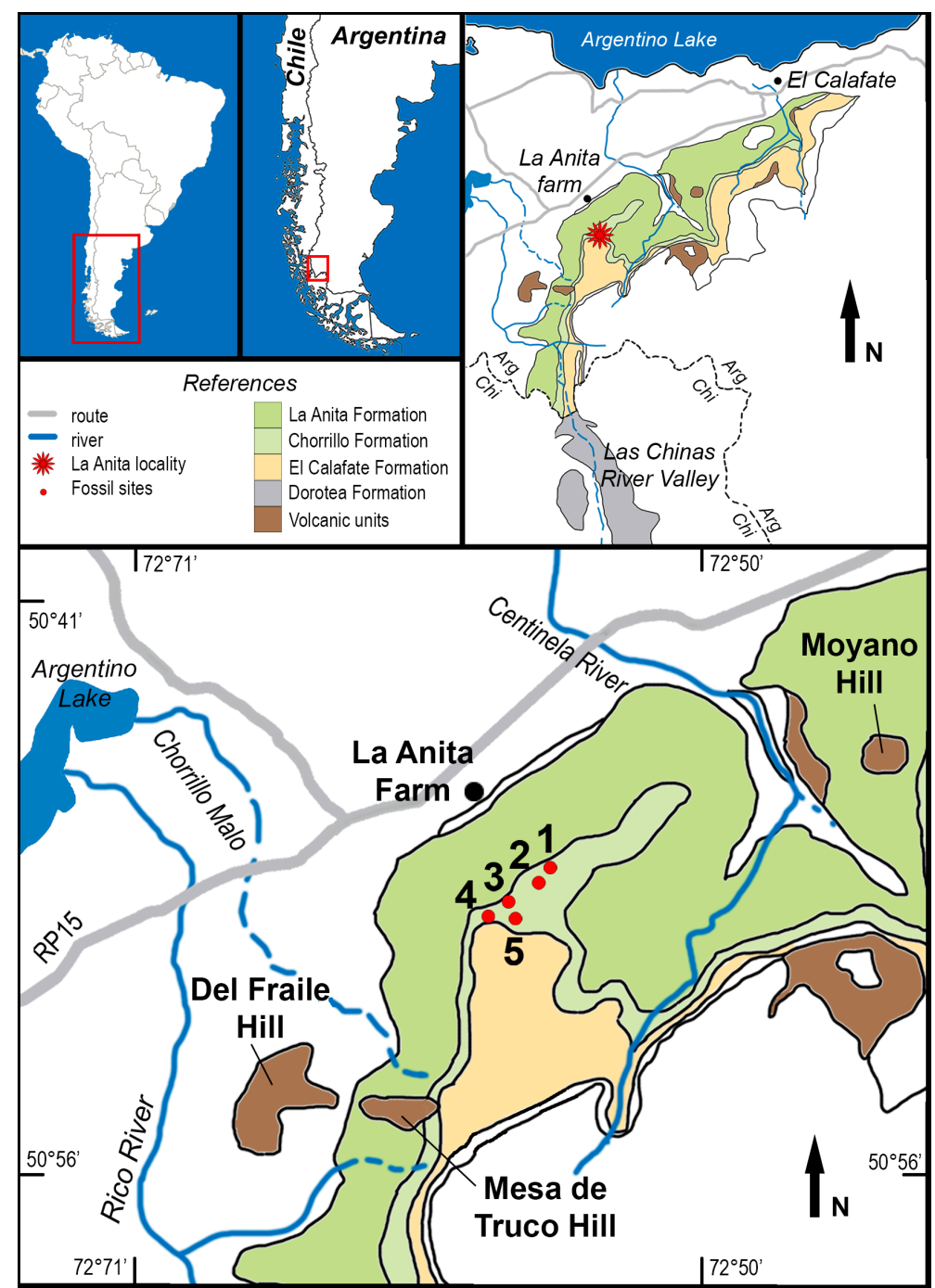

Figure 1. Map showing studied area. Numbers 1 through 5 indicate the localities from which fossil specimens were collected.

\section{Rivadavia" (MACN), Buenos Aires.}

\section{Specimen preparation}

Vertebrates were extracted and prepared as is the usual technique in vertebrate paleontology. Most bones here described do not need mechanical preparation because they were found free of sediment in most cases. The bones that were embedded in sedimentary matrix were prepared with mechanical hammers at the Laboratorio de Anatomía Comparada y Evolución de los Vertebrados preparation lab.

The fossil woods were thin-sectioned in transverse (TS), longitudinal tangential (TLS) and longitudinal radial (RLS) sections, and stu- died using light Microscopy (Olympus BX51). At least 25 measures were taken, and data is given as the mean and standard deviation, and range (in parenthesis). For the generic classification of the studied woods we followed the key for fossil genera proposed by Philippe \& Bamford (2008). Descriptive terminology used here follows the IAWA list of microscopic features for softwood identification (Baas et al., 2004), with the addition of terms defined in Philippe and Bamford (2008), seriation and contiguity indices proposed by Pujana et al. (2016). Pit counting method follows suggestions made by Philippe et al. (2013). The palynological samples were treated following standard techniques for extraction and 
concentration of palynomorphs (Volkheimer \& Melendi, 1976). Observations were made with an Olympus BX-51 microscope while photographs were taken with an Olympus DP25 digital camera. Coordinates of the illustrated specimens are given as England Finder coordinates.

\section{Institutional abbreviations}

MPM, Paleontological Collection, Museo Regional Provincial "Padre Molina", Río Gallegos, Santa Cruz province, Argentina; MACN-Pv, Paleontological Vertebrate Collection, RN, Río Negro Collection, Museo Argentino de Ciencias Naturales "Bernardino Rivadavia", Buenos Aires, Argentina.

\section{SYSTEMATIC PALEONTOLOGY}

Vertebrata Cuvier, 1812

Teleostei Müller, 1844

Genus and species indeterminate

Referred material: MPM 21516, three crushing tooth crowns (locality 4) (Figure 2E-G).

Description: Three isolated crushing teeth crowns have been collected. The largest one is $13 \mathrm{~mm}$ in diameter. They are subcircular in contour in occlusal view, with a gently convex occlusal surface, and a concave ventral surface. The tooth bases show concentric growth lines on the ventral side.

Comments: Crushing teeth similar to those described here resemble pharyngeal teeth of semionotiforms, sparids, sciaenoids, and basal percoids, among others (e.g., Cione, 1987). Similar teeth were previously reported from the Maastrichtian Loncoche (González Riga, 1999; Previtera \& González-Riga, 2008), Los Alamitos (Cione, 1987), and Allen (Martinelli \& Forasiepi, 2004) formations. The semionotiform genus Lepidotes, was repeatedly reported from Argentina, and South America (Arratia \& Cione, 1996). These semionotiforms bear crushing vomerine teeth, with short roots and exceptionally broad and rounded crowns, thus differing from the low crowns with concave roots here described (see Jain, 1985). Information at hand forbids referral of crushing teeth from the Chorrillo beds to any particular teleostean clade.

Amiiformes Hay, 1929

Amiidae Bonaparte, 1838

cf. Vidalamiinae Grande \& Bemis, 1998

Genus and species indeterminate
Referred material: MPM 21517, isolated tooth (locality 2) (Figure $2 \mathrm{H}$ ).

Description: This is a lanceolate and acute tooth, with vitreous enamel surface. Under the enamel layer there is a relatively thick layer of dentine constituted by vascular canals. At its base, the tooth is not crenulated, indicating the absence of plicidentine. Tooth crown possesses elongated, narrow peduncles which are constricted below the apex. The apex is formed by a short, translucent, and flattened acrodin cap with both acute mesial and distal carinae.

Comments: The combination of lanceolate teeth lacking plicidentine at its base (presence of plicidentine is typical of lepisosteiforms; Cione, 1987; Grande, 2010) and a translucent cap with mesial and distal carinae is diagnostic of vidalamiine amiiform fishes (Grande \& Bemis, 1998; Martinelli et al., 2013). In spite of such similarities, the isolated nature of MPM 21517 precludes a more accurate determination.

The fossil record of Mesozoic amiiforms in the southern Hemisphere is strongly biased (Grande \& Bemis, 1998; Martinelli et al., 2013; Brito et $a l_{.2}$ 2017). From the southern cone, only three localities have yielded amiid remains (Bogan et al., 2010, 2013), of which only two (i.e., El Anfiteatro and Cerro Tortuga localities, Río Negro province, Argentina; Bogan et al., 2010) belong to the Late Cretaceous. Because of their fragmentary nature, these remains from Río Negro have indeterminate affinities below family level. Present report, if correctly identified, constitutes an important addition to the meager record of the clade for the continent, and may represents the southernmost record for Amiiformes.

\section{Anura Fischer von Waldheim, 1813}

Genus and species indeterminate

Referred material: MPM 21518, isolated tibiofibula (locality 4) (Figure 2D).

Description: The distal halves of a tibia and a fibula have been collected. These bones are separated by a narrow and relatively shallow longitudinal groove. The distal end of each bone is subcircular in cross-section. Based on preserved fragments, the tibiofibula may have been measured $25 \mathrm{~mm}$ when complete.

Comments: The presence of an elongate and fused tibiofibula is a feature diagnostic of anurans (Jenkins \& Shubin, 1998). However, the morphology of the distal half of tibiofibula lacks diagnostic features to offer a more precise allocation within the clade. Present specimen, to- 
A
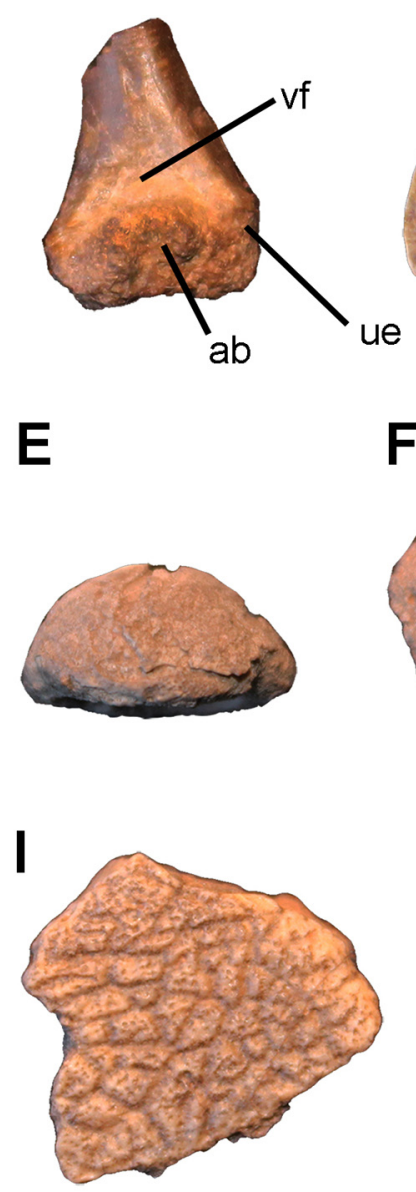

B

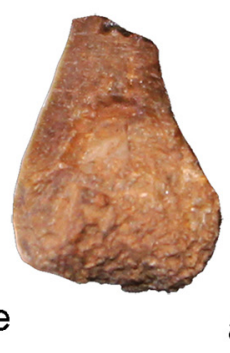

$\mathbf{F}$

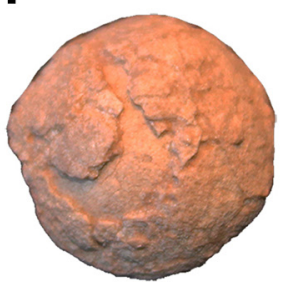

C

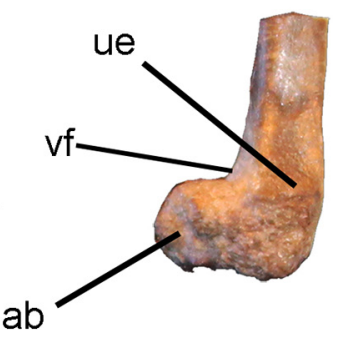

D

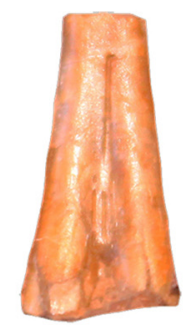

H

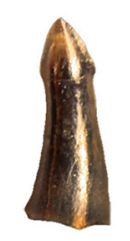

Figure 2. Fishes, anurans, and turtles. (A-C), Indeterminate Calyptocephalellidae, MPM 21519, distal end of right humerus with eroded distal margin in anterior $(\mathbf{A})$, posterior $(\mathrm{B})$, and medial $(\mathbf{C})$ views. (D) Indeterminate anuran, MPM 21518, incomplete tibiofibula. (E-G) Indeterminate Teleostei, MPM 21516, tooth crown in lateral $(\mathbf{E})$, occlusal $(\mathbf{F})$, ventral $(\mathbf{G})$ views. (H) cf. Vidalamiinae indet., MPM 21517, isolated tooth in side view. (I-K) Indeterminate Chelidae, carapace fragments. (I) Plastral fragment. (J) Incomplete costal plate. (K) Middle peripheral plate. Abbreviations: ab, articular ball; ue, ulnar epicondyle; vf, ventral fossa. Scale bar: $5 \mathrm{~mm}$.

gether with remains described below, represents the southernmost records for a fossil frog from the Late Mesozoic.

Calyptocephalellidae Reig, 1960

Genus and species indeterminate

Referred material: MPM 21519, distal end of right humerus with eroded distal margin (locality 4) (Figure 2A-C).

Description: The distal end of the humerus (1.5 $\mathrm{mm}$ in maximum transverse width), probably belongs to an adult individual, as suggested by degree ossification and well-finished structures.
The distal articular ball, as well as both epicondyles, are distally eroded. The humeral shaft is subtriangular in cross-section, with a relatively sharp crest running along its medial margin, which probably ended in a well-developed deltoid crest as it occurs in living anurans. The distal end of humerus bears a ball-shaped and ventrally projected articular condyle, bordered by similarsized, flange-like, and transversely expanded ulnar and radial epicondyles. The ulnar epicondyle shows a flattened anterior surface that is separated from the articular ball by a shallow groove. The radial epicondyle is broader than the ulnar epicondyle and its anterior surface is concave 
and crescent-shaped in anterior view. The ventral fossa is not clearly outlined.

Comments: MPM 21519 exhibits the following unique combination of features, only observed in the extant genus Calyptocephalella (Báez, 1987; Otero et al., 2014): 1) distal articular ball large and placed at the center of the distal end; 2) prominent, subequal-sized and flange-like radial and ulnar epicondyles, resulting in a roughly symmetrical distal end; 3) humeral shaft distally unexpanded; 4) poorly defined ventral fossa. The incomplete nature of MPM 21519 does not allow referral the specimen beyond the family level.

The Mesozoic record of anurans in South America is patchy. Basal anurans of the clade Pipoidea have been recorded from the Early Cretaceous of Brazil (Carvalho et al., 2019) and from mid-to Late Cretaceous localities of Brazil and Argentina (see Báez, 2000). The record of neobatrachians is also restrictive, being currently represented by nearly complete specimens from the Early and Late Cretaceous of Brazil (e.g., Báez \& Perí, 1989; Báez et al., 2009, 2012), and disarticulated specimens from Campanian-Maastrichtian localities in Chubut and Río Negro provinces of Argentina (i.e., Báez, 1987; Martinelli \& Forasiepi, 2004; Muzzopappa \& Baez, 2009; Agnolin, 2012).

Most neobatrachians are represented by highly fragmentary remains assigned to the nonmonophyletic clade "Leptodactylidae", and most of them have been assigned (or related with) the living Helmeted toad Calyptocephalella (Báez, 1987; de la Fuente et al., 2007; Agnolin, 2012), the only extant member of Calyptocephalellidae. This genus is currently restricted to a single species, Calyptocephalella gayi, being endemic from the temperate region of south-central Chile (Otero et al., 2014). However, during the Mesozoic and Cenozoic, calyptocephalellids were geographically widespread, with possible reports from Late Cretaceous of India, Africa and Madagascar (see Agnolin, 2012). In South America, Calyptocephalellids are recorded from Late Cretaceous to Miocene beds, in several localities along the Patagonia of Argentina and Chile (Agnolin, 2012; Otero et al., 2014). Because of its great antiquity, calyptocephalellids were considered as being part of the "ancient assemblage" or "Andean-Antarctic" batrachofaunas that inhabited the southern end of South America during the Mesozoic, up to Miocene times (Vuilleumier, 1968; Cei, 1980; see Agnolin, 2012).
Testudines Linnaeus, 1758

Chelidae Gray, 1825

Genus and species indeterminate

Referred material: Chelid materials include MPM 21520 (consisting in two peripheral and one costal plates; locality 2), MPM 21521 (consisting of an anterior peripheral, one mid-peripheral, three posterior peripherals, fragment of plastral bridge, three incomplete costal plates, and distal end of radius; locality 4) (Figure $2 \mathrm{I}-\mathrm{K}$ ). Based on locality and size differences, specimens belong to at least two different individuals.

Description: In both localities, available specimens were found in an area of few square meters. However, the different degree of preservation and different size of the specimens indicate the presence of different individuals. The plates resemble each other in being relatively thin and in having a similar ornamentation, suggesting that all belong to the same taxon. Largest available plates suggest a maximum carapace length of $40 \mathrm{~cm}$, approximately. Peripheral plates are relatively small and dorsoventrally thin. Midperipherals show relatively small and shallow costal fossae. There is no suture for the contact with costal plates. Plate decoration consists of small and well-defined polygonal figures, separated by anastomosed sulci. In some sections the polygones became smaller, conferring the plate a rugose texture. Preserved costal plates are incompletely preserved. They show ornamentation similar to that of peripheral plates, but polygones are more elongate.

Comments: In spite of the incomplete nature, available specimens can be referred with confidence to Chelidae, based on the combined presence of free peripheral plates lacking firm contact with the costal ones, and external surface decoration consisting of dichotomizing sulci and polygones (Broin \& De la Fuente, 1993; Lapparent de Broin \& De la Fuente, 2001; Lapparent de Broin, 2003). Plates here described are indistinguishable from those reported by Broin (1987) under the name of "Chelidae indet. № 3", and by Gasparini \& de la Fuente (2000) as "Chelidae indet. №5", from the Maastrichtian Los Alamitos and La Colonia formations (Río Negro and Chubut provinces, respectively).

Squamata Oppel, 1811

Serpentes Linnaeus, 1758

Genus and species indeterminate

Referred material: MPM 21522, partial mid- 


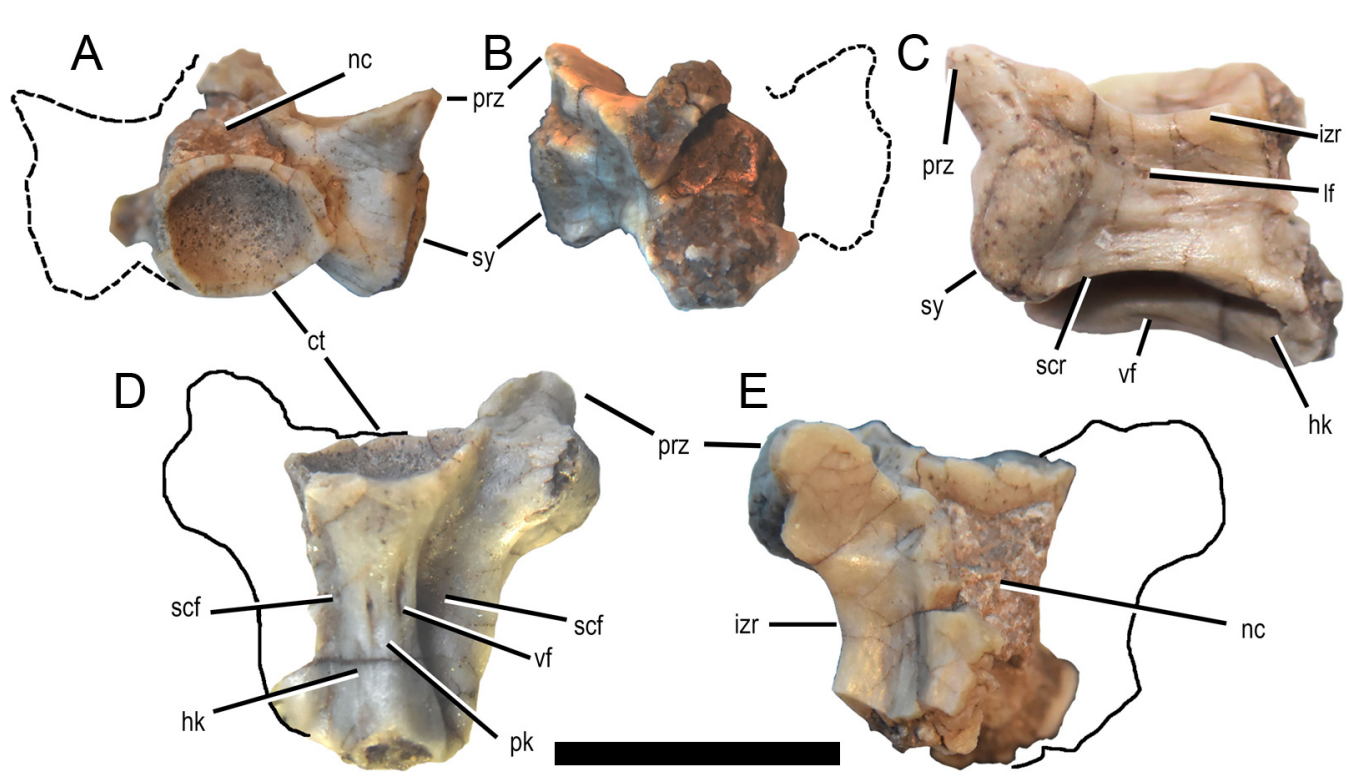

Figure 3. Serpentes indet. (MPM 21522) partial mid-posterior vertebra in anterior (B), posterior (B), lateral (C), ventral (D) and dorsal (E) views. Abbreviations: ct, cotyle; izr, interzygapophiseal ridge; hk, haemal keel; lf, lateral foramen; prz, prezygapophysis; pk, pseudo keel; scf, subcentral foramen; scr, subcentral ridge; sy, synapophisis; vf, ventral foramen. Scale bar: $5 \mathrm{~mm}$.

posterior vertebra (locality 4) (Figure 3).

Description: MPM 21522 is a small vertebra, $7 \mathrm{~mm}$ long, consisting of centrum, left prezygopophysis, and ventral region of the neural canal. As in most snakes, it shows an anteroventrally facing articular cotyle, subcentral ridges, grooves and foramina and synapophyses. This element is identified as a precloacal vertebra because of the absence of pleurapophyses, lymphapophyses, and hemapophyses (LaDuke, 1991). It shares a combination of characters present in middle and posterior precloacals (wide and shallow haemal keel, elongated vertebral centrum, and synapophyses with a strong lateral component ventrally located).

In anterior view the articular cotyle is subcircular in contour. The neural canal was dorsoventrally low and with a subtriangular contour in anterior view. There are two well-defined paracotylar foramina, located close and at mid height of the cotyle. The foramina are situated within shallow paracotylar fossae, adjacent to the left side of the cotyle. The prezygapophysis has the articular facet inclined about $20^{\circ}$ above the horizontal plane, and barely surpass the lateral margin of the paradiapophysis (=synapophysis). The ventral margin of the synapophysis is lower than the ventral margin of the articular cotyle.

In dorsal view, the prezygapophyseal facet is oval-shaped, with its main axis obliquely orien- ted, about $40-50^{\circ}$ from the sagittal plane. At the base of the facet there is a well-defined and small fossa. The prezygapophiseal accessory process is absent and the interzygapophyseal rim is shallow.

The posterior articular condyle is below the level of paradiapophysis. The neural canal seems taller than in anterior view, and is sub-triangular in contour. A small portion of the posterodorsal surface of the vertebral centrum is preserved, and bears no medial keel.

The centrum has a parallelogram-shaped profile in lateral view, with the posterior region in a lower level than the anterior region. The paradiaphophysis is massively built, with no clear differentiation from the both dia- and parapophyses. The paradiapophysis is sub-rectangular in contour and is postero-ventrolaterally faced, with a strong lateral component. Posterior to it, at mid-length of the vertebral length, there is a lateral foramen. The diapophyseal region is wider and more posteriorly placed than the parapophyseal region. Posterior to the paradiapophysis there is a moderately developed subcentral ridge that laterally surrounds the subcentral fossa. The haemal keel is low and ventrally concave, and the subcentral foramina are not visible due the great depth of the subcentral fossa.

In ventral view, the vertebral centrum is subtriangular shaped, its lateral margins converging 
posteriorly. The haemal keel is transversely wide and is hourglass shaped, with the anterior region transversely wider than the posterior half. The subcentral fossae are well developed and laterally delimit the haemal keel. On the ventral surface of the haemal keel there are present two foramina. Between them there is a pseudo-keel that extends all the length of the haemal keel. This pseudo-keel is poorly-developed, but distinctive.

Comments: Albino (Albino, 1986, 1987, 1994; see also Martinelli \& Forasiepi, 2004) described several serpent taxa based on isolated vertebrae from the Latest Cretaceous (Maastrichtian) Los Alamitos Formation, Rio Negro province. These specimens belong to basal snakes of the "madtsoiid" grade. More recently, Gómez et al. (2008) described from coeval beds the "anilioid" Australophis anilioides from northern Patagonia. In spite of this relative rich record, they restrict to the NW corner of Patagonia. Thus, present report extends paleogeographic distribution of these reptiles up to the southern region of South America.

In spite of being incomplete, the specimen MPM 21522 shows a combination of characters unique among snakes. Presence of a paracotylar foramen is shared with madtsoiids, Dinilysia, several specimens of Colombophis (Simpson, 1933; Albino, 1986, 1994, 2000; Rage \& Wagner, 1999; Scanlon, 2006), boiids (Albino, 2010), and it is variably present among anilioids (Hsiou et $a l ., 2019)$. Paracotylar foramina are absent in Najash, Menarana, and most anilioiids (Rage, 1984, 1998; Gómez et al., 2008; Zaher et al., 2009; La Duke et al., 2010). As occurs in the madtsoiids Madtsoia, Adinophis, and Alamitophis, MPM 21522 presents two paracotylar foramina (Simpson, 1933; Albino, 1994; La Duke et al., 2010; Pritchard et al., 2014).

Resembling Dinilysia, and the madtsoiids Alamitophis (Albino, 1986; MACN-RN 27,38), Nidophis, Menarana and Madtsoia pisdurensis (La Duke et al., 2010; Mohabey et al., 2011; Vasile et al., 2013), the prezygapophysis of MPM 21522 extends slightly beyond the lateral margin of the synapophysis. In Colombophis and anilioiids (Rage, 1984, 1998; Hsiou et al., 2010) the prezygapophyses extend much further than the synapophisys, whereas the reverse condition applies for Najash, Adinophis, Gigantophis, Nanowana, Patagoniophis and several Madtsoia species (Scanlon, 1997; Rage, 1998; Zaher et al., 2009; La Duke et al., 2010; Pritchard et al., 2014). The absence of a prezygapophiseal accessory process is a plesiomorphic feature shared by
MPM 21522, madtsoiids, and Najash (Rage \& Wagner, 1999; Albino, 2000; Scanlon, 2006; La Duke et al., 2010; Mohabey et al., 2011; Zaher et al., 2009).

The haemal keel present in MPM 21522 is low and wide, similar to the condition of posterior precloacal vertebrae in most madtsoiids and anilioiids. It is flanked by two small subcentral foramina, as occurs in posterior precloacal vertebrae of Dinilysia (MACN-RN 116). Furthermore, MPM 21522 differs from all known madtsoiids and other fossil snakes because of the presence of a pseudo-keel, flanked by two foramina located on slits, on the ventral surface of the haemal keel. A somewhat similar condition is found in Colombophis and in the supposed tropidophiid Dunnophis (Rage, 1984), where the haemal keel is wide and flat and two subcentral foramina are present on the ventral surface of the keel; however, there is no presence of a pseudo-keel (Rage, 1984; Hsiou et al., 2010). Rage (2013) reported for Paraungaliophis a ventral longitudinal keel producing a shallow sagittal ridge, but this keel differs from MPM 21522 in being sharp and restricted to the posterior end of the keel. Another distinguishable feature of MPM 21522 is that the foramina present on the ventral surface are placed in a slit, similar to the anilioiid Hoffstetterella, where the subcentral fossa of the anterior and mid precloacal vertebra are located within slits (Rage, 1998).

The synapophyses of MPM 21522 is well developed and the diapophyseal and parapophyseal regions are plesiomorphically poorly differentiated. This condition is also present in Alamitophis, Colombophis, Anilius and Coniophis (Rage, 1984; Albino, 1994; Hsiou et al., 2010). On the contrary, the synapophyses in most of the madtsoiids and the anilioiid Hoffstetterella are well-defined into para- and diapophyseal regions (Simpson, 1933; Rage, 1998; Zaher et al., 2009; La Duke et al., 2010; Mohabey et al., 2011; Vasile et al., 2013; Pritchard et al., 2014; Rio \& Mannion, 2017), a derived condition found in all alethinophidian snakes (Rieppel et al., 2002; Apesteguía \& Zaher, 2006).

As in Dinilysia, Najash, and the madtsoiids Madtsoia madagascarensis, Nidophis and Menarana (Zaher et al., 2009; La Duke et al., 2010; Vasile, 2013), the subcentral ridges and fossae in MPM 21522 are well developed. This contrast with some madtsoiids (e.g., Madtsoia, Gigantophis, Adinophis) and most anilioids (Simpson, 1933; Rage, 1998; Gómez et al., 2008; Mohabey et al., 2011; Pritchard et al., 2014; Rio 
\& Mannion, 2017; Hsiou et al., 2010) which have poorly defined subcentral ridges and fossae.

In lateral view, a lateral foramen can be observed in most madtsoiids and anilioiids (Simpson, 1933; Rage, 1998; Albino, 2000; Zaher et al., 2009; La Duke et al., 2010; Vasile et al., 2013; Pritchard et al., 2014).

The interzygapophyseal constriction in MPM 21522 is shallow as in Dinilysia, Madtosoia pisdurensis and most anilioiids (Rage, 1998; Gómez et al., 2008; Mohabet et al., 2011), which differ from Najash, Colombophis and most madtsoiids, where it is notably deep (Simpson, 1933; Rage, 1998; Zaher et al., 2009; La Duke et al., 2010; Vasile et al., 2013; Rio \& Mannion, 2017; Hsiou et al., 2010).

In spite of its distinctiveness, MPM 21522 is here regarded as an indeterminate Serpentes because of its fragmentary condition.

\section{cf. Rionegrophis madtsoioides Albino, 1986}

Referred materials: MPM 21523, partial vertebra (locality 2) (Figure 4).

Description: Description: MPM 21523 is an incomplete vertebra, approximately $14 \mathrm{~mm}$ long as preserved. As in most snakes, the cotyle faces anteroventrally, the subcentral ridges and grooves are well-defined, and synapophysis are present. The vertebra corresponds to the precloacal region because of the absence of pleurapophyses, lymphapophyses, and hemapophyses (LaDuke, 1991). Due to the tall and narrow haemal keel, and the absence of a hypoapophysis, this element corresponds to the mid-precloacal region.

The cotyle is notably deep and dorsolaterally flanked by a deep paracotylar foramen. The distal end of the prezygapophysis is missing, thus the presence of a prezygapophyseal process remains unknown. In dorsal view, the prezygapophysis shows a subtriangular contour, its major axis forming an angle about $45^{\circ}$ with the sagittal plane. The paradiaphophysis is widely exposed; the diapophysis region of the synapophysis is more developed and more posteriorly located than the parapophyseal region of the synapophysis.

The condyle is prominent, sub-circular shaped in posterior view, and slightly dorsally pointed. The ventral surface of centrum exhibits on its posteriormost region an haemal keel, flanked by two small depressions, probably representing the posterior portion of the subcentral grooves. Subcentral ridges are present.

Comments. Due to the fragmentary na- ture of MPM 21523, comparisons are limited. However, its size and general morphology closely resembles Rionegrophis madtsoioides (Albino, 1986). MPM 21523 shows a well-developed and narrow haemal keel, similar to some madtsoiids and the anilioiid Hoffstetterella brasiliensis (Scanlon, 1997; Rage, 1998; Vasile et al. 2013), whereas Dinilysia and Najash show a notably wider haemal keel (Zaher et al. 2009; MACN-RN 2019). Further, the synapophysis of MPM 21523 resembles most madtsoiids synapophyses because the diapophysis is wider than the parapophysis.

Presence of a well-developed keel present on the dorsal surface of the centrum is shared with Alamitophis and Rionegrophis madtsoioides (Albino, 1986; MACN-RN 27, 32). However, MPM 21523 differs from Alamitophis and resembles Rionegrophis in the presence of a subtriangular-shaped centrum when viewed dorsally or ventrally.

In gross-morphology and main features MPM 21523 resembles Rionegrophis madtsoioides. However, its fragmentary nature precludes a clear determination, and thus is identified here as cf. Rionegrophis madtsoioides.

\section{Squamata Oppel, 1811 \\ Mosasauridae Gervais, 1852 \\ Genus and species indeterminate}

Referred material. MPM 21524, seven isolated teeth (locality 5) (Figure 5).

Description. Seven mosasaur teeth have been collected from the upper levels of the Chorrillo Formation, all of them coming from a single fossil spot which also yielded ornithopod remains (described below). We assume these teeth, found in close association, belong to a single mosasaur individual. Available teeth share the following combination of characters supporting their referral as to Mosasauridae (Hornung \& Reich, 2015): 1) crowns bearing distal and mesial carinae, 2) different level of enamel striation, 3) crown polygonal-shaped in cross-section, and 4) crown tip posteriorly curved.

Available teeth can be sorted into two different types, in accordance with size, enamel ornamentation and morphology. One type is represented by fragments of three large teeth, the best preserved of which has an almost complete crown (Figure 5A-C), being $44 \mathrm{~mm}$ in total height and $20 \mathrm{~mm}$ in diameter at its base. The basal quarter of these teeth is devoid of enamel, striations, and carinae, indicating proximity to bone 

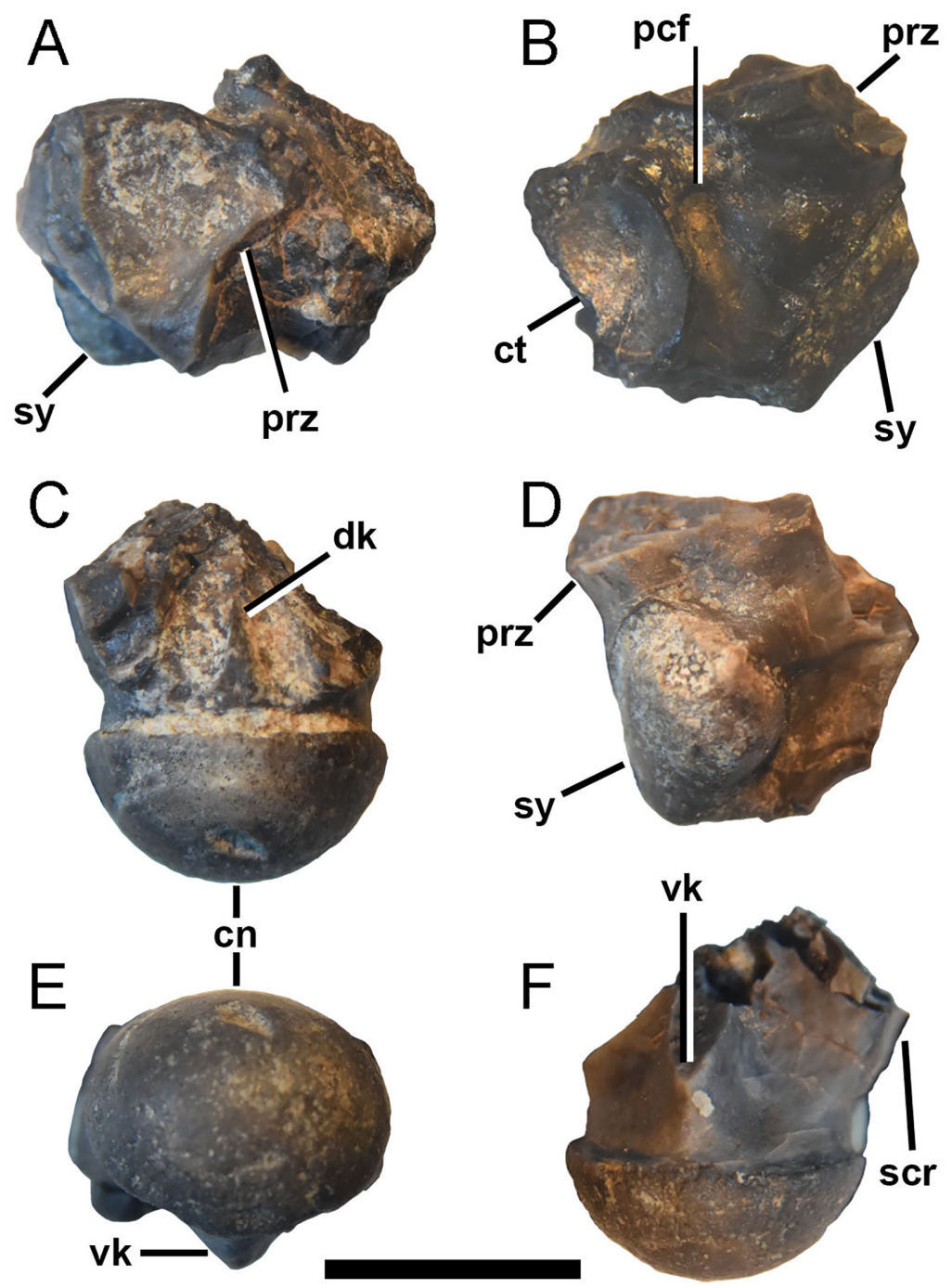

Figure 4. cf. Rionegrophis madtsoiids (MPM 21523), one partial vertebrae in dorsal (A, C), anterior (B), lateral (D), posterior (E) and ventral (F) views. Abbreviations: ct, cotyle; cn, condyle; dk, dorsal keel; pcf, paracotylar foramina; prz, prezygapophysis; scr, subcentral ridge; sy, synapophisis; vk, ventral keel. Scale bar: 5 mm.

attachment (Figure 5). The crowns are conicalshaped, being only slightly distally curved in side view. Tooth crowns lack striations on their apical quarter, but show a gently convex wear facet. Crown bases are elliptical in cross-section, with the labial side strongly convex and lingual side slightly more flattened than the opposite side. Mesial and distal carinae are sharp and devoid of serrations, being the distal carina stronger than the mesial one. Applying the terminology for enamel ornamentation used by Hornung \& Reich (2015) these crowns have primary and secondary striae with no ramifications, with some of the primary striae converging adapically with secondary striae. Labially, the crowns exhibit three main convex prism faces (sensu Hornung \& Reich, 2015), which are absent on the lingual surface.

The second tooth type is represented by an almost complete tooth crown (Figure 5D,E). It is small sized (total height $15 \mathrm{~mm}$, basal diameter $10 \mathrm{~mm}$ ), subtriangular-shaped in side view, and elliptical in cross-section. Both mesial and distal margins are slightly convex. The labial side of the crown is smooth and devoid of ornamentation, whereas the lingual side bears fine basal striae. The base of this tooth is devoid of enamel.

Comments. The Campanian-Maastrichtian fos- 

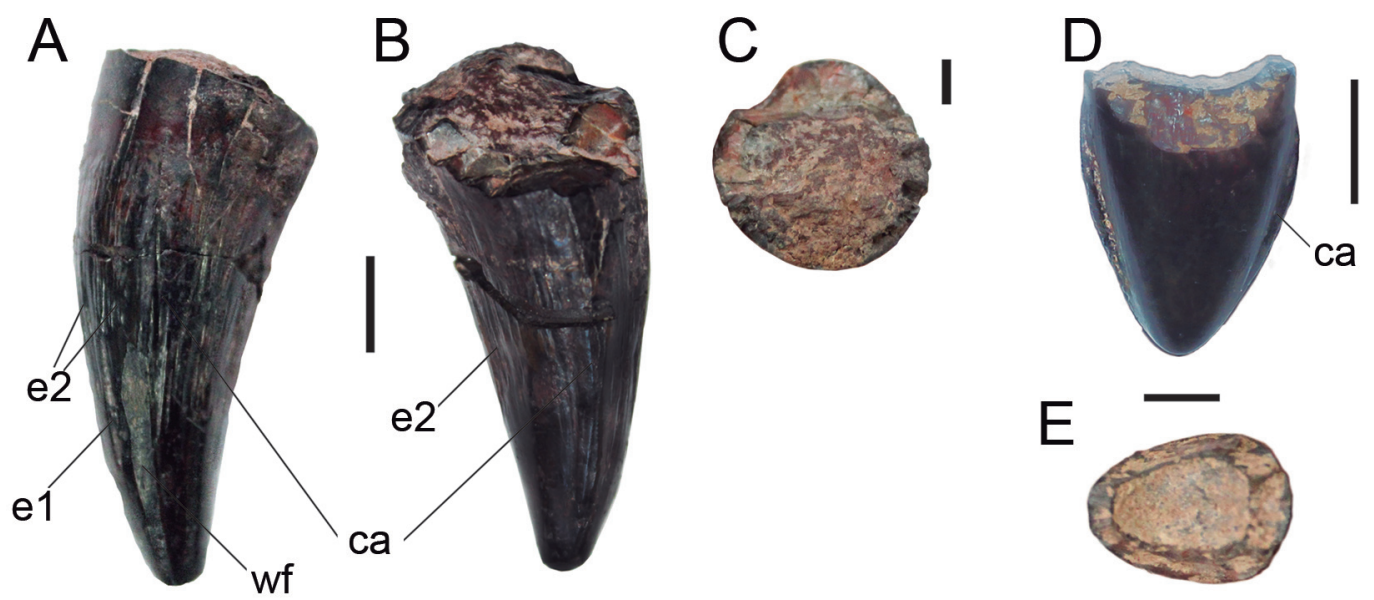

Figure 5. Mosasauridae indet. (MPM 21524). Tooth types 1 (A-C) and 2 (D-E) in mesial (A), distal (B), basal (C, E), and lingual views. Abbreviations: e1, primary striation; e2, secondary striation; ca, carina; wf, wear facet. Scale bars: $10 \mathrm{~mm}$.

sil record of mosasaurs described for southern Patagonia and Antarctic Peninsula includes remains referred as to mosasaurines, halisaurines, tylosaurines, and plioplatecarpines (Ameghino, 1893; Gasparini \& Del Valle, 1981; Martin et al., 2002; Otero et al., 2017). Most of them are based upon shed teeth and isolated vertebrae, and have been considered of dubious affinities by Novas et al. (2002). Currently, only two taxa have been confidently identified on the basis of cranial, dental and postcranial remains: Taniwhasaurus antarcticus (Novas et al., 2002; Fernandez \& Martin, 2007) and Kaikaifilu hervei (Otero et al., 2017), both of them belonging to Tylosaurinae. Teeth of Taniwhasaurus antarcticus (Novas et al., 2002) differ from those reported here in having slenderer and posterolingually curved crowns, narrower striae, and feebly developed unserrated carinae. Besides, teeth here described resemble the large Antarctic mosasaur Kaikaifilu on their large size, overall shape and cross section of the crown. However, teeth of Kaikaifilu bear only a mesial carina and are more finely striated.

Several tooth remains from the Late Cretaceous of Antarctica have been reported as belonging to indeterminate mosasaurines (e.g., Martin, 2006; Martin and Crame, 2006). These teeth differ from those here described in being more labiolingually compressed, with enamel surface smooth, and prism faces greater and flatter. Besides, isolated teeth from Antarctica referred as to tylosaurines and platecarpines (e.g., Martin, 2006; Martin \& Crame, 2006) consist on poorly preserved materials, precluding detailed comparisons with present specimens.
Teeth of Mosasaurus aff. M. hoffmani from the Late Cretaceous of Río Negro province (Fernández et al., 2008) differ from those reported here in having lingual surface wider, and enamel surface smooth. Teeth of "Liodon argentinus" (Ameghino, 1893), from the Cenomanian Mata Amarilla Formation, Pari Aike, Santa Cruz province, share with those collected in Chorrillo beds in bearing both anterior and posterior carinae, but differ in being more laterally compressed, with stronger carinae and serration in the anterior carina.

In sum, MPM 21523 could not be referred to any of the previously listed Patagonian and Antarctic mosasaur taxa, and thus they are considered as Mosasauridae indet.

Some authors (e.g., Lindgren, 2005; Fernández, 2008; Lindgren \& Siverson, 2002, 2004) have conferred a great taxonomic value to mosasaur shed teeth, taking them as enough evidence for the presence of a particular mosasaur family, or even mosasaur genera. However, we agree with Caldwell and Diedrich (2005) in that the taxonomic importance of dentition has been overestimated. For example, the presence of strong facets has been considered diagnostic for mosasaurines, instead the presence of deep striations was interpreted distinctive for plioplatecarpines (e.g., Martin \& Crame, 2006). However, as indicated by specimens from the Chorrillo beds, these characters are vague and are present in many non-related taxa. It has been shown that tooth morphology varies along dental series of a single individual (see for example Konishi et al., 2012), and some taxa display up 
to four distinct tooth types along the jaws (e.g., Schulp et al., 2004; Thevenin, 1896; Otero et al., 2017). Further, ontogenetic changes have been also recognized in mosasaur literature (Lindgren \& Siverson, 2004). In sum, we consider that the taxonomic value of isolated mosasaur teeth have to be taken with caution.

Regarding the possible paleoenvironmental significance of mosasaur teeth, it is outstanding their close taphonomic association with ornithopod bones. The presence of mosasaur remains is suggestive of marine influence during the entombing of basal iguanodontians. This resembles the El Puesto "member" of the upper third of the Dorotea Formation, which yielded hadrosaurs remains (Jujihara et al., 2014; Soto Acuña et al., 2014), immediately below marine levels with aquatic fossils (including mosasaurs; Soto Acuña et al., 2016).

\author{
Dinosauria Owen, 1842 \\ Ornithischia Seeley, 1887 \\ Ornithopoda Marsh, 1881 \\ Euiguanodontia Coria \& Salgado, 1996 \\ Elasmaria Calvo, Porfiri \& Novas, 2007
}

Isasicursor santacrucensis gen. et sp. nov. Figure 6

Holotype. MPM 21525, proximal end of left tibia (Figure 7). The specimen comes from locality 5.

Paratypes: MPM 21526, incomplete cervical centrum; MPM 21527, two dorsal vertebrae; MPM 21528, sacrum lacking sacral 3rd; MPM 21529, 30 caudal vertebrae; MPM 21530, proximal end of right scapula ; MPM 21531, distal half of left humerus; MPM 21532, iliac process of left pubis; MPM 21533, set of juvenile specimens represented by proximal end of right femur , three proximal end of left femora, three distal end of left femora, and two fragments of femur mid-shaft; MPM 21534, distal end of tibia; MPM 21535, proximal and distal end of metatarsal II; MPM 21536, distal end of left metatarsal III; MPM 21537, proximal and distal ends of metatarsal IV; MPM 21538, nearly complete metatarsal IV of a juvenile individual; MPM 21539, pedal phalanges I-1, II-1, IV-2/IV-3; MPM 21540, six pedal ungual phalanges; MPM 21541, pedal phalanges II-2 and III-2 of juvenile individuals. As for the holotype, all the referred specimens come from locality 5 .

Diagnosis. Medium-sized elasmarian ornithopod having the following autapomorphies: 1) ventrally arched sacrum; 2) peg-and-socket ar- ticulation between the first and second sacral vertebrae in ventral view; 3) tibia with strongly proximally projected and thickened cnemial crest, 4) lateral condyle of tibia with an additional anterolateral process; and 5) metatarsal II with a proximally displaced collateral ligament pit on its lateral surface.

The preserved elements of the hindlimb, especially metatarsals are more robust than other elasmarians of comparable size, such as Morrosaurus and Talenkauen.

Horizon and Locality. Collected specimens come from locality 5 .

Etymology. Isasicursor honors the skilled technician Marcelo P. Isasi (Conicet - MACN), who discovered the remains of this new iguanodontian, and cursor, meaning runner in Latin; santacrucensis, in regards to Santa Cruz, the Argentine province where fossils were found.

\section{Description}

Cervical vertebra (Figure 8). The only recovered cervical vertebra of Isasicursor is represented by the anterior third of a centrum. In anterior view the articular surface is concave and roughly hexagonal in contour. The parapophyses are represented by poorly developed processes, subtriangular in contour when viewed from the side. Ventral to the parapophyses the lateral surfaces of centrum are transversely concave. In ventral view, there is a sharp ventral longitudinal keel, a condition considered synapomorphic for Elasmaria (Rozadilla et al., 2019).

Dorsal vertebrae (Figure 8). Two incomplete dorsal vertebrae are preserved. The centra are laterally compressed, conferring an hourglass contour in ventral view. In lateral view, the ventral margin of the centra possesses ventral buttresses near the anterior and posterior articular surfaces, with a concave margin between them. The anterior and posterior articular surfaces are slightly concave and oval in contour. They are dorsoventrally taller than transversely wide, indicating these centrae correspond to the mid-dorsal series. The ventral surface bears a stout ventral keel, as occurs in most basal ornithopods including elasmarians (i.e., Coria \& Salgado, 1996; Martínez, 1998; Coria \& Calvo, 2002; Novas et al., 2004; Calvo et al., 2007; Coria et al., 2013; Ibiricu et al., 2014; 2019; Cruzado-Caballero et al., 2019; Rozadilla et al., 2019). Some vascular foramina are present on the lateral and ventral surfaces of the centra.

Sacral vertebrae (Figure 9). The sacrum is represented by six disarticulated 


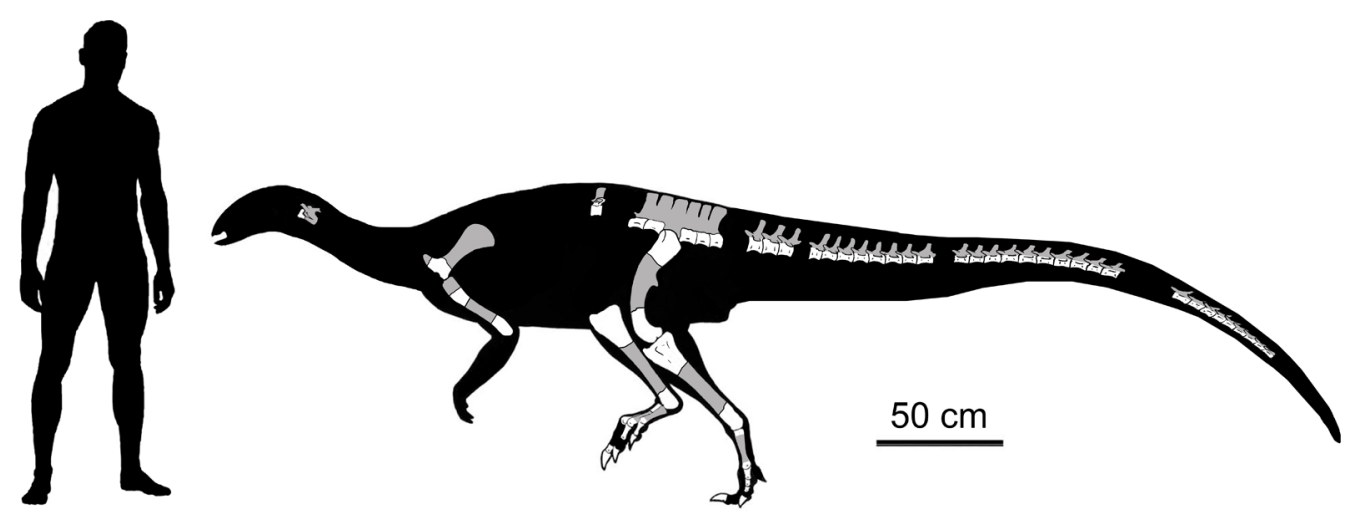

Figure 6. Isasicursor santacrucensis gen. et sp. nov. Skeletal reconstruction and body shape, indicating the discovered bones in white.

centra,corresponding to sacrals 1,2 and 4,5 and 6 . They lack signs of fusion and pneumatization, and the intervertebral attachment surfaces are ornamented by radiating grooves.

The sacrum is relatively stout, with ventral margin is strongly arched in side view, a condition absent in other known elasmarians. The first sacral is box-shaped and is the transversely wider element of the series. In ventral view, its anterior margin is notably transversely wide and presents large, fan-like transverse processes that bear articulation facets for the sacral ribs. This strong lateral projection is shared with Jeholosaurus and Anabisetia (Cambiaso, 2007; Han et al., 2012), whereas in Macrogryphosaurus these projections are feebly developed and in Sektensaurus are totally absent (Ibiricu et al., 2019; Rozadilla et al., 2019). The articular surface for ribs is oval in contour and bears a rugous surface, being dorsolaterally facing. The anterior articular surface of the centrum is kidney-shaped, dorsoventrally low and transversely wide. The posterior surface has a dorsoventrally oriented groove that ends in a socket-like pit on its ventral margin. This pit articulates with a process located on the anteroventral surface of the second sacral, resulting in a peg-and socket articulation. In other elasmarians, such as Gasparinisaura and Sektensaurus the contact between both elements is nearly flat (Ibiricu et al., 2019; Rozadilla et al., 2019). On the ventral surface, this sacral has a shallow ventral keel located at the bottom of a wide and shallow longitudinal groove. Some nutritious foramina occur on the ventral and lateral surfaces of the centrum.

The second sacral centrum is box-shaped and transversely compressed, which results in an hourglass outline in ventral view. The posterior end of the centrum bears sacral rib facets, which expand laterally resulting in the transversely widest portion of the bone. The sacral rib facet is anteroposteriorly short, with a rugose attachment surface. The ventral surface of centrum has a smooth longitudinal keel, which projects anteriorly into a peg-like process that fits into the socket present in the posterior surface of the first sacral. On the sides of this ventral keel there are subparallel and shallow longitudinal grooves. The anterior articular surface of the centrum is suboval in contour, with the main axis transversely oriented. The posterior articular surface is suboval in contour, being slightly transversely wider than the anterior half of centrum.

The third sacral is not preserved. The fourth sacral is box-shaped and its lateral surface bears laterally projected processes for the attachment with the sacral ribs on its anterior and posterior ends. The anterior attachment for the sacral rib is more dorsally located and anteroposteriorly elongated than the posterior one. These surfaces are concave and rugose. The ventral surface of centrum shows a shallow median longitudinal groove. A low median ridge exists near its anterior end. The anterior articular surface of centrum is rugose and sub-quadrangular in contour, instead the posterior articular surface is hexagonal-shaped and transversely wider than the anterior one.

The fifth sacral vertebra is box-shaped, with a trapezoidal outline in ventral view, its anterior end transversely wider than its posterior one. The floor of the neural canal is narrow and bears an oval pit at mid-length. Sacral rib facets are anteroposteriorly elongate and located at the anterior half of the bone. These articulation surfaces are suboval in contour and show strong rugosi- 

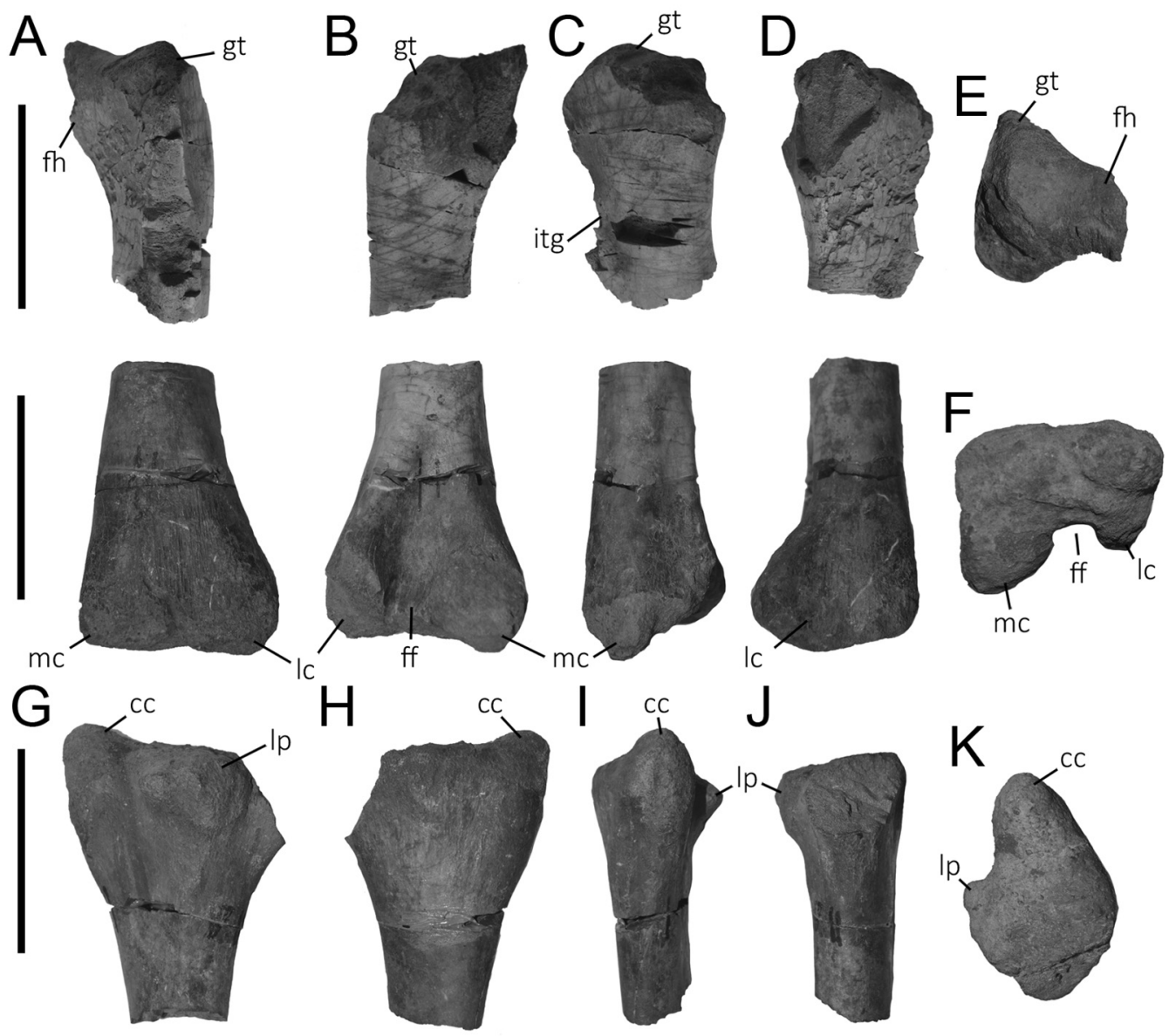

$\mathrm{J}$
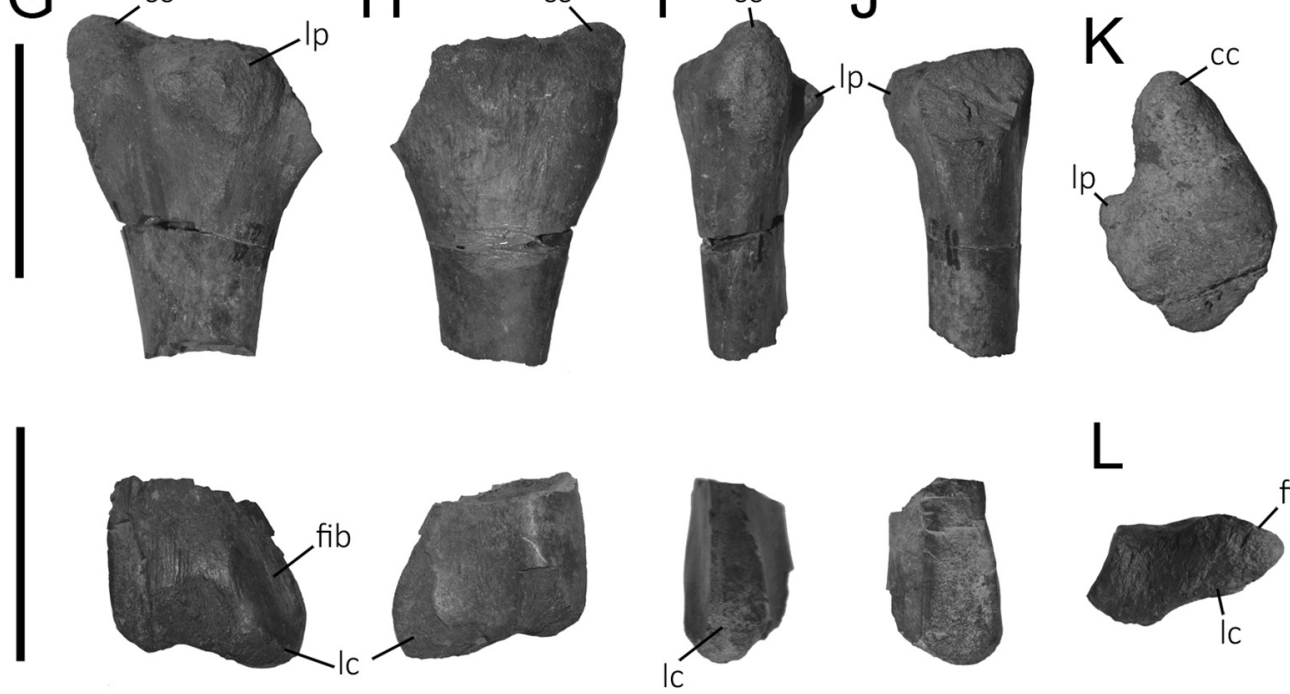

Figure 7. Isasicursor santacrucensis gen. et sp. nov. Femur (MPM 21533a) in (A) anterior, (B) posterior, (C) lateral, (D) medial, (E) proximal and (F) distal views. Tibia (MPM 21525a) in (G) lateral, (H) medial, (I) anterior, (J) posterior, (K) proximal and (L) distal views. Abbreviations: cc, cnemial crest; fib, fibular facet; ff, flexor fossa; fh, femoral head; gt, greater trochanter; itg, intertrochanteric groove; lc, lateral condyle; lp, lateral process; mc, medial condyle. Scale bar: $10 \mathrm{~cm}$.

ties on its attachment surface. Posterior and dorsal to the sacral rib facets, the centrum becomes transversely narrower. The ventral surface of centrum bears a shallow and wide longitudinal groove, with a low and smooth ridge restricted to its anterior margin. The anterior articular surface is suboval in contour, dorsoventrally low and transversely wide. Its dorsal edge has an anterior process that fits into the concavity of the posterior surface of the preceding vertebra. The posterior articular surface is sub-quadrangular in contour, dorsoventrally high and transversely narrower than the anterior articular surface.

The sixth sacral vertebra is represented by a weathered centrum. The centrum is box-shaped, with a wide and shallow longitudinal ventral groove. Few nutritious foramina exist on its lateral and ventral surfaces. The anterior articular sur- 


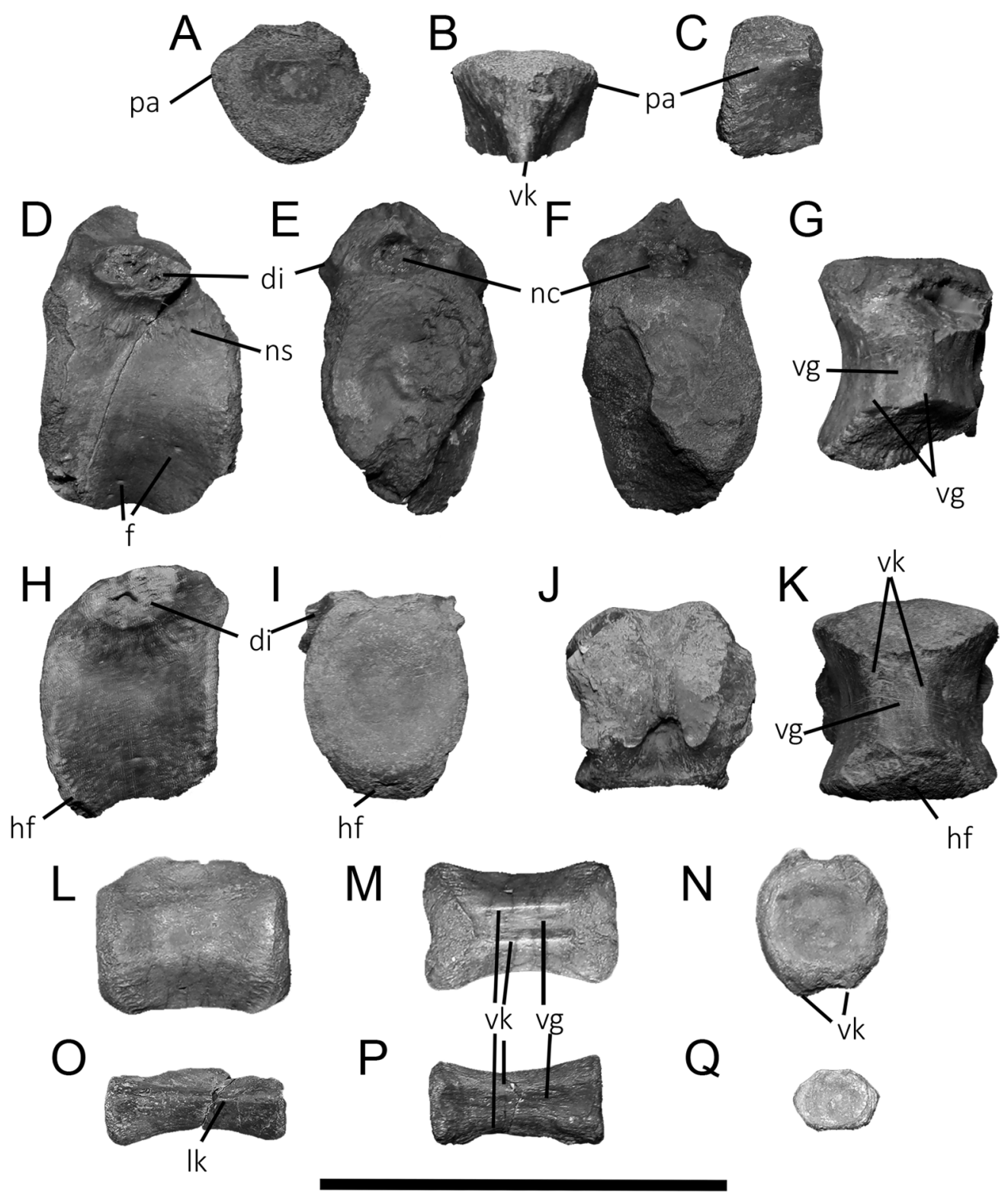

Figure 8. Isasicursor santacrucensis gen. et sp. nov. Selected vertebral elements. Cervical vertebra (MPM 21526) in (A) anterior, (B) ventral and (C) lateral. Dorsal Vertebra (MPM 21527) in (D) lateral, (E) anterior, (F) posterior and $(\mathbf{G})$ ventral views. Proximal caudal vertebra (MPM 21529) in (H) lateral, (I) anterior, (J) dorsal and (K) ventral views. Middle caudal vertebra (MPM 21529) in (L) lateral, (M) ventral and (N) anterior views. Posterior caudal vertebra (MPM 21529) in (O) lateral, (P) ventral and (Q) anterior views. Abbreviations: di, diapophysis; hf, haemal facet; lk, lateral keel; nc, neural canal; ns, neural suture; vg, ventral groove; vk, ventral keel. Scale bar: 5 cm.

face is sub-rectangular in contour. There is a small prominence at the lateral margin that contacts a shallow concavity present at the posterior articular surface of the preceding vertebra, resulting in a shallow peg and socket articulation. The posterior articular surface is subcircular in contour.
Caudal vertebrae (Figure 8). Thirty caudal vertebrae, corresponding to different individuals, have been recovered. These vertebrae belong to the anterior, median and posterior portions of the tail. Anterior caudal vertebrae are robust and slightly amphicoelous. The neural arches preserve the base of the diapophyses, which is 
suboval in cross-section. The centra are dorsoventrally taller than anteroposteriorly long; they are laterally concave, resulting in a spoolshaped profile in ventral view. In lateral view, the ventral margin of the centra shows an extensive haemal facet, which is sub-triangular in contour and strongly anteroventrally oriented. The ventral surface of the centra bears a deep longitudinal groove. Shallow longitudinal striations are present near both anterior and posterior articular surfaces.

Mid-caudals are represented by isolated centra. These are slightly amphicoelous, and dorsoventrally lower and anteroposteriorly longer than in anterior caudals. The lateral surface shows lateral longitudinal ridges, which become sharper towards the distal end of the tail. In ventral view, the centra are hourglass-shaped and show a ventral longitudinal groove, which becomes deeper towards the distal end of the tail. The haemal facet is relatively smaller than in anterior caudals. The anterior and posterior articular surfaces are subcircular in contour and sub-equal in size and shape.

Vertebrae of the distal section of the tail resemble those of the middle section, excepting for being anteroposteriorly longer and with more prominent lateral longitudinal ridges, resulting hexagonal-shaped in cross-section. The ventral longitudinal groove is well developed and bounded by two subparallel longitudinal ridges. Distal caudals are indistinguishable from other basal ornithopods (e.g. Gasparinisaura, Anabisetia, Talenkauen, Macrogryphosaurus, Diluvicursor, Sektensaurus, Trinisaura, Jeholosaurus; Coria \& Salgado, 1996; Cambiaso, 2007; Calvo et al., 2007; Barrett et al., 2011; Han et al., 2012; Barrett, 2016; Herne et al., 2018; Ibiricu et al., 2019; Rozadilla et al., 2019).

Scapula (Figure 10). The right scapula is represented by its proximal end. It is anteroposteriorly extensive, with thick acromial process. It narrows anteriorly, showing a wide and flat dorsal surface. The acromial process is laterally expanded, forming the deltoid rim, which delimits the dorsal margin of a shallow deltoid fossa. The glenoid cavity is severely damaged. It is ventrolaterally oriented and its anterior margin is delimited by a shallow supraglenoid fossa. This fossa is subcircular in contour and is ornamented by small striations, being relatively shallow, as occurs in Gasparinisaura and Trinisaura (Coria \& Calvo, 2002; Coria et al., 2013), whereas in Anabisetia, Talenkauen and Mahuidacursor it shows a deep supraglenoid fossa (Coria \& Calvo,
2002; Cruzado-Caballero et al., 2019; Rozadilla et $a l ., 2019)$. Near the coracoidal suture the medial surface of the scapula is covered by numerous ligament scars. The coracoidal articular facet is sub-rhomboidal in outline and strongly rugose.

Humerus (Figure 10). The left humerus is represented by isolated and incomplete shaft and distal end. The shaft is laterally bowed, as synapomorphic for Elasmaria (e.g., Anabisetia, Notohypsilophodon, Talenkauen, Trinisaura, Sektensaurus, Mahuidacursor; Martínez, 1998; Coria \& Calvo, 2002; Novas et al., 2004; Coria et al., 2013; Ibiricu et al., 2014; 2019; CruzadoCaballero, 2019; Rozadilla et al., 2019). The deltopectoral crest is reduced and represented by a low ridge, its lateral surface crossed by longitudinal muscle scars, as diagnostic for Elasmaria (e.g., Anabisetia , Notohypsilophodon, Talenkauen, Trinisaura, Sektensaurus, Mahuidacursor; Martínez, 1998; Coria \& Calvo, 2002; Novas et al., 2004; Coria et al., 2013; Ibiricu et al., 2014; 2019; Cruzado-Caballero, 2019; Rozadilla et al., 2019), in contrast with the well-developed deltopectoral crest present in most ornithopods, including Gasparinisaura (Coria \& Salgado, 1996; Rozadilla et al., 2019). The anterior surface of the humeral shaft is concave, while the posterior one is convex. The medial surface bears an oval nutritious foramen. The shaft is reniform in cross-section. The distal end of the bone is slightly transversely expanded. The anterior surface of the bone is deeply concave proximal to the distal condyles. In distal view, the lateral condyle is more extensive than the medial one. The flexor fossa is transversely wider than the extensor one.

Pubis. The pubis is only represented by the iliac process. This process is oval in cross-section. The articular margin is almost flat and slightly projected ventrally in a short process, being not fused with the obturator process, indicating a posteriorly opened obturator foramen, resembling the condition of basal ornithopods (e.g., Hypsilophodon, Gasparinisaura, Anabisetia, Trinisaura; Galton, 1974a; Coria \& Calvo, 2002; Cambiaso, 2007; Barrett et al., 2011; Coria et al., 2013).

Femur (Figures 7, 11). The femora are represented by several specimens, including a proximal end belonging to a juvenile individual. The femoral head is not preserved, but the neck is well-defined. The greater trochanter is completely preserved only in the juvenile specimen. In proximal view, the lateral margin of the greater trochanter is sigmoidal in outline. In lateral 


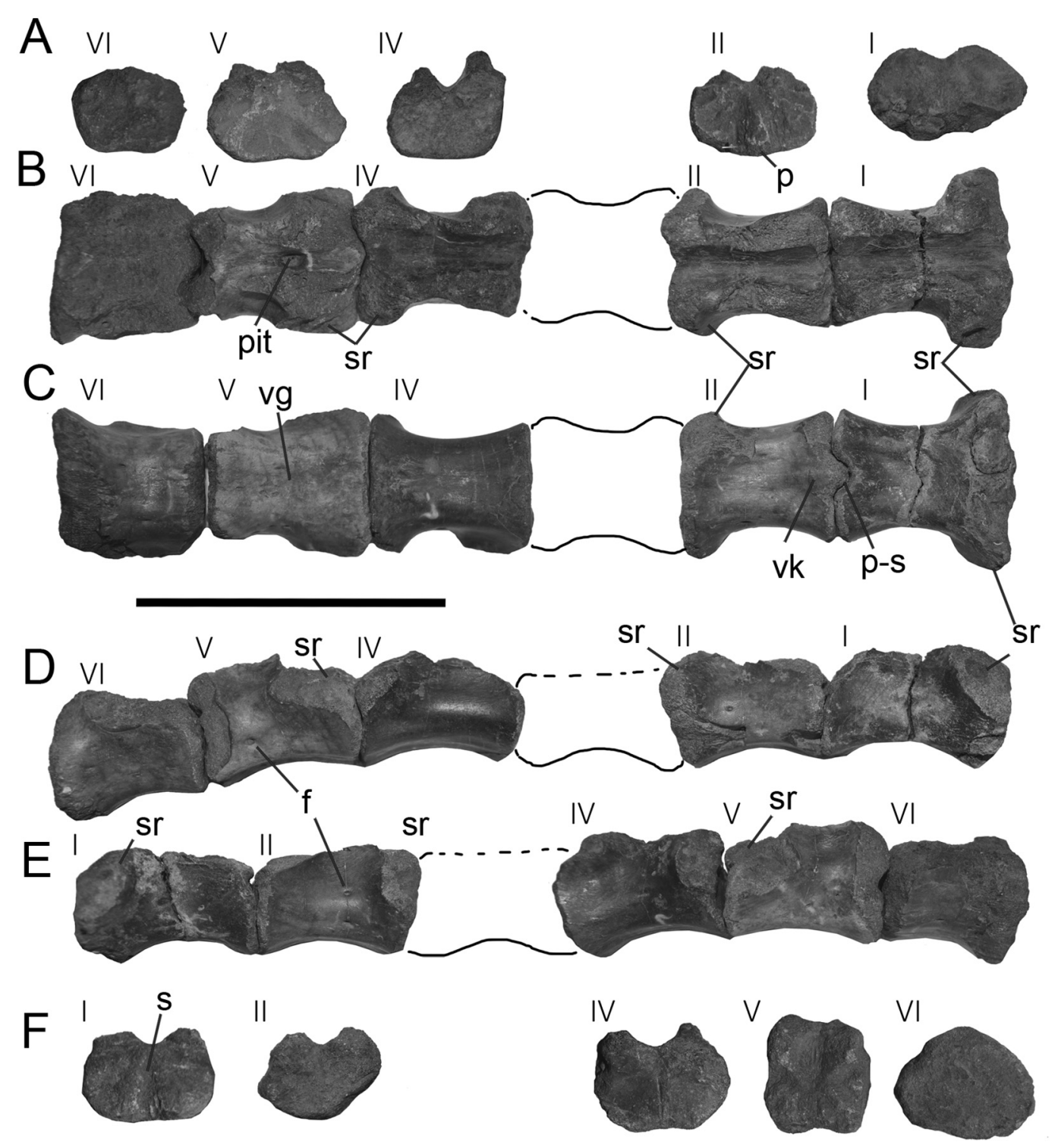

Figure 9. Sacrum of Isasicursor santacrucensis gen. et sp. nov. (MPM 21528) in (A) anterior, (B) dorsal, (C) ventral, (D) right, (E), left and (F) posterior views. I-VI indicates anteroposterior position in vertebral series. Abbreviations: f, vascular foramen; p, peg; pit, pit; p-s, peg and socket articulation; s, scar; sr, sacral rib; vg, ventral groove; vk, ventral keel. Scale bar: $3 \mathrm{~cm}$.

view, this trochanter is proximally convex, and is medially delimited by the groove that separates it from the lesser trochanter. This indicates that the lesser trochanter was not fused to the major one, a condition different from Gasparinisaura (Coria \& Salgado, 1996). The lesser trochanter is represented by its base, indicating that towards its anterior end it was notably narrow, a condition shared with Morrosaurus, Anabisetia, Trinisaura and Gasparinisaura (Coria \&
Salgado, 1996; Coria \& Calvo, 2002; Coria et al., 2013; Rozadilla et al., 2016).

The lateral surface near the proximal end shows a bump ornamented with longitudinal scars, which likely represents the anchoring of the for the $M$. iliofemoralis externus. The anterior surface between the greater trochanter and the femoral head is concave. The femoral shaft is subtriangular in cross-section, being posteriorly flat and anteriorly narrow. 

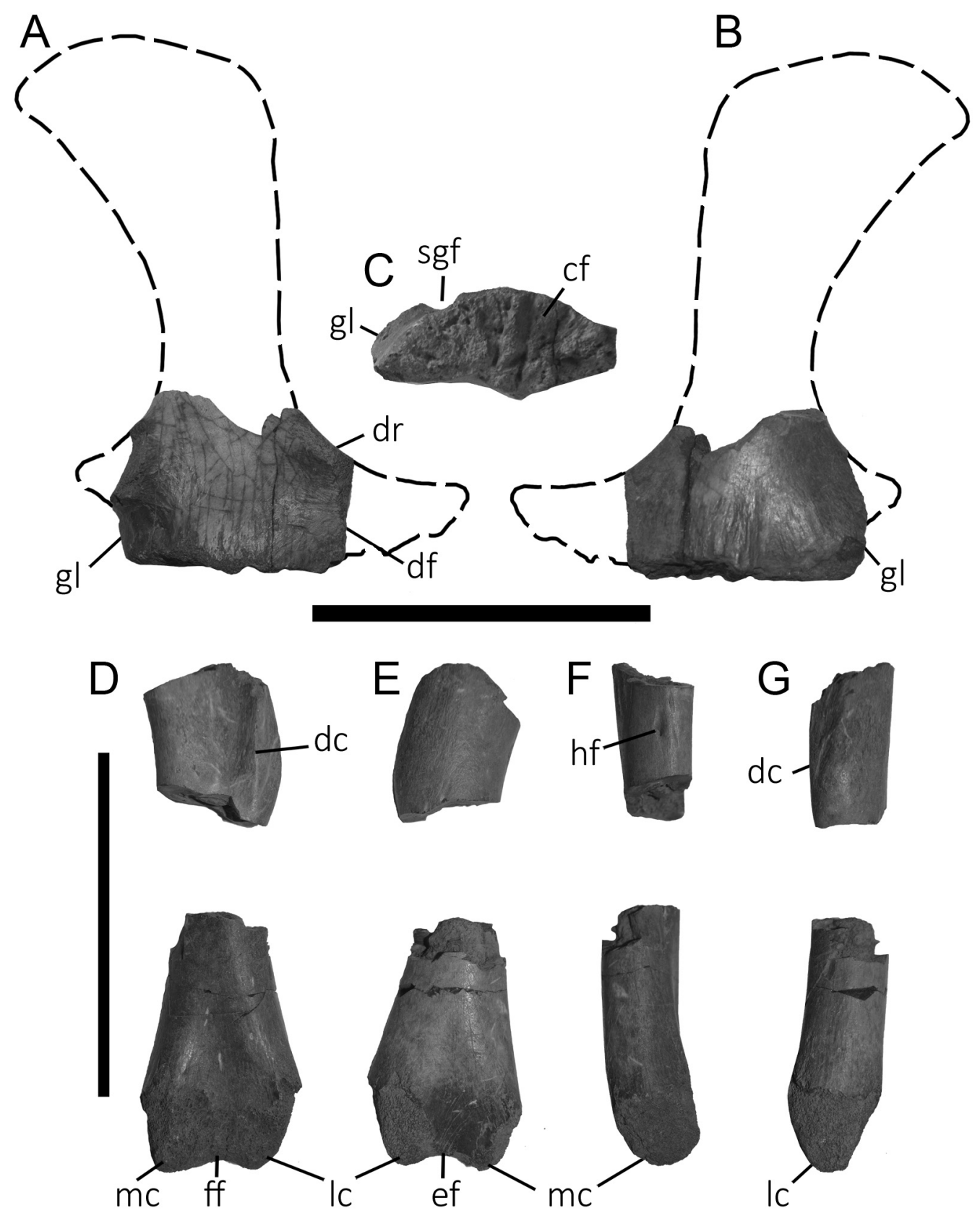

Figure 10. Isasicursor santacrucensis gen. et sp. nov. Scapula (MPM 21530) in (A) lateral (B), medial and (C) coracoidal views. Humerus (MPM 21531) in (D) anterior, (E) posterior, (F) medial and (G) lateral views. Abbreviations: dc, deltopectoral crest; df, deltoid fossa; dr, deltoid rim; ef, extensor fossa; ff, flexor fossa; gl, glenoid fossa; hf, humeral foramen; lc, lateral condyle; mc, medial condyle; sgf, supraglenoid fossa. Scale bar: $10 \mathrm{~cm}$.

The distal end of the femur is transversely expanded. In distal view, the medial condyle is transversely wider than the lateral one. This asymmetry is present in many elasmarians, such as Anabisetia, Morrosaurus and Kangnasaurus, as well as in more derived Iguanodontia (Cooper, 1985; Coria \& Calvo, 2002; Norman 2004; Norman et al., 2004; Rozadilla et al., 2016). The medial condyle has a sub-rectangular outline, and slightly tapers posteriorly. In medial view, 

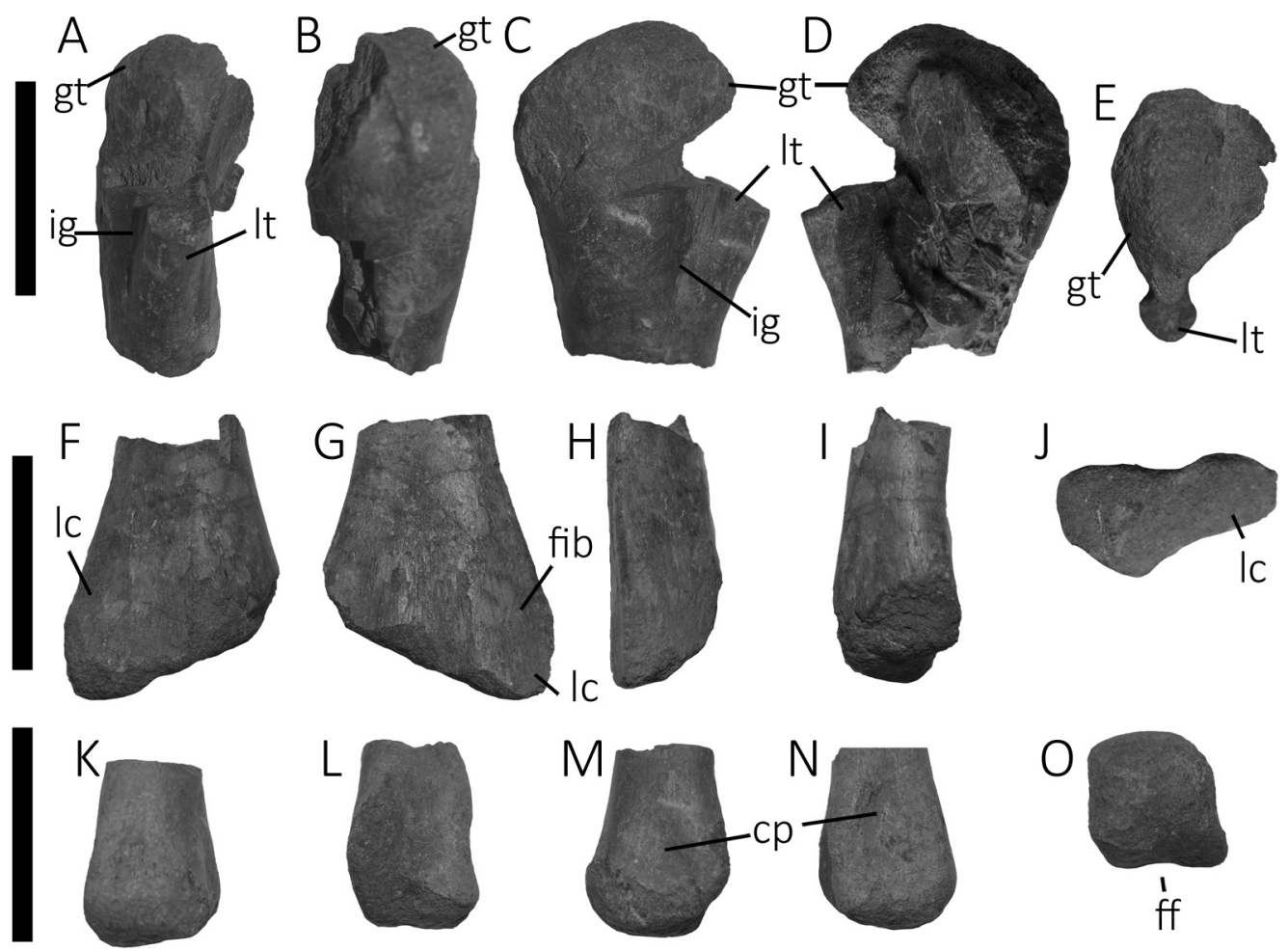

$\stackrel{1}{f f}$
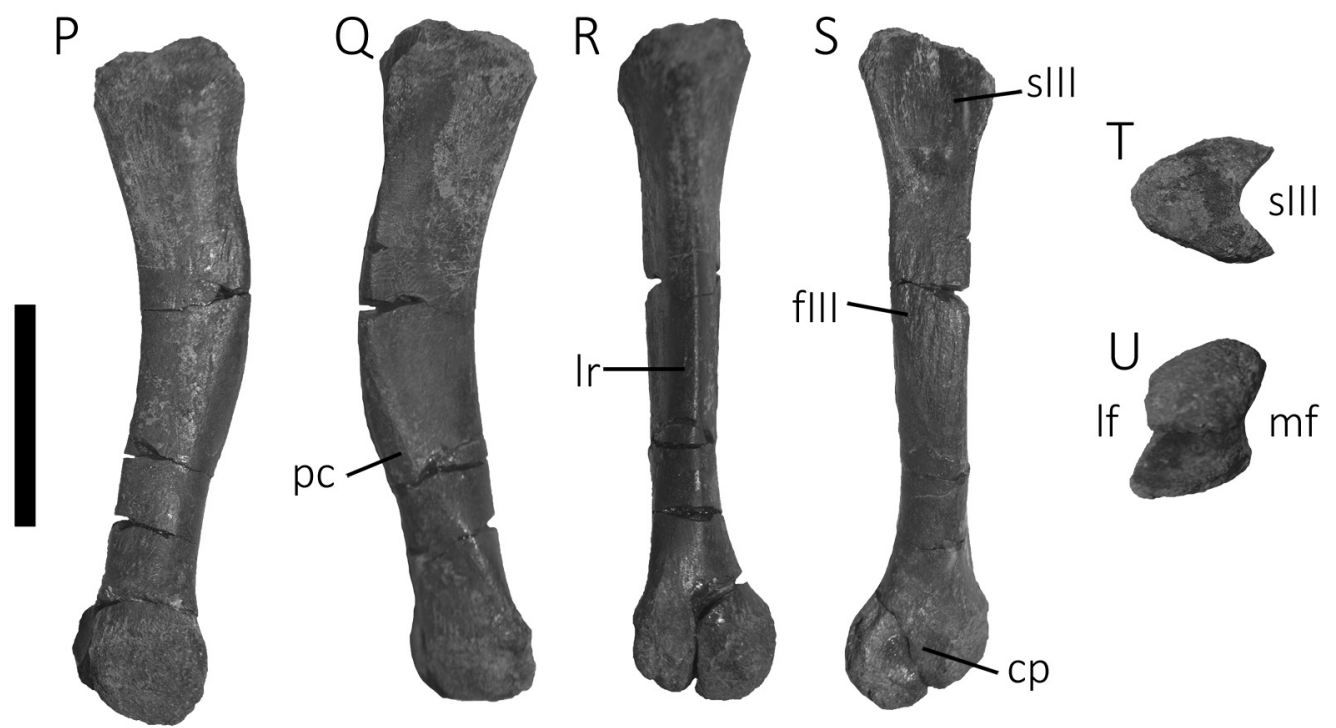

Figure 11. Isasicursor santacrucensis gen. et sp. nov. Selected juvenile materials. Right femur (MPM 21533b) in (A) anterior, (B) posterior, (C) lateral (D) medial and (E) proximal views. Left tibia (MPM 21534b) in $(\mathbf{F})$ anterior, $(\mathbf{G})$ posterior, $(\mathbf{H})$ lateral $(\mathbf{I})$ medial and $(\mathbf{J})$ distal views. Metatarsal II in (K) anterior, (L) posterior, (M) lateral (N) medial and (O) distal views. Metatarsal IV (MPM 21538b) in (P) anterior, (Q) posterior, (R) lateral (S) medial (T) proximal and (U) distal views. Abbreviations: cp, collateral pit; fib, fibular facet; gt, greater trochanter; ig, intertrochanteric groove; lc, lateral consyle; lf, lateral fossa; lr, lateral ridge; lt, lesser trochanter; mf, medial fossa; pc, plantar crest; sIII, surface for mtt III. Scale bar: $3 \mathrm{~cm}$. 
the medial condyle is posteriorly expanded and its medial surface is smoothly concave. The lateral condyle is gently laterally projected, resulting in a well-defined longitudinal groove on its lateral surface. This groove separates the lateral condyle from the tibiofibular crest. The medial condyle is not laterally expanded as in Morrosaurus and Kangnasaurus (Cooper, 1985; Rozadilla et al., 2016). The anterior surface of the bone lacks a well-developed extensor fossa, a condition shared with many basal ornithopods, such as Thescelosaurus, Hypsilophodon, Jeholosaurus, Gasparinisaura, Trinisaura, Notohypsilophodon and "Fulgurotherium" (Galton, 1974a,b; Molnar \& Galton, 1986; Coria \& Salgado, 1996; Coria et al., 2013; Martínez, 1998; Han et al., 2012; Ibiricu et al., 2014), while Anabisetia, Morrosaurus, Kangnasaurus, Tenontosaurus, Rhabdodontidae, Dryosauridae and Ankylopollexia show a well-developed extensor groove (Cooper, 1985; Sereno, 1986; Coria \& Calvo, 2002; Norman, 2004; Norman et al., 2004; Godefroit et al., 2009; Rozadilla et al., 2016). In posterior view, the flexor fossa is deep and limited laterally and medially by stout ridges that end in the distal condyles.

Tibia (Figure 7,11 ). The proximal end of the tibia is anteroposteriorly expanded, its proximal surface is medially inclined and exhibits a rugose surface. The cnemial crest is anteriorly extended and is strongly proximally projected, resulting in a subtriangular profile in lateral view. This trait is unique for Isasicursor, different from the remaining ornithopods in which the cnemial crest does not project further proximally than the articular surface of the tibia (e.g. Gasparinisaura, Notohypsilophodon, Tenontosaurus, Ouranosaurus; Coria \& Calvo, 1996; Tennant, 2013; Ibiricu et al., 2014; Bertozzo et al., 2017), or has a distally deflected anterior margin (e.g. Anabisetia, Talenkauen, Morrosaurus, Zalmoxes; Coria \& Calvo, 2002; Godefroit et al., 2009; Rozadilla et al., 2016, 2019). The cnemial crest of Isasicursor is transversely thickened and shows a proximally rounded apex. In lateral view, the lateral crest shows a straight anterior margin. In Isasicursor it is more extensive than in Kangnasaurus, Talenkauen and Morrosaurus (Cooper, 1985; Novas et al., 2004; Rozadilla et al., 2016, 2019). The lateral condyle is subtriangular in proximal view. It shows a well-developed process at the anterolateral corner, being absent in other basal ornithopods such as Gasparinisaura, Anabisetia, Talenkauen, Jeholosaurus, Kangnasaurus,
Notohypsilophodon, Hypsilophodon, Zalmoxes, Trinisaura, and theiguanodontian Ouranosaurus (Galton, 1974a; Cooper, 1985; Coria \& Salgado, 1996; Cambiaso, 2007; Godefroit et al., 2009; Barrett et al., 2011; Han et al., 2012; Ibiricu et al., 2014; Bertozzo et al., 2017; Rozadilla et al., 2019). The lateral surface of the lateral condyle is convex and rugose. The posterior margin of the lateral condyle is defined by a dorsoventrally oriented groove. There is a notch between the lateral and the posteromedial processes. The medial surface of the cnemial crest is posteriorly delimited by a low prominence. The tibial shaft is oval in cross-section on its proximal third.

The distal end of tibia of Isasicursor is transversely expanded and anteroposteriorly compressed. The distal malleoli are weathered. Both have a subtriangular outline in anterior view and are distally rounded, as occurs in related taxa with the exception of Morrosaurus, in which the medial condyle has a sharp trapezoidal outline (Cooper, 1985; Coria \& Salgado, 2002; Cambiaso 2007; Ibiricu et al., 2014; Rozadilla et al., 2016). The lateral malleolus is transversely wider and more distally projected than the medial one. The anterior surface of the lateral malleolus bears a mound-like longitudinal crest, as occurs in Talenkauen and Anabisetia (Cambiaso, 2007; Rozadilla et al., 2019). Lateral to this crest there is a smoothly concave surface for contact with the fibula. This crest and concave surfaces are shallower in the juvenile specimen. The posterior surface of the lateral malleolus is concave. In the juvenile specimen of Isasicursor, the lateral malleolus is anteroposteriorly narrower. The medial malleolus is subtriangular in distal view, concave anteriorly and convex posteriorly, lacking the anterior curvature present in Morrosaurus and Trinisaura (Barrett et al., 2011; Rozadilla et al., 2016). The distal malleoli are separated anteriorly by a shallow anterior intermalleolar fossa and posteriorly by a thick intermalleolar crest. The anterior intermalleolar fossa is shallower in the juvenile specimen.

Metatarsals (Figures 11, 12). Metatarsal II of Isasicursor is represented by isolated proximal and distal ends. The proximal end is anteroposteriorly expanded and transversely compressed a condition that was previously considered synapomorphic for Elasmaria by Rozadilla et al. (2016, 2019). However, metatarsal II of Isasicursor is not as expanded anteroposteriorly as in Anabisetia and Diluvicursor (Coria \& Calvo, 2002; Herne et al., 2018). The lateral surface of metatarsal II shows a flattened surface for artic- 

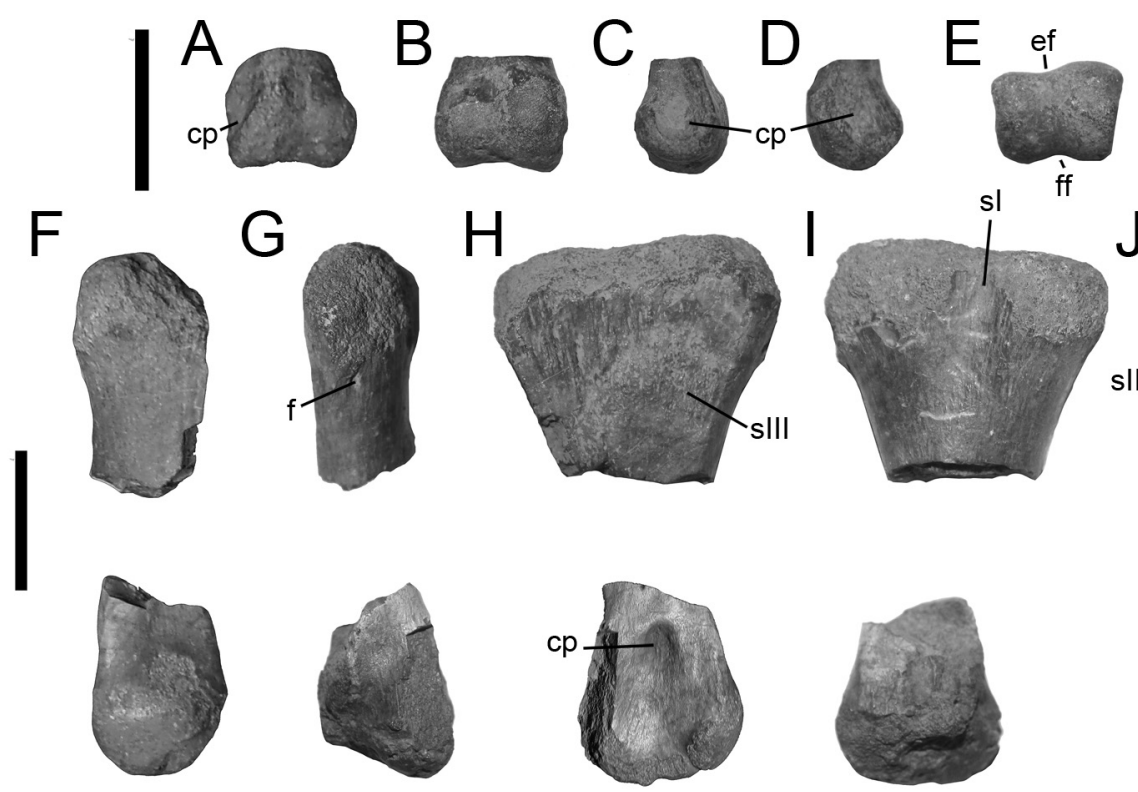

$\mathrm{G}$
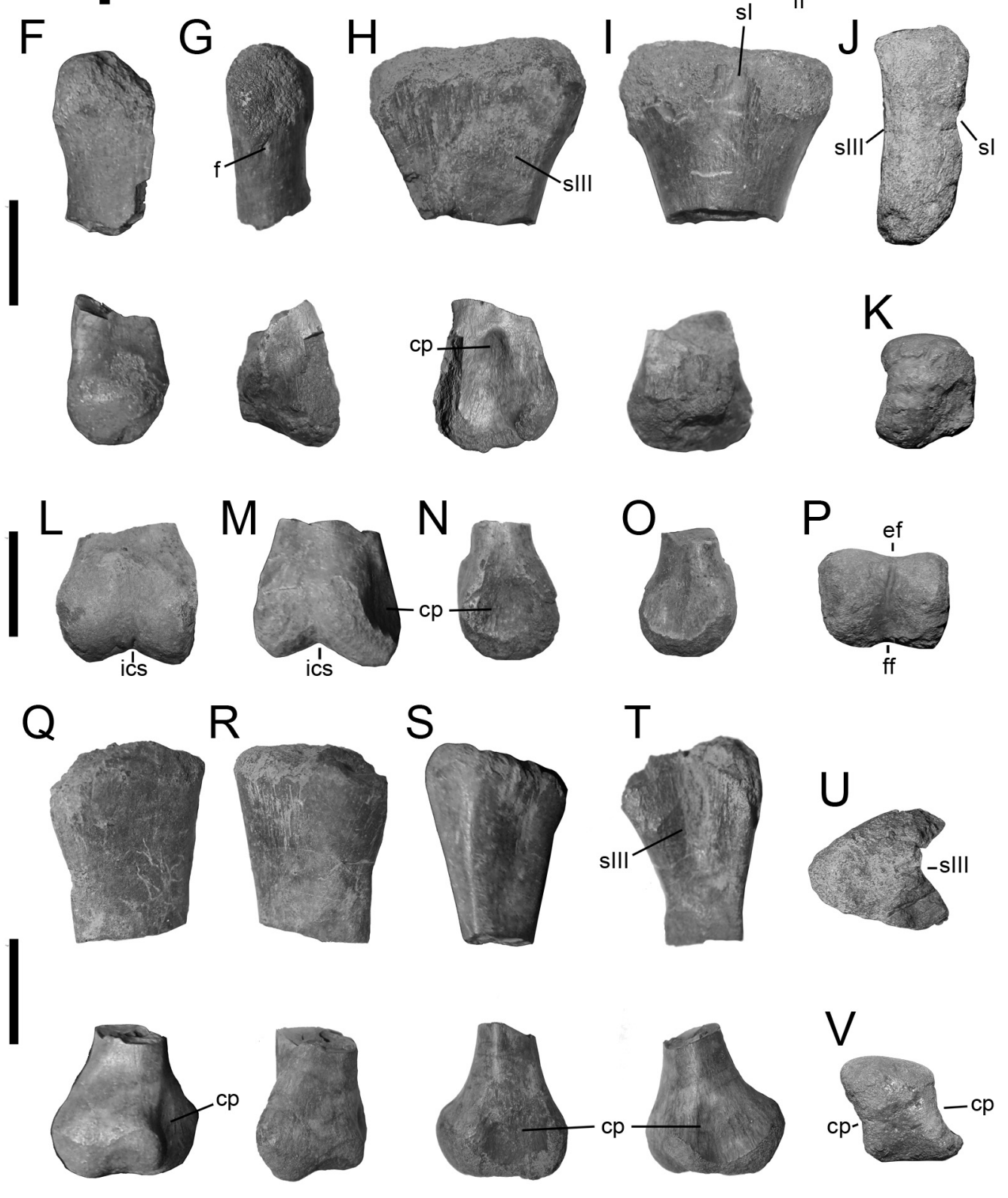

Figure 12. Isasicursor santacrucensis gen. et sp. nov. Metatarsal I in (A) anterior, (B) posterior, (C) lateral, (D) medial and (E) distal views. Proximal (above) and distal end (below) of metatarsal II (MPM 21535a) in (F) anterior, (G) posterior, (H) lateral, (I) medial (J) proximal and (K) distal views. Metatarsal III (MPM 21536) in (L) anterior, (M) posterior, (N) lateral, (O) medial and (P) distal views. Proximal (above) and distal end (below) of metatarsal IV (MPM 21537) in (Q) anterior, (R) posterior, (S) lateral, (T) medial (U) proximal and (V) distal views. Abbreviations: cp, collateral pit; ef, extensor fossa; f, foramen; ff, flexor fossa; ics, intercondylar sulcus; sI, surface for the mtt I; sIII, surface for the mtt III. Scale bar: $3 \mathrm{~cm}$. 
ulation with the medial surface of metatarsal III. The anterior surface of the bone is transversely thicker than the posterior one and is more laterally expanded. The distal end of metatarsal II has a sub-rectangular outline in distal view. The anterior surface is smooth and bears a rounded distal articular surface that is distally convex. The posterior surface has a deep flexor groove. The lateral surface is deeply concave and bears a distinct and deep collateral ligamental pit that is proximally located. This condition is absent in other elasmarians and may constitute an autapomorphy of Isasicursor. The lateral condylid is transversely thicker than the medial one. In an available juvenile metatarsal II (MPM 21535) both extensor and flexor grooves and collateral ligamental pits are shallower.

Metatarsal III is only represented by its distal end. The articular surface is asymmetrical in shape, being proximally expanded at its medial surface. The distal condylids are separated by a well-developed intercondylar groove. In distal view, the condyles are asymmetrical, the medial one being larger than the lateral one, resembling the condition of Anabisetia (Coria \& Calvo, 2002; Cambiaso, 2007), but differing from that of Morrosaurus, which shows a notably larger lateral condylid (Rozadilla et al., 2016). The lateral surface of the bone has a deep and sub-circular collateral pit, while the medial one is shallower.

Metatarsal IV is represented by several elements of different specimens. The most complete metatarsal IV belongs to a juvenile specimen, while larger specimens are represented by isolated proximal and distal ends. The proximal end is transversely expanded and is subtriangular in proximal view, with a tapering lateral surface, as occurs in Gasparinisaura, Anabisetia, Thescelosaurus and Trinisaura (Galton, 1974b; Coria \& Salgado, 1996; Coria \& Calvo, 2002; Barrett et al., 2011), whereas in Talenkauen, Morrosaurus and Styracosterna the lateral surface is rounded (Norman, 2004; Rozadilla et al., $2016 ; 2019)$. The proximal surface is gently concave and its posterior margin is more proximally extended than the anterior one. The medial surface is deeply concave with a narrow proximal groove that receives the lateral process of metatarsal III. Distal to this groove, the medial surface of the bone shows a flat contact for the lateral surface of metatarsal III. The anterior and posterior surfaces of the proximal end of the bone are flattened and smooth. In cross section, the bone is subtriangular proximally and oval distally. The lateral margin of the shaft shows a sharp longitudinal keel. The anterior surface of the shaft is smooth, while the posterior one possesses an oblique ridge that runs from the medial margin to the lateral distal condyle. The distal end is strongly anteroposteriorly expanded. In anterior view, the articular surface lacks a welldefined extensor groove. In lateral view, there is a shallow collateral pit that is suboval in contour and with a strongly anteriorly projected anterior articular surface. In distal view, the articular surface has sub-parallelogram outline, with its anterior margin more laterally projected than the posterior one. The posterior margin is medially projected, forming a lip-like process that projects laterally, a condition shared with Anabisetia and Trinisaura (Cambiaso, 2007; Barrett et al., 2011). This projection posteriorly bounds the outer collateral pit. In posterior view a shallow flexor groove separates both condylids.

MPM 21538 is proximodistally short and transversely stout. In related taxa, such as Gasparinisaura, Anabisetia and Morrosaurus, the adult specimens possess a more slender metatarsal IV than in different-sized Isasicursor specimens (see Coria \& Salgado, 1996; Cambiaso, 2007; Rozadilla et al., 2016).

Phalanges (Figure 13). Pedal toes of Isasicursor are represented by several damaged phalanges belonging to several individuals. Available phalanges are relatively stout and short, with a flattened ventral surface and wide and deep collateral ligamental pits.

Phalanx I-1 is represented by its distal end. The distal trochlea is well developed, with low condyles divided by a deep intercondylar groove. The preserved portion of the shaft is slender and the distal trochlea is strongly transversely expanded. Deep and sub-circular collateral pits are present. Phalanx II-1 shows a concave and subtriangular-shaped proximal articular surface. The proximal end narrows distally. The medial surface has several muscular scars near its proximal surface, which are continuous ventrally with a ventral ridge. In ventral view, the proximal portion of this phalanx possesses two collateral ridges, in which the medial one is more robust and ventrally extended. The lateral ridge is shallower and more laterally projected. These ridges are separated by a proximal concavity. The shaft is sub-rectangular in cross-section. Three notably anteroposteriorly short phalanges from digit IV were recovered. We identify these elements as IV-2/IV-3? The proximal surface is weathered, but shows a well-developed dorsoventral ridge separating it symmetrically, as occurs in phalanges of 

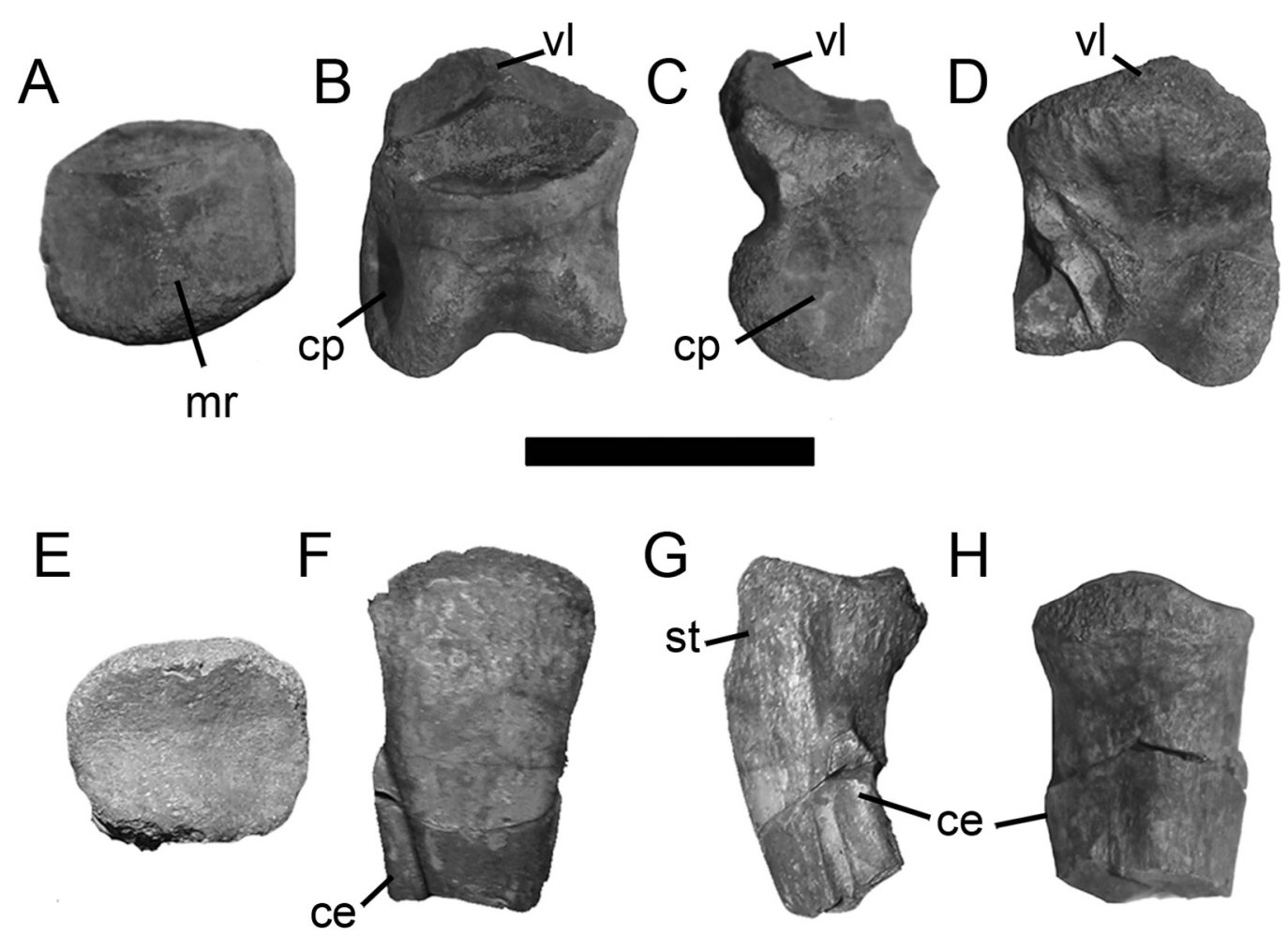

Figure 13. Isasicursor santacrucensis gen. et sp. nov.Pedal phalanx IV-2/IV-3? (MPM 21539) in (A) proximal, (B) dorsal, (C) lateral and (D) ventral views. Ungual phalanx (MPM 21540) in (E) proximal, (F) dorsal, (G) lateral and $(\mathbf{H})$ ventral views. Abbreviations: ce, collateral expansions; cp, collateral pit; mr, median ridge; st, striations; vl, ventral lip. Scale bar: $3 \mathrm{~cm}$.

the fourth digit in other elasmarians (Rozadilla et al., 2019). The ventral margin of the proximal surface is proximally projected, forming a welldeveloped posteroventral process. The distal trochlea is well-defined and is proximally delimited by a transversely oriented groove. In the dorsal surface of the bone there is a small extensor pit proximal to the distal articular surface. Distal condyles are well developed and separated by a deep intercondylar groove. Deep collateral pits occur at the sides of each distal condyle. These phalanges are anteroposteriorly short, as occurs in Talenkauen and derived iguanodontians (Norman et al., 2004; Norman 2004; Rozadilla et al., 2019), whereas more basal ornithopods and smaller elasmarians show proportionally longer pedal phalanges (Coria \& Calvo, 2002; Cambiaso, 2007; Coria et al., 2013).

At least six pedal unguals were recovered. We tentatively identify the most complete elements as unguals of the third digit. The proximal surface is suboval in proximal view, being transversely wider than dorsoventrally deep. This surface is asymmetrically divided by a dorsoventral ridge, with the lateral articular surface larger than the medial one. The dorsal margin of the articular surface projects proximally into a proximal lip. The blade is dorsoventrally flattened, and slightly medially curved. The dorsal surface is smooth and convex, while the ventral one is flat. The ungual possesses two flattened longitudinal steplike expansions that are dorsally delimited by a longitudinal collateral groove. The distal end of the ungual is notably acute. The ungual is decorated with striations near its proximal and distal ends and on the ventral surface. The flexor tubercle is represented by a poorly developed and transversely expanded bump, decorated with muscle-scar striations. The overall morphology of these phalanges resembles that of other basal ornithopods (e.g., Norman et al., 2004; Canudo et $a l ., 2013)$, but contrasting with the blunt hooflike unguals of styracosternan ornithopods (e.g., Norman 2004; Horner et al., 2004).

Comments. The morphology of the proximal end of femur and humerus shows synapomorphic features supporting Isasicursor belongs to the Elasmaria (e.g., cervical vertebrae laterally 
compressed and with a sharp ventral keel; laterally bowed humerus with a rudimentary deltopectoral crest; femur with greater trochanter showing a sigmoidal lateral margin in proximal view; and metatarsal II laterally compressed in proximal view; Rozadilla et al., 2016; 2019). Among elasmarians, Isasicursor shows unique features in several elements, especially the proximal end of tibia and sacrum, indicating that it is a clearly distinctive and diagnosable taxon. Its size is similar to that of larger taxa, such as Sektensaurus, Morrosaurus, Talenkauen and Macrogryphosaurus. However, the incomplete nature and dissociated preservation of available material precludes the recognition of the relationships of Isasicursor within Elasmaria.

The Upper Cretaceous record of basal iguanodontians from Argentina and Antarctica includes the Cenomanian-Turonian Talenkauen and Anabisetia, and the Campanian Trinisaura and Morrosaurus from Antarctica (Coria et al., 2013), whereas Sektensaurus has a poorly constrained age that ranges from Coniacian to Maastrichtian (Ibiricu et al., 2018). Previous reports of Campanian-Maastrichtian basal ornithopods from Northern Patagonia were dismissed (Agnolin et al., 2010). In this way, Isasicursor constitutes the first Maastrichtian basal iguanodontian from the southern cone.

Ornithopods are frequently recorded as taphonomic associations composed by several individuals (e.g, Horner \& Makela, 1979; Salgado et al., 1997; Andrzejewski et al., 2019). Isasicursor is known from several specimens corresponding to different sizes that likely represent different ontogenetic stages, found together in a reduced fossiliferous spot (i.e., a bed roughly $5 \mathrm{~m}$ long and $0.50 \mathrm{~m}$ thick). This leads to the interpretation that this taxon had a gregarious behavior, at least at the time of their death. In South America the finding of different individuals in close association is common, as demonstrated by Talenkauen santacrucensis, in which the holotype specimen was found associated with a neonatal tooth (Egerton et al., 2013), and Anabisetia and Gasparinisaura which are known from several individuals (Salgado et al., 1997; Coria \& Calvo, 2002). This may indicate that Isasicursor and other elasmarians were gregarious, a condition well-known among their Laurasian counterparts (Andrzejewski et al., 2019).

Hadrosaurs appear in the South American fossil record at the Campanian-Maastrichtian time span, being represented by abundant remains corresponding to different species (Brett-
Surman, 1979; Bonaparte et al., 1984; JuarezValieri et al., 2010; Coria et al., 2012; CruzadoCaballero \& Powell, 2017). These dinosaurs were outstanding components of the South American "Allenian vertebrate assemblage" (see Leanza et al., 2004), which includes other herbivorous dinosaurs such as titanosaurs and ankylosaurs (Bonaparte, 1986). In a global context, the record of Campanian-Maastrichtian basal ornithopods suggests a decline in diversity with respect to previous times, whereas hadrosaurs exhibit a notorious "evolutionary explosion" during the end of the Late Cretaceous (Horner et al., 2004). In that time span, basal ornithopods are nearly exclusively represented by the European Rhabdodontidae and the North American Thescelosauridae (Weishampel et al., 2003; Boyd et al., 2009; Ösi et al., 2012; Boyd, 2015). The same seems to be true for South America, where ornithopods are only represented by small to medium sized elasmarians.

The discovery of diverse elasmarian in Campanian-Maastrichtian beds of Patagonia and Antarctica (e.g. Trinisaura, Morrosaurus, Sektensaurus, Isasicursor; Ibiricu et al., 2010; 2019; Coria et al., 2013; Rozadilla et al., 2016) suggest that some of these basal ornithopods coexisted with hadrosaurs. This, together with the much smaller size of elasmarians, suggests that some kind of niche partitioning occurred among Gondwanan ornithopods (see Brett-Surman, 1979; Case et al., 2000).

\section{Sauropoda Marsh, 1878}

Titanosauriformes Salgado, Calvo \& Coria, 1993

Titanosauria Bonaparte \& Coria, 1993

Genus and species indeterminate

Referred material: MPM 21542, three isolated teeth (locality 4).

Description. Available teeth lack the tip of the crown and most of the enamel. They are pencil-like as typical for titanosaurs (e.g. García \& Cerda, 2010). The enamel is smooth and the teeth are subcircular in cross-section. There is no clear difference in thickness between crown and root.

Comments. The general crown outline is similar in the three collected teeth, including a pencillike general aspect with poor labiolingual compression and lacking mesial and distal carinae. These are features typical of titanosaur dentition (García \& Cerda, 2010). Further, the absence of needle-like teeth and lack of strong enamel ornamentation, argue against rebbachisaurid af- 
finities for the collected specimens (Salgado et $a l .$, 2004). In sum, MPM 21542 is regarded as Titanosauria indet.

\section{?Colossosauria González Riga, Lamanna, Otero, Ortíz, Kellner and Ibiricu, 2019}

\section{Nullotitan glaciaris gen. et sp. nov.} Figure 14

Holotype. MACN-PV 18644 and MPM 21542, the specimen consists of isolated cervical centrum (presumably Cv3; MACN-PV 18644), fragmentary cervical rib shaft, dorsal rib shaft fragments, several caudal vertebrae, fragmentary left scapula, proximal and distal ends of right femur, almost complete right tibia, fibula, and astragalus. The holotype specimen comes from locality 1 . It also includes an isolated cervical catalogued with collection number MACN-PV 18644 by J. F. Bonaparte in 1981, and then catalogued as cf. Antarctosaurus. Later, Bonaparte et al. (2002) interpreted this titanosaur as related with Aeolosaurus; Powell (2003), instead, referred the material as to Titanosauridae indet.

Referred specimens. The following specimens were collected from other nearby localities, from levels above and below the holotype: 1) MPM 21545 , complete humerus, lacking cortex of midshaft, partial rib, and vertebra, which were found preserved ex situ, about 100 meters far from the place of the holotype specimen. These elements were found relatively high on the slope, indicating they correspond to a different individual than the holotype. Further, the humerus belongs to an individual smaller than the holotype. 2) MPM 21546 (locality 1), isolated and partially preserved distal caudal centra. 3) MPM 21547 (locality 5), sequence of five mid-caudal vertebrae with their respective haemal arches, found articulated in situ. This specimen still remains in the field. 4) MPM 21548 (locality 2), isolated complete left tibia. 5) MPM 21549 (locality 2), proximal to mid-caudal centrum, found ex situ some meters far from the isolated tibia.

Stratigraphic provenance. All aforementioned specimens come from the lower and middle sections of the Chorrillo Formation, being absent from the upper third of this unit. The upper-most record is from locality 4 , which was found from beds lying above a thick conglomerate bank. This later specimen is not yet numbered, still remaing in the field. This later specimen still remains unnumbered, waiting to be excavated from the field.
Diagnosis. Large titanosaurian sauropod diagnosable on the basis of the following combination of characters (autapomorphies marked with an asterisk*): 1) anterior caudal centra notably anteroposteriorly short, its transverse diameter duplicating its anteroposterior length; 2) proximal and mid-caudal centra with lateral and ventral surfaces profusely excavated by large blind depressions*; 3) mid-caudal vertebrae with lateral surface with a tabicate large fossa below the transverse process; 4) centra of all available caudal vertebrae lacking signs of pneumatization; 5) mid-caudals with a deep ventral longitudinal furrow surrounded by two longitudinal thick ridges; 6) fibula with a pronounced sigmoid curvature when viewed anteriorly or posteriorly*; and 7) distal end of tibia strongly anteroposteriorly compressed and more transversely expanded than in other titanosaurs.

Etymology. Nullotitan, in honor of geologist Francisco E. Nullo, discoverer of the holotype specimen, and titan, powerful giant; the specific name glaciaris refers to the majestic Perito Moreno Glacier, observable from the excavation site.

Remarks. Fossil remains of sauropods from Chorrillo beds, albeit fragmentary, consist of bones, teeth and egg-shell fragments. Bones that are here referred as to Nullotitan glaciaris were found broken and forming different bone accumulations, spread over 100 square meters on a slope surface. All collected elements belong to large titanosaur sauropods, and no overlapping bones exist among these five discrete bone accumulations. The available bones that were found in situ, come from a reduced spot of hard green sandstone exposed at the top of the slope; in contrast, the remaining sets of bones were collected down on the slope, and were exposed ex situ, but some of them still preserving bits of the green sandstone exposed on the top of the slope. No dermal ossifications have been discovered in Chorrillo beds, either isolated or in association with bone remains.

Description. Almost all the collected titanosaur bones belong to large sized individuals. Estimated length of the holotype specimen almost probably surpassed 20 meters long, based on extrapolations of available elements with the fairly complete titanosaurs Dreadnoughtus and Patagotitan (Lacovara et al., 2014; Carballido et al., 2017).

Cervical vertebra (Figure 15). Neck vertebrae are represented just by a single, incomplete centrum, collected by J. F. Bonaparte in 1981 


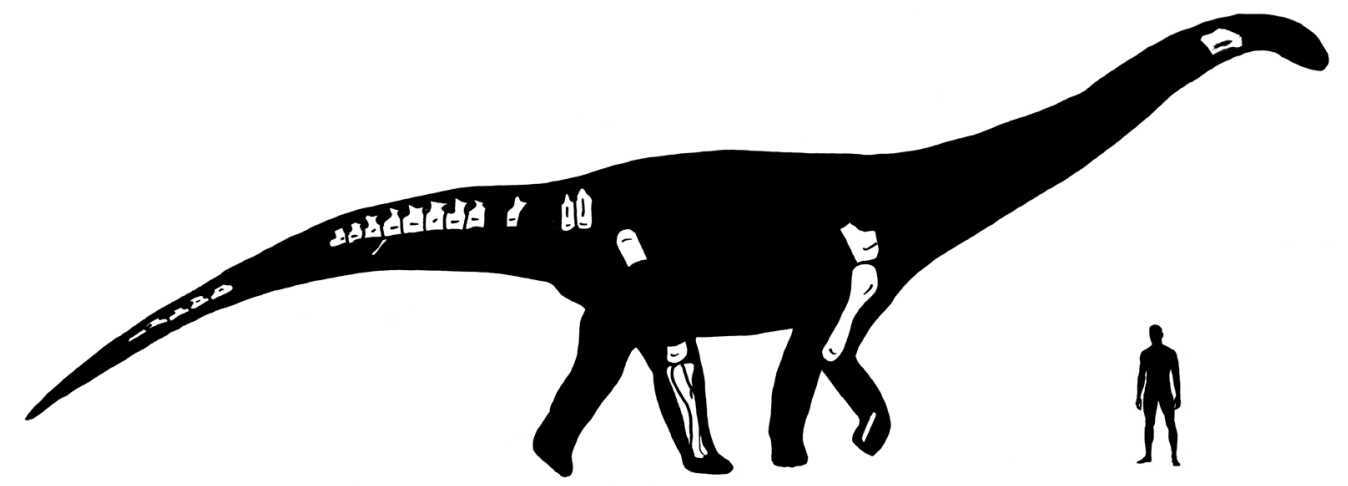

Figure 14. Nullotitan glaciaris gen. et sp. nov. Silhouette showing the recovered elements.

(MACN-PV 18644). It is elongate (45cm long) and dorsoventrally low $(22 \mathrm{~cm})$. The centrum is opisthocoelous. The parapophyses are tabular shaped, dorsoventrally depressed, and anteroposteriorly extended. The sides of the centrum are deeply excavated between parapophysis and diapophysis, bearing a large and elliptical pleurocoel at the bottom of the excavation. In anterior view the vertebra is cross-shaped, due to the development of para- and diapophyses bounding the centrum. There are subhorizontally oriented longitudinal ridges that run from diapophyses to parapophyses. The ventral surface of centrum is flattened and smooth, as is usual in basal sauropods (Tazoudasaurus, Shunosaurus, Patagosaurus), basal macronarians (Camarasaurus), and titanosaurs (Malawisaurus, Rapetosaurus, Isisaurus, Trigonosaurus,Neuquensaurus andSaltasaurus), and unlike some basal Titanosauriformes (Giraffatitan, Paluxysaurus and Tendaguria) and diplodocoids (Apatosaurus, Diplodocus and Limaysaurus) where it is transversely concave. This combination of features suggests it may correspond to $\mathrm{Cv} 3$. The internal structure is camellate, as occurs in some basal Titanosauriformes (Giraffatitan), basal somphospondylians (Erketu, Ligabuesaurus, Phuwiangosaurus), titanosaurs (Mendozasaurus, Malawisaurus, Rapetosaurus, Isisaurus, Trigonosaurus, Alamosaurus, Neuquensaurus, Saltasaurus) and some diplodocids (Apatosaurus and Diplodocus), and unlike other sauropods where inner pneumaticity of the cervical centrum is absent (e.g., Patagosaurus) or present but with several small and complex internal cavities (Camarasaurus, Limaysaurus). Caudal vertebrae (Figures 16-18). The holotype of Nullotitan glaciaris includes different caudal elements, corresponding to proximal and middle section of the tails. Most of them are only represented by incomplete centra, with limited information regarding transverse processes and neural arches. Location of each of these isolated elements along the caudal series is tentative and based on the ratio between anteroposterior length vs. transverse width of centra, contour of centra (i.e., proportional development of primary and secondary lateral surfaces), presence and relative development of articular surfaces for haemal arches, degree of convexity of the posterior articulation of centrum, and profusion and size of blind perforations on lateral and ventral surfaces. In contrast with cervical elements, all available caudals are apneumatic, and the internal tissue is compact.

Proximal caudals characterize for the following combination of features: 1) anteroposteriorly short centra; 2) centrum transversely wide and elliptical-shaped in anterior view; 3) lateral and ventral surfaces profusely excavated by large, blind perforations; 4) centrum lateral surface (below transverse process) steeply inclined ventrally and medially; 5) transverse processes dorsoventrally deep and anteroposteriorly compressed. Mid-caudals exhibit: 1) squared-shaped centra in side view; 2) ball-shaped distal articular surface; 3 ) centra with a deep ventral longitudinal furrow; 4) blind excavations reduced in size, but still abundant in number; 5) transverse processes reduced in size, cone-shaped, and located at centrum mid-height. Finally, distal caudals exhibit: 1) relatively elongate centra; and 2) posterior articular surface cone-shaped and transversely wide in posterior view.

Regarding the distribution among Titanosauria of the blind, apneumatic excavations which do not enter inside the centrum, there are some cases in which similar depressions exist (see Martinelli et al., 2011). For ex- 

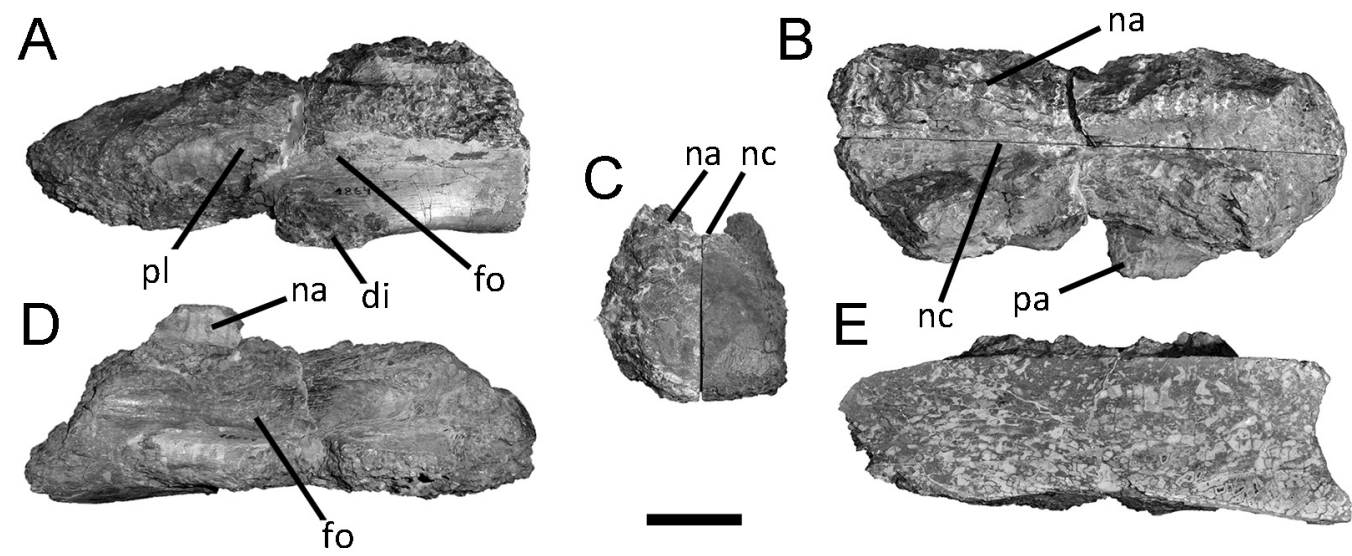

Figure 15. Nullotitan glaciaris gen. et sp. nov. Cervical vertebra (MACN Pv 18644) in left lateral (A), dorsal (B), posterior (C), right lateral (D), and longitudinal section (E) views. Abbreviations: di, diapophysis; fo, fossa; na, neural arch; nc, neural canal; pa, parapophysis; pl, pleurocoele. Scale bar: $10 \mathrm{~cm}$.

ample, in Drusilasaura the ventral surface of Cd4? exhibits a pair of large elliptical openings which were considered autapomorphic for this species (Navarrete et al., 2011). Similarly, Salgado (1996) reported on caudals 2 through 4 of Pellegrinisaurus the presence of small holes on each side of the centrum. However; in Nullotitan the excavations are larger than in other titanosaurs, and much more abundant.

The following description of caudal elements positions the ventral surface of centrum on the horizontal plane. The dorsoventral axis of centrum (especially in proximal caudals) is vertically positioned, and forming a right angle with the ventral surface of centrum. Thus, the floor of the neural canal results inclined ventrodistally (in side view) with respect to ventral surface of centrum. This means that the caudal series, when reconstructed articulated in line with the sacrum, show the neural canal inclined, accompanying the dorsoventral lowering of vertebrae.

Caudal 1 1t? (Figure 16). It is represented by most of its centrum and the base of the neural arch. The later one occupies a central to cranial position in lateral view, similar to other titanosaurs (e.g., Patagotitan; Carballido et al., 2017). The centrum is $40 \mathrm{~cm}$ in transverse width, $34 \mathrm{~cm}$ in dorsoventral depth, and $22 \mathrm{~cm}$ in anteroposterior length (but probably $25 \mathrm{~cm}$ when complete). Transverse processes are broken at their bases but revealing a prominent vertical structure. They are dorsoventrally deep, extending over the dorsal half of the lateral centrum surface. In side view it is seen that the transverse process occupies a central position on the lateral surface of the vertebra. The anterior articular surface is surrounded by a well-developed rim. The dorsal part of transverse processes extends dorsally, well above level of neural arch. Transverse processes are cranially concave and caudally convex. On its cranial surface, the transverse process bears a pair of large, eye-shaped, blind excavations. On the surface behind the transverse process, there is only one of these excavations. Below the transverse processes, the centrum becomes strongly constricted due to the ventromedial slope of the lateral surface. Notably, this lateroventral surface of the centrum exhibits large and blind, randomly distributed perforations, consisting in fossae separated by ridges. The lateroventral surface of centrum forms an inflexion with the flattened ventral surface. The ventral surface of the centrum is perforated by isolated longitudinally oriented, blind depressions, which develop on the posterior half of the bone.

The cranial articular surface is deeply concave. The distal articular cone is eroded, so its caudal projection is difficult to discern; however, it seems to have been hemispheric, as usual among titanosaurs.

The neural canal is oval-shaped, with its floor concave that widens posteriorly (in dorsal view). The later region is highly vascularized, as suggested by abundant foramina. On the posterior surface of the base of neural arch, there is a median fossa immediately above the neural canal. No facets for haemal arches are present.

Caudal 2 ${ }^{\text {nd }}$ ? (Figure 17). It is represented by the dorsal half of centrum and the badly preserved bases of the neural arch, including the base of the right transverse process. As in Cd1st, the centrum is anteroposteriorly very short, but 

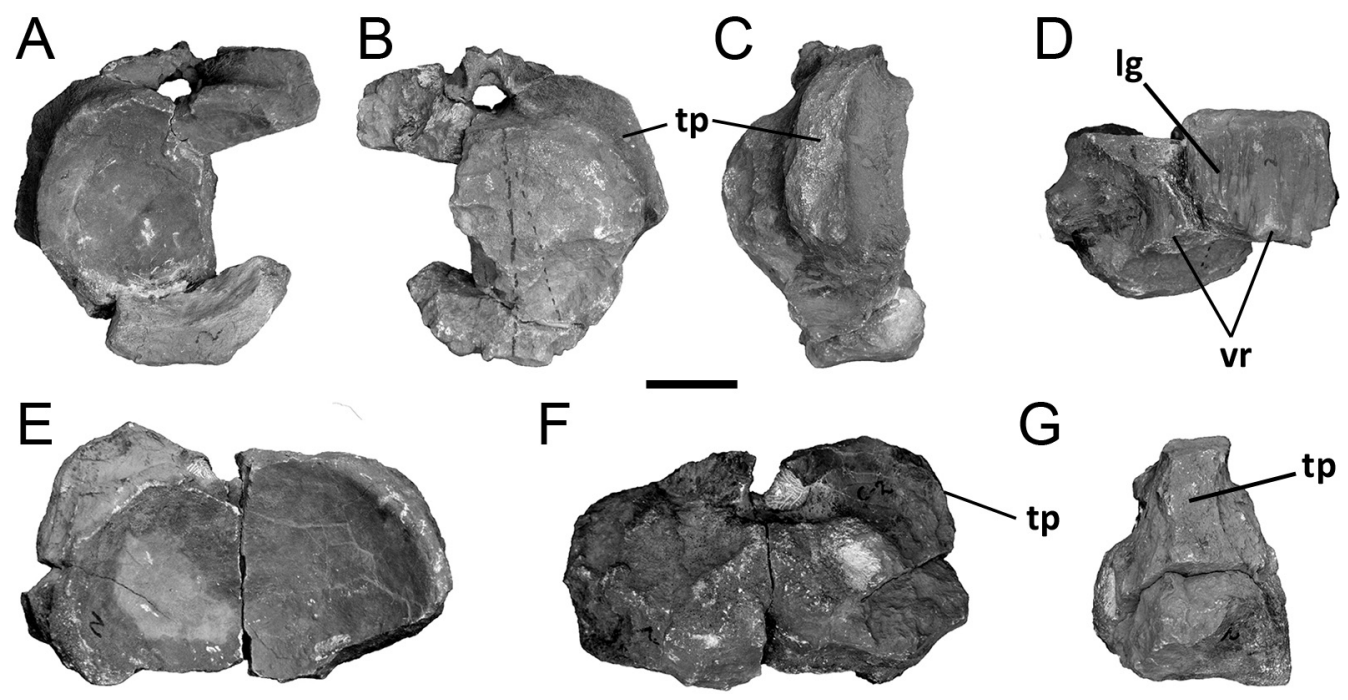

G

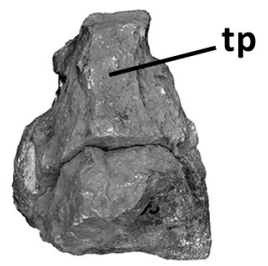

Figure 16. Nullotitan glaciaris gen. et sp. nov. Caudal vertebrae?1st (A-D) and ?2nd (E-G) (MPM 21542) in anterior $(\mathbf{A}, \mathbf{E})$, posterior $(\mathbf{B}, \mathbf{F})$, right lateral $(\mathbf{C}, \mathbf{G})$, and ventral (D) views. Abbreviations: lg, longitudinal groove; tp, transverse process. Scale bar: $10 \mathrm{~cm}$.

transversely wide. The transverse processes are eroded, but the preserved portions indicate they were dorsoventrally deep. However, they are shallower than in Cd1st, due to the lower margin in a higher position on the lateral surface. The cranial and caudal surfaces of the transverse process are concave-convex, as in Cd1st. Regarding the blind depressions, they are similar to those of Cd1st. The cranial articular surface seems more concave than in Cd1st. The floor of the neural canal is fan-shaped in dorsal view, being transversely expanded towards the rear.

Caudal $4^{\text {th }}$ ? or $5^{\text {th }}$ ? (Figure 18). It is represented by most of the centrum and base of neural arch and base of left prezygapophysis. The centrum is dorsoventrally and transversely smaller than the caudals previously described, but it is anteroposteriorly as long as these centra. The lateral surface of centrum orientates lateroventrally. The base of right transverse process is sub-conical, and it locates immediately below level of neural canal. Due to the higher position of transverse process, the lateral surface of centrum is more developed than in more proximal caudals. In sharp difference from more proximal caudals, the base of the transverse process reaches the anterior margin of centrum, thus the later results devoid of a lateral surface in front the transverse process. Regarding the blind depressions, they are similar to those of more proximal caudals, being more developed towards the posterior margin of centrum. Blind depressions on the ventral sur- face are more elongate and deeper than those of the lateral surface. The ventral surface of centrum is almost flat.

The base of prezygapophysis indicates that it was anterodorsally projected. The base of the spinoprezygapophyseal lamina, the only portion preserved, is nearly horizontal and sharp. On the internal surface of neural arch, behind the base of prezygapophysis, and above the intraprezygapophyseal lamina (TPRL), there is an elongate fossa. The floor of neural canal is flat; it widens posteriorly as in the remaining proximal caudals. Due to poor preservation, there is no evidence of facets for articulation with the haemal arches.

Mid-caudals (Figure 18). Possible caudals 11 and 12 are preserved. Because it is not easy to elucidate the respective position of these vertebrae, we describe them together. They are approximately half the size of the available proximal caudals. The base of the neural arch occupies most of the anteroposterior length of centrum (discounting the hemispherical posterior articular surface). The floor of the neural canal exhibits foramina and longitudinal grooves on its posterior half. The centrum is damaged along the anterior articular rim. The caudal surface is hemispherical, but slightly eccentric in side view, with the maximum convexity on the dorsal half. In distal view, the contour of the articular surface is sub-quadrangular, with the major axis vertically oriented. The lateral surface has a large fossa below the transverse process, as well 

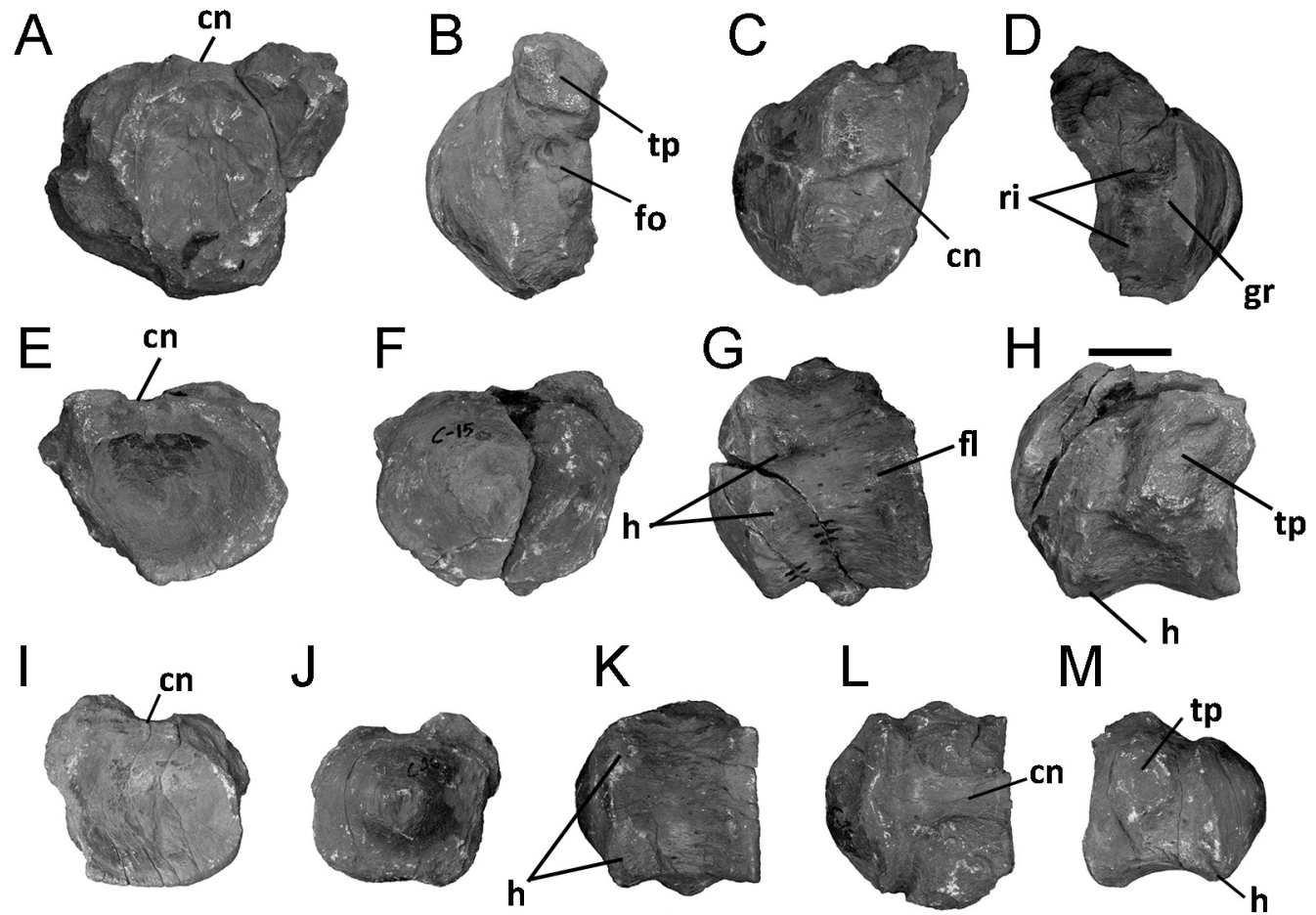

M

$\mathrm{N}$

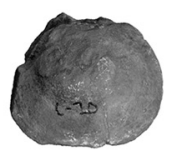

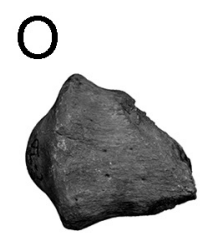
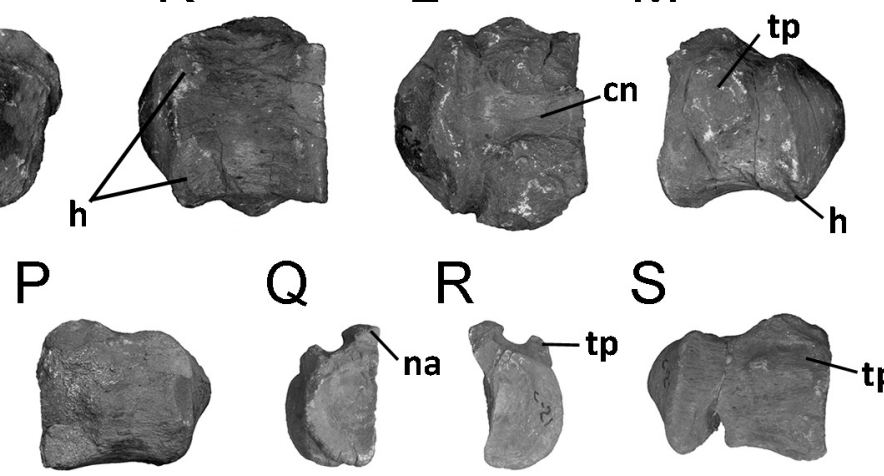

Figure 17. Nullotitan glaciaris gen. et sp. nov. Caudal vertebrae ?11th (A-D), ?15th (E-H), ?16th (I-M), ?20th (N-Q), and ?21th (R, S) (MPM 21542). The elements are figured in anterior (A, E, I, Q, R), lateral (B, H, M, P, $\mathbf{S})$, dorsal $(\mathbf{C}, \mathbf{L})$, ventral $(\mathbf{D}, \mathbf{G}, \mathbf{K}, \mathbf{O})$, posterior $(\mathbf{F}, \mathbf{J}, \mathbf{N})$ views. Abbreviations: cn, neural canal; tp, transverse process; fo, fossa; $\mathbf{h}$, haemal facet; gr, groove; na, neural arch. Scale bar: $10 \mathrm{~cm}$.

as deep blind depressions, which are located on the central region of the centra.

The ventral surface exhibits a deeply excavated central depression, flanked by strong longitudinal ridges. The inner side of these ridges exhibits randomly distributed, and longitudinally elongate foramina, which are much smaller that the blind fossae described for the proximal caudals. Facets for articulation with the haemal arches are present. Transverse processes are located at level of neural canal, and the preserved bases suggest they were robust.

Caudals 15 $^{\text {th }}$ and $\mathbf{1 6}^{\text {th }}$ (Figure 18). They are quadrangular in caudal view, being wider than tall, different from the mid-caudals described above. The posterior surface is less spherical than in previous caudals, and the spherical articulation is placed on the center of the surface and with a flat surface surrounding it.

In caudal 15, the articulation for the haemal arches, placed on the posteroventral border of centrum, are closer to each other $(5 \mathrm{~cm})$ than in caudal 16th $(6-7 \mathrm{~cm})$; the primary lateral surfaces (Salgado \& García, 2002) are dorsoventrally oriented and dorsoventrally deeper $(7 \mathrm{~cm})$ than in caudal 16 th $(4 \mathrm{~cm})$, where they are ventrally oriented. According to the interpretation of Salgado and García (2002), this would indicate that the M. caudofemoralis extended distally as much as caudal 16th.

Distal caudal centra (Figure 18). No complete distal centra are available. The centra are procoelous, and notably dorsoventrally compressed. The anterior articular surface is subcircular in contour. The posterior articular surface is kidney-shaped and shows an eccentric distal cone, 

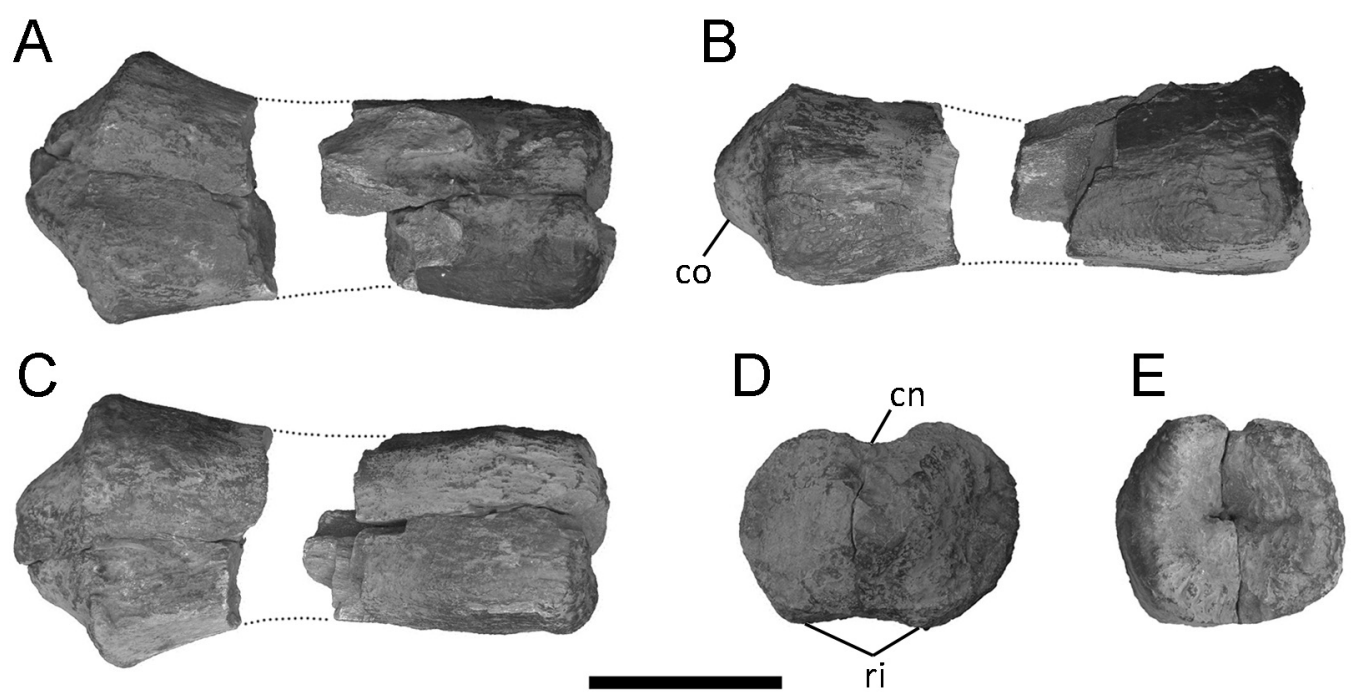

Figure 18. Nullotitan glaciaris gen. et sp. nov. Distal caudal vertebrae (MPM 21542) in dorsal (A), lateral (B), ventral $(\mathbf{C})$, posterior $(\mathbf{D})$, anterior (E) views. Abbreviations: cn, neural canal; co, articular cone; ri, ridge. Scale bar: $10 \mathrm{~cm}$.

dorsally displaced. At least in caudal 19th, the primary lateral surfaces are constrained to the ventral face of centrum.

Haemal arches. Haemal arches are represented by two single elements. They are rod-shaped and proximally opened. In lateral view they show a gentle sigmoid curvature.

Scapula (Figure 19). The central portion of a left scapula is preserved (the following description assumes the long axis of scapula as vertically oriented). This portion of the scapula lacks both glenoidal and acromial regions. It is a plate-like bone, medially concave and laterally convex. The most notable feature preserved on this fragmentary scapula is a medial tubercle with a muscle scar located dorsal to the level of the acromial process and close to the anterior margin of the bone. The tubercle is triangular-shaped, with the apex oriented ventrally. Such prominence has been also reported in other titanosauriforms (e.g., Wintonotitan, Alamosaurus; D`Emic, 2012; Poropat et al., 2015). A ventromedial process is observed on the ventral margin of the scapula, as reported in Ligabuesaurus (Bonaparte et al., 2006).

Humerus (Figure 20). A fairly complete right humerus (MPM 21545) is available. It measures 114 $\mathrm{cm}$ in total length, $44 \mathrm{~cm}$ in maximum proximal width, and $40 \mathrm{~cm}$ of maximum distal width (midshaft is damaged, and its reconstructed maximum width is estimated in $25 \mathrm{~cm}$ ). The robust index (RI; maximum distal width/total length) of Nullotitan is estimated in 0.28 , being comparable to that of Epachthosaurus (RI=0.27), Mendozasaurus, $(\mathrm{R}=0.24$; Martínez et al., 2004; Mannion \& Otero, 2012), Patagotitan (RI estimated $=0.28$; Carballido et al., 2017), and Notocolossus (RI $=0.28$; González Riga et al., 2016). These humeral proportions differ from the robust humeri (RI more than 0.28) of Dreadnoughtus $(\mathrm{RI}=0.33)$, Neuquensaurus $(\mathrm{RI}=0.35$, Salgado et al., 2005; Otero, 2010), Saltasaurus (RI=0.36; Powell, 2003), and Opisthocoelicaudia ( $\mathrm{RI}=0.41$; Borsuk-Bialynicka, 1977). Bonaparte et al. (2002) considered the humerus of Nullotitan similar to Aeolosaurus rionegrinus (Powell, 2003) in their slender proportions, but the RI of the latter one can not calculated because the humerus is incomplete.

The humeral deltopectoral crest of Nullotitan is markedly expanded distally as it occurs in practically all sauropods. In Nullotitan, the greater anterior expansion of the lower portion of the deltopectoral crest is placed at nearly $25 \%$ of the total length of the bone beginning from the top. This means a shorter deltopectoral crest, with values more similar to those of basal titanosaurs such as Paralititan and Epachthosaurus the ratio is nearly 31\% (Smith et al., 2001; Martínez et al., 2004). In other forms, in turn, the deltopectoral crest is more distally extended, such as in Elaltitan (36\%; Mannion \& Otero, 2012), Dreadnoughtus (37\%), Patagotitan (33.6\%; Carballido et al., 2017), Narambuenatitan and Mendozasaurus 


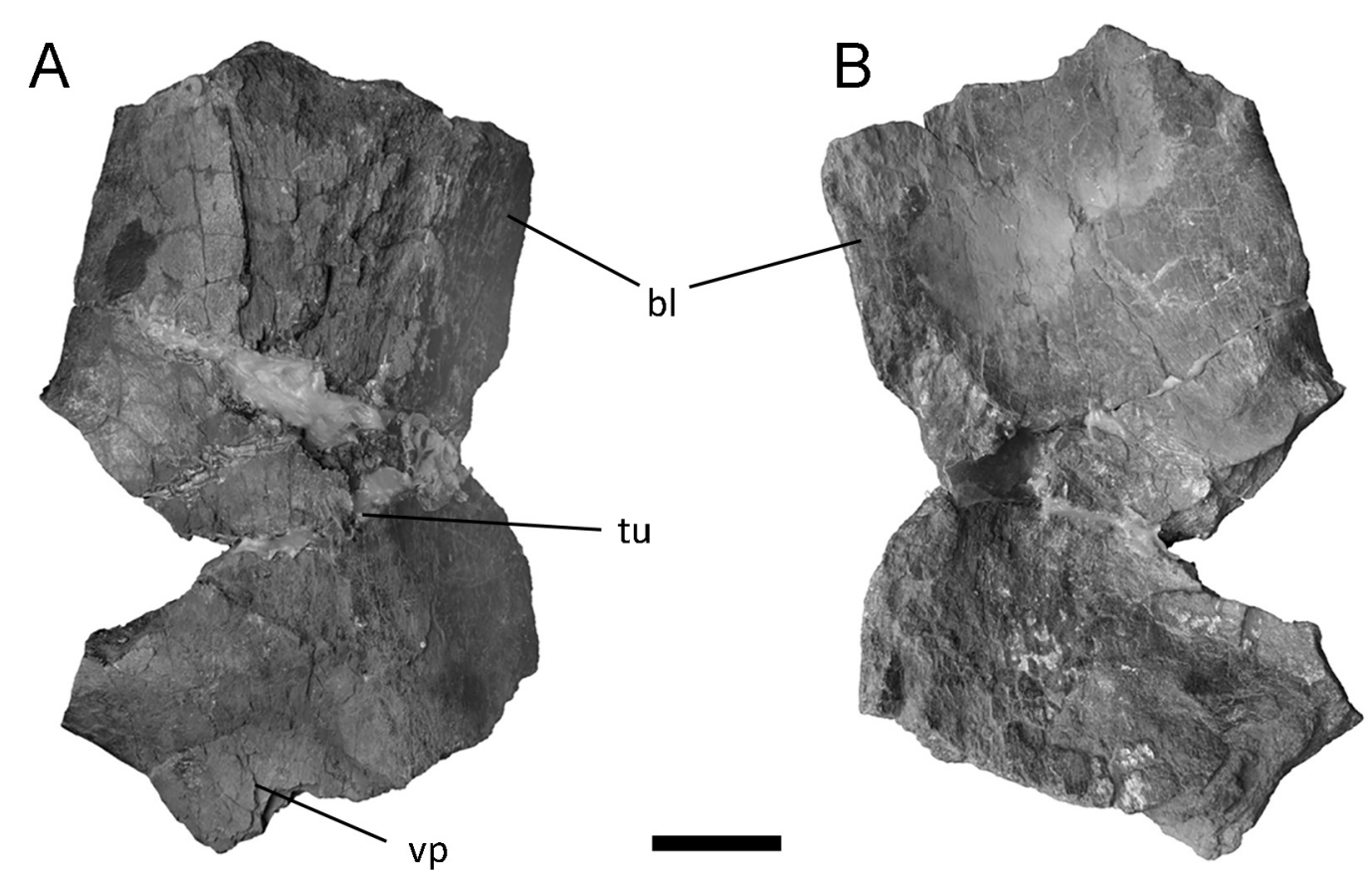

Figure 19. Nullotitan glaciaris gen. et sp. nov. Left scapula (MPM 21542) in lateral (A), and medial (B) views. Abbreviations: bl, blade; tu, tubercle; vp, ventral process. Scale bar: $10 \mathrm{~cm}$.

(35\%; Filippi et al., 2011; González Riga et al., 2018).

Femur (Figure 21). The femoral head and neck are poorly preserved. They seem to be proximomedially elongate, describing an obtuse angle with the longitudinal axis of femur, a condition typical for titanosauriforms (González Riga et al., 2019).

The femur shaft shows a minimum width of about $44 \mathrm{~cm}$, and the distal end of the right femur is $53 \mathrm{~cm}$ in maximum transverse diameter, with globe-shaped, sub-equal articular condyles, $28 \mathrm{~cm}$ in anteroposterior diameter. They are separated through a marked anteroposterior constriction, visible in distal aspect. This separation is also evident on the cranial surface, which exhibits a shallow distal concavity. In correlation, the cranial surface of distal femur forms a wide, shallow but deeply grooved, extensor sulcus. Articular condyles are not extended on the cranial surface of the distal end. Subequal distal condyles may indicate that Nullotitan is close to the lithostrotian clade (Upchurch et al., 2004), but the lack of dorsomedial beveling of the distal condyles onto the cranial side of the shaft excludes it from Saltasaurinae (Wilson, 2002). The medial surface of distal femur is flat but strongly decorated by proximodistally oriented ridges almost probably corresponding with the insertion of adductor muscles. The tibial condyle is more conical-shaped (in cranial view) than the more rounded lateral condyle. Also, the later one is carved by deep sulci, giving a brain-like aspect, different from the tibial condyle with a less marked decoration. Both the tibiofibular crest and the posterior projection of the medial condyle are broken at their bases. The distal end of femur described above resembles that of Mendozasaurus. Notably, the femur shaft (immediately proximal to the distal condyles) is highly compressed anteroposteriorly $(10 \mathrm{~cm})$.

Tibia (Figure 22). The tibia of the holotype (MPM 21542) consists of a right element, broken and slightly distorted. It measures $105 \mathrm{~cm}$ in total length, and $44 \mathrm{~cm}$ in maximum distal width. It exhibits remarkable features interpreted as diagnostic for the species (see below). A second tibia (MPM 21548), discovered in isolation, is tentatively referred as to the same genus and species, although its features do not completely agree with those of the holotype.

The tibia of Nullotitan is robust. As in other titanosaurs, the distal end of tibia of Nullotitan is transversely expanded to twice midshaft breadth (Ullman \& Lacovara, 2016) and the proximal end is anteroposteriorly expanded. However, the distal end of tibia of Nullotitan is strongly anteroposterior compressed and more trans- 


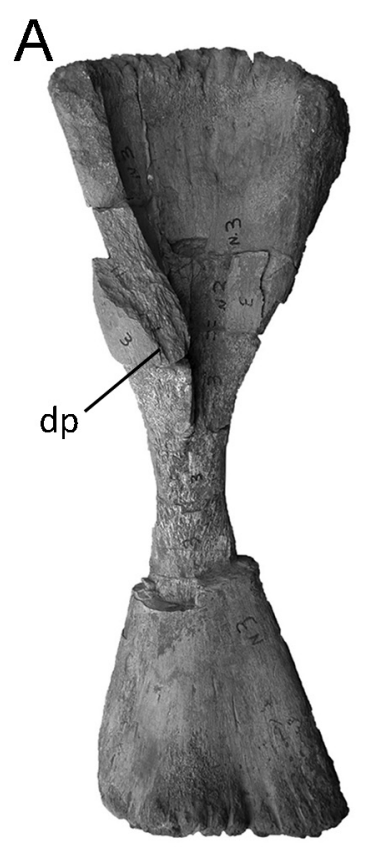

B

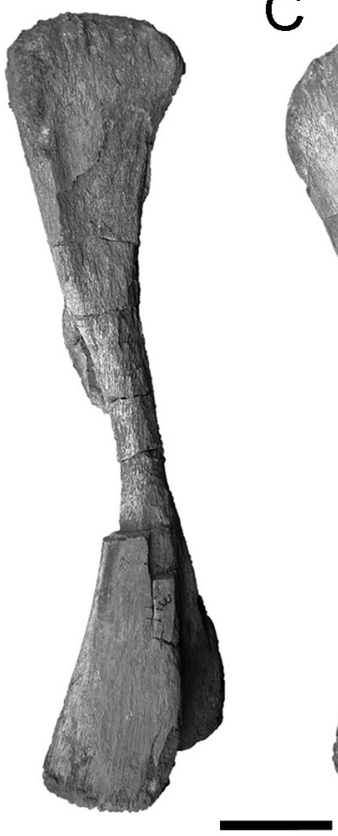

C D

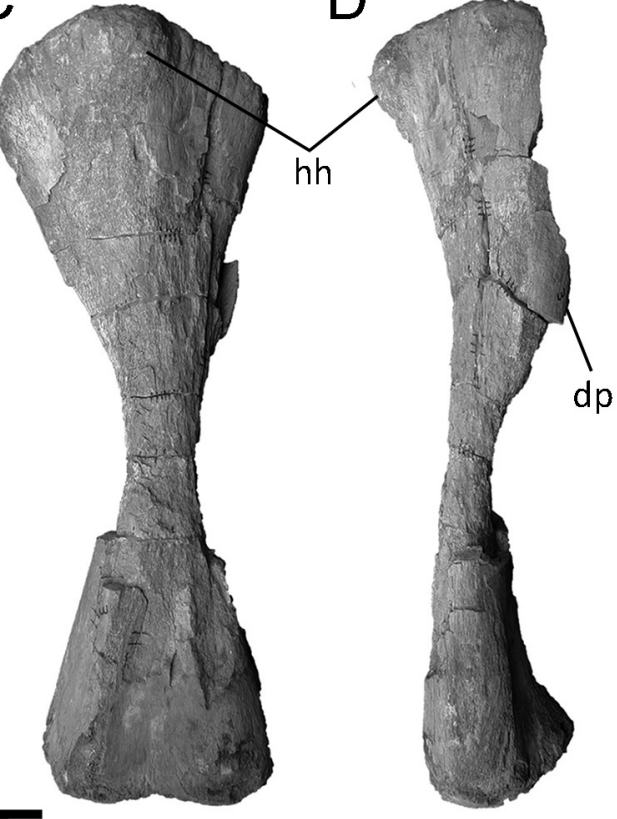

E
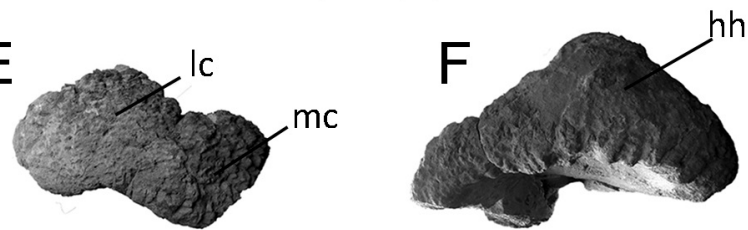

Figure 20. Nullotitan glaciaris gen. et sp. nov. Right humerus (MPM 21546) in anterior (A), lateral (B), posterior (C), medial (D), distal (E), and proximal (F) views. Abbreviations: dp, deltopectoral crest; hh, humeral head; lc, lateral condyle; mc, medial condyle. Scale bar: $10 \mathrm{~cm}$.

versely expanded than in other titanosaurs (e.g., Mendozasaurus; González Riga et al., 2019), suggesting that may constitute an autapomorphic trait of Nullotitan.

Fibula (Figure 23). A nearly complete right fibula is available. The fibula of Nullotitan measures $109 \mathrm{~cm}$ long, being a bit longer than the fibula of Dreadnoughtus (103 cm; Lacovara et al., 2014). The fibula of Nullotitan is rubust $(\mathrm{RI}=0.4)$, more than Neuquensaurus (RI=0.172-0.232; Otero, 2010), but less than in Uberabatitan (0.6).

The anterior margin of the bone is straight, whereas the posterior one is strongly sigmoid, much more than in other titanosaurs (for instance, Uberabatitan, Mendozasaurus, Elaltitan; Salgado \& Carvalho, 2008; Silva Junior et al., 2019; González Riga et al., 2018; Mannion \& Otero, 2012). The fibular shaft is also strongly sigmoidal in posterior view, with the lateral surface markedly convex at level of the biceps tubercle (Figure 23C). In general terms, the fibula is similar to that of Dreadnoughtus (Ullman \&
Lacovara, 2016). The sigmoid curve present in both Nullotitan and Dreadnoughtus is exaggerated in lateral view, for the notable anteroposterior expansion of both proximal and distal ends of the bone. In lateral view, the proximal margin of the fibula is nearly horizontally oriented, as occurs in Dreadnoughtus (Ullman \& Lacovara, 2016), Mendozasaurus (González Riga et al., 2018), Saltasaurus (Powell, 2003), and Neuquensaurus (Otero, 2010), and unlike other titanosaurs such as Uberabatitan (Salgado \& Carvalho, 2008; Silva Junior et al., 2019) in which it is posteriorly inclined. On the lateral surface, there is the tubercle for the $M$. iliofibularis.

Astragalus (Figure 24). As usual among sauropods, the astragalus is conical-shaped, with an excavated lateral surface for articulation with the calcaneum and the fibula, and a pointed end oriented medially, which is partially broken and coincident with the medial expansion of the distal end of tibia. Apparently, the medial expansion of astragalus was more developed in Nullotitan 

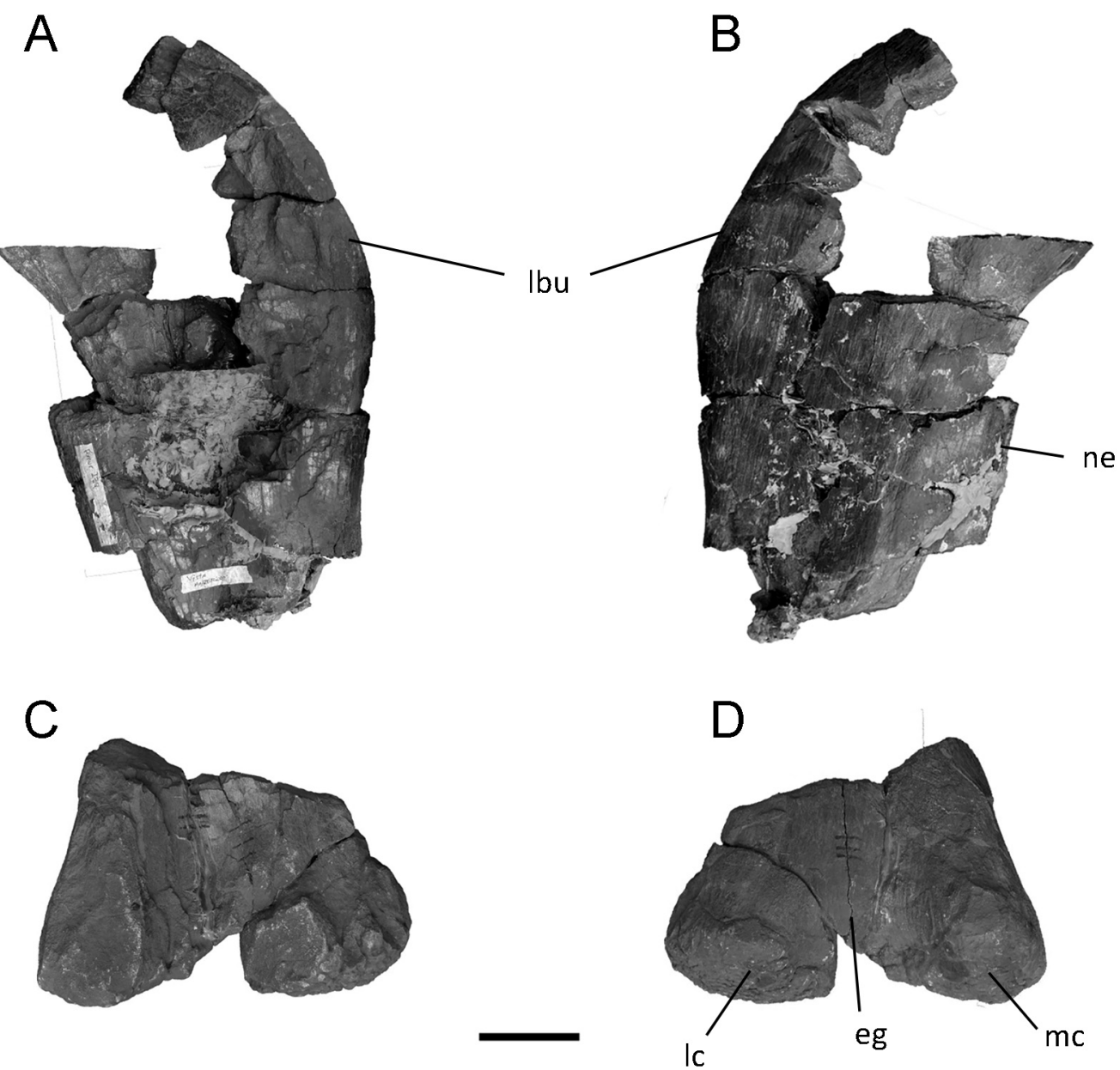

Figure 21. Nullotitan glaciaris gen. et sp. nov. Proximal (A-B) and distal (C-D) ends of right femur (MPM 21542) in anterior (A, C), and posterior (B, D) views. Abbreviations: eg, extensor groove; lc, lateral condyle; lbu, lateral bump; mc, medial condyle; ne, neck. Scale bar: $10 \mathrm{~cm}$.

than in Uberabatitan (Salgado \& Carvalho, 2008; Silva Junior et al., 2019). The ascending process of the astragalus is low.

Comparisons. Because of the paucity of the available materials, the phylogenetic position of Nullotitan among titanosaurs is difficult to discern. This taxon exhibits features diagnosing Titanosauria, as well as characteristics of less inclusive clades such as Lithostrotia, Colossosauria, and Lognkosauria (González Riga et al., 2019). In addition, Nullotitan lacks features diagnosing the derived titanosaur clades Saltasauridae and Aeolosaurini.

Nullotitan exhibits the following titanosaurian features: caudal vertebrae procoelous, with neural arches located on the anterior half of centrum; femur medially bowed on its proximal end; presence of a prominent lateral bulge distal to the greater trochanter; and femoral shaft anteroposteriorly compressed (Salgado et al., 1997; Mannion et al., 2013; González Riga et al., 2019). Furthermore, presence of subequal-sized condyles on distal femur may suggest lithostrotian affinities for Nullotitan (Upchurch et al., 2004). Characters of Colossosauria present in Nullotitan are: deltopectoral mediolateral thickness of anterior attachment surface with distal half mediolaterally expanded relative to proximal half and a value near 0.15 of minimum mediolateral width vs. proximodistal length (González Riga et al., 2019).

Proximal caudals of Nullotitan are notably anteroposteriorly short, showing awl-like transverse processes and a slightly convex posterior articular surface. This combination of traits is also shared with most lognkosaurians (González 

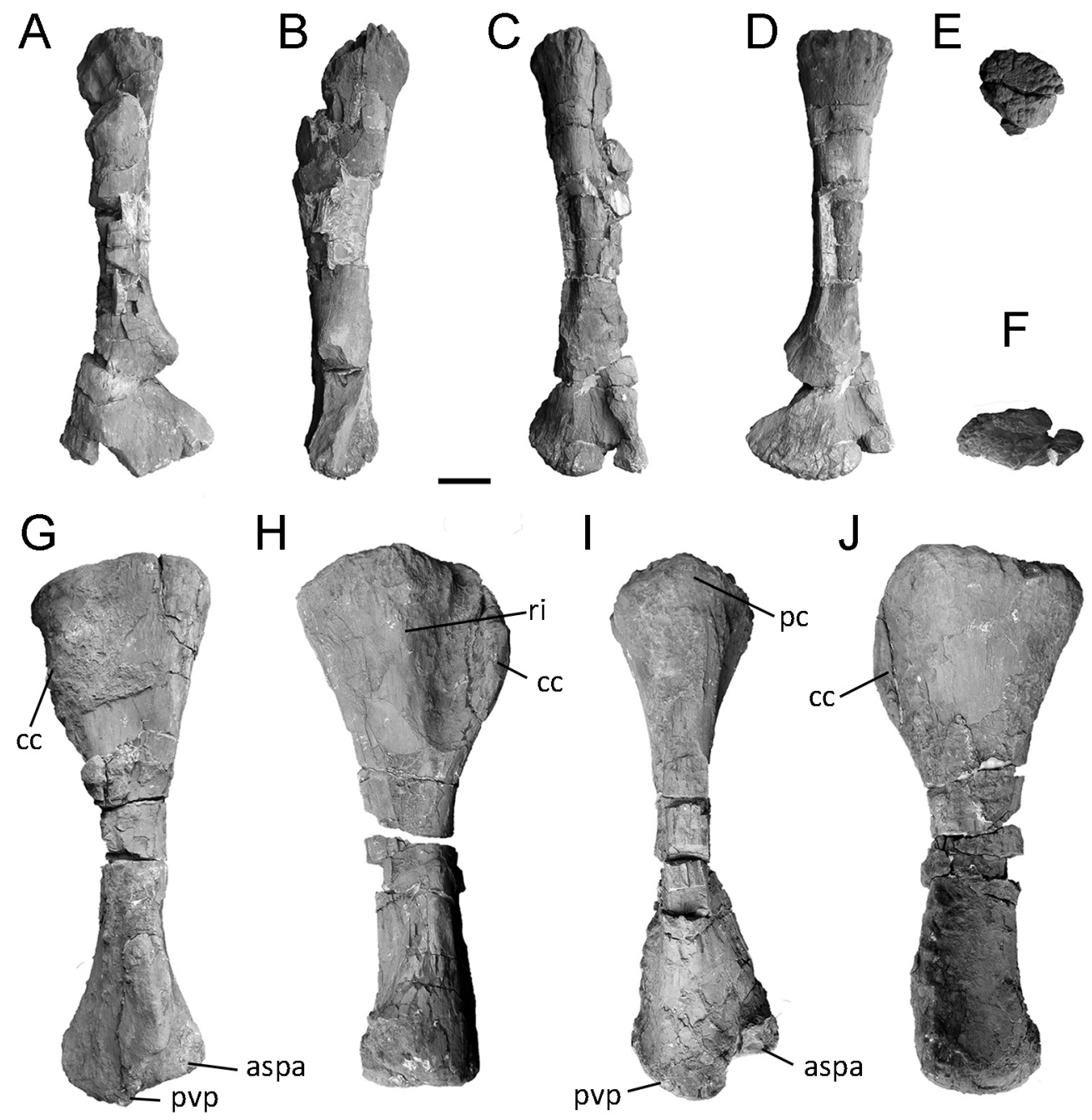

Figure 22. Nullotitan glaciaris gen. et sp. nov. Tibia (A-F) right tibia of MPM 21542 specimen and (G-J) left tibia of MPM 21548 specimen. The elements are figured in anterior $(\mathbf{A}, \mathbf{G})$, medial $(\mathbf{B}, \mathbf{H})$, posterior $(\mathbf{C}, \mathbf{I})$, lateral $(\mathbf{D}$, J), proximal (E) and distal (F) views. Abbreviations: aspa, ascending process for astragalus; cc, cnemial crest; pc, proximal condyle; pvp, posteroventral process; ri, ridge. Scale bar: $10 \mathrm{~cm}$.

Riga et al., 2019).

As follows, we compare Nullotitan with other gigantic members of the colossosaurian clade Lognkosauria (sensu Carballido et al., 2017; González Riga et al., 2019). This clade is actually composed by the genera Argentinosaurus, Futalognkosaurus,

Mendozasaurus,

Notocolossus, Patagotitan, Puertasaurus, Dreadnoughtus and Drusilasaura (Carballido et al., 2017; González Riga et al., 2018, 2019). Patagotitan, Futalognkosaurus, and Notocolossus show the first caudal transverse processes with a notably dorsoventrally narrow base, a condition not observed in Nullotitan (Carballido et al.,
2017). In addition, Patagotitan shows a ventral pocket at the base of centrum, which is absent in n Nullotitan. Notocolossus, Futalognkosaurus, Dreadnoughtus and Puertasaurus show vertebrae that are proportionally anteroposteriorly longer than Nullotitan, with a distal articular surface more spherical. Also, in Notocolossus and Futalognkosaurus the transverse processes are more dorsally located on the sides of centra (Lacovara et al., 2014). As occurs in Patagotitan, the mid-caudals show a large fossa below transverse process (Carballido et al., 2017). However, in Nullotitan this fossa is tabicated by an obliquely oriented ridge of bone. 

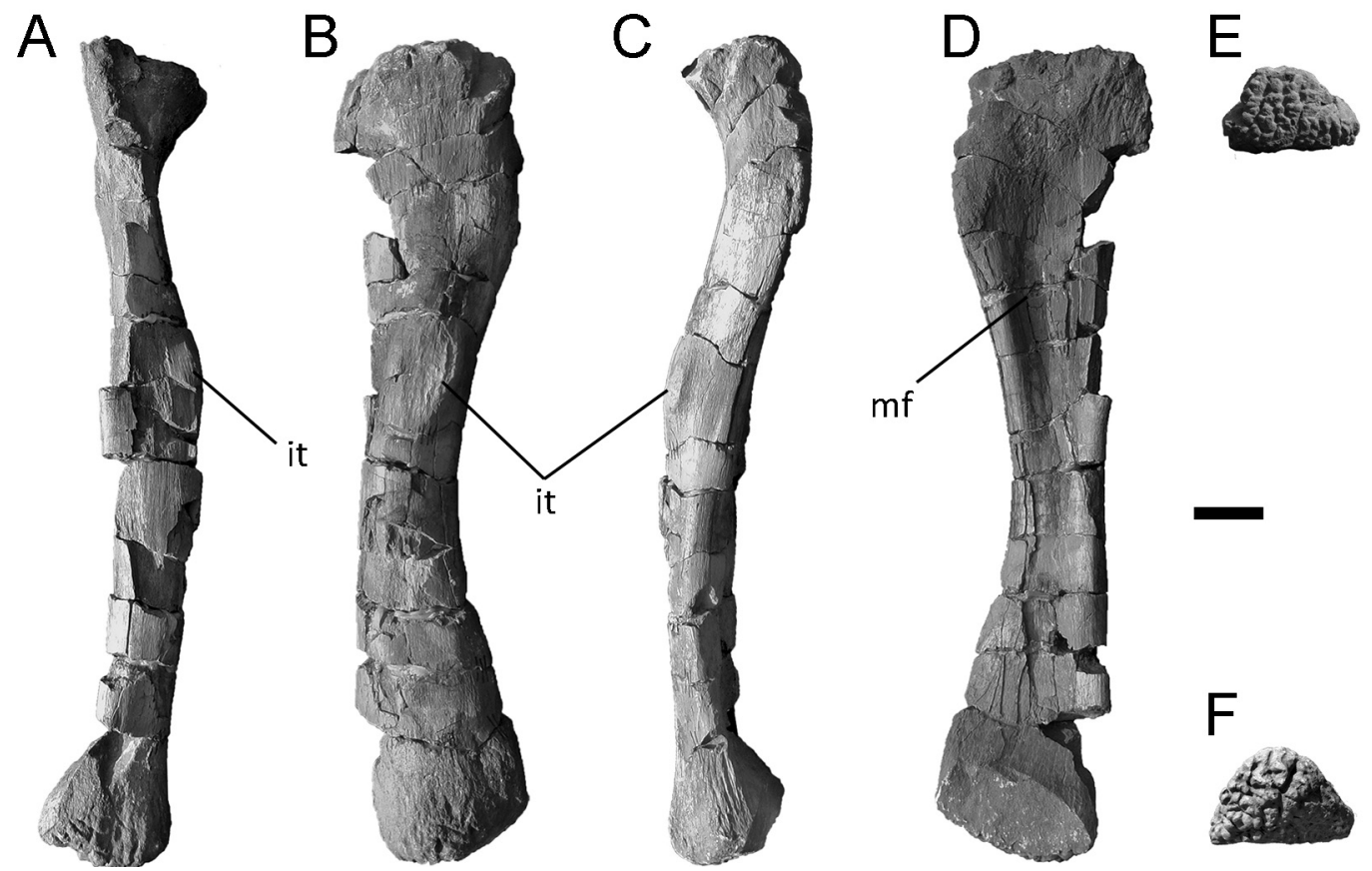

Figure 23.Nullotitan glaciaris gen. et sp. nov. Right fibula (MPM21542) in anterior (A), lateral (B), posterior (C), me$\operatorname{dial}(\mathbf{D})$, proximal (E), and distal(F) views.Abbreviations: it, iliofibularistubercle; mf, medial fossa. Scalebar $10 \mathrm{~cm}$.

As already said, proximal caudal centra distinguish for the presence of profuse blind excavations. These are considered autapomorphic for the new species. Small vascular foramina were reported in caudal vertebrae of some titanosaurs (Mannion \& Calvo, 2011; Mannion et al., 2013), but are much smaller than in Nullotitan. The excavations in caudals of Nullotitan are elongate and subparallel to the main axis of the tail. On proximal caudals, the excavations are relatively large (i.e., $5 \mathrm{~cm}$ long in a centrum $22 \mathrm{~cm}$ long), but are reduced or absent in more distal caudals. Such excavations are randomly distributed over centrum surface, being different from the symmetrical ventral perforations present in some titanosaurs, such as Pellegrinisaurus and Drusilasaura (Salgado, 1996; Navarrete et al., 2011). Clearly, the perforations do not invade the vertebral centrum. Such pattern of blind randomly distributed excavations, resemble the excavations observed on the nuchal crest of felids (Duckler, 1997), which are produced by muscular activity, particularly overstretched muscles that create depressions (due to bone necrosis) at attachment sites. In humans, this pattern is evidenced in athletic individuals who place high strain on selected active muscles and have skeletal responses at attachment sites in consequence (Duckler, 1997). Our best guess is that such large and elliptical-shaped blind excavations on the proximal caudals of Nullotitan (as well as other titanosaurs) may have anchored thick tendons of hypaxial and epaxial muscles. If this interpretation proves to be correct, then it represents a different anatomical adaptation for tail support and movement control than that known in other dinosaurs.

Humeral proportions of Nullotitan $(\mathrm{RI}=0.28)$ are more gracile in comparison with the robust humerus exhibited by Dreadnoughtus $(\mathrm{RI}=0.33)$, Elaltitan and Argyrosaurus (Huene, 1929; Powell, 2003; Mannion \& Otero, 2012; Lacovara et al., 2014; González Riga et al., 2019). Although Nullotitan exhibits a RI similar to that of Notocolossus, this genus exhibits a humerus with markedly asymmetrical proximal margin in anterior view (nearly straight laterally but strongly expanded and rounded proximomedially) (González Riga et al., 2019), features absent in Nullotitan.

The proximal end of the femur is strongly medially bent in Nullotitan, forming a large convex surface that is not present in Dreadnoughtus, Mendozasaurus, and Patagotitan. In respect to robustness of femur, Nullotitan resembles more Dreadnoughtus than Patagotitan and Mendozasaurus, which show a more elongate and narrow femur. The fibula of Nullotitan is 

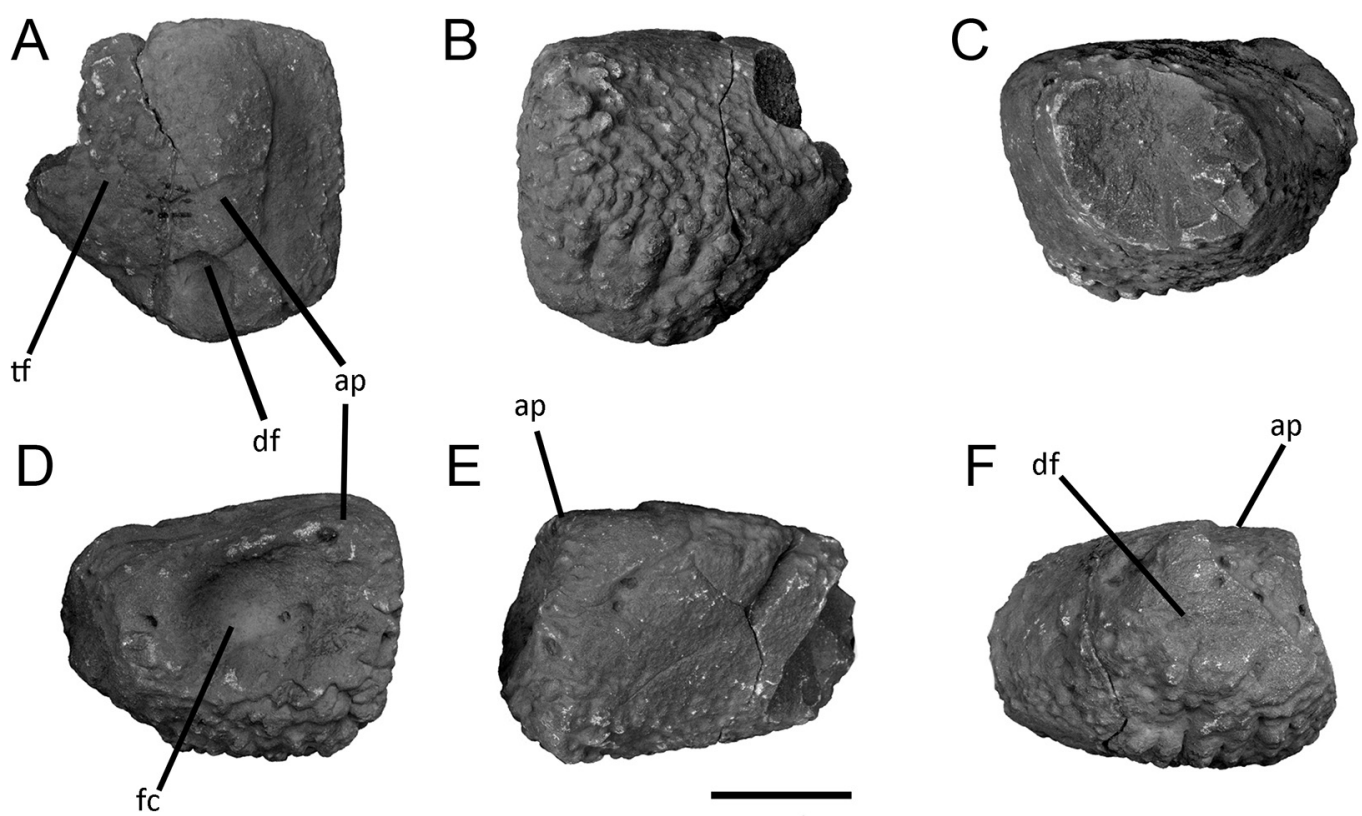

Figure 24. Nullotitan glaciaris gen. et sp. nov. Right astragalus (MPM 21542) in dorsal (A), ventral (B), anterior $(\mathbf{C})$, lateral (D), posterior (E), and medial (F) views. Abbreviations: ap, ascending process; dff, dorsal fossa; fc, calcaneum facet; tf, tibial facet. Scale bar: $10 \mathrm{~cm}$.

different from that of other large titanosaurs, including Dreadnoughtus and Argentinosaurus (Bonaparte \& Coria, 1993), in being strongly sigmoidal in both anterior and lateral views.

In the case of Drusilasaura, the few overlapping elements preclude proper comparisons with Nullotitan. Both taxa share proximal caudals strongly anteroposteriorly compressed with awllike transverse processes that extend towards the vertebral centrum, a longitudinal ventral groove delimited by thick ridges, and distal caudals dorsoventrally compressed (Navarrete et al., 2011). However, Drusilasaura apomorphically shows two large ventral foramina that are absent in Nullotitan. Further, Drusilasaura lacks the blind fossa present along the lateral surface of caudal vertebrae of Nullotitan.

Nullotitan differs from saltasaurids (sensu Gonzáles-Riga et al., 2019) in having proximal caudals anteroposteriorly short, with posterior articular surfaces slightly convex, and apneumatic centra. These are plesiomorphic traits indicating that Nullotitan is not related with saltasaurids, which usually have caudal vertebrae with dorsoventrally depressed and strongly procoelous centra, and highly pneumatic centra and neural arches (e.g., Powell, 1993; Salgado et al., 1997; Bonaparte et al., 2000; Salgado \& Azpelicueta, 2000; Rose, 2007; Taylor, 2009; González Riga et al., 2019). In this regard, the ventral aspect of the caudal vertebrae of Nullotitan is unique in that the proximal and distal caudals show a relatively flat ventral surface of centrum, whereas mid-caudals exhibit a deep longitudinal furrow surrounded by two thickened ridges. Presence of deep ventral furrow in Nullotitan should not be confused with the deep pneumatic excavations present in derived titanosaurs such as Saltasaurus and Rocasaurus (Powell, 2003; Salgado \& Azpelicueta, 2000).

Besides, caudal vertebrae of Nullotitan differs from the caudal type reported for aeolosaurines (i.e., Aeolosaurus patagonicus and A. colhuehuapensis; Powell, 2003; Casal et al., 2007; Martinelli et al., 2011) because in the latter ones the neural arches are strongly inclined anteriorly and have a more developed procoelous condition. Thus, the sum of features of the caudal vertebrae of Nullotitan clearly distinguishes it from other Late Cretaceous derived titanosaurs from South America.

In sum, although the scarcity of currently available materials of Nullotitan precludes a clear taxonomic referral, its anatomical details (mainly from the caudal vertebrae), support it as a valid gen. et sp.. Also, the large size of Nullotitan, in joint with the lack of saltasaurid and aeolosaurine features, plus all the character- 
istics listed above suggest its placement among colossosaurian titanosaurs.

\section{Theropod dinosaurs}

Remains of theropod dinosaurs (including birds) collected in the Chorrillo beds include several isolated bones and a single tooth identified as Megaraptoridae indet., as well as some pedal phalanges referred with doubts to Noasauridae and Unenlagiidae. Besides, eggshell fragments are described as belonging to Theropoda indet. Available evidence, albeit fragmentary, clearly shows that the dinosaur fauna from the Chorrillo Formation was taxonomically diverse, formed by clades also documented in other regions of Patagonia and Gondwana, but with an apparent dominance of megaraptorids over other theropod groups. From the equivalent Dorotea Formation in Chile, Manriquez et al. (2019) mention the discovery of theropod teeth, but no details on their phylogenetic affinities was given.

Coelurosauria Huene, 1914

Megaraptora Benson, Carrano and Brusatte, 2010

Megaraptoridae Novas et al., 2013

Megaraptoridae gen. et sp. indet. 1

Referred material. MPM 21545, fragmentary specimen composed of a posterior dorsal centrum, transverse process of a dorsal vertebra, partial neural arch of a caudal vertebra, fragments of two indeterminate vertebrae, rib fragments and proximal end of pubis (locality 3 ) (Figure 25). The specimen was found in a $5 \times 3 \mathrm{~m}$ surface area.

Horizon. Base of the upper third of the Chorrillo Formation, lying above a thick bank of conglomerates.

Description. Available elements belong to a megaraptorid similar in size to Aerosteon (Sereno et al., 2008), approximately 8-9 meters in whole length.

Dorsal vertebrae. The isolated centrum is incomplete, lacking most of its dorsal portion. It probably corresponds to a posterior dorsal vertebra, with transverse width vs maximum length ratio of 1.16, almost the same as dorsal 10th of Aerosteon. The anterior articular surface of centrum is concave, but the posterior one is flat. The lateral surfaces are remarkably concave, as occurs with other big-sized theropods (Brochu, 2003; Sereno \& Brusatte, 2008). Ventrally, the centrum is smooth and transversely convex. This condition is observed in other big-sized megarap- torids as Aerosteon and Murusraptor, in which these surfaces become progressively deeper posteriorly. Large paired pleurocoels are present on both sides of the centrum; they are separated by a wide and oblique septum, a diagnostic feature of Megaraptoridae (Novas et al., 2013). The pleurocoels penetrate the centrum medially and slightly ventrally. The internal structure of the centrum is camellate, as occurs in other megaraptorids (e.g, Orkoraptor, Megaraptor; Calvo et al., 2004; Novas et al., 2008; Benson et al., 2010, 2012; Porfiri et al., 2014).

An isolated transverse process is interpreted as belonging to a dorsal vertebra. It is oval in cross section, and with camellate internal structure. Distally the process bears a concave and oval surface for articulation with the rib tuberculum. The articular surface of the process is proportionally much bigger than in the cervical vertebrae of other theropods.

Caudal vertebra. This element is represented by the right side of a neural arch, including the base of the transverse process and the base of the postzygapophysis. The presence of a tall neural arch suggests it corresponds to the proximal third of the tail. As in other vertebral elements, this neural arch possesses a camellate internal structure. The preserved part of the neural arch appears to be dorsoventrally more depressed than in Aoniraptor and Murusraptor (Coria \& Currie, 2016; Motta et al., 2016), but similar to Megaraptor and Orkoraptor (Novas, 1998; Novas et al., 2008). The transverse process is robust, dorsoventrally tall and posterolaterally directed. Below it there is the anterior centrodiapophyseal lamina, which is robust and anteroventrally directed, delimiting anteriorly the prezygadiapophyseal-centrodiapophyseal fossa, and posteriorly the centrodiapophyseal fossa. The presence of two laminae delimiting three fossae is observed in other megaraptorids such as Aoniraptor, Orkoraptor, Murusraptor, and Megaraptor (Calvo et al., 2004; Novas et al., 2008; Coria \& Currie, 2016; Motta et al., 2016). In contrast, in other theropod groups (e.g., abelisaurids, carcharodontosaurids, tyrannosaurids) the neural arch lacks these laminae below the transverse process. Interestingly, the anteroventral limit of the prezygadiapophyseal-centrodiapophyseal fossa is made up by an anteroposteriorly wide and anteriorly inclined lamina. This robust lamina is observed in Aoniraptor, Murusraptor and Megaraptor, but not in Aerosteon and Orkoraptor. The postzygapophysis is small and slightly longer than wide. Above it, the postspinal laminae 

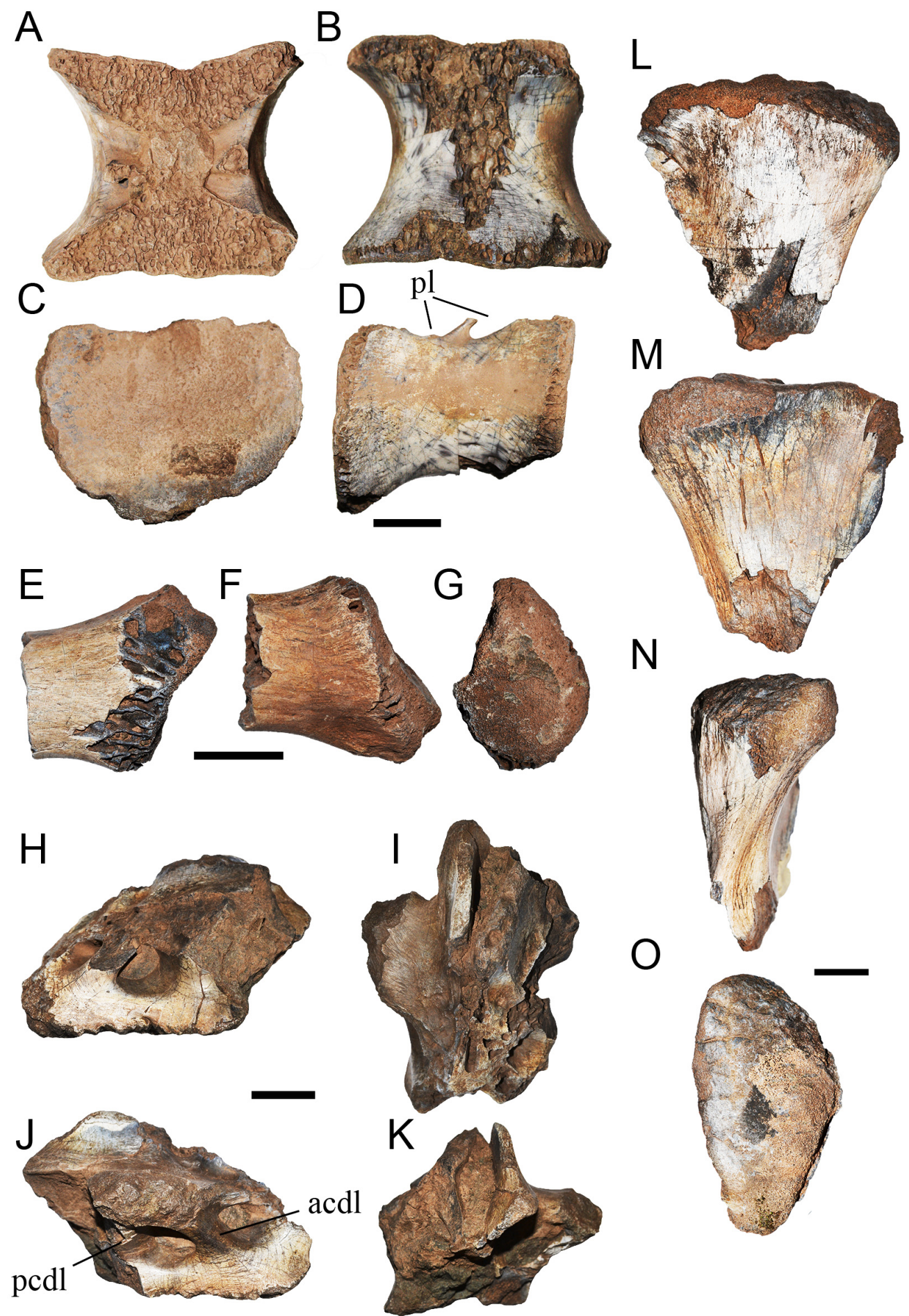

Figure 25. Megaraptoridae indet. (MPM 21545). (A-D) Partial dorsal centrum in dorsal (A), ventral (B), posterior (C) and right lateral (D) views. (E-G) Isolated dorsal transverse process in anterior $(\mathbf{E})$, posterior $(\mathbf{F})$ and distal $(\mathbf{G})$ views. (H-K) Partial caudal neural arch in left lateral (H), dorsal (I), right lateral (J) and anterior (K) views. (L-O) Proximal end of right pubis in lateral $(\mathbf{L})$, medial $(\mathbf{M})$, anterior $(\mathbf{N})$ and proximal $(\mathbf{O})$ views. Abbreviations: acdl, anterior centrodiapophyseal lamina; pcdl, posterior centrodiapophyseal lamina; pl, pleurocoel. Scale bars $3 \mathrm{~cm}$ 
ascends vertically and delimits the postspinal fossa. This fossa is narrow and does not show interspinous ligament tuberosity.

Pubis. The pubis is represented by the proximal end of the right bone. Its lateral surface is convex, while the medial one is both anteroposteriorly and dorsoventrally concave. The medial surface shows vertical striations probably for ligament attachment. The anterior margin is transversely thick and convex in cross-section, whereas the posterior margin is thin and sharp. The pubis is oval in proximal view, with a rugose articular surface for the iliac pedicle, and seems morphologically less complex than in other megaraptorans, such as Aerosteon or Murusraptor (Sereno et al., 2008; Coria \& Currie, 2016). The proximal margin of pubis seems simple, lacking differentiation into acetabular, ischiadic and iliac articular surfaces present in another megaraptorids.

Discussion. MPM 21545 exhibits the following megaraptorid synapomorphies: 1) dorsal centra with two pleurocoels separated by a septum (Novas et al., 2013); and 2) two centrodiapophyseal laminae separating three fossae below the transverse process of the anterior-middle caudal vertebrae (Calvo et al., 2004). This morphology is absent in other theropods such as ceratosaurs, spinosaurids, allosauroids, tyrannosauroids, and ornithomimosaurs.

\section{Megaraptoridae gen. et sp. indet. 2}

Referred material. MPM 21546, isolated dorsal centrum (locality 4) (Figure 26).

Description. This small vertebra measures 2.72 cm long, $2.43 \mathrm{~cm}$ tall, and $2.79 \mathrm{~cm}$ wide. It is internally pneumatized through a complex pattern of lateral pleurocoels, similar to those of megaraptoran theropods (e.g., Sereno et al., 2008). Based on extrapolations with complete theropods (e.g., Allosaurus; Madsen, 1976), we estimate this specimen being approximately three meters long. The maturity of the specimen is uncertain, but the small size of the element together with the lack of fusion with the neural arch suggests it corresponds to a juvenile. This vertebra is even smaller than those of the juvenile specimen of Megaraptor namunhuaquii described by Porfiri et al. (2014).

The centrum has a slightly concave anterior articular surface and a flat posterior one, as occurs in posterior dorsal vertebrae of megaraptorids (e.g., Murusraptor, Aerosteon; Sereno et al., 2008; Coria \& Currie, 2016). The lateral and ven- tral surfaces are concave. Laterally, the centrum shows a rounded fossa with an anterior pleurocoel and a posterior pleurofossa separated by an oblique septum, as it occurs in other megaraptorans (e.g., Fukuiraptor, Aerosteon, Megaraptor, Murusraptor, Tratayenia). The centrum is quadrangular in side view, devoid of articular surfaces for both ribs and haemal arches, thus indicating it may correspond to the posterior dorsals. Also, the ventral surface is smooth and transversely convex, contrasting with the caudal vertebrae of megaraptorans, which possess strong ventral keels (Méndez et al., 2012; Motta et al., 2016). Furthermore, in this element the posterior articular surface is flat but the anterior one shows a moderate concavity.In dorsal view, the floor of the neural canal is shallow and has a constant transverse width. This condition is observed in isolated dorsal centra of the megaraptorids Aerosteon and Murusraptor (Sereno et al., 2008; Coria \& Currie, 2016), while the caudal centra of these theropods have a neural canal constricted around mid-length. In lateral view, the centrum is squared-shaped in outline, contrasting with other megaraptorids, in which the centrum is shorter and taller (e.g., Megaraptor Aerosteon, Murusraptor, Tratayenia; Sereno et al., 2008; Coria \& Currie, 2016; Porfiri et al., 2014, 2018). However, Wilson et al. (2016) noted that this feature seems size-dependant, and may be related with the fact that all of the above mentioned megaraptorids are 8-10 meters long.

Comments. Up to now, the Patagonian record of Megaraptoridae corresponds to large-sized animals, approximately 8-9 m long. For their size and relative abundance, these theropods may have constituted the main predators during the Early Maastrichtian in southern Patagonia. Even juveniles may have played an important ecological role in these southern dinosaur faunas, considering that the specimen here reported attained a whole length of, at least, $2 \mathrm{~m}$. This means that megaraptorids probably preyed upon different sized herbivore dinosaurs (small to medium sized elasmarians, and bigger titanosaurids) in the course of their ontogeny.

Megaraptoridae gen. et sp. indet. 3

Referred material. MACN-Pv 19066, isolated shed tooth crown, presumably coming from the lower levels of the Chorrillo Formation (Figure 27). Collected by J. F. Bonaparte in 1981 on the same large area were the holotype of Nullotitan glaciaris was found. 

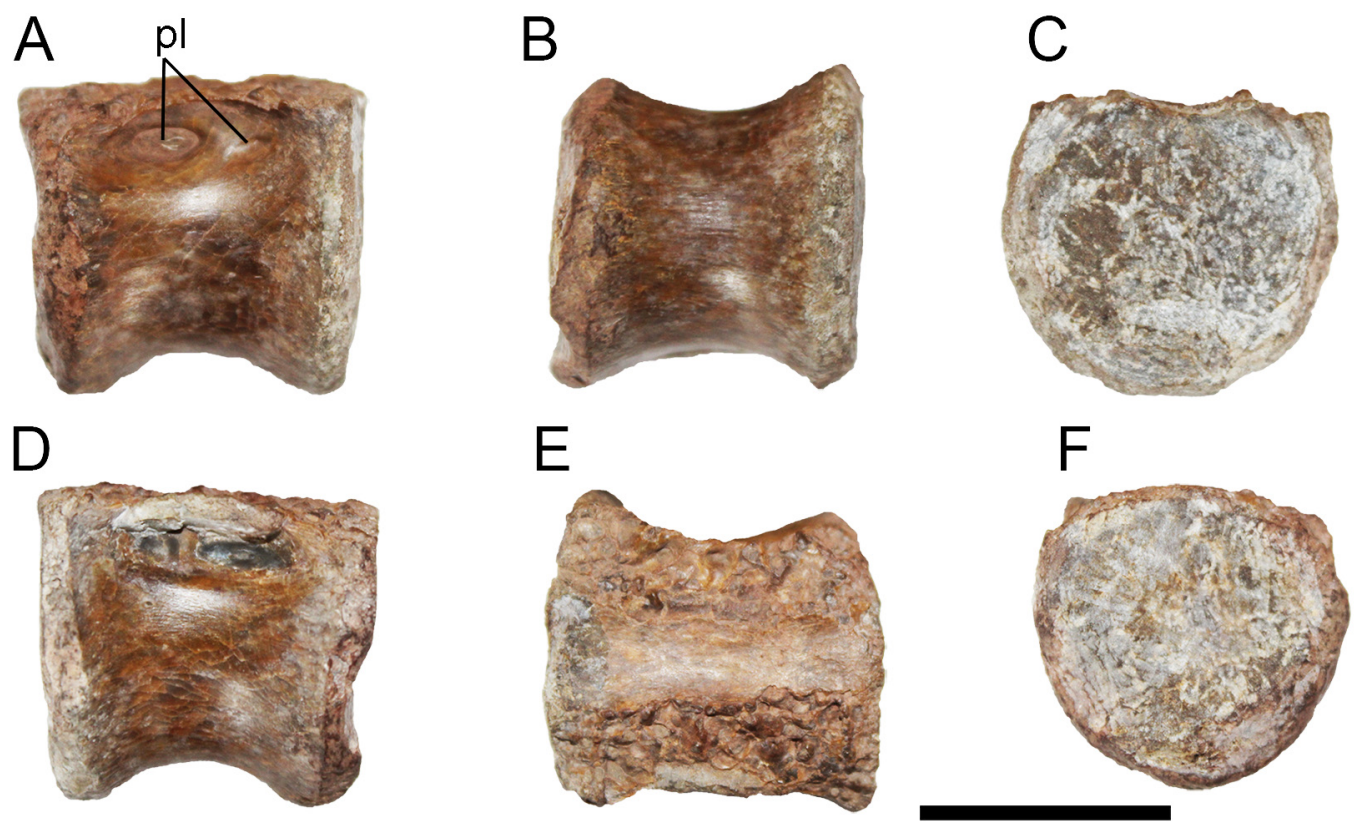

Figure 26. Megaraptoridae indet. (MPM 21546). (A-F) Posterior dorsal centrum in left lateral (A), ventral (B), posterior $(\mathbf{C})$, right lateral $(\mathbf{D})$, dorsal $(\mathbf{E})$ and anterior $(\mathbf{F})$ views. Abbreviations: pl, pleurocoel. Scale bar: $3 \mathrm{~cm}$.

Description. MACN-PV 19066 is represented by a shed tooth crown that lacks its apex, a portion of the mesial margin, and some denticles in the distal margin. The crown is slightly curved to the right in distal view and the mesial carina is displaced to the right of the distal one, thus indicating that the tooth represents a left anterior maxillary or dentary dental piece. The crown has an apicobasal height of $19.0 \mathrm{~mm}$, a basal labiolingual width of $6.8 \mathrm{~mm}$, and a basal mesiodistal length of $10.7 \mathrm{~mm}$.

The crown is distinctly recurved in labial and lingual views, with the apex being located distally to the base, as occurs in other megaraptorans (e.g. Fukuiraptor: Azuma \& Currie, 2000; Australovenator, Hocknull et al., 2009; Megaraptor, Porfiri et al., 2014; Orkoraptor, Novas et al., 2008; Murusraptor, Coria \& Currie, 2016). The entire labial surface of the crown is apicobasally and mesiodistally convex, whereas the distal one-third of the lingual surface is apicobasally concave. This concavity produces the slight curvature of the crown in distal view. The rest of the lingual surface is homogeneously convex. The distal margin of the crown possesses a sharp carina that begins $1 \mathrm{~mm}$ from the base and reaches the apicalmost preserved portion of the crown. This carina is serrated along its entire length, with a rather constant density of five denticles per $\mathrm{mm}$. Thus, the density of den- ticles of MACN-PV 19066 is higher than that in Fukuiraptor kitadaniensis (3-4 denticles per mm; Azuma \& Currie, 2000), Orkoraptor burkei (3-4 denticles per mm; Novas et al., 2008) and Megaraptor namunhuaiquii (3-4 denticles per mm; MUCPv 595). The denticles are mesiodistally deeper and apicobasally tall and their main axis is orthogonal to the distal edge of the crown, resembling the condition in the above mentioned megaraptorans. The distal denticles of MACN-Pv 19066 have a rounded edge and are separated from each other by short interdenticular sulci that do not extend as blood grooves, as occurs in megaraptorids (e.g., Australovenator, Megaraptor, Orkoraptor, Murusraptor; Hocknull et al., 2009; Porfiri et al., 2014; Novas et al., 2008; Coria \& Currie, 2016). In contrast, at least some check tooth crowns of the non-megaraptorid Fukuiraptor have well-defined, oblique -basally oriented- blood grooves (Azuma \& Currie, 2000). The mesial surface is considerably labiolingually broader than the distal one and has a carina which extends along the total length of the crown. The carina reaches the apicalmost preserved portion of the crown and lacks denticles, as occurs in Megaraptor (Porfiri et al., 2014), Orkoraptor (Novas et al., 2008) and Murusraptor (with exception of the premaxillary teeth of this species; Coria \& Currie, 2016). In contrast, Fukuiraptor (Azuma \& Currie, 2000) and Australovenator 

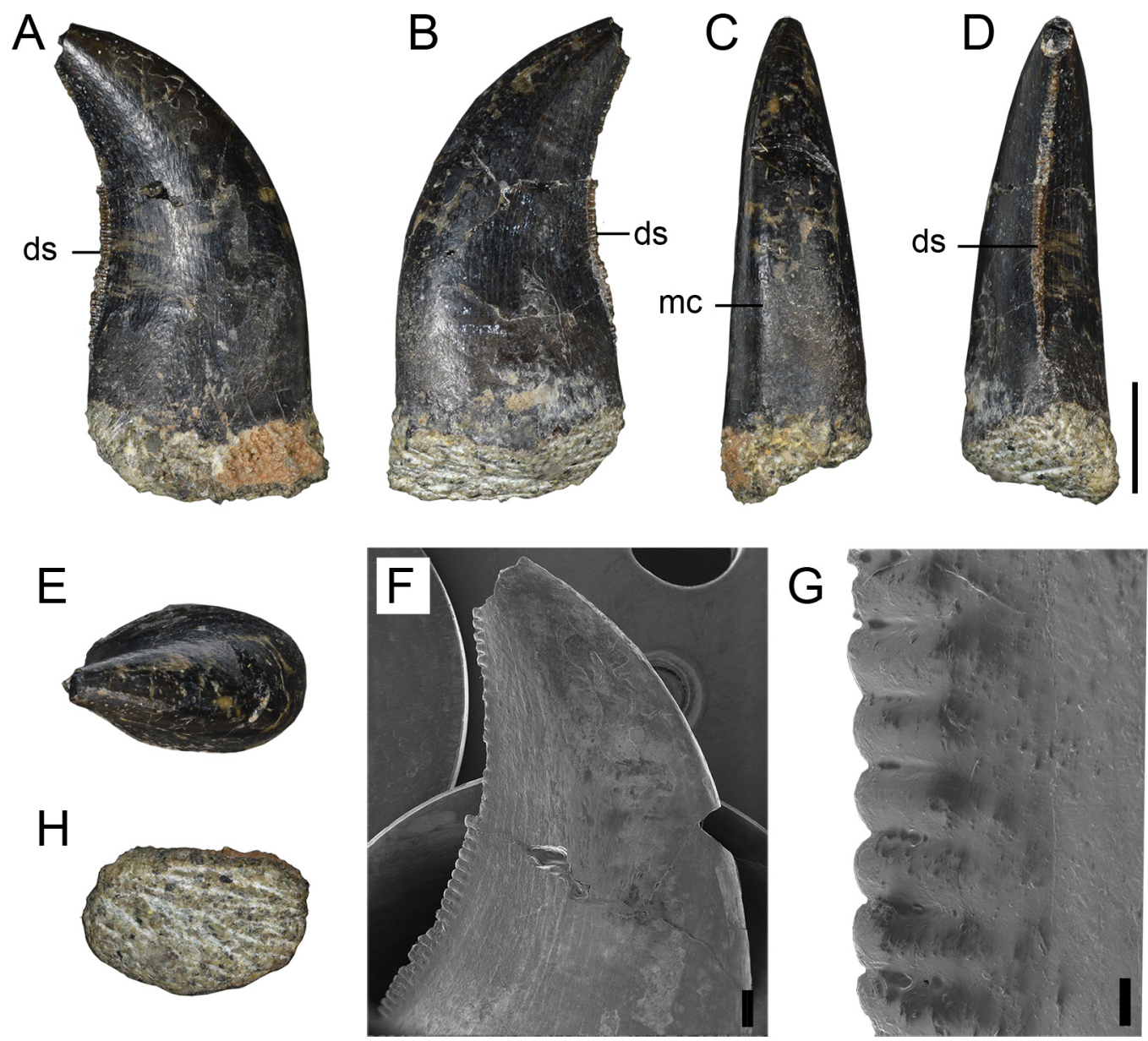

Figure 27. Megaraptoridae indet. (MACN-Pv 19066), isolated shed tooth crown in (A), labial; (B), lingual; (C), mesial; (D), distal; (E), apical; and (H), basal views. F, G, selected anatomical details. Abbreviations: ds, distal serrations; mc, mesial carina. Scale bar: $1 \mathrm{~cm}$.

(Hocknull et al., 2009) possess denticles on both mesial and distal carina. As far as it is preserved, the enamel of MACN-Pv 19066 is smooth, without wrinkles or wear facets. In contrast, extensive wear facets, but not wrinkles, are usually present in other megaraptorids (e.g. Novas et al., 2008; Hocknull et al., 2009). The base of the crown is sub-oval in cross-section, with a labial margin distinctly more convex than the lingual one. There is no labiolingual constriction of the base of the crown, contrasting with the eightshaped cross-section of the base of the crowns of the megaraptorids Orkoraptor (Novas et al., 2008), Murusraptor (Coria \& Currie, 2016) and Megaraptor (Porfiri et al., 2014).

Comments. MACN-PV 19066 can be referred to Megaraptoridae because of the presence of the following combination of characters: strongly distally recurved crown, with apex located distal to the base, and absence of mesial serrations. The Chorrillo Formation megaraptorid tooth differs from those of other megaraptorids in its higher density of distal denticles and the absence of an 8-shaped cross-section at the base of the crown (Novas et al., 2013). Although MACN-PV 19066 suggests the presence of a previously unknown megaraptorid taxon we refrain of erecting a new species because of the fragmentary condition of the megaraptorid specimens currently known from the Chorrillo Formation.

Abelisauroidea Bonaparte and Novas, 1985

Noasauridae Bonaparte and Powell, 1980

Gen. et sp. indet.

Referred material. MPM 21547, isolated right 
pedal phalanx IV-2? (locality 4) (Figure 28).

Description. The non-ungual pedal phalanx is almost complete, lacking the ventral portion of the distal condyles. The bone is $15 \mathrm{~mm}$ long and 8 $\mathrm{mm}$ high proximally. The element is proximodistally short, dorsoventrally deep, and transversely narrow. The proximal articular surface of the phalanx has a dorsoventral keel separating two concavities, the medial one being slightly wider than the lateral one. Proximally, the phalanx has a well-developed ventral projection, sub-triangular in contour as viewed from above. The phalanx is ventrally flat and smooth. Dorsally is transversely narrower with respect to the ventral surface, a condition resembling other abelisauroids (e.g., Novas \& Bandyopadhyay, 2001; Novas et al. 2004; Brissón Egli et al., 2016). Distally, the medial condyle is more developed than the lateral one. The lateral collateral ligament pit is wider and deeper than the medial one.

Comments. The pedal phalanx MPM 21547 resembles Noasauridae in being transversely narrow and dorsoventrally deep, a condition shared with Velocisaurus and Vespersaurus (Brissón Egli et al., 2016; Langer et al., 2019). Further, a well-developed, transversely thick, and posteriorly extended posterodorsal process is also shared with noasaurids, including Noasaurus, Ligabueino, Velocisaurus and Vespersaurus (Langer et al., 2019), constituting a synapomorphic feature of Noasauridae (Agnolin \& Chiarelli, 2010). However, in the case for the phalanx here described the ventral projection proximally surpasses the level of the dorsal lip, contrasting with known noasaurids in which the projections are sub-equal in proximal extension (e.g., Laevisuchus, Noasaurus; Novas \& Bandyopadhyay, 2001, Sampson et al., 2001, Novas et al., 2004; Agnolin \& Chiarelli, 2010; Brissón Egli et al., 2016).

Noasaurids have been recorded in different Late Cretaceous localities of Gondwana, including India (Novas \& Bandyopadhyay, 2001; Novas et al., 2004), Africa (Sampson et al., 2001) and South America (Bonaparte \& Powell, 1980; Bonaparte, 1991; Brissón Egli et al., 2016; Langer et al., 2019; Martinelli et al., 2019). Present specimen constitutes the southernmost record for this theropod family, and forms part of a small-sized theropod fauna also integrated by megaraptorids and unenlagiids (see below).

Paraves Sereno, 1997

Unenlagiidae Bonaparte, 1999

Gen. et sp. indet.
Referred material. MPM 21548, pedal ungual of digit II; MPM 21549, phalanx III-2. (locality 4) (Figure 28).

Description. MPM 21548 consist on the proximal portion of the ungual phalanx of right pedal digit II, lacking its proximodorsal lip. The ungual is laterally compressed, being $9.9 \mathrm{~mm}$ in transverse width, comparable in size with the correspondent ungual of Neuquenraptor argentinus (MCF PVPH 77; Novas \& Pol, 2005; Brisson et $a l ., 2017)$. It is elliptical-shaped in cross-section, with collateral grooves asymmetrically placed, as typical of paravians (Rauhut \& Werner, 1995). The lateral surface is flat, while the medial one is dorsoventraly convex. The proximoventral flexor tubercle is well-developed and shows rugosities on its ventral surface, as typically occurs among paravian theropods (e.g., Ostrom, 1969). The proximal articular surface presents a well-defined dorsoventral keel separating two sub-equals concavities. The ventral margin of ungual forms a cutting edge that is continuous with the lateral surface of the ungual blade. The cutting edge is medially displaced, as it also occurs in other paravians (e.g., Neuquenraptor, Deinonychus, Velociraptor, Buitreraptor; Ostrom, 1969; Norell \& Makovicky, 1999; Makovicky et al., 2005; Brisson Egli et al., 2017). The longitudinal collateral grooves are proximally forked, depicting the characteristic horizontal oriented "Y"-shaped groove.

Besides, specimen MPM 21549 is a complete pedal non-ungual phalanx, probably corresponding to pedal phalanx III-2. It was found nearby MPM 21548 and their sizes are congruent to refer them to a single individual. Phalanx MPM 21549 measures $45 \mathrm{~mm}$ long and $19 \mathrm{~mm}$ high, being larger than that of Neuquenraptor (Brisson Egli et al., 2017).

The proximal articular surface lacks the medial keel and shows a sub-triangular contour, with a straight ventral margin. The proximodorsal lip has a sub-triangular profile in dorsal view, proximally surpassing the level of the articular surface. The proximal articular surface is gently concave. The proximal portion of the ventral surface has a rugose and flat shelf. Distally, the extensor fossa is wide. The distal condyles are circular-shaped in lateral view and have wide collateral ligament pits. In lateral view, the distal condyles slightly surpass the dorsal margin of the body of the phalanx.

Comments. Unenlagiids were recorded in NW Patagonia and NW Argentina (Agnolin and Novas, 2013). MPM 21548 and MPM 21549 con- 

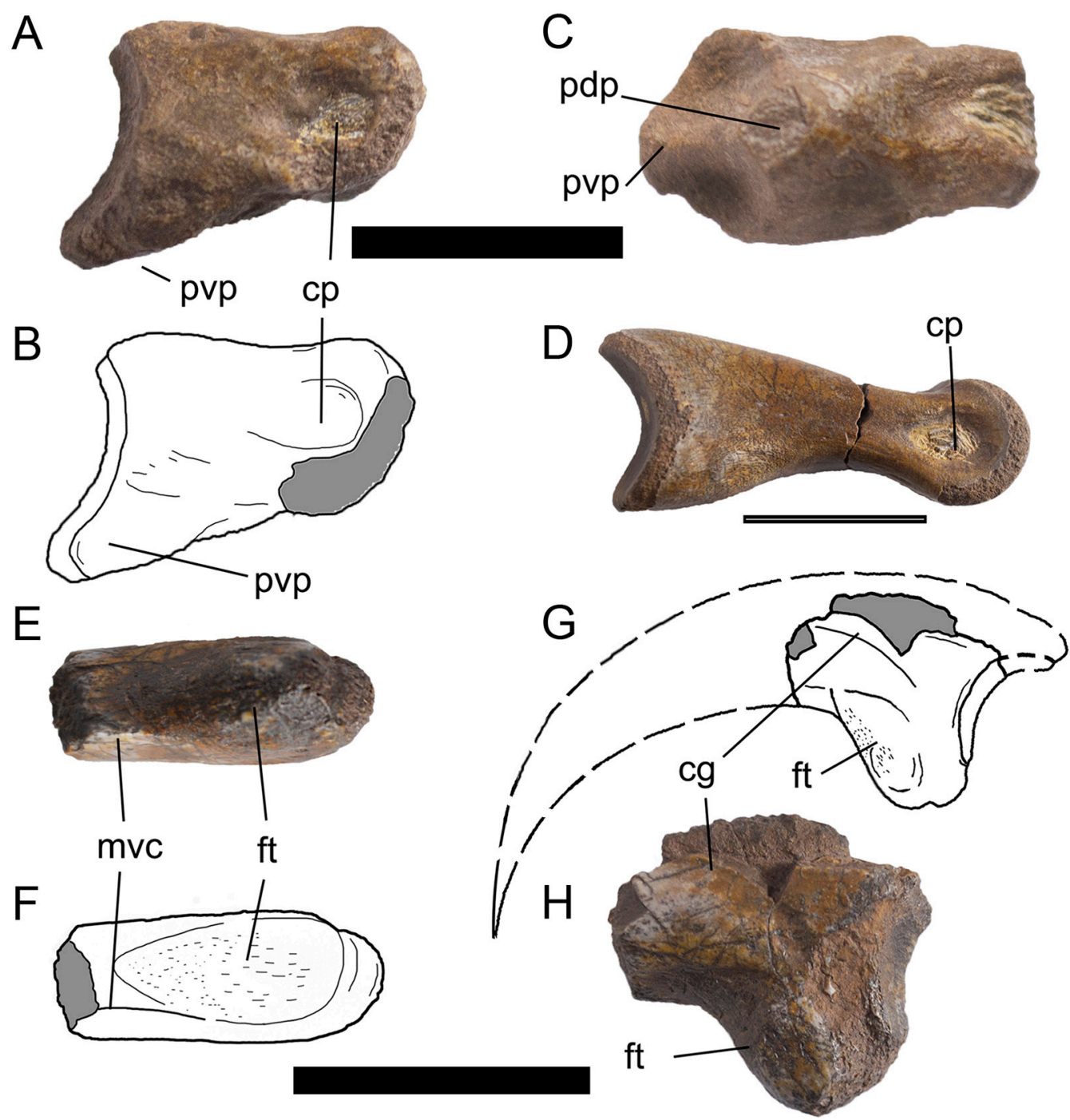

Figure 28. Theropod pedal elements. (A-C), isolated noasaurid right pedal phalanx IV-2? (MPM 21547) in medial (A-B) and dorsal (C) views; (D-H), Unenlagiid pedal elements. Right pedal phalanx III-2 (MPM 21549, D) and right pedal ungual of digit II (MPM 21548, E-G) in lateral (D), ventral (E, F), and medial (G-H) views. Abbreviations: cp, colateral pit; ft, flexor tubercle; mvc, medioventral crest; pdp, posterodorsal process; pvp, posteroventral process. Scale bar: $10 \mathrm{~cm}$

stitute the southernmost unenlagiid record for South America. This unenlagiid, similar in size and shape to Neuquenraptor, expands the meagre record of Maastrichtian unenlagiids from Argentina, up to the date represented by the large bodied Austroraptor (Novas et al., 2009).

Aves Linnaeus, 1758

Ornithurae Haeckel, 1866

Kookne yeutensis nov. gen. et sp.
Holotype. MPM 21550, incomplete right coracoid lacking sternal end and proximal end damaged (locality 2) (Figure 29).

Diagnosis. Medium-sized derived ornithurine diagnosable on the basis of the following unique combination of characters (autapomorphies marked by an asterisk*): 1) robust coracoidal shaft with well-defined and proximodistally extended procoracoid process; 2) ligamentum coracoscapulare ventralis forming a well-defined scar, resulting in a notch that separates the scapular cotyla from the facies articularis humeralis; 3) 
facies articularis humeralis ovoidal in shape, with its distal half more transversely expanded than the proximal half; 4) cup-shaped impression for the acrocoracohumeral ligament, with thickened and well-defined margins*.

Etymology. "Kookne", mythological swan companion of the Aonikenk hero Elal; and yeutensis, from "yeut", "mountain" in Aonikenk language.

Description. Kookne yeutensis is represented by an isolated coracoid lacking the sternal end and showing badly damaged acrocoracoidal process. The coracoid is robust, and belongs to a mediumsized bird, the size of a tern (maximum preserved proximodistal length of coracoid is $23.4 \mathrm{~mm}$, minor coracoidal transverse width is $4.8 \mathrm{~mm}$, and the preserved transverse width at level of scapular cotyla is $6.3 \mathrm{~mm}$ ). The distal end of the bone exhibits a transverse linear ridge for the impression of the $M$. sternocoracoidei. This ridge is obliquely oriented and runs from the laterodistal to the medioproximal edges of the bone.

The procoracoid process is present, but lacks its distal tip. It is represented by an acute lamina. This process is relatively dorsoventrally short, distally extending as a narrow but well-defined ridge, constituting the medial edge of the distal half of the coracoid. Distal to the procoracoid process there is a strap-like impression for the $M$. subscapularis, as is observed in modern anseriforms (e.g., Anas) and Maaqwi (McLachlan et al., 2017). At the base of the procoracoidal process there is a small, ellipsoidal-shaped foramen for the $N$. supracoracoidei. This foramen penetrates the bone dorsally and leaves the bone medially, within the supracoracoidei groove. This foramen is distal to the medial margin of the scapular cotyla, and is slightly recessed.

The scapular cotyla is roughly subtriangular in contour. The margins of the cotyle are notably thick, especially the lateral and distal ones. Laterally, the distal margin of the cotyle is delimited by a notch formed by the scar of the ligamentum coracoscapulare ventralis. This scar separates the scapular cotyle form the articular surface for the humerus. The humeral articular surface is relatively large, roughly ovoidal in contour and its surface is slightly concave. Its distal half is transversely wider than its proximal half. The lateral margin is slightly thickened. Its distal end is more proximally located than the distal level of the scapular cotyla and is delimited by the scar of the ligamentum coracoscapulare ventralis. The humeral articular surface is laterodorsally oriented and slightly proximally tilted. The proximal edge of the humeral articular surface is narrow and bifurcates in two main ridges that delimit a well-defined and cup-shaped impressio for the acrocoracohumeral ligament. The dorsal crest becomes proximally prominent and medially wraps the triosseous canal.

The lateral surface of the coracoid shows a subtriangular flattened surface with its tip pointing distally. This surface is ventrally delimited by a very narrow but conspicuous ridge corresponding with the M. supracoracoidei. Distal to this ridge, there is preserved the proximalmost portion of the intermuscular ridge between the $M$. coracobrachialis caudalis and M.supracoracoideus (see Jasinoski et al., 2006).

In medial view the coracoid shows a very deep and wide triosseal canal. This is represented by the excavation for the M.supracoracoidei which forms a deep groove that is distally extended as a narrow sulcus reaching the distal end of the procoracoidal process. Proximally, this groove shows a dorsal depression that is subcircular in contour. Comments. The coracoid is one of the most diagnostic elements of the avian skeleton (Hope, 2002). Because of its taphonomical attributes, the coracoid is the most commonly preserved element among Mesozoic birds (see Higgins, 1999; Longrich et al., 2011). In spite of being represented by a single, isolated coracoid, Kookne is referred to derived Ornithurae by having an acrocoracoid process that curves medially to embrace a wide and deep triosseal canal, and a broad furcular articulation (Agnolin, 2010; McLachlan et al., 2017). Within Ornithurae, the coracoid is similar to Palintropus, Ichthyornis, and more derived forms in having a ligament scar on the dorsal surface of the acrocoracoid (Longrich, 2009). As occurs in Ichthyornis and crown Aves it exhibits a triosseal canal passing ventral to the scapular articular facet (McLachlan et al., 2017). Further, Kookne is more derived than Ichthyornis, and resembling crown Aves, in having the following features: humeral articular facet anteriorly displaced relative to the scapular articular facet, scapular and humeral facets well-separated each other, and acrocoracoid that medially wraps the triosseal canal (Hope, 2002; Agnolin, 2010; McLachlan et al., 2017). In sum, all features exhibited by Kookne are shared with derived Ornithurae, mostly Neornithes. In this way, we refer Kookne to crown birds.

Mesozoic Neornithines or stem-Neornithines are scarce in the fossil record. Most taxa are grouped within Cimolopterygidae (Longrich, 2009; Agnolin, 2010; Longrich et al., 2011; McLachlan et al., 2017), Palintropidae (Brodkorb, 

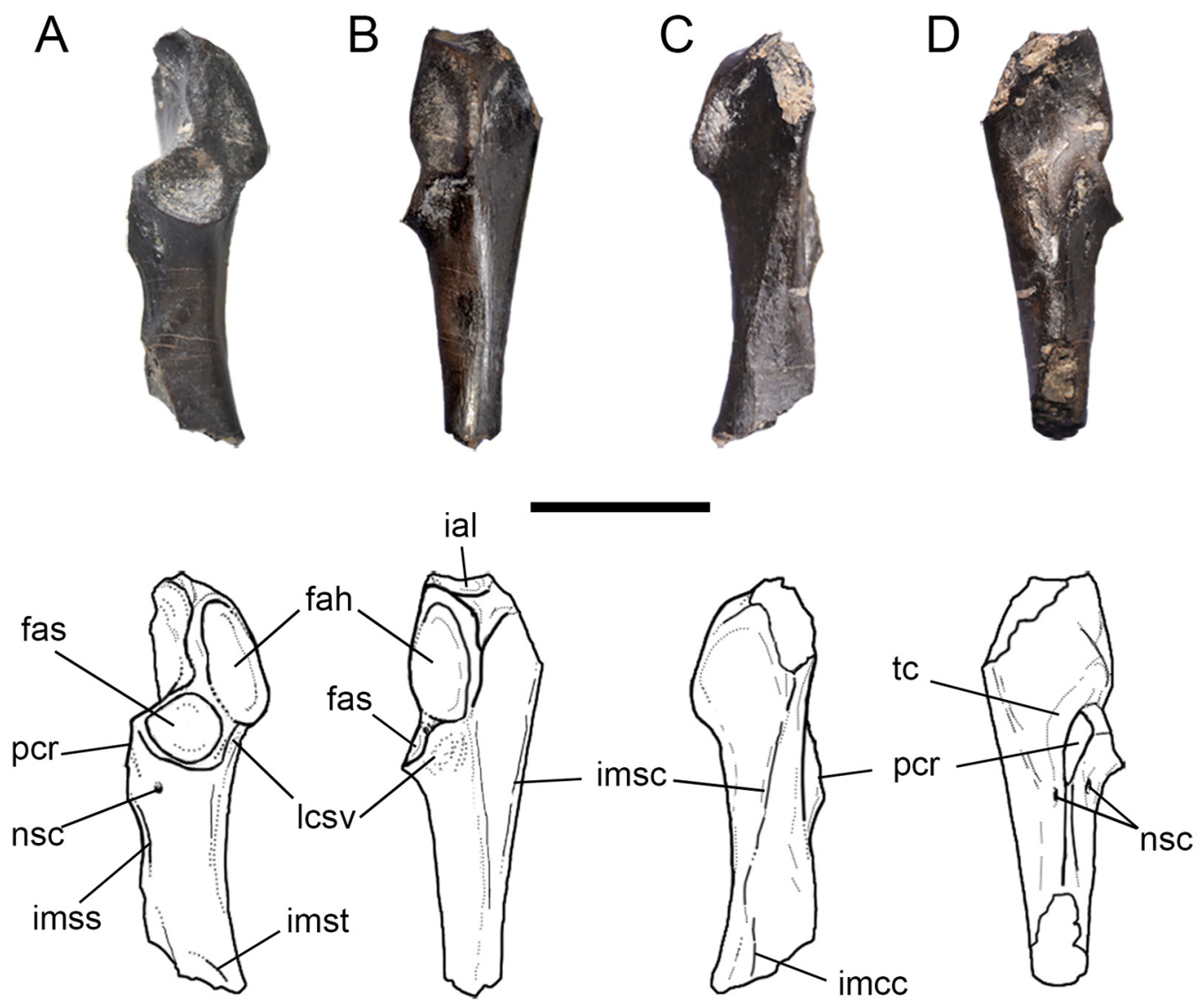

Figure 29. Kookne yeutensis gen. et sp. nov. Right coracoid (MPM 21550; holotype) in dorsal (A), lateral (B), ventral (C) and medial (D) views. Abbreviations: fah, facies articularis humeralis; fas, facies articularis scapularis; ial, impression for the acrocoracohumeral ligament; imce, impressio for the m. coracobrachialis caudalis; imsc, impressio for the $m$. supracoracoideus; imss, impressio of the $m$. subscapularis; imst, impressio for the $m$. sternocoracoidei; lcsv, ligamentum coracoscapularis ventralis; nsc, foramen for $n$. supracoracoidei; pcr, procoracoidal process; tc, triosseal canal. Scale bar: $1 \mathrm{~cm}$

1970; Hope, 2002), and Vegaviidae (Agnolin et al., 2017). Kookne does not fit with any previously named derived ornithurine from the Mesozoic. It differs from Palintropus and kin by a large number of features, including retention of a well-developed procoracoidal process, foramen for N.supracoracoidei proximally located at the base of the procoracoid process, scapular facet not laterodistally positioned, and ventral margin with a straight anterior edge (Hope, 2002).

Further, Kookne differs from Vegaviidae in lacking thickened bone cortex on the coracoid and in having more gracile proportions (McLachlan et al., 2017). Detailed comparisons with Vegavis resulted in the following differential features: in Kookne the procoracoid is more ventrally extended, the humeral facet is dorsolaterally faced (instead of being laterally faced as in Vegavis), the ventral margin is straight (instead of strongly concave as in Vegavis and Maaqwi) resulting in a subvertically oriented acrocoracoid process.

Cimolopterygids are a widespread clade of Cretaceous and possibly Paleogene birds that include a large variety and diversity of morphotypes (Longrich, 2009). Most cimolopterygids are based on isolated and often fragmented coracoids, with a wide morphological divergence. However, cimolopterygids share some common traits that are absent in Kookne. For example, Cimolopteryx and Lamarqueavis show a very large and distally located foramen for the $N$. supracoracoidei, procoracoid process laminar and dorsoventrally extended, and humeral articular surface dorsoventrally oriented (Brodkorb, 1963; Hope, 2002; Agnolin, 2010). This combination of characters is absent in Kookne. 
Iaceornis is a purported neornithine coming from the Late Cretaceous of USA, and described by Hope (2002) under the name of Apatornis (see also Clarke, 2004). It was previously referred to Galloanseres (Hope, 2002; Clarke, 2004). It sharply differs from Kookne in having a notably elongate omal end, with proportionately smaller acrocoracoid and humeral facet, and a narrow scapular cotyla and shallower triosseal canal (Hope, 2002; Clarke, 2004).

Among neornithines, Kookne shows a combination of characters (e.g., well-developed acrocoracoid and procoracoid processes, well-developed foramen for $N$. supracoracoidei, coracoidal shaft relatively short and stout) clearly distinguishing it from ratites, tinamids, galliforms, gruiforms and podicipediforms (Hope, 2002). Further, the coracoid of Kookne differs from that of Charadriiformes in that the humeral facet is not large and ovate, the foramen for the $N$. supracoracoidei is not caudally recessed from the scapular cotyla, and the scapular cotyla is not particularly large and subcircular in contour (Hope, 2002). Further, in charadriiforms the humeral facet and coracoidal shaft are usually medially tilted (Hope, 2002).

Kookne is reminiscent of Anseriformes in sharing several derived features, including: transverse linear ridges within the impressio sternocoracoidei (Ericson, 1997; Mayr \& Smith, 2001); expanded articular surface for the furcula (a feature recovered diagnostic for Anseriformes in recent analyses; Clarke et al., 2016); ventral border of sulcus for the $M$. supracoracoidei columnar-shaped, and increasing in diameter towards the clavicular facet; and well-defined fossa within the supracoracoideus groove (Hope, 2002), and well-excavated acrocoracohumeralis impression (Mayr \& Smith, 2001). In Kookne the ligamentum coracoscapulare ventralis forms a welldefined scar, a feature shared with Anseriformes (Hope, 2002). A similar condition is observed in Ceramornis (figured as "lateral fossa" by Longrich et al., 2011), but in this case the fossa is notably wider and crescent-shaped. In sum, this combination of characters strongly suggests anseriform affinities for Kookne. However, its fragmentary nature makes this referal tentative.

Most frequently cited Latest Cretaceous anseriforms belong to Presbyornithidae. Presbyornithid coracoid, as exemplified by Presbyornis and Telmatornis. is characterized by a notably elongate neck and narrow humeral facet which is proximodistally expanded and notably flattened, scapular facet large and subcircular in contour, and foramen for N. supracoracoidei more distally located (Hope, 2002; De Pietri et $a l ., 2016)$. This combination of traits is absent in Kookne. In addition, Kookne differs from the early Paleocene anseriform Conflicto in retaining a foramen for the $N$. supracoracoidei, humeral shaft more robust, and scapular facet ovoidal, among other minor details (see Tambussi et al., 2019).

In spite of its fragmentary nature, Kookne represents an important addition to the fossil record of Late Cretaceous birds from the in South America and Antarctica. Most relevant evidence comes from NW Argentina, NW Patagonia, and Antarctic Peninsula (e.g., Agnolin, 2010; Agnolin et al., 2017). Bird remains have been also recorded from the Dorotea Formation (Manriquez et al., 2019). Kookne expands avian diversity for the southern extreme of Patagonia, and demonstrates, in join with Lamarqueavis and Vegavis, that an important morphological divergence existed in the southern cone during Maastrichtian times (Agnolin et al., 2006; Agnolin, 2010; Clarke et al., 2016). This also supports the idea (firstly expressed by Chatterjee, 2002) that the Southern Hemisphere played a key role in the origin and early evolution of modern birds.

\section{Dinosaur eggshells}

Abundant dinosaur eggshells have been recorded from the lower and middle sections of the Chorrillo Formation. Dinosaur egg-shell fragments of two types have been collected from Titanosaur tibia (locality 2) and Puma Cave (locality 4) sites. The microstructural patterns observed in the eggshells agrees with that previously described for sauropods (i.e., Fusioolithidae) and theropods (i.e., Prismatoolithidae).

\section{Oofamily Fusioolithidae Fernández \& Khosla, 2015 \\ Fusioolithus Fernández \& Khosla, 2015 Fusioolithus ichnosp.}

Referred material. MPM 21543, thirty four eggshells collected from locality 4; MPM 21544, twenty two eggshells collected from locality 2 (Figure 30).

Description. The outer eggshell surface displays a compactitubercular ornamentation with coalescent nodes, showing partial fusion of shell units into more nodes (Figure 30A,B,E), with pore apertures located in the depressions among them. The eggshell is $0.97 \mathrm{~mm}$ thick and each node is about $0.7 \mathrm{~mm}$ in diameter. The pore system is 

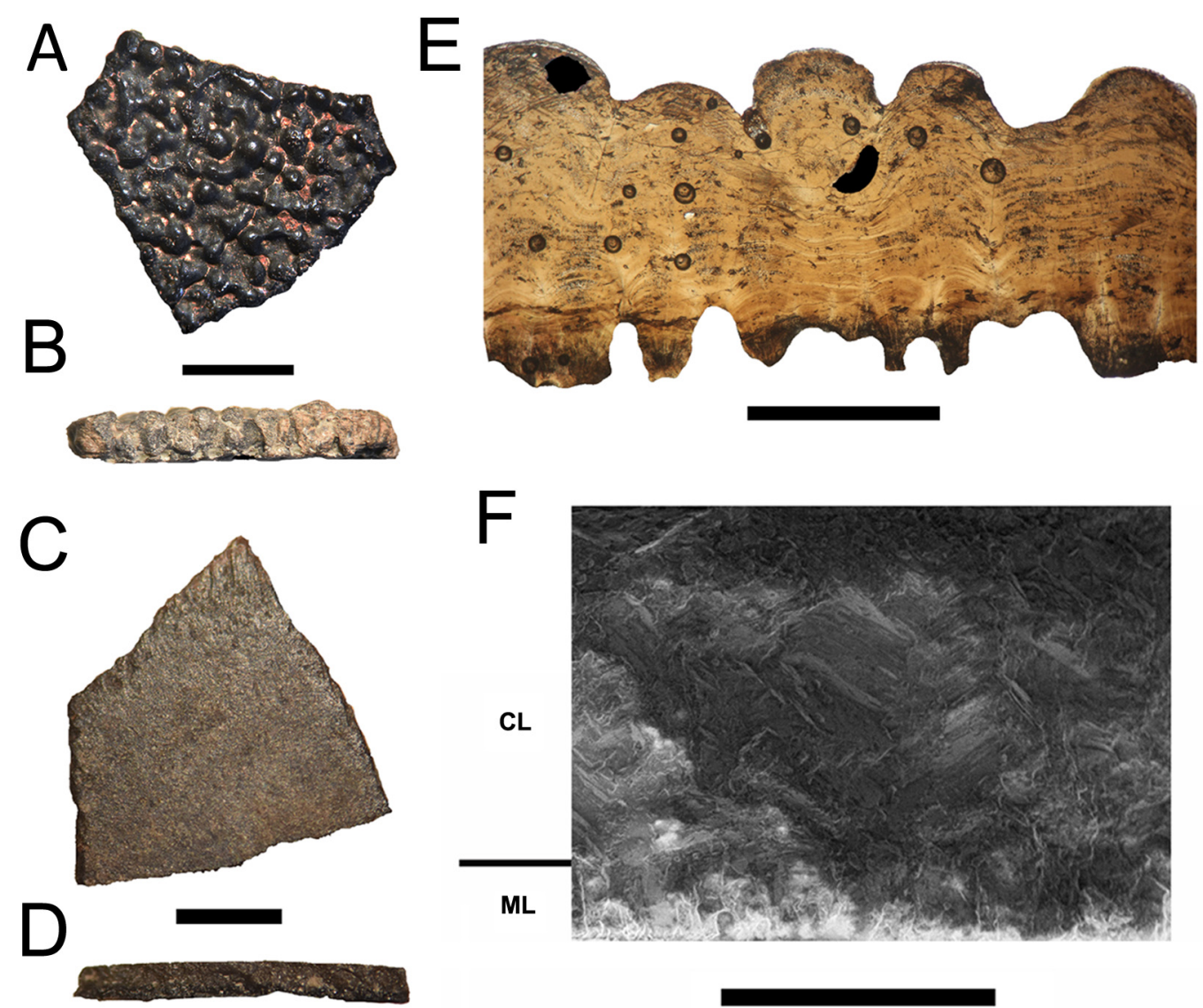

Figure 30. Dinosaur eggshells. (A-B, E) Fusioolithus sp. eggshell fragment (MPM 21543). A, external view; B, radial section; E, radial section showing the microstructure of the sample. (C-D, F) Prismatoolithidae eggshell fragment (MPM 21551) (C) external view; (D) radial section; (F) radial section under MEB showing three main structural layers: mammillary, prismatic and external. Abbreviations: CL, continuous layer; ML, mammillary layer. Scale bar $1 \mathrm{~mm}$ in A-E, $200 \mu \mathrm{m}$ in F.

tubocanaliculate. This set of features allows referral of specimens MPM 21543 and MPM 21544 as to the Fusioolithidae oogenus Fisuoolithus (see Fernández \& Khosla, 2016).

Comments. Late Cretaceous eggs and eggshells from Patagonia, usually interpreted as corresponding to Titanosauria, have been sorted into three different oofamilies: Fusioolithidae, Faveoloolithidae, and Megalolithidae. The Fusioolithidae, including Fusioolithus baghensis Fernandez \& Khosla 2016, documented in the Campanian Anacleto Formation, Auca Mahuevo, Neuquen, and Maastrichtian Allen Formation from Santa Rosa and Trapalcó (Rio Negro). Fusioolithidae characterize by a dinosauroidspherulitic basic type, tubospherulitic morphotype, tubocanaliculate pore system. Its ornamentation is compactituberculate. Thins sections shows that the accretion lines cross the bound- ary between shell units starting on the one-third of the inner of the eggshell thickness and sometimes continue to the external surface. Eggshell is composed of circular cones without clearly demarcated boundary lines; the shell units are partially fused. The shell units are fan shaped similar to the eggs of oofamily Megaloolithidae but it differ in the nature of the eggshell units in which they are partially fused. (Fernández and Khosla, 2014).

Besides, Faveoloolithidae is abundantly represented in Patagonia in Allen and Los Alamitos formations, Salitral Moreno, Rio Negro), and distinguish for being coarse-shell eggs, with compactituberculated ornamentation, filiesferulitic structural morphotype, and multicaniculated pore system. Paquiloolithus rionegrinus (Simón, 2006) has been referred to this oofamily.

Finally, Megaloolithidae is represented 
Megaloolithus jabalpurensis (Fernández \& Khosla, 2014; 2016), documented in Bajo de la Carpa Formation, Neuquén City, and the Campanian-Maastrichtian Allen Formation at Santa Rosa, Trapalcó, and Salitral Moreno (Rio Negro Province). These eggshells have a discretispherulitic morphotype, eggs are spherical to sub-spherical in shape with diameter variable from 140 to $160 \mathrm{~mm}$. The eggshell thickness ranges from 1.0 to $2.38 \mathrm{~mm}$ and shows compactituberculate ornamentation. The average node diameter is about $0.67 \mathrm{~mm}$ with diameter ranging from 0.35 to $1 \mathrm{~mm}$. The shell units are fan shaped and of variable width and shape. The lateral margins of shell units are non-parallel. The average height/width ratio is $2.45: 1$. The growth lines are moderately arched upwards, and have tubocanaliculate pore system (pore canals are straight).

Features enumerated above for MPM 21543 and MPM 21544 are consistent with Fusioolithidae, and sharply differ from both Faveoloolithidae and Megaloolithidae. Faveoloolithidae have $5 \mathrm{~mm}$ thick eggshells, while MPM 21543 and MPM 21544 are thinner, faveoloolithid nodes from external surface are smaller than fusioolithid nodes, then faveoloolithis eggshells have different pore canal sytem (multicanaliculated) and shell units are multispherulitic (Mikhailov, 1997). On the other hand Megaloolithidae eggs have compactutuberculated ornamentation, but each node at the external surface appears isolated. Shell units are sharply separated from each other, constituting an important diference with fusioolithid eggshells (Mikhailov. 1997).

Oofamily PRISMATOOLITHIDAE Hirsch, 1994 Ichnogenus and Ichnospecies indet.

Referred material. MPM 21551, five eggshells collected in locality 4 (Figure 30 ).

Description. The sculpture of the outer surface is nearly smooth, with some areas finely sculptured (Figure 30C,D and F). The eggshell is 0.2 through $0.3 \mathrm{~mm}$ thick. Observed under SEM it shows a prismatic structure separated into two different layers: a mammillary layer (ML), 0,06 $\mathrm{mm}$ thick, and a continuous layer (CL) $0.23 \mathrm{~mm}$ thick. The CL:ML ratio is 1:0.2. The boundary between layers is not abrupt. The mammillary layer exhibits a tabular structure, showing radial sections with slender mammillae with straigth limits between each mammilla. The mammillae are built up by spherulites rising from the base of the mammillae, with no evidence of nucletion center. These spherulites growth distally, up to the limit with the continuous layer, changing their orientation to form compact aggregates of vertical rhombohedral crystals. These crystals gradualy change into the continuous layer. For this reason, and because of indistinct boundary, these eggshells belong to the "dinosauroidprismatic basic type" (Mikhailov, 1997). The continuous layer reveals more homogeneous and compact tabular ultrastructure. The organic core is not preserved. Whitin the continuous layer, the prismatic and external zones can be distinguished, the last one showing a more compact material. This set of features allows referral of specimen MPM 21551as to the Prismatoolithidae oofamily.

Comments. Late Cretaceous eggs and eggshells from Patagonia interpreted as belonging to Theropoda are restricted to the single oospecies Arriagadoolithus patagoniensis, from the Maastrichtian Allen Formation, Río Negro (Agnolin et al., 2012). MPM 21551 differs from Arriagadoolithus patagoniensis in that in the later one the shell is much thicker (about $1 \mathrm{~mm}$ ), and the outer ornamentation is much more complex (it composes of low irregular nodes, isolated node-like ridges, low an elongate ridges interconnected each other to form a net; Agnolin et al., 2012).

$$
\begin{gathered}
\text { Mammalia Linnaeus, } 1758 \\
\text { Genus and species indeterminate }
\end{gathered}
$$

Referred material. MPM 21552, anterior caudal vertebra (Figure $31 \mathrm{~A}-\mathrm{E}$ ), and MPM 21553, mid-to-posterior caudal vertebra (Figure $31 \mathrm{~F}-\mathrm{K}$ ). Both caudals were collected from locality 4 .

Description. MPM 21552 and MPM 21553 are identified as caudal vertebrae of Mammalia on the basis of following combination of features: 1) platycoelous centra; 2) presence of two longitudinal keels on the ventral surface of centrum; 3) neural spine anteroposteriorly long and very low; 4) postespinal fossa present; 5) transverse processes aliform; 6) transverse processes divided into anterior and posterior portions, separated through a medial constriction; 7) transverse process with a blunt lip on both anterior and posterior ends; 8) prezygapophyseal process more extensive than the postzygapophyseal one; and 9) absence of neural canal. This set of characters is not observed in caudal vertebrae of other vertebrate groups, including turtles, lizards, crocodiles and dinosaurs. 
The MPM 21552 is an incomplete posterior half of centrum of a relatively large vertebra, being robust and transversely wide $(8.99 \mathrm{~mm})$. The vertebral centrum is subcircular in transverse section, slightly dorsoventrally depressed, and becomes notably narrower at mid- length. The posterior articular surface is platycoelous. The base of the transverse processes is located at centrum mid-height, it is anteroposteriorly extended and reaching the posterior margin of centrum. The neural arch is poorly preserved. The bases of the postzygapophysial processes are located on the dorsolateral corner of centrum. The base of the neural spine is located on the middle portion of the dorsal surface of neural arch. The neural spine is posteriory forked, bounding a narrow postespinal fossa, "V"-shaped in contour. On ventral surface the centrum has two shallow longitudinal keels. The combined presence of these keels in join with the position of transverse processes, indicate that this element is an anterior caudal vertebra.

MPM 21553 is a complete caudal vertebra, smaller $(7.7 \mathrm{~mm}$ long and $4.3 \mathrm{~mm}$ of maximum transverse width) but proportionally more slender than MPM 21552. This vertebra is notably elongate and dorsoventrally depressed, being cylindrical in gross-shape. The centrum is transversely wide at both anterior and posterior ends, being more constricted at mid-length. Both articular surfaces are subcircular and with a shallow notochordal notch. Several nutrient foramina are present on the ventral surface of centrum. Both anterior and posterior transverse processes are separated by a constriction at mid-length; they are wing-shaped, sharp and slightly laterally projected. Transverse processes ends in blunt lips, probably representing the insertion of M.ischiocaudalis and M.abductor caudae dorsalis (Argot, 2003). The anterior lips are ventrally projected and are longer and more robust than the posterior lips. There is a small concave depression at the dorsal surface of the transverse processes for probable attachement of M. sacrocaudalis dorsalis (Kielan-Jaworowska \& Gambaryan, 1994). On the ventral surface, the transverse processes exhibit a depression, deeper than the dorsal one, probably corresponding to the insertion of the $M$. sacrocaudalis ventralis (Kielan-Jaworowska \& Gambaryan, 1994). The ventral surface of centrum has two, well-developed longitudinal keels, which extend along the anterior half of the vertebra. On the contrary, these keels are reduced on the posterior half of the centrum. These crests probably contacted with the haemal arches

The neural spine is low and feebly developed. Near the anterior and posterior ends, the neural spine is subdivided into two crests that delimit the preespinal and postespinal fossae, respectively. Prezygapophyseal processes are well developed, dorsolaterally projected and located laterally with respect to the preespinal fossa. Postzygapophyseal processes are absent. There are several nutrient foramina on both sides of the neural spine; one foramen is located between the anterior and posterior transverse processes. The position and shape of transverse processes and neural spine indicate that this element belongs to a mid-caudal or posterior portion of the tail.

Comments. Excepting for domestic species, comparative studies on caudal vertebrae in extant and extinct mammals are scarce (e.g., Horovitz \& Sánchez-Villagra, 2003). Specimens here reported show transverse processes slightly laterally projected, low neural spines, and poorly developed ventral keels. This combination of characters is shared with mammals having long and gracile tails, as reported for Jeholodens, Yanoconodon, Agilodocodon, Henkelotherium, Akidolestes, Eomaia, Pucadelphys, and Mayulestes, for example (Nessov et al., 1998; Ji et al., 1999; VázquezMolinero et al., 2001; Ji et al., 2002; Argot, 2003; Luo et al., 2007; Chen \& Luo, 2013; Meng et al., 2015). The morphology described above for MPM 21552 and MPM 21553 are also present in some living mammals with elongate tails, such as felids (e.g., Panthera leo MACN 21.621), platyrrhins (e.g., Alouatta caraya MACN 33.170), and metatherians (e.g., Macropus giganteus MACN 48.214).

As far as for Mesozoic mammals from South America, caudal vertebrae have been described only for Vincelestes (Rougier, 1993). Unlike MPM 21552 and MPM 21553, in Vincelestes the caudal vertebrae show different proportions, being notably short and stout, with enlarged transverse processes, higher neural spines, and very large neural canals (Rougier, 1993).

Some traits described above for Vincelestes have been also reported for other Mesozoic mammals, such as Castorocauda, Fruitafossor, and Repenomamus (Hu et al., 2005; Luo \& Wible, 2005; Ji et al., 2006), as well as many Cenozoic and Recent mammals with robusts tails (e.g, Paleonodonta, Pantodonta, Xenarthra, Pholidota, Talpa, and some rodents; Krause \& Jenkins, 1983; Rose et al., 1992; Muizon et al., 2015). These taxa possess robust caudal vertebrae, 

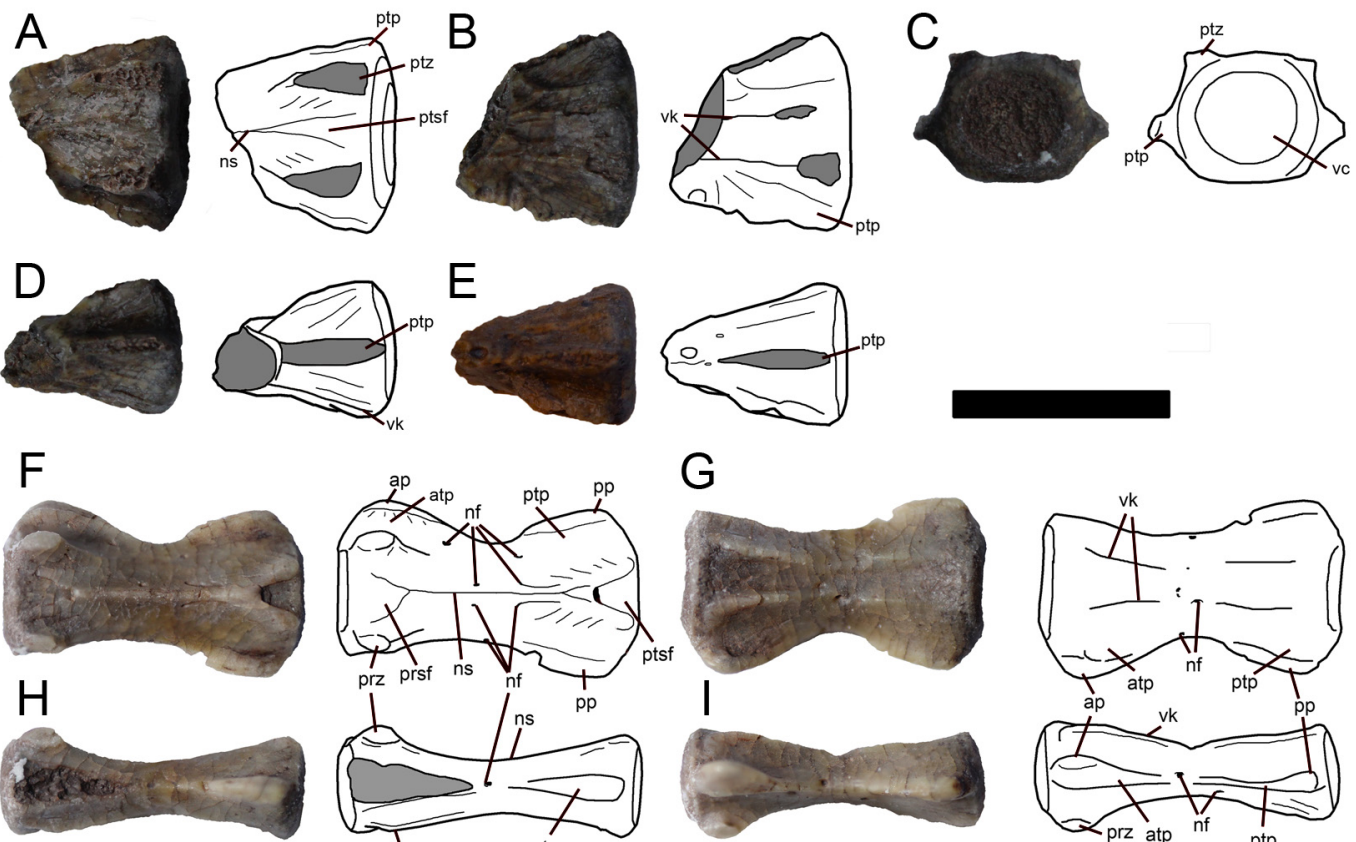

G
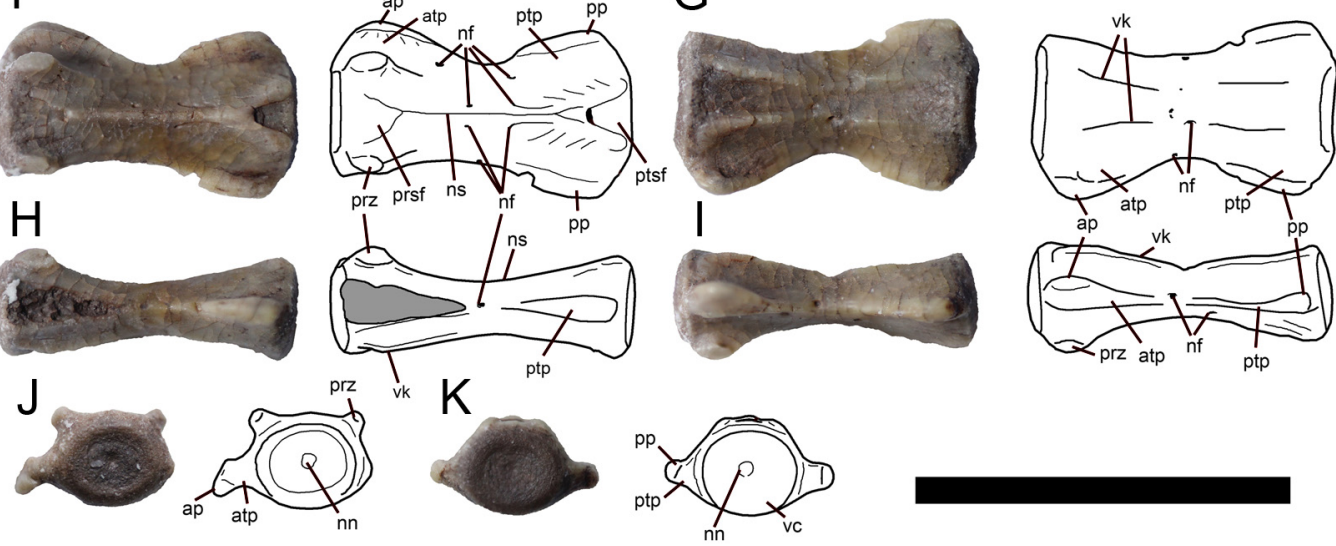

Figure 31. Mammalia indet, caudal vertebrae in A, F, dorsal; B, G, ventral; C, K, posterior; D, H, left lateral; E, I, right lateral; and J, anterior views. (A-E) MPM 21552 and (F-K) MPM 21553. Abbreviations: ap, anterior pit; atp, anterior transverse process; nf, nutrient foramina; nn, notochordal notch; ns, neural spine; pp, posterior pit; ptp, posterior transverse process; prsf, prespinal fossa; prz, prezygapophyseal process; ptsf, postspinal fossa; vc, vertebral centrum; vk, ventral keel. Scale bars: $10 \mathrm{~mm}$.

with laterally extended transverse processes, high neural spines, postzygapophyseal processes present along the tail, and robust haemal arches. This robust tail has been related with either swimming or digging behaviors (Ji et al., 2006).

MPM 21553 is a mid- to posterior caudal, perforated by several nutrient foramina and presence of transverse processes with marked muscle attachments. These two features suggest that the mammal from Chorrillo had a tail with marked neurovascular innervation and a strong muscular development, possibly related with a semi-arboreal lifestyle.

Upper Cretaceous beds from Patagonia (mainly Los Alamitos and Candeleros formations, Río Negro province) yielded a variety of gondwanatherians and meridiolestidans (Bonaparte, 1986; 1990; 1992; 1994; 2002; Rougier et al., 2009a, 2009b, 2011), including forms the size of a squirrel, such as the meridiolestidans Cronopio and Leonardus (Rougier et al., 2011; Chornogubsky, 2011). Whether the small-sized mammalian ver- tebrae from the Chorrillo Formation belong to a meridiolestidan, need to be corroborated with more anatomical evidence.

\section{Invertebrates: Freshwater and Land Mollusks}

Abundant gastropod material (mainly fossil casts) has been collected at locality 4 , corresponding to the base of the upper third of Chorrillo beds. Available material consists of 56 specimens, found in close association with isolated vertebrate remains. Mollusk specimens belong to the freshwater families Ampullariidae, Pleuroceridae, Tateidae and Physidae, as well as to the terrestrial families Holospiridae, Bulimulidae and Achatinidae. Aquatic forms predominate at level of families $(60 \%)$, as well as number of collected specimens (80\%).

Classification here followed corresponds to the WoRMS Editorial Board (2019). For some families, new genera and species will be described elsewhere (Miquel \& Brito, in press). 
Subclass Caenogastropoda Cox, 1959

Order Architaenioglossa Haller, 1892

Superfamily Ampullaroidea Gray 1824

Ampullariidae Gray, 1824

Pomacea sp.

Referred material. MPM 21554, four fragmentary casts (Figure $32 \mathrm{~A}$ ).

Description. Casts globose, with short spires, and last whorl very convex and with rapid growth. Larger specimen measures $18.1 \mathrm{~mm}$ of maximum size and $15.1 \mathrm{~mm}$ of maximum width, and 2.25 whorls.

Comments. Ampullariidae has a Gondwanan distribution, with fossil taxa from the Eocene of Africa, Asia and America (http://www.bagniliggia.it /WMSD/ WMSDhome.htm, 2017). Extant representatives are widely distributed in the Neotropical Region, with no living representatives in Patagonia (Castellanos \& Landoni, 1995). Pomacea, in particular, has been recorded from the Eocene of La Pampa province (Argentina; Melchor et al., 2002). Specimens here described represent the first Cretaceous worldwide record for Ampullaridae, and the southern-most record for the genus Pomacea.

\section{Superfamily Cerithioidea Flemming, 1822 Pleuroceridae P. Fischer, 1885 Genus and species indeterminate}

Referred material. MPM 21555, MPM 21556, two fragmentary casts (Figure 31, B-C).

Description. Casts with whorls of uniform growth, with last whorl well-developed; sutures delineated by an angular rim; one specimen with maximum size of $31.5 \times 17.3 \mathrm{~mm}$ and 6 whorls. In another specimen, whorls are slightly convex, of regular growth, and suture marked with a quite strong shoulder; one specimen with maximum size of $20.1 \times 11.6 \mathrm{~mm}$ and 5 whorls.

Comments. Pleuroceridae is known from the Lower Cretaceous (Goniobasis multicarinata Russell, 1932) from Alberta, Canada (Henderson, 1935). The genus Paleanculosa Parodiz, 1969 has been recorded from Paleocene beds of South America, including P. bullia Ihering, 1907, P. macrochilinoides Doello Jurado, 1927, P. rionegrina Parodiz, 1969, and Paleoanculosa sp. (Parodiz, 1969). Some taxa related with Pleuroceridae were also described from the Cenomanian Mata Amarilla Formation (Pyrgulifera Meek, 1872; Santa Cruz Province; Griffin \& Varela, 2012). Extant representatives of Pleuroceridae inhabit aquatic systems in warm regions of South
America (Simone, 2006), being absent from Patagonia.

\author{
Superfamily Truncatelloidea Gray, 1840 \\ Tateidae Thiele, 1925 \\ Potamolithus sp.
}

Referred material. MPM 21557, thirty-six fragmentary casts (Figure $31 \mathrm{D}$ ).

Description Casts globose, with low spire and last whorl large and barely convex; one specimen with maximum size of $11.4 \times 9.2 \mathrm{~mm}$ and 4.50 whorls.

Comments. Cretaceous record of Tateidae Forasiepi \& López Armengol (1999) mentioned the presence of Potamolithus windhauseni (Parodiz, 1961) for the Los Alamitos Formation (Campanian - Maastrichtian) from Río Negro Province, Argentina. The genus has a restricted areal distribution in South America, comprehending the Río de la Plata basin and relict populations in southern Argentina and Chile (Miquel, 1998; de Lucía \& Gutiérrez Gregoric, 2017). The specimens here described constitute the southern-most record of Potamolithus.

Superfamily Planorboidea Rafinesque, 1815 Physidae Fitzinger, 1833

Referred material. MPM 21558, Physa sp., one incomplete cast (Figure $32 \mathrm{E}$ ); MPM 215599, Stenophysa sp., two incomplete casts (Figure $32 \mathrm{~F})$.

Description. Sinistral gastropods, ovoid to fusoid, with little to well-developed spire, and with last whorl prominent. One of the specimens referred as to Physa sp. has a maximum size of 8.9 $\mathrm{x} 5.5 \mathrm{~mm}$ and 1.5 whorls. Specimen referred as to Stenophysa sp. attains a maximum size of $13.7 \mathrm{x}$ $7.5 \mathrm{~mm}$ and 4 whorls.

Comments. Physidae are pulmonate gastropods, historically classified in a confused way (Taylor, 2003). This family has an almost worldwide distribution, with no living representatives Patagonia.

Genus Physa has been reported from different Upper Cretaceous localities of North America (White, 1877; Taylor, 2003; Russell, 1935) and South America (Cabrera et al., 2018; Mezzalira, 1974; Ghilardi et al., 2011). For Patagonia, the species Physa doeringi Doello Jurado, 1927, and Physa wichmanni Parodiz, 1961, have been described for the Maastrichtian-Danian Jagüel Formation (Río Negro province; Salvador et al., 2018). Thus, discovery of specimens of Physa in 
the Campanian - Maastrichtian Chorrillo beds expands to the south the paleobiogeographic distribution of the genus. Regarding Stenophysa Martens, 1898, the specimens collected from the Chorrillo Formation represent the first worldwide Cretaceous records for this genus.

Superfamily Achatinoidea Swainson, 1840

?Achatinidae Swainson, 1840

?Subulininae P. Fischer \& Crosse, 1877

Referred material. MPM 21560, MPM 21561, two fragmentary casts and shells (Figure 32 G-H).

Description. Fragments with general appearance of "Subulinidae", one of them large, with axial sculpture, and another specimen medium and smooth. The former with maximum size of $14.4 \times 8.9 \mathrm{~mm}$ and 2 whorls; the latter with maximum size of $16.2 \times 11.0 \mathrm{~mm}$ and 2 whorls.

Comments. Subulininae is recorded from the upper Paleocene of the Americas (Zilch, 1959) and the Eocene of China (Pan, 1977). In South America, the subulinine genus Neobeliscus Pilsbry, 1896 is recorded from the Miocene Pebas Formation (Brazil). Extant subulinines inhabit South America (Simone \& Mezzalira, 1994; Salvador et al., 2018), being absent from Patagonia. The specimens collected from the Chorrillo Formation may represent the first records for the subfamily for the Cretaceous worldwide.

Urocoptoidea Pilsbry, 1898

Holospiridae Pilsbry, 1946 Holospira sp.

Referred material. MPM 21562, one fragmentary cast (Figure $32 \mathrm{I}$ ).

Description. Columnar shape, with numerous whorls, which rapidly reaches a large size and then progresses more slowly; available specimen attains a maximum size of $18.5 \times 8.5 \mathrm{~mm}$ and 10 whorls.

Comments. This record constitutes the first one of Holospira for South America, also constituting the oldest known record for the entire family worldwide.

\section{Superfamily Orthalicoidea Martens, 1860 Bulimulidae Tryon, 1867 Genus and species indeterminate}

Referred material. MPM 21563, MPM 21564, five fragmentary casts (Figure $32 \mathrm{~J}-\mathrm{K}$ ).
Description. General aspect "bulimoid", similar to the extant genus Bulimulus Leach, 1814, Bostryx Troschel, 1847, and Naesiotus Albers, 1850 , of medium size, with several whorls that increase its size gradually; one specimen with maximum size of $23.3 \times 16.0 \mathrm{~mm}$ and other ones with maximum size of $13.9 \times 7.6 \mathrm{~mm}$, with 6 and 8.5 whorls, respectively.

Comments. This is a family with extant relict populations in Patagonia (Breure, 1979). Some Cretaceous Bulimulidae recorded from South America include: Bulimulus klappenbachi (Parodiz, 1969) from the Queguay Formation (Uruguay, Late Cretaceous) (Cabrera et al., 2018; Veroslavsky et al., 2019); others, more modern, are Thaumasthus patagonicus Parodiz, 1946 (Eocene), Paleobulimulus eocenicus Parodiz, 1949 from the Eocene-Miocene of Chubut (Argentina), and Bostryx sp. and Bulimulus sp. from the Eocene of La Pampa (Argentina) (Melchor et al., 2002; Salvador et al., 2018). Bostryx sp. aff. Bostryx jujuyensis (Holmberg, 1900) as Bulimulus aff. jujuyensis was mentioned from early Late Miocene of Catamarca (Miquel, 1995; Salvador et al., 2018).The specimens here reported constitute the first record for the family for the Cretaceous of Patagonia.

\section{Marine invertebrates}

Fossil marine invertebrates are represented by a few taxa that were collected from locality 5. Rock samples (MPM 21565; MPM 21566) contain different bivalve species. Preliminary determinations encompass bivalves of diverse clades, including ostreids of the genera Gryphaeostrea (species similar to G. callophyla Ihering, 1903) and Cubitostrea (species similar to C. ameghinoi Ihering, 1902), pectinids related with the Danian species "Chlamys" salamanca Ihering, 1902, and an indeterminate Mytilidae (D. Pérez, B.Santelli, and M.Álvarez, pers. comm.).

\section{Plants - Fossil woods}

Pinidae Cronquist, Takht \& Zimmerm. 1966 ?Podocarpaceae Endlicher 1847

Fossil genus Podocarpoxylon Gothan 1904

Type species Podocarpoxylon juniperoides Gothan, in Gagel (1904)

Podocarpoxylon dusenii Kraüsel 1924

Referred material. MPM 21568, fragmentary wood from locality 1 (Figure 33).

Description. Growth ring boundaries distinct. Latewood consisting of c. 6 tracheids with re- 

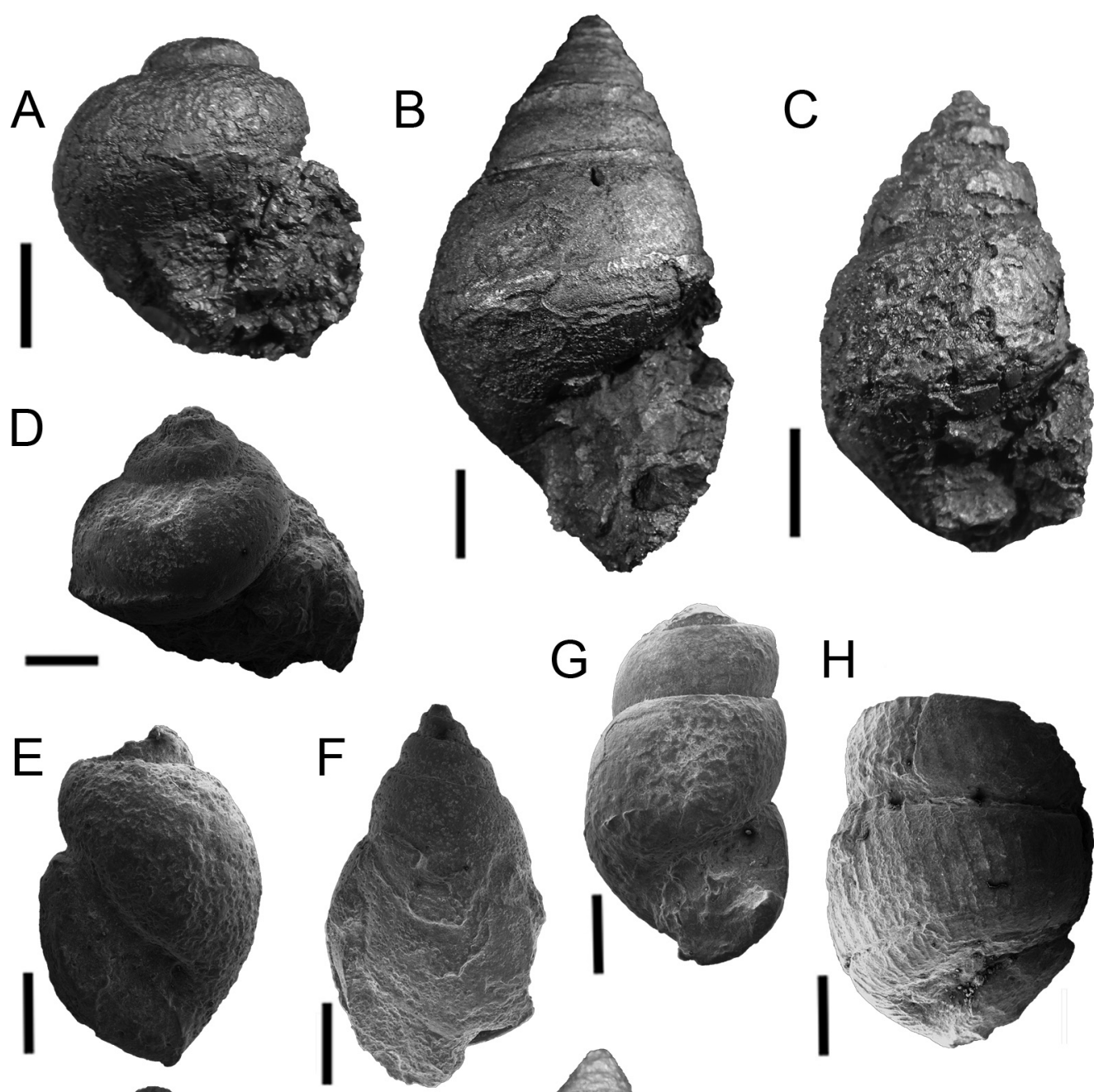

\section{$\mathrm{H}$}
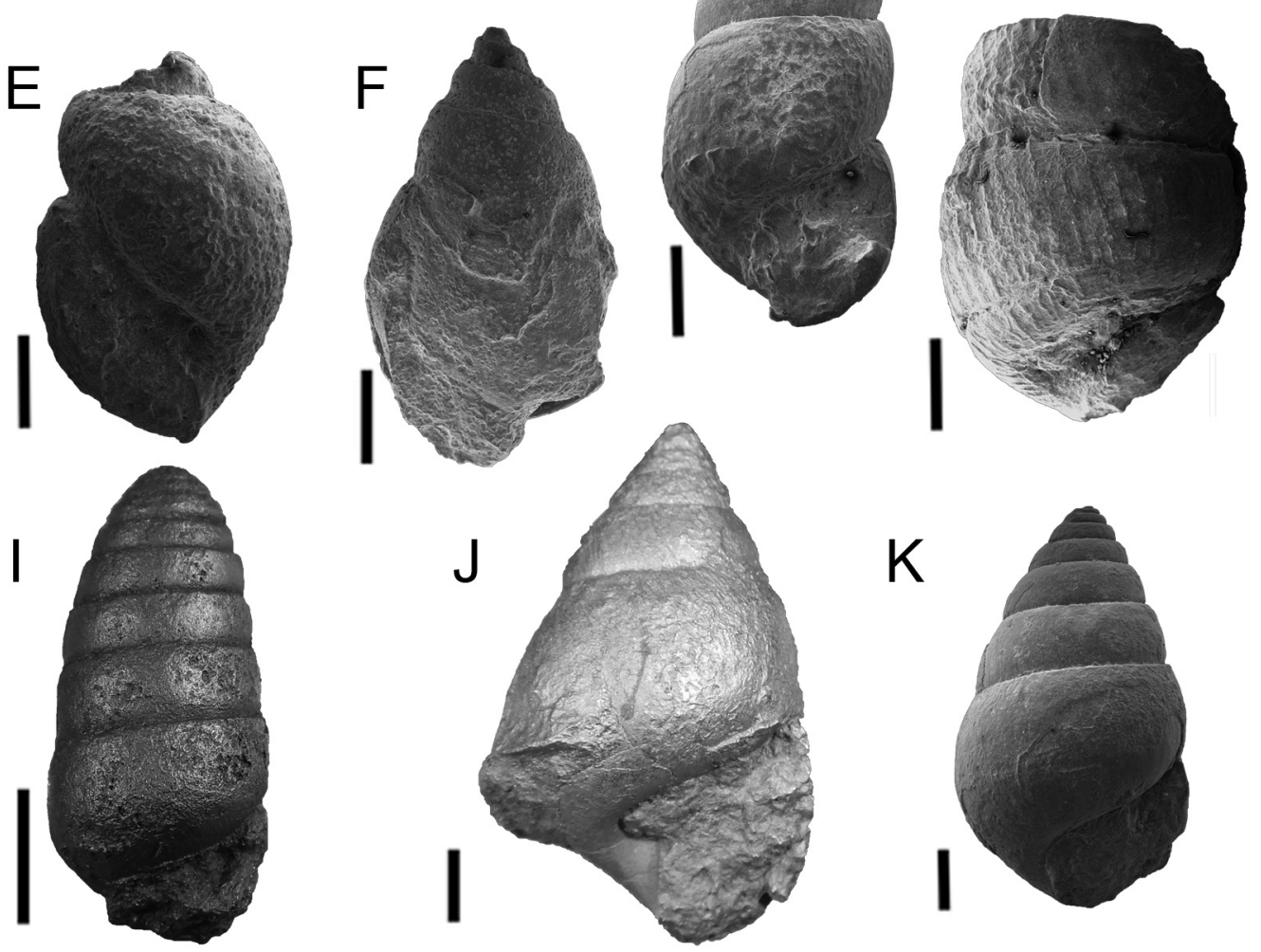

Figure 32. Gastropoda. A, Ampullariidae. Pomacea sp. MPM 21554. B, Pleuroceridae. Genus et species indet. MPM 21555. C, Pleuroceridae. Genus et species indet. MPM 21556. D, Tateidae. Potamolithus sp. MPM 21557. E, Physidae. Physa sp. MPM 21558. F, Stenophysa sp. MPM 21559. G, Achatinidae. Genus et species indet.MPM 21560. H, Achatinidae. Genus et species indet. MPM 21561. I, Holospiridae. Holospira sp. MPM 21562. J, Bulimulidae. Genus et species indet. MPM 21563. K, Bulimulidae. Genus et species indet. MPM 21564. Scale bars $0.5 \mathrm{~cm}$ in A-C, I and J. Scale bars $2 \mathrm{~mm}$ in D-H and $\mathbf{K}$. 
duced radial diameter. Transition from earlywood to latewood gradual. Earlywood tracheid tangential diameter $24.8+/-7$ (16.9-46.5) $\mu \mathrm{m}$. Latewood tracheids thin walled. Intercellular spaces rare to absent. Tangential pits and axial parenchyma not observed.

Rays homogeneous, parenchymatous, with cells $20+/-4(11.7-28.5) \mu \mathrm{m}$ in vertical diameter. Horizontal and end walls of ray parenchyma cells smooth. Rays very low to medium, 3+/-2 (1-9) cells high, uniseriate and with a frequency of $4+/-1(2-6)$ rays per $\mathrm{mm}$.

Tracheid radial pitting uniseriate $(\mathrm{Si}=1)$, abietinean, with $\mathrm{Cp}=7 \%$. Radial pits circular to oval 12.5+/-1.1 (9.6-14.1) $\mu \mathrm{m}$ in vertical diameter. Cross-field pitting podocarpoid, 1 (rarely 2) pits per cross field. When 2 pits are present, they are arranged vertically. Cross-field pits $8.3+/-1$ $.3(6.8-11.1) \mu \mathrm{m}$ in vertical diameter. Pits oval, oblique, with narrow areola.

Comments. Kraüsel (1924) erected this species for specimens recovered at Santa Cruz Province, Argentina. Following his description, this taxon is characterized by: lack of axial parenchyma, cross-fields with one (or rarely 2) pits, uniseriate pitting of the radial walls of the tracheids, and uniseriate (rarely biseriate) rays 1-20 cells tall. The material here studied falls within the described features by Kraüsel for this taxon. Rays described by Kraüsel (1924) seem to be taller than our materials, but this feature may show instraspecific variation (Carlquist, 1988; Poole et $a l ., 2001$ ). Provenance data of the original specimen of this taxon is unclear, and Kraüsel (1924) states that it was found near the La Leona River. Coordinates provided by this author suggest that it was found at the northern margin of the Lago Argentino, near La Leona river mouth. The age of this taxon is currently regarded as Cenozoic, as originally pointed by Kraüsel ("Tertiär"), given its unclear stratigraphic provenance.

Podocarpoxylon aparenchymatosum Gothan from the Eocene (and probably the Paleocene) of Antarctica (Pujana et al., 2014; Pujana \& Ruiz, 2017) shares with the material here studied the absence of axial parenchyma, but rays are taller (9(1-17)). Furthermore, cross-fields typically have 2 pits, reaching up to 5 , whereas the specimens here studied have only one (or rarely 2 pits). Podocarpoxylon fildesense Zhang \& Wang from the Paleocene of Antarctica has slightly taller rays, and cross-fields typically have 1-2 pits, but up to 4 pits per cross fields were reported (Zhang \& Wang, 1994; Poole et al., 2001; Pujana \& Ruiz, 2017), and may be synonym of $P$. aparenchy- matosum (Pujana et al., 2014). Podocarpoxylon garciae Del Fueyo (1998) from the CampanianMaastrichtian Allen Formation has axial parenchyma, a feature not recorded in the specimens here studied. Podocarpoxylon mazzoni (Petriella) Müller-Stoll \& Schultze-Motel, an ubiquitous taxon found in Campanian-Maastrichtian to Paleocene units of northern Patagonia differs from this species by having uniseriate to triseriate pits in radial walls, partially biseriate (and locally triseriate) very tall rays, and septa-like structures (see Vera et al., 2019, and references therein).

Affinities. Many species of Podocarpoxylon have been recognized from regions where no conclusive Podocarpaceae remains were identified, supporting the fact that this type of wood cannot be conclusively referred to Podocarpaceae (see discussion in Pujana \& Ruiz, 2017). Nevertheless, given that gymnosperm pollen grains recorded in this unit, are essentially represented by Podocarpaceae (see below), the fossil woods are tentatively referred to this family.

\section{Palynology}

Well-preserved palynological assemblages were obtained for the first time from the Chorrillo Formation. Two palynological samples (MPM 21570, 21571; Figure 34) were recovered from locality 3 and yielded palynofloras with a moderate specific diversity. Eighteen spore species, 7 gymnosperm pollen grains and 4 angiosperm pollen grains were identified. The assemblage is characterized by the presence of spores related with different ferns (Polypodiopsida), such as Gleicheniaceae (Clavifera triplex (Bolkhovitina) Bolkhovitina 1966 and Gleicheniidites senonicus Ross 1949), Osmundaceae (Baculatisporites comaumensis (Cookson) Potonie 1956, Baculatisporites kachaikensis Archangelsky \& Llorens 2005) and Polypodiaceae (Tuberculatosporites parvus Archangelsky 1972). It is also recorded the family Dicksoniaceae (Trilites fasolae Archangelsky 1972, Trilites sp. cf. T. parvallatus Krutzsch 1959 and Trilites sp. cf. T. tuberculiformis Cookson 1947), and particularly Cyatheacidites annulatus Cookson ex Potonie 1956, with affinities with extant genus Lophosoria C. Presl. Other fern spores cannot be related to any particular family, such as Concavissimisporites sp., Laevigatosporites ovatus Wilson \& Webster 1946 and Leptolepidites sp. cf. L. major Couper 1953, and representatives of the genus Cyathidites Couper. Within the latter, three species are identified, namely: 

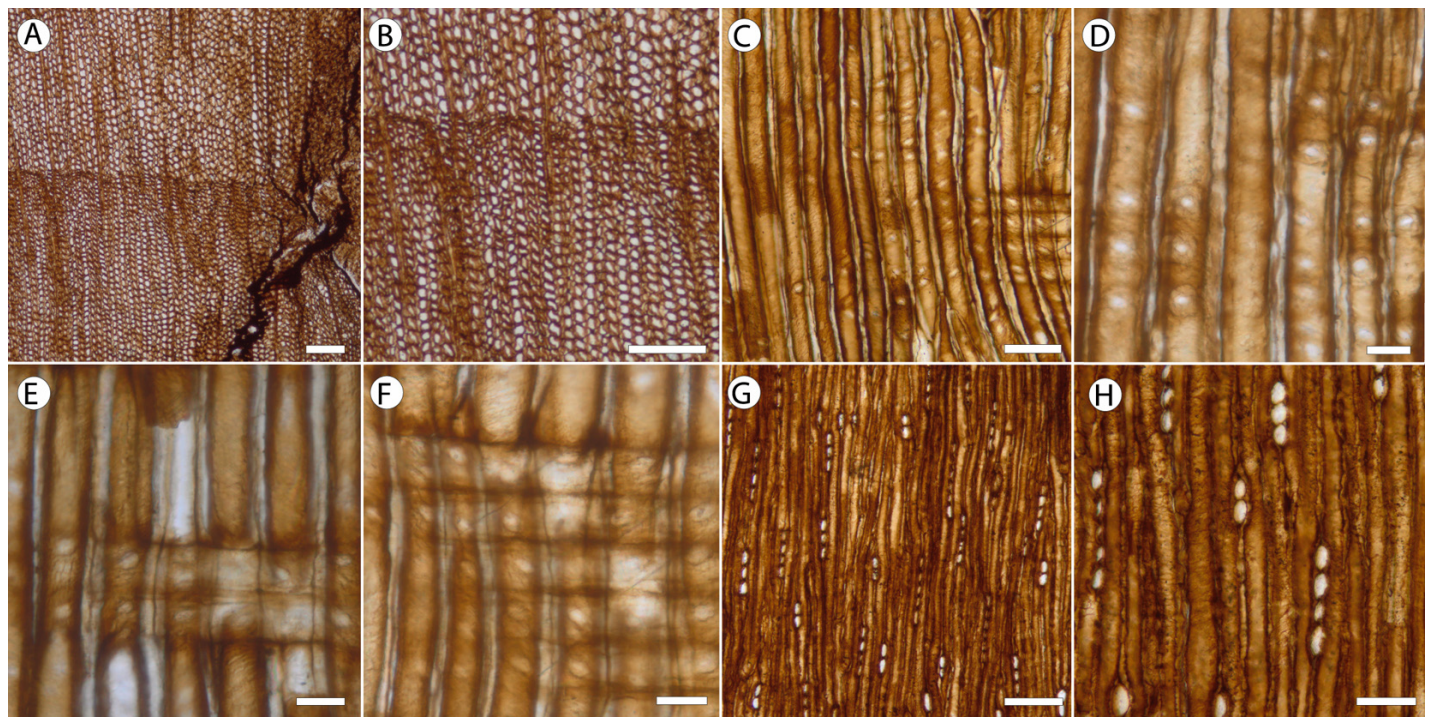

Figure 33. Podocarpoxylon dusenii Kraüsel 1924. A, (MPM 21568) Growth ring in a transverse section (TS). Bar: $20 \mu \mathrm{m}$. B, (MPM 21568) Detail of growth ring (TS). Bar: $20 \mu \mathrm{m}$. C, (MPM 21567) Spaced uniseriate radial pitting and cross fields (LRS). Bar: $50 \mu \mathrm{m}$. D, (MPM 21567) Spaced uniseriate radial pitting and cross fields (LRS). Bar: $20 \mu \mathrm{m}$. E, F, (MPM 21567) Cross fields with 1 or 2 podocarpoid pits (LRS). Bar: $20 \mu \mathrm{m}$. G, (MPM 21567) Uniseriate rays (LTS). Bar: $20 \mu \mathrm{m}$. H, (MPM 21567) Detail of uniseriate rays (LTS). Scale bar: $50 \mu \mathrm{m}$

Cyathidites australis Couper 1953, C. minor Couper 1953 and C. rafaeli Burger 1980, all psilate triangular spores related to Cyatheaceae, Dicksoniaceae, Dipteridaceae, or Matoniaceae. Lycopodiopsida are recorded with spores referable to Selaginellales (Ceratosporites equalis Cookson \& Dettmann 1958 and Foveosporites canalis Balme 1957) and Lycopodiales Retitriletes austroclavatidites (Cookson) Doring et al., in Krutzsch 1963).

Gymnosperm pollen grains are less diverse than spores, and are represented by taxa related to Podocarpaceae (Microcachryidites antarcticus Cookson 1947, Phyllocladidites mawsonii Cookson 1947 ex Couper 1953, Podocarpidites ellipticus Cookson 1947, P. sp. cf. P. herbstii Burger 1966, P. sp., and Trichotomosulcites subgranulatus Couper 1953) and pteridosperms (Vitreisporites signatus Leschik 1955).

Similarly, the angiosperm pollen grains show a low diversity, being Peninsulapollis gilli (Cookson) Dettmann and Jarzen 1988 the only angiosperm abundant in the studied palynoflora (at least representing $90 \%$ from the total angiosperm pollen grains). This species is related to Proteaceae, probably with Beauprealike forms (Dettman \& Jarzen, 1988). Other taxa include Clavatipollenites sp. (related to the Chloranthaceae), Tricolpites reticulatus Cookson 1947 ex Couper 1953 (related to Gunnera), along with Tricolpites sp. (of unknown affinities), being all these species scarce in the assemblages recovered from Chorrillo Formation.

\section{DISCUSSION}

\section{Dinosaur assemblages}

1.1. Vertebrate assemblage yielded by Chorrillo and Dorotea Formations

Marcelo Leppe (e.g., Leppe et al., 2014; Vogt et al., 2014; Manriquez et al., 2019) has conducted successful explorations in the Las Chinas River Valley (NE from the Torres del Paine National Park, Magallanes Region, Ultima Esperanza Province, Chile). This locality is approximately $4.2 \mathrm{~km}$ southeast from the border to Argentina (Figure 1). Leppe and crew reported semi-articulated skeletons of dinosaurs at levels of the Dorotea Formation. Dinosaur remains include indeterminate titanosaurs, ornithischians, and also abundant hadrosaur remains (e.g., Leppe et al. 2014, Jujihara et al., 2014; Soto Acuña et al., 2014; Vogt et al., 2014; Manriquez et al., 2019). In Las Chinas River Valley, Leppe et al. (2014) distinguished three stratigraphic sections for the Dorotea Formation: the lower Casa Las Chinas, the middle Saurópodo, and the upper El Puesto section. The Saurópodo stratgraphic section shows abundance of titanosaur remains, and may be partially equivalent to the lower and mid- 
dle levels that shed the many titanosaur remains of the Chorrillo beds. In Las Chinas site the El Puesto section sheds at its base Nothofagus leaf imprints, followed upward by levels with abundant hadrosaur remains, and plesiosaur and mosasaur bones at the top of the section. The El Puesto is considered here equivalent with the upper portion of the Chorrillo Formation, on the Argentine side, which shed the basal iguanodontian Isasicursor associated with the mosasaur teeth.

Current information about tetrapod taxonomic diversity in both Chorrillo and Dorotea includes turtles, ophidians, colossosaurian titanosaurs, basal iguanodontians, hadrosaurids, megaraptorids, abelisauroids, basal paravians, basal neornithes, and mammals. Integrative studies on both sides of the Argentina-Chile border will eventually result in considerable increase in knowledge of this Maastrichtian ecosystem from the southern tip of South America.

\subsection{Dinosaur-bearing beds from southern Patagonia}

Dinosaur-bearing beds of Upper Cretaceous age crop out in the SW corner of Santa Cruz province, comprising the vicinities of Viedma Lake (to the north) up to Argentino Lake (to the south), as well as along La Leona River, the water course connecting both lakes. These dinosaur-bearing beds extend south, crossing the international border with Chile, including (from north to south) Mata Amarilla, Cerro Fortaleza, Chorrillo and Dorotea. The stratigraphic correlations among these continental beds have been, and still are, a theme of intense debate among geologists (see, Varela et al., 2012; Sickman et al., 2018). Available radimetric dating shows that the Mata Amarilla Formation is Cenomanian in age (approximately 97my; Varela et al., 2012), Cerro Fortaleza Formation is Campanian (around 76.2Ma, based on studies by Sickman et al., 2018), and upper terms of the Dorotea is Maastrichtian (as supported by radiometric dating and paleontological evidence; Manriquez et al., 2019). Explorations carried on in SW Santa Cruz province by the senior author since 1998, have produced different dinosaur species from these beds: Mata Amarilla, in proximities of the Sheuen River, afforded carcharodontosaurid remains (Novas et al., 1999) which are congruent with a Cenomanian age obtained by radiometric studies (Varela et al., 2012). The Cerro Fortaleza beds, at Cerro de Los Hornos fossil site, shed different dinosaur taxa (i.e., Talenkauen, Orkoraptor, Puertasaurus, Dreadnoughtus; Novas et al., 2004, 2005, 2008; Lacovara et al., 2014) which resemble forms from the Neuquina Basin (i.e., Macrogryphosaurus, Megaraptor, Futalognkosaurus) recorded in the Turonian Portezuelo Formation (Calvo et al., 2007). The age based on paleovertebradological fossil content does not fit with the radiometric ages obtained by Sickman et al. (2018) which support a Campanian age for the Cerro Fortaleza Formation. Besides, the upper third of the Dorotea Formation yielded abundant hadrosaurid material (Jujihara et al., 2014; Soto Acuña et al., 2014), as it also occurs in Maastrichtian localities from NW and Central Patagonia (e.g., Bonaparte et al., 1984; Gasparini et al., 2015; Brett-Surman, 1979; Becerra et al., 2018). The Chorrillo beds apparently corresponds to an age (i.e., late Campanian-early Maastrichtian), intermediate between the Campanian Cerro

Figure 34 (next page). Palynology. A, Baculatisporites comaumensis (Cookson) Potonie 1956, MPM 21571-2:M62/1; B, Baculatisporites kachaikensis Archangelsky \& Llorens 2005, MPM 21571-2:R48/1; C, Ceratosporites equalis Cookson \& Dettmann 1958, MPM 21571-3:S40/0; D, Concavissimisporites sp., MPM 21571-3:H27/0; E Clavifera triplex (Bolkhovitina) Bolkhovitina 1966, MPM 21571-5:R42/3; F, Cyatheacidites annulatus Cookson ex Potonie 1956, MPM 21571-4:Z48/2; G, Cyathidites australis Couper 1953, MPM 21571-3:X55/4; H, Cyathidites minor Couper 1953, MPM 21570-6:T24/4; I, Cyathidites rafaeli Burger 1980, MPM 21570-6:D55/4; J, Foveosporites canalis Balme 1957, MPM 21571-6:C42/3; K, Gleicheniidites senonicus Ross 1949, MPM 21571-6:Y24/0; L, Laevigatosporites ovatus Wilson \& Webster 1946, MPM 21571-6:C32/3; M, Retitriletes austroclavatidites (Cookson) Doringet al. in Krutzsch 1963, MPM 21571-4:Q41/0; N, Trilites fasolae Archangelsky 1972, MPM 21571-1:D36/1; O, Leptolepidites sp. cf. L. major Couper 1953, MPM 21571-2:O24/1; P, Trilites sp. cf. T. tuberculiformis Cookson 1947, MPM 21571-5:R57/0; Q, Trilites sp. cf. T parvallatus Krutzsch 1959, MPM 21571-2:X58/2; R, Tuberculatosporites parvus Archangelsky 1972, MPM 21571-6:O48/0; S, Microcachryidites antarcticus Cookson 1947, MPM 215713:Y36/0; T, Podocarpidites sp. cf. Pellipticus Cookson 1947, MPM 21571-3:S19/4; U, Podocarpidites sp. cf. P. herbstii Burger 1966, MPM 21571-2:B55/1; V, Podocarpidites sp., MPM 21571-2:H55/4; W, Phyllocladidites mawsonii Cookson 1947 ex Couper 1953, MPM 21571-1:Q63/4; X, Trichotomosulcites subgranulatus Couper 1953, MPM 21571-8:V31/0; Y, Vitreisporites signatus Leschik 1955, MPM 21571-8:J39/2; Z, Clavatipollenites sp., MPM 21571-7:V47/0; AA, Peninsulapollis gilli (Cookson) Dettmann \& Jarzen 1988, MPM 21571-3:P31/6; BB, Peninsulapollis gilli (Cookson) Dettmann \& Jarzen 1988, MPM 21571-7:L27/4; CC, Tricolpites reticulatus Cookson 1947 ex Couper 1953, MPM 21571-7:L48/3; DD, Tricolpites sp., MPM 21571-7:J28/3. Scale bar: $10 \mu \mathrm{m}$. 


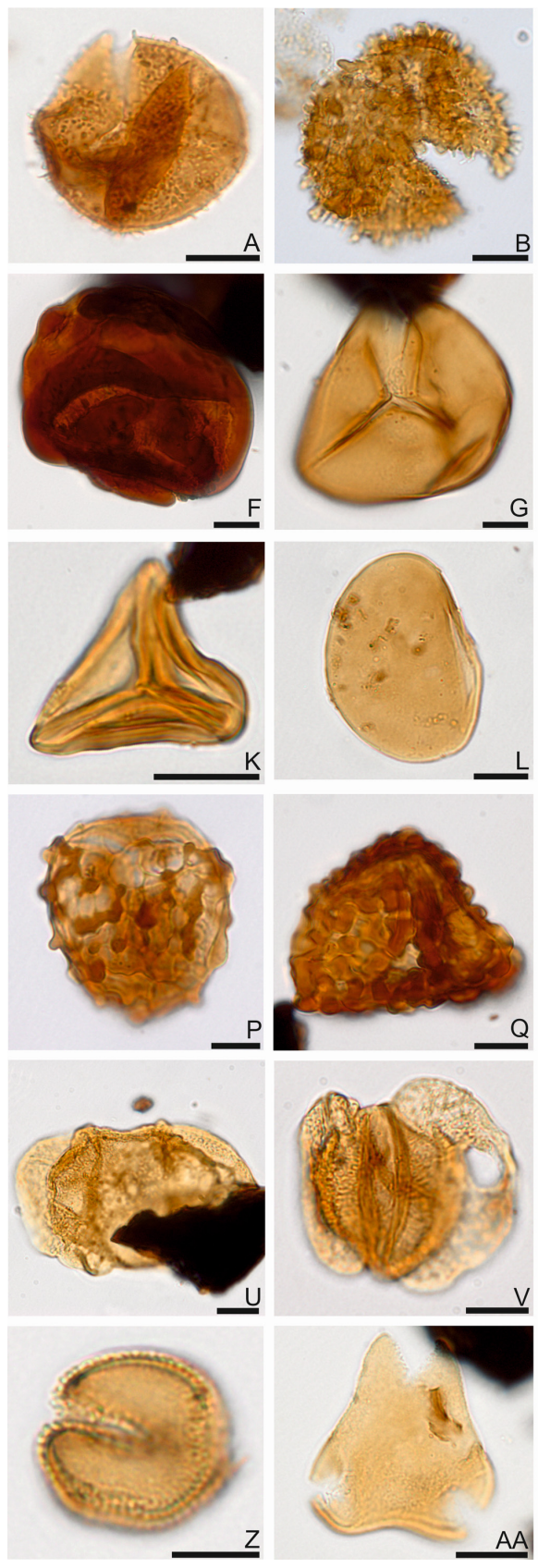

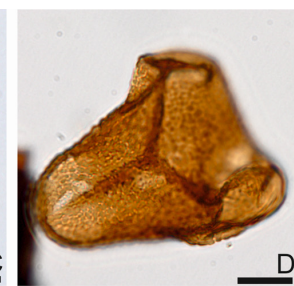
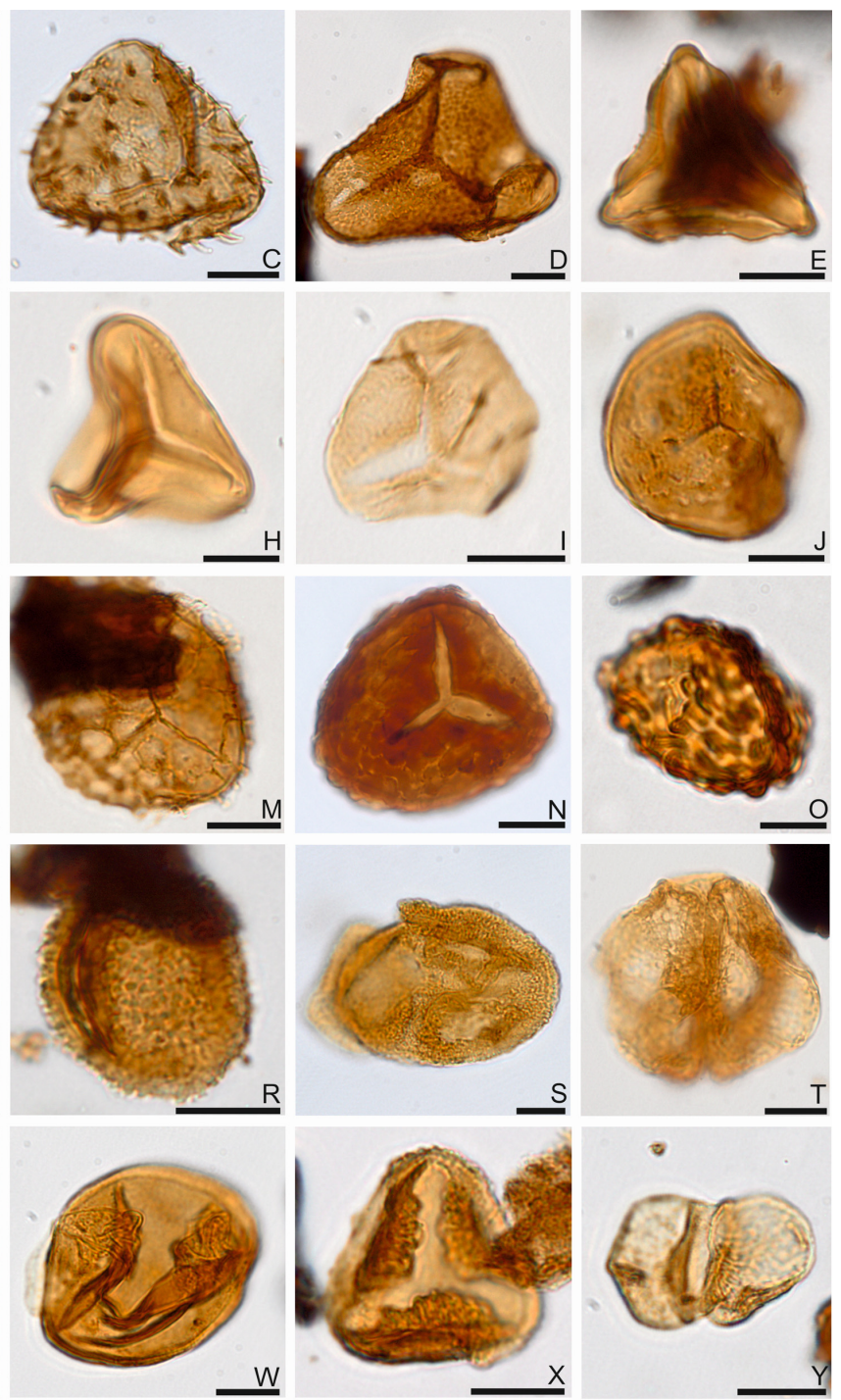

0
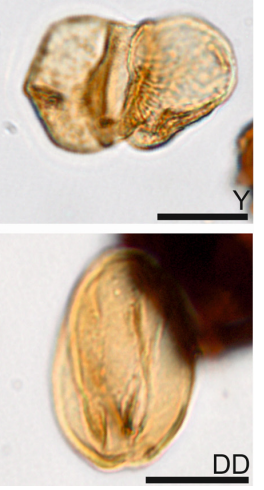

Fortaleza and the upper Maastrichtian Calafate formations.

Summing up, we identify a succession of at least four different dinosaur assemblages from beds exposed in the SW corner of Santa Cruz: the oldest ones corresponding to the Cenomanian Mata Amarilla Formation, the Campanian Cerro Fortaleza Formation, the upper Campanian lower Maastrichtian Chorrillo Formation, and the upper Maastrichtian hadrosaurid-bearing levels of the Dorotea Formation. The sequence is capped by marine beds (i.e., Calafate, Monte Chico, and upper terms of Dorotea formations) which yielded remains of plesiosaurs and mosasaurs (Bonaparte et al., 2002; Leppe et al., 2014; Vogt et al., 2014; Novas et al., 2016; Soto Acuña et al., 2016).

Such biostratigraphic succession has to be 
taken as a tentative one, and new paleontological discoveries (dinosaurs in particular) are needed to confirm or correct these interpretations. An important topic requiring consideration concerns with the taxonomic distinctions that may exist between vertebrate faunas documented in the Chorrillo Formation with respect to the underlying Cerro Fortaleza beds. Both units share the same inclusive clades (i.e., Titanosauridae, Elasmaria, Megaraptoridae), although some generic distinctions exist among titanosaurians and elasmarians: the Chorrillo beds yielded Nullotitan and Isasicursor, while Cerro Fortaleza Formation yielded the titanosaurids Puertasaurus and Dreadnoghthus, and the elasmarian Talenkauen.

\subsection{Paleobiogeographic comments on di- nosaur faunas}

The following preliminary paleobiogeographic interpretations emerge from comparing Maastrichtian dinosaur faunas from the Austral Basin with those from other regions of Gondwana:

1.3.a. Theropod records here reported include the southernmost records for unenlagiid paravians and noasaurid abelisauroids. In addition, at least three different megaraptorid specimens were found, indicating that this theropod clade was relatively abundant during the deposition of the Chorrillo Formation. The set of megaraptorid specimens described in the present paper constitutes evidence for their survival into the Maastrichtian. This information counters previous interpretations (Novas et al., 2013) proposing megaraptorids went extinct before the Campanian, and that abelisaurids were dominant in Campanian-Maastrichtian theropod faunas (Novas, 2009). Recurrent discovery of megaraptorid remains in the Chorrillo beds, alongside with the paucity in abelisauroid remains, sharply contrast with the Campanian-Maastrichtian theropod assemblages from northern Patagonia, Madagascar and India, in which abelisauroids are common and megaraptorids virtually absent. Interestingly, theropod assemblages from the southern end of the continent resembles the early Late Cretaceous record from Australia, were carnivorous dinosaur assemblages were dominated by megaraptorids, whereas abelisaurids seem absent (Benson et al., 2012; Novas et al., 2013; Poropat et al., 2019).

1.3.b. Regarding the presence of possible neornithine birds in the Chorrillo Formation, this clade has been recorded in northern Patagonia and
Antarctica, in contrast with the Late Cretaceous from Brazil and northwestern Argentina, were enantiornithines are the only known birds so far (see discussion in Agnolin, 2017). In spite that the fossil record of Mesozoic birds in the Southern Hemisphere is still relatively poor, the discovery of a variety of neornithine-related birds indicates that southern Gondwana constituted a cradle for the early evolution of extant bird clades (Ericson et al., 2001; Cracraft, 2001; Agnolin et al., 2016). 1.3.c. Concerning sauropod dinosaurs, the Maastrichtian record of the clade in the Austral basin is still meagre. Together with the Chilean records (Manriquez et al., 2019), Nullotitan represents one of southernmost records of Titanosauria for South America. The presence of large-sized forms in both Chorrillo and Dorotea coincides with that of the underlying Cerro Fortaleza beds, from which very large titanosaurs have been collected (Puertasaurus, Dreadnoughthus; Novas et al., 2005; Lacovara et al., 2014). This faunal component contrasts with the smaller-sized saltasaurines and mid-to large-sized aeolosaurines documented in lower latitudes of Gondwana (e.g., northern of Santa Cruz, Neuquén, Río Negro, and Salta provinces of Argentina, and São Paulo and Minas Gerais states of Brazil; Powell, 2003; Casal et al., 2007; Santucci \& Arruda-Campos, 2011).

Besides, the abundance of titanosaur specimens in southern Patagonia contrasts with the infrequent records of these herbivores in the Antarctic Peninsula (Novas, 2009; Cerda et al., 2011). However, such distinction may be related with the marine-influenced paleoenvironments that dominated the Antarctic Peninsula during the Late Cretaceous. In agreement with this, titanosaurid bones are abundant in the continental deposits of the lower and middle thirds of the Chorrillo Formation, contrasting with the virtual absence of sauropods from the marine-influenced upper third of the unit, were ornithopod remains are recorded in association with mosasaur remains.

Sauropod bones have been reported from Las Chinas River Valley (Manriquez et al., 2019). Although such discovery still awaits formal description, available information shows the common presence of large titanosaurs in both Dorotea and Chorrillo formations. Whether the remains of these animals from Chile and Argentina belong to a same titanosaur species needs to be confirmed. Previous contributions considered that gigantic titanosaurs were restricted to midCretaceous times (pre-Campanian-Maastrich- 
tian; Salgado and Bonaparte, 2007; Carballido et al., 2017), but recent research indicates that giant forms, such as Antarctosaurus, survived up to the Campanian-Maastrichtian time interval (Garcia and Salgado, 2013). Nullotitan confirms the survival of gigantic colossosaurian sauropods up to the latest Cretaceous.

Although knowledge on Maastrichtian dinosaur faunas from the southern tip of South America is just at the beginning, available information indicates that no small-sized sauropods (e.g., saltasaurines) have been found so far neither in Chorrillo nor in Dorotea beds, in contrast with their abundant record in northwestern Argentina and northern Patagonia. Such distinction, in join with the taxonomic differences noted above for Theropoda, suggest the influence of environmental controls in paleobiogeographic distribution of Patagonian dinosaurs.

1.3.d. In respect to ornithischians, documentation of the basal iguanodontian Isasicursor, constitutes a novelty of the present report, because it conforms the first Maastrichtian elasmarian for southern Patagonia. Basal iguanodontian diversity during Campanian-Maastrichtian time span in Southern Patagonia and Antarctic Peninsula (see Rozadilla et al., 2016) agrees with the idea expressed by Brown et al. (2011) indicating that basal ornithopods increased in diversity from the Campanian through the late Maastrichtian. Alongside basal iguanodontians, hadrosaurids are commonly found in Maastrichtian localities in NW and central Patagonia, as well as in the upper section of the Dorotea Formation, where they have been commonly recorded (Jujihara et al., 2014; Soto Acuña et al., 2014).

The Chorrillo Formation vertebrate assemblage has some similarities with those from the Late Cretaceous of Australia and Antarctica, including the common presence of Chelidae, Calyptocephalellidae, Elasmaria, and Megaraptoridae, together with the absence or scarcity of saltasaurine and aeolosaurine titanosaurs and abelisaurid theropods, dinosaur clades which are frequently documented in NW and central Patagonia. Such differences in faunal composition need to be investigated in depth to elucidate if they mirror different paleoenvironmental conditions in southern Patagonia.

\section{Terrestrial and freshwater mollusks}

Until relatively recently, the records of Mesozoic land snails were almost restricted to North America and Europe (Solem, 1979). In contrast, the Cretaceous records of conti- nental gastropods from South America were barely represented by some specimens of the families Pleuroceridae (Early Cretaceous), Physidae (Early Cretaceous), Bulimulidae (Late Cretaceous) and "Endodontidae" (Late Cretaceous) (Salvador et al., 2018) (see Table 1). Pleuroceridae and Bulimulidae were unknown from Mesozoic beds, and their respective fossil records were restricted to the Cenozoic of Patagonia (Parodiz, 1969). Discoveries here reported from the Chorrillo Formation allow modifying this situation with the documentation of the first Mesozoic remains of Ampullariidae and Holospiridae for South America, and confirming the presence of Tateidae, Physidae and Bulimulidae in the South American Mesozoic. Further, such discoveries constitute the southernmost records for these families. Holospiridae is recorded for the first time in South America. Notably, almost all families exhibit features corresponding to new genera and species, which will be studied elsewhere (Miquel and Brito, in press).

Holospiridae is a group that currently lives in Central and North America, with numerous genera and species, with fossil records from the Paleocene of USA (Zilch, 1960). Excepting this group, the remaining families have been recorded in South America, some with numerous taxa, as Bulimulidae and Subulininae (Breure, 1979; Schileyko, 1999). Bulimulidae has a distribution restricted to Australasian and Neotropical realms (Solem, 1981). In Argentina, specimens of Bulimulidae are currently dispersed mainly in the north and center of the country, even in high altitudes in the Andes mountains (Breure, 1979). The Achatinidae Subulininae is recorded in wet tropical climates (Fernández, 1973; Schileyko, 1999).

Besides, Ampullariidae, Pleuroceridae, Tateidae and Physidae are abundant in rivers and lakes and can live in estuary environments of low salinity (e.g., Rio de la Plata, Argentina; Castellanos \& Landoni, 1995). Holospiridae, Achatinidae and Bulimulidae would show the existence of areas with different tree formations, as well as habitats and microhabitats favorable for the development of gastropods, and some dryhumid climate seasonality.

\section{Paleobotany and palynology}

3.1. Comparisons with other Maastrichtian palynological assemblages from Patagonia. In spite that present palynological report is preliminary, and the collected samples are meagre, 
Table 1. Records of mollusks according to time and geographical area. ?Achatinidae is excluded because of the doubtful taxonomic location of the described fragments.

\begin{tabular}{lcccc}
\hline & $\begin{array}{c}\text { CRETACEOUS } \\
\text { South America }\end{array}$ & $\begin{array}{c}\text { PALEOGENE } \\
\text { South America }\end{array}$ & $\begin{array}{c}\text { RECENT } \\
\text { South America }\end{array}$ & $\begin{array}{c}\text { RECENT } \\
\text { Patagonia }\end{array}$ \\
\hline Ampullariidae & $\mathrm{X}$ & $\mathrm{X}$ & $\mathrm{X}$ & --- \\
Pleuroceridae & $\mathrm{X}$ & $\mathrm{X}$ & $\mathrm{X}$ & -- \\
Tateidae & $\mathrm{X}$ & $\mathrm{X}$ & $\mathrm{X}$ & $\mathrm{X}$ \\
Physidae & $\mathrm{X}$ & $\mathrm{X}$ & $\mathrm{X}$ & --- \\
Holospiridae & $\mathrm{X}$ & --- & --- & -- \\
Bulimulidae & $\mathrm{X}$ & $\mathrm{X}$ & $\mathrm{X}$ & $\mathrm{X}$ \\
\hline
\end{tabular}

some interesting comparisons and conclusions are exposed as follows.

Povilauskas et al. (2008) reported palynofloras from the La Irene Formation (at Calafate hill, southwestern Santa Cruz Province), which underlies the Chorrillo Formation. The palynological assemblages from La Irene Formation share many species with those here studied, among them the presence of Peninsulapollis gillii. Furthermore, both Chorrillo and Irene Formations lack Nothofagidites. Angiosperms in the La Irene Formation show higher diversity than the one recorded in the assemblages here studied, including Arecipites minutiscabratus Mc. Intyre 1968, Liliacidites cf. variegatus Couper 1960, Longapertites sp., Proteacidites sp. and Spinozonocolpites hialinus Archangelsky \& Zamaloa 1986 (Povilauskas et al., 2008), currently absent from samples got in Chorrillo Formation.

Povilauskas (2016) reported diverse palynological assemblages obtained from the Cerro Cazador Formation (upper Campanian-lower Maastrichtian) from outcrops near Rio Turbio (southwest Santa Cruz Province) and from the Monte Grande Hill near the limit with Chile. These palynofloras share some species with those here studied, such as Trilites fasolae, Cyatheacidites annulatus and Peninsulapollis gilli. The angiosperm pollen grains are more diverse than the palynofloras here studied, and the genus Nothofagidites is recorded in low proportions in the Cerro Cazador Formation. Noteworthy, palynofloras from Cerro Cazador Formation lack subtropical to tropical families. The overlying Monte Chico Formation (upper Maastrichtian-Danian) studied by Povilauskas $(2011,2012,2013,2017)$ at the same localities, share several taxa with the Chorrillo Formation assemblages, including the marker taxon Peninsulapollis gilli. A floristic replacement seems apparent in the assemblages of Monte Chico
Formation, when compared with the ones present in the underlying Cerro Cazador Formation. Although Nothofagidites is still present in Monte Chico Formation, an increase in diversity of angiosperm families with tropical or subtropical distribution is recorded (Povilauskas, 2013).

The Danian Cerro Dorotea Formation (Povilauskas, 2017) contains a less diverse palynoflora, sharing with the assemblages of Chorrillo beds the presence of Peninsulapollis gilli, Cyatheacidites annulatus, and few other taxa. Noteworthy, this unit contains pollen referable to Bombacaceae, of tropical or subtropical distribution, along with Nothofagidites and Proteaceae.

Assemblages from the Dorotea Formation reported from Cerro Guido and other localities (Leppe et al., 2012) contain no stratigraphically significant taxa. Some taxa, as Baculatisporites kachaikensis, Gleichenites senonicus and Cyathidites minor are shared with the Chorrillo Formation. Noteworthy, although five angiosperms pollen grains are reported from the Dorotea Formation, none of those is shared with the palynoflora here studied.

In summary, the palynofloras recovered from Chorrillo Formation share many taxa with units from southern Argentine Patagonia, including many species of spores and gymnosperm pollen grains, including Peninsulapollis gilli. Furthermore, the absence of Nothofagidites in the Chorrillo beds is shared with La Irene Formation. One remarkable difference with most of these palynofloras is the absence of pollen grains related with subtropical to tropical taxa, a feature shared with the Cerro Cazador Formation. However, the poor representation of angiosperm pollen grains on the palynofloras of Chorrillo Formation may be a preservation issue making comparisons less reliable. Future detailed studies based on a larger sample number would allow more detailed comparisons. 
3.2. Paleoclimatological implications. The palynoflora recovered from Chorrillo Formation contains some taxa that, using modern analogs, may provide information regarding the paleoclimate where these plants grew. Peninsulapollis is allied to Proteaceae related with Beauprea, a genus that nowadays grow in temperate to cold environments (Quattrochio \& Ruiz, 1999). The abundant and diverse ferns, along with subordinate Chloranthaceae, may have grown in the understory, associated with ponds, small streams or rivers just landward of the shoreline. Cyatheacidites annulatus is an indicative of ferns similar to the large fern Lophosoria quadripinnata, that lives in cloud forest in the tropics and in cool, wet regions further south (Hill et al., 2001). It grows in a variety of habitats and readily colonizes disturbed areas (Tryon \& Tryon, 1982). Cantrill (1998) compiled and analyzed the distribution of this species, suggesting this fern grows in temperate to tropical climates. Finally, the arboreal stratum was essentially composed by Podocarpaceae, a conifer family almost entirely restricted to rainforest or wet montane environments (Hill \& Brodribb, 1999).

In summary, presence of these taxa suggests cool and humid climatic conditions during the deposition of the Chorrillo Formation. The presence of well-developed growth rings in the fossil woods (see above) suggests periods of arrested growth.

3.3.Palaeobiogeographical implications. From a paleophytogeographical point of view, the region under study (i.e., southern Patagonia) constituted part of an intermixed/transitional floral province that extended in between two main provinces (Herngreen \& Chlonova, 1981; Herngreen et al., 1996; Vajda \& Bercovici, 2014): the Palmae province, ranging from the paleoequator up to northern Argentina and Chile, and characterized by the presence of palm pollen grains representing $10-50 \%$ of the palynological assemblages; and the Proteacidites/Nothofagidites province, well recorded in Antarctica. The Maastrichtian palynological assemblage recorded in La Irene, Chorrillo, Cerro Cazador and Monte Chico formations belongs to a transitional floral province, having neither Proteacidites/Nothofagidites nor palms as dominant elements (Herngreen \& Chlonova, 1981; Herngreen et al., 1996; Vajda \& Bercovici, 2014).

The late Campanian to Maastrichtian fossil plant record (both palynological and megafloristic) recovered from Patagonia (including those from southern Lago Argentino) reveals a mix- ture of tropical (e.g., Arecales, Bombacaceae, Casuarinaceae, Aquillafoliaceae, Olacaceae) and austral (e.g., Nothofagaceae, Proteaceae) elements, suggesting cool-temperate to warm climatic conditions. However, assemblages from northern Patagonia (e.g., Allen, Lefipán, Paso del Sapo, Puntudo Chico, and Lago Colhué Huapí Formations) show a tendency towards a warmer climate respect to the southern ones, having yielded abundant palms (e.g., Spinizonocolpites Muller 1868, Longapertites Van Hoeken Klinkenberg 1964, Palmoxylon Schenk 1882), encephalartoid cycads (e.g., Wintucycas Martínez et al., 2012, Brunoa Artabe et al., 2004, Wordsellia Artabe et al., 2004; see Martínez et al., 2018), and pollen grains of tropical-subtropical families (e.g. Bombacacidites sp., Ilexpollenites sp., Haloragacidites harrisii (Couper) Harris in Mildenhall \& Harris, Anacolosidites diffusa Archangelsky 1973). Proteaceae (e.g., Peninsulapollis gilli, Proteacidites sp., Triatriopollenites spp.) and Podocarpaceae (Podocarpidites sp., Phyllocladidites mawsonii Cookson 1947 ex Couper 1953) are recorded in variable proportions in these assemblages. Nothofagaceae, on the other hand, are almost absent from these assemblages, being recorded in very small proportions in the Lefipán Formation (Barreda et al., 2012). Available information indicates that Maastrichtian floras from Patagonia were influenced by climatic conditions depending on latitude, a fact that should be extrapolated to vertebrate associations, as indicated above.

The palynological assemblages here studied may be, a priori, comparable with the ones at Cerro Cazador Formation, mostly by the absence of tropical or subtropical elements. However, for the time being, it is difficult to establish if the absence of these elements is reflecting a characteristic of the flora or a preservation artifact, since only two samples have been studied. Future works on the megafloristic and palynological assemblages of the Chorrillo Formation may shed light on the relationships between this ecosystem and others recorded in coeval units.

\section{CONCLUDING REMARKS}

Present contribution includes the first detailed description of fossil vertebrates, invertebrates, plants and polen from the Chorrillo Formation. Previous reports of its fossil content consisted on brief mentions confirming the presence of dinosaur bones and fragmentary plant remains. Now, the taxonomic diversity is con- 
siderably expanded with the description of different members of a Maastrichtian continental biota, including gastropods of a variety of aquatic and terrestrial families, and different groups of vertebrates including fishes, anurans, turtles, snakes, mosasaurs, titanosaurids, elasmarians, megaraptorids, neognathans, and mammals. Palynological assemblage from Chorrillo beds includes fern spores and both gymnosperm and angiosperm pollen. Although less diverse than other Maastrichtian units, the palynological content may increase with better sampled rock levels. Main novelties afforded by Chorrillo Formation include the remains of small vertebrates (especially birds and mammals), the survival of large titanosaurs and elasmarian into the Maastrichtian, and the documentation of a wide diversely of continental gastropods, the Cretaceous record of which remained virtually unknown from this region of Patagonia.

Maastrichtian vertebrate faunas associated with litoral environments have been extensively documented in northern and central Patagonia (e.g., Casamiquela, 1978; Gasparini et al., 2015), and evidence gained in recent years from both Chorrillo and Dorotea formations, demonstrate that such faunal assemblage extended, with some distinctions, up to the southern extreme of South America. This conforms a sharp distinction with respect to North America, where marine flooding occurred at its maximum stage during Campanian times, being followed by a regressive phase during the late Maastrichtian (see Roberts \& Kirschbaum, 1995). This is different from Patagonia, in which the maximum transgression occurred during the late Maastrichtian and persisted into the early Tertiary (see Malumián \& Náñez, 2011). The paleoecological effects of such paleoenvironmental distinctions between South and North America need to be investigated in more detail.

A better knowledge of floristic and faunistic Maastrichtian record from southern South America will eventually contribute in future discussions about mass extinction occurred at K-Pg boundary, which are mostly based on Maastrichtian fossil record from the northern hemisphere.

Discussions about dinosaur mass extinction are mostly based on Maastrichtian fossil record from North America. South America, and other Gondwanan regions, are overlooked from these discussions, due to unavailability of dinosaur remains corresponding to latest Maastrichtian age. Aside from sharp distinctions in dinosaur taxo- nomic composition, paleogeographic evolution of North America shows marine flooding during Campanian times, being in regressive phase during the Maastrichtian. This is different from Patagonia, in which the latter stage coincides with the maximum transgression persisting onto the early Cenozoic. Maastrichtian vertebrate faunas associated with littoral environments have been extensively documented in northern and central Patagonia (Casamiquela, 1978; Gasparini et al., 2015), and evidence gained in recent years in Chorrillo and Dorotea Formations demonstrates that such faunal assemblage, but with some distinctions, extended up to the southern extreme of South America. Present contribution includes the first detailed description of fossil vertebrates, invertebrates, plants and palynomorphs from the Chorrillo Formation. Vertebrate and plant assemblages are similar to those of other southern Gondwana landmasses, including other Santa Cruz localities, Antarctica, and Australia. Further, in contrast with northern Patagonia and Chubut province, abelisaurid theropods and relatively small sauropods of the aeolosaurine and saltasaurine clades, are totally absent in latest Cretaceous Santa Cruz provinces. Further, in contrast to northern Patagonia, basal ornithopods are abundant in the Austral basin.

\section{ACKNOWLEDGEMENTS}

Thanks to Coleman Burke (New York), for his encouragement and financial assistance to carry on field exploration. Facundo Echeverría and his wife Daphne Fraser (La Anita farm) offered their valuable geographic knowledge of these territories, allowing us an easy access to fossil sites with our $4 \times 4$ vehicles. Special thanks to Federico Braun for allowing access to his property. The following people gave formidable logistic support: Julian Foster (Patagonia Profunda; El Calafate), Marisa and Luis Calleja (Centro de Interpretación Histórica; El Calafate), Paz Fiorito (Kaulen Hostería, El Chaltén), and Anahí Pallone (Aguisac). Cruz del Sur for transporting fossil specimens to Buenos Aires. Oscar Canto and Carla Almazán (Secretaría de Cultura) for supporting our projects and explorations in Santa Cruz. Participants of the exploration carried on in January 2019 were: M.Isasi, M. Motta, S. Rozadilla, F. Brisson, and A. Vega. Participants of the exploration carried on in March 2019 were: M. Isasi, M. Motta, F. Agnolín, M. Cerroni and F. Novas. Special thanks to the geologists F. Nullo, F. Varela, and D. Moyano Paz for their valuable 
comments on stratigraphy and regional geology at Santa Cruz province. Daniel Pérez, Belen Santelli, and Maximiliano Álvarez are acknowledged for taxonomical idenitification of marine invertebrates. Special thanks to the reviewers Diego Pol, Marcelo de la Fuente, Sergio Martínez, and an anonymous reviewer which greatly improved the quality of the original manuscript.

\section{REFERENCES}

Agnolin, F.L. 2010. An avian coracoid from the Upper Cretaceous of Patagonia, Argentina. Studia Geologica Salmanticensia 46(2): 99-120.

Agnolin, F.L. 2012. A new Calyptocephalellidae (Anura, Neobatrachia) from the Upper Cretaceous of Patagonia, Argentina, with comments on its systematic position. Studia geologica salmanticensia 48(2): 129-178.

Agnolin, F. L. \& P. Chiarelli. 2010. The position of the claws in Noasauridae (Dinosauria: Abelisauroidea) and its implications for abelisauroid manus evolution. Paläontologische Zeitschrift 84(2): 293-300.

Agnolín, F.L., Brisson Egli, F., Chatterjee, S., García Marsá, J.A. \& F.E. Novas. 2017. Vegaviidae, a new clade of southern diving birds that survived the K/T boundary. The Science of Nature 104: 87.

Agnolin, F. L., Ezcurra, M. D., Pais, D. F. \& S. W. Salisbury. 2010. A reappraisal of the Cretaceous non-avian dinosaur faunas from Australia and New Zealand: evidence for their Gondwanan affinities. Journal of Systematic Palaeontology 8(2): 257-300.

Agnolin, F. L., Powell, J. E., Novas, F. E. \& M. Kundrát. 2012. New alvarezsaurid (Dinosauria, Theropoda) from uppermost Cretaceous of north-western Patagonia with associated eggs. Cretaceous Research 35: 33-56.

Agnolin, F.L., Novas, F.E. \& G.L. Lío. 2006. Neornithean bird coracoid from the Upper Cretaceous of Patagonia. Ameghiniana 43: 245-248.

Agnolín, F.L. \& F.E. Novas. 2013. Avian ancestors: a review of the phylogenetic relationships of the theropods Unenlagiidae, Microraptoria, Anchiornis, and Scansoriopterygidae. In: G. Lohmann, L.A. Mysak, J. Notholt, J. Rabassa \& V. Unnithan (eds.), South America and the Southern Hemisphere, pp. 1-96, Springer Verlag, Dordrecht, Heidelberg, New York, London.

Albino, A.M. 1986. Nuevos Boidae Madtsoiinae en el Cretácico tardío de Patagonia (Formación Los Alamitos, Río Negro, Argentina). IV Congreso Argentino de Paleontología y Bioestratigrafía, Actas 4: 15-21.

Albino, A.M. 1987. The Late Cretaceous fauna of Los Alamitos, Patagonia, Argentina, Part V. The Ophidians. Revista del Museo Argentino de Ciencias Naturales, Paleontología 3(3): 141-146.

Albino, A.M. 1994. Una nueva serpiente (Reptilia) en el Cretácico Superior de Patagonia, Argentina. Pesquisas 21: 58-63.

Albino, A.M. 2000. New record of snakes from the
Cretaceous of Patagonia (Argentina). Geodiversitas 22(2): 247-253.

Albino, A.M. 2010. Morfología vertebral de Boa constrictor (Serpentes: Boidae) y la validez del genero Mioceno Pseudoepicrates Auffenberg, 1923. Ameghiniana 48(1): 53-62.

Ameghino, F. 1893. Sobre la presencia de vertebrados de aspecto mesozóico, en la formación santacrucena de la Patagonia austral. Revista del Jardín Zoológico de Buenos Aires 1: 76-84.

Andrzejewski, K.A., Winkler, D.A. \& L.L. Jacobs. 2019 A new basal ornithopod (Dinosauria: Ornithischia) from the Early Cretaceous of Texas. PloS one 14(3): e0207935.

Apesteguía, S. \& H. Zaher. 2006. A Cretaceous terrestrial snake with robust hindlimbs and a sacrum. Nature 440: 1037-1040.

Arbe, H.A. 2002. Análisis estratigráfico del Cretácico de la Cuenca Austral. En: M.J. Haller (Ed.), Geología y Recursos Naturales de Santa Cruz. 15을 Congreso Geológico Argentino, Relatorio 1(8): 103-128.

Arbe, H. \& J.J. Hechem, 1984. Estratigrafía y facies de depósitos marinos profundos del Cretácico superior, Lago Argentino. $9^{\circ}$ Congreso Geológico Argentino 5: 7-14.

Argot, C. 2003. Functional-adaptive anatomy of the axial skeleton of some extant marsupials and the paleobiology of the Paleocene marsupials Mayulestes ferox and Pucadelphys andinus. Journal of Morphology 255(3), 279-300.

Arratia, G. \& A. Cione. 1996. The record of fossil fishes of southern South America. Münchner Geowissenschaftliche Abhandlungen 30(A): 9-72.

Azuma, Y. \& P.J. Currie. 2000. A new carnosaur (Dinosauria: Theropoda) from the Lower Cretaceous of Japan. Canadian Journal of Earth Sciences 37: 1735-1753.

Baas, P., Blokhina, N., Fujii, T., Gasson, P.E., Grosser, D., Heinz, I., Ilic, J., Xiaomei, J., Miller, R., Newsom, L.A., Noshiro, S., Richter, H.G.H.G., Suzuki, M., Terrazas, T., Wheeler, E., Wiedenhoeft, A., Grosser, D. et al, Heinz, I. \& P.E. Gasson. 2004. IAWA List of microscopic features for softwood identification. IAWA Journal 25: 1-70.

Báez, A. M. 1987. Anurans. In: J.F. Bonaparte (Ed.), The Late Cretaceous fauna of Los Alamitos, Patagonia, Argentina. Revista del Museo Argentino de Ciencias Naturales Bernardino Rivadavia, Paleontología 3(3): 121-130.

Báez, A.M. \& S. Perí. 1989. Baurubatrachus pricei, nov. gen. et sp., un Anuro del Cretacio Superior de Minas Gerais Brasil. Anais Academica Brasileira Ciencias 61: 447- 458.

Báez, A. M. 2000. Tertiary anurans from South America. In: H. Heatwole \& R.L. Carroll (eds). Amphibian Biology, Volume 4: Palaeontology, pp. 1388-1401, Surrey Beatty and Sons, Chipping Norton, Australia,

Báez, A.M., Moura, G.J.B. \& R.O. Gómez. 2009. Anurans from the Lower Cretaceous Crato Formation of northeastern Brazil: implications for the early divergence of neobatrachians. Cretaceous Research 
30: 829-846.

Báez, A.M., Gómez, R.O., Ribeiro, L.C.B., Martinelli, A.G., Teixeira, V.P.A. \& M.L.F. Ferraz. 2012. The diverse cretaceous neobatrachian fauna of South America: Uberabatrachus carvalhoi, a new frog from the Maastrichtian Marília Formation, Minas Gerais, Brazil. Gondwana Research 22: 1141-1150.

Bardet, N., Suberbiola, X.P., Corral, J.C., Baceta, J.I., Torres, J.Á., Botantz, B. \& G. Martin. 2012. A skull fragment of the mosasaurid Prognathodon cf. sectorius from the Late Cretaceous of Navarre (Basque-Cantabrian Region). Bulletin de la Société géologique de France, 183(2): 117-121.

Barreda, V.D., Cúneo, N.R., Wilf, P., Currano, E.D., Scasso, R.A. \& H. Brinkhuis, 2012. Cretaceous/ Paleogene Floral Turnover in Patagonia: Drop in Diversity, Low Extinction, and a Classopollis Spike. PLoS ONE 7(12): e52455]

Barrett, P.M. 2016. A new specimen of Valdosaurus canaliculatus (Ornithopoda: Dryosauridae) from the Lower Cretaceous of the Isle of Wight, England. Memoirs of Museum Victoria 74: 29-48.

Barrett, P. M., Butler, R.J., Twitchet, R.J. \& S. Hutt. 2011. New material of Valdosaurus canaliculatus (Ornithischia: Ornithopoda) from the Lower Cretaceous of southern England. Special Papers in Palaeontology 86: 131-163.

Benson, R. B., Carrano, M. T., \& S. L. Brusatte. 2010. A new clade of archaic large-bodied predatory dinosaurs (Theropoda: Allosauroidea) that survived to the latest Mesozoic. Naturwissenschaften 97: 71.

Benson, R. B., Rich, T. H., Vickers-Rich, P. \& M. Hall. 2012. Theropod fauna from southern Australia indicates high polar diversity and climate-driven dinosaur provinciality. PLoS One 7(5): e37122.

Bertozzo, F., Dalla Vecchia F.M. \& M. Fabbri. 2017. The Venice specimen of Ouranosaurus nigeriensis (Dinosauria, Ornithopoda). PeerJ 5: e3403.

Blasco, G., Nullo, F. \& C.A. Proserpio, 1980. SantonianoCampaniano: Estratigrafía y contenido amonitífero, Cuenca Austral. Revista de la Asociación Geológica Argentina 35(4): 467-499.

Bogan, S., Taverne L. \& F.L. Agnolin, 2010. First fossil record of an amiid fish (Halecomorphi, Amiidae) from the Latest Cretaceous of Patagonia, Argentina, and comments on the status of Pappichthys patagonicus Ameghino, 1906 (Teleostei, Osteoglossidae). Bulletin de'l Institut Royal des Sciences Naturelles de Belgique 80: 163-170.

Bogan, S., Taverne, L., \& F.L. Agnolin. 2013. First Triassic and oldest record of a South American amiiform fish: Caturus sp. from the Los Menucos Group (lower Upper Triassic), Río Negro province, Argentina. Geologica Belgica 16: 191-195.

Bonaparte, J.F. \& J.E. Powell. 1980. A continental assemblage of tetrapods from the Upper Cretaceous beds of El Brete, northwestern Argentina (Sauropoda-Coelurosauria-CarnosauriaAves). Société Géologique de France, Mémoir, n. s. 139: 19-28.

Bonaparte, J.F. 1986. Sobre Mesungulatum houssa$y i$ y nuevos mamíferos cretácicos de Patagonia,
Argentina. IV congreso Argentino de Paleontología y Bioestratigrafía 2: 48-61.

Bonaparte, J.F. 1986. History of the terrestrial Cretaceous vertebrates of Gondwana. IV Congreso Argentino de Paleontologì y Bioestratigrafia 2: 6395.

Bonaparte, J.F. 1990. New Late Cretaceous mammals from the Los Alamitos Formation, Northern Patagonia. National Geographic Research 6(1): 6383.

Bonaparte, J.F. 1991. The Gondwanan theropod families Abelisauridae and Noasauridae. Historical Biology 5(1): 1-25.

Bonaparte, J.F. 1992. Una nueva especie de Triconodonta (Mammalia), de la Formación Los Alamitos, Provincia de Río Negro y comentarios sobre su fauna de mamíferos. Ameghiniana 29(2): 99-110.

Bonaparte, J.F. 1994. Approach to the significance of the Late Cretaceous mammals of South America. Berliner geowissenschaftliche Abhandlugen $E$ 13(3): 31-44.

Bonaparte, 1996. Dinosaurios de América del Sur. Museo Argentino de Ciencias Naturales "Bernardino Rivadavia", Buenos Aires, Argentina. 2da Edición. 174 pp.

Bonaparte, J.F. 2002. New Dryolestida (Theria) from the Late Cretaceous of Los Alamitos, Argentina, and paleogeographical comments. Neues Jahrbuch für Geologie und Paläontologie, Abhandlungen 224(3): 339-371.

Bonaparte, J.F. \& R.A. Coria. 1993. Un nuevo y gigantesco saurópodo titanosaurio de la Formación Río (Albiano-Cenomaniano) de la provincia de Neuquén, Argentina. Ameghiniana 30: 271-282.

Bonaparte, J.F., Franchi, M.R., Powell, J.E. \& E.G. Sepulveda. 1984. La Formación Los Alamitos (Campaniano-Maastrichtiano) del sudeste de Río Negro, con descripción de Kritosaurus australis n. sp. (Hadrosauridae). Significado paleogeográfico de los vertebrados. Revista de la Asociación Geológica Argentina 39(3-4): 284-299.

Bonaparte, J.F., Heinrich, W.D., \& R. Wild. 2000. Review of Janenschia WILD, with the description of a new sauropodfrom the Tendaguru beds of Tanzania and a discussion on the systematicvalue of procoleous caudal vertebrae in the sauropoda. Palaeontographica Abteilung A: 25-76.

Bonaparte, J.F., González Riga B. \& S. Apesteguía. 2006. Ligabuesaurus leanzai gen. et sp. nov. (Dinosauria, Sauropoda), a new titanosaur from the Lohan Cura Formation (Aptian, Lower Cretaceous) of Neuquén, Patagonia, Argentina. Cretaceous Research 27: 364-376.

Bonaparte, J.F., Báez, A.M., Cione, A.L., \& J.L. Panza. 2002. Vertebrados Mesozoicos. In: M.J. Haller (Ed.), Geología y Recursos Naturales de Santa Cruz. $15^{\circ}$ Congreso Geológico Argentino, Relatorio (2) $4: 421-43$.

Borsuk-Bialynicka, M. 1977. A new camarasaurid sauropod Opisthocoelicaudia skarzynskii gen. n., sp. n. from the Upper Cretaceous of 
Mongolia. Palaeontologia Polonica 37(5): 5-64.

Boyd, C.A. \& D.C. Pagnac. 2015. Insight on the anatomy, systematic relationships, and age of the Early Cretaceous ankylopollexian dinosaur Dakotadon lakotaensis. PeerJ 3: e1263.

Boyd, C.A., Brown, C.M., Scheetz, R.D. \& J.A. Clarke. 2009. Taxonomic revison of the basal neornithischian taxa Thescelosaurus and Bugenasaura. Journal of Vertebrate Paleontology, 29(3): 758-770.

Brett-Surman, M.K. 1979. Phylogeny and palaeobiogeography of hadrosaurian dinosaurs. Nature 277(5697): 560-562.

Breure, A.S.H. 1979. Systematics, Phylogeny and Zoogeography of Bulimulinae (Mollusca). Zoologische Verhandelingen te Leiden 168: 1-215.

Brissón Egli, F., Agnolín, F.L. \& F.E. Novas. 2016. A new specimen of Velocisaurus unicus (Theropoda, Abelisauroidea) from the Paso Córdoba locality (Santonian), Río Negro, Argentina. Journal of Vertebrate Paleontology 36(4): e1119156.

Brissón Egli, F., Aranciaga Rolando, A.M., Agnolín, F.L. \& F.E. Novas. 2017. Osteology of the unenlagiid theropod Neuquenraptor argentinus from the Late Cretaceous of Patagonia. Acta Palaeontologica Polonica 62(3): 549-562.

Brito, P.M., Nava, W.R. \& A.G. Martinelli. 2017. A new fossil amiid (Holostei: Halecomorphi) from the Late Cretaceous Adamantina Formation, southeastern Brazil, with comments on western Gondwana amiid. Cretaceous Research 77: 39-43.

Brochu, C.A. 2003. Osteology of Tyrannosaurus rex: insights from a nearly complete skeleton and highresolution computed tomographic analysis of the skull. Society of Vertebrate Paleontology Memoir 7: 1-138.

Brodkorb, P. 1963. Birds from the upper Cretaceous of Wyoming. Proceedings of the XIII International Ornithological Congress, American Ornithologists Union Baton Rouge 1962: 55-70.

Brodkorb, P. 1970. An Eocene puffbird from Wyoming. University of Wyoming Contributions to Geology 9(1): 13-15.

Broin, F.de. 1987. The Late Cretaceous Fauna of Los Alamitos, Patagonia, Argentina. IV: Chelonia. Revista del Museo Argentino de Ciencias Naturales "Bernardino Rivadavia” n. s. Paleontología 3(3): 131-139.

Broin, F.L.de. \& M.S. de la Fuente. 1993. Les tortues fossiles d'Argentine: Synthese. Annales de Paléontologie 79(3): 169-232.

Brown, C.M., Boyd, C.A. \& A.P. Russell. 2011. A new basal ornithopod dinosaur (Frenchman Formation, Saskatchewan, Canada), and implications for late Maastrichtian ornithischian diversity in North America. Zoological Journal of the Linnean Society 163(4): 1157-1198.

Cabrera, F., Martínez, S. \& M. Verde. 2018. Continental Late Cretaceous gastrops assemblages from Uruguay. Paleoecology, age, and the oldest records of two families and a genus. Historical Biology, DOI: 10.1080/08912963.2018.1471478.

Caldwell, M.W. \& C.G. Diedrich. 2005. Remains of
Clidastes Cope, 1868, an unexpected mosasaur in the upper Campanian of NW Germany. Netherlands Journal of Geosciences 84(3): 213-220.

Calvo, J.O., Porfiri, J.D. \& F.E. Novas. 2007. Discovery of a new ornithopod dinosaur from the Portezuelo Formation (Upper Cretaceous), Neuquén, Patagonia, Argentina. Arquivos do Museu Nacional Rio de Janeiro 65:471-483.

Calvo, J.O., Porfiri, J.D., Veralli, C., Novas, F.E. \& F. Poblete, 2004. Phylogenetic status of Megaraptor namunhuaiquii Novas based on a new specimen from Neuquén, Patagonia, Argentina.Ameghiniana 41(4): 565-575.

Cambiaso, A.V. 2007. Los ornitópodos e iguanodontes basales (Dinosauria, Ornithischia) del Cretácico de Argentina y Antártida. Unpublished Ph. D. dissertation, Universidad de Buenos Aires, Buenos Aires.

Cantrill, D.J. 1998. Early Cretaceous fern foliage from President Head, Snow Island, Antarctica. Alcheringa 22(3): 241-258.

Canudo, J.I., Carballido, J., Garrido A. \& L. Salgado. 2013. Primera evidencia de dinosaurios ornitópodos en la base de la Formación Huincul (Cenomaniense Superior-Turoniense, Cuenca Neuquina, Argentina). Geogaceta 53: 1-5.

Carlquist, S.J. 1988. Comparative wood anatomy: systematic, ecological, and evolutionary aspects of dicotyledon wood. Springer Science \& Business Media.

Carballido, J.L., Pol, D., Otero, A., Cerda, I.A., Salgado, L., Garrido, A.C. \& J.M. Krause. 2017. A new giant titanosaur sheds light on body mass evolution among sauropod dinosaurs. Proceedings of the Royal Society B: Biological Sciences 284(1860): 20171219

Carvalho, I., Agnolin, F.L., Aranciaga Rolando, A.M., Novas, F.E., Xavier-Neto, J., Freitas, F.I.de \& J.A.F. de Andrade. 2019. A new genus of pipimorph frog (anura) from the early Cretaceous Crato formation (Aptian) and the evolution of South American tongueless frogs. Journal of South American Earth Sciences 92: 222-233.

Casal, G., Martínez, R., Luna, M., Sciutto, J. C. \& Lamanna, M. 2007. Aeolosaurus colhuehuapensis sp. nov. (Sauropoda, Titanosauria) de la Formación Bajo Barreal, Cretácico Superior de Argentina. Revista Brasileira de Paleontologia 10(1): 53-62.

Casamiquela, R.M. 1978. La zona litoral de la transgresión maastrichtense en el norte de la Patagonia. Aspectos ecológicos. Ameghiniana 15(1-2): 137 148.

Case, J.A., Martin, J.E., Chaney, D.S., Reguero, M., Marenssi, S.A., Santillana, S.M. \& M.O. Woodburne. 2000. The first duck-billed dinosaur (Family Hadrosauridae) from Antarctica. Journal of Vertebrate Paleontology 20(3): 612-614.

Castellanos, Z.J.A. de \& N.A. Landoni. 1995. Mollusca Pelecypoda y Gastropoda. In: E.C. Lopretto \& G. Tell (dirs), Ecosistemas de Aguas Continentales. Metodologías para su estudio, 2: pp. 759-801, La Plata.

Cecioni, G. (1957). Età della flora del Cerro Guido e 
stratigrafía del Departamento Última Esperanza. Bollettino della Società Geologica Italiana 76: 3-16.

Cei, J.M. 1980. Amphibians of Argentina. Universitá degli studi di Firenze, vol. 2, 609 pp.

Chatterjee, S. 2002. The morphology and systematics of Polarornis, a Cretaceous loon (Aves, Gaviidae) from Antarctica. In: Z. Zhou \& F. Zhang (eds.), Proceedings of the 5th Symposium of the Society of Avian Paleontology and Evolution. Science Press, Beijing, pp. 125-155.

Chen, M. \& Z.-X. Luo. 2013. Postcranial skeleton of the Cretaceous mammal Akidolestes cifellii and its locomotor adaptations. Journal of Mammalian Evolution 20(3): 159-189.

Chornogubsky, L. 2011. New remains of the dryolestoid mammal Leonardus cuspidatus from the Los Alamitos Formation (Late Cretaceous, Argentina). Paläontologische Zeitschrift 85(3): 343-350.

Cione, A.L. 1987. The Late Cretaceous fauna of los Alamitos, Patagonia, Argentina. II: The fishes. Revista del Museo Argentino de Ciencias Naturales Bernardino Rivadavia e Instituto Nacional de Investigación de las Ciencias Naturales. Paleontología 3(3): 111-120.

Clarke J.A., Chatterjee, S., Li, Z., Riede, T., Agnolin, F.L., Goller, F., Isasi, M.P., Martinioni, D.R., Mussel, F.J. \& F.E. Novas. 2016. Fossil evidence of the avian vocal organ from the Mesozoic. Nature 538: 502505.

Clarke, J.A. 2004. Morphology, phylogenetic taxonomy, and systematics of Ichthyornis and Apatornis (Avialae: Ornithurae). Bulletin of the American Museum of Natural History 286: 1-179.

Cooper, M.R. 1985. A revision of the ornithischian dinosaur Kangnasaurus coetzeei Haughton, with a classification of the Ornithischia. Annals of the South African Museum 95(8): 281-317.

Coria, R.A. \& J.O. Calvo. 2002. A new iguanodontian ornithopod from the Neuquén Basin, Patagonia, Argentina. Journal of Vertebrate Palaeontology 22: 503-509.

Coria, R.A. \& L. Salgado. 1996. A basal Iguanodontia (Ornithopoda - Ornithischia) from the Late Cretaceous of South America. Journal of Vertebrate Palaeontology 16(3): 445-457.

Coria, R. A., Moly, J.J., Reguero, M., Santillana, S. \& S. Marenssi. 2013. A new ornithopod (Dinosauria; Ornithischia) from Antarctica. Cretaceous Research 41: 186-193.

Coria, R.A., González Riga, B. \& S. Casadío, S. 2012. Un nuevo hadrosáurido (Dinosauria, Ornithopoda) de la Formación Allen, provincia de la Pampa, Argentina. Ameghiniana 49(4): 552-573.

Coria, R.A. \& P.J. Currie. 2016. A new megaraptoran dinosaur (Dinosauria, Theropoda, Megaraptoridae) from the Late Cretaceous of Patagonia. PLoS One 11(7): 0157973.

Cruzado-Caballero, P. \& J. Powell. 2017. Bonapartesaurus rionegrensis, a new hadrosaurine dinosaur from South America: implications for phylogenetic and biogeographic relations with
North America. Journal of Vertebrate Paleontology 37(2): e1289381.

Cruzado-Caballero, P., Gasca, J.M., Filippi, L.S., Cerda, I.A. \& A.C. Garrido 2019. A new ornithopod dinosaur from the Santonian of Northern Patagonia (Rincón de los Sauces, Argentina). Cretaceous Research 98: 211-229.

D'Emic, M. D. 2012. The early evolution of titanosauriform sauropod dinosaurs. Zoological Journal of the Linnean Society 166(3): 624-671.

de la Fuente, M.S., Salgado, L., Albino, A., Báez, A.M., Bonaparte, J.F., Calvo, J.O., Chiappe, L.M., Codorniú, L.S., Coria, R.A., Gasparini, Z., González Riga, B.J., Novas, F.E. \& D. Pol. 2007. Tetrápodos continentales del Cretácico de la Argentina. Una síntesis actualizada. Asociación Paleontológica Argentina, Publicación Especial 11: 137-153.

de Lucía, M. \& D.E. Gutiérrez Gregoric, 2017. The genus Potamolithus Pilsbry, 1896 (Gastropoda: Tateidae) on the Somuncurá Plateau, Patagonia, Argentina. Molluscan Research 37(3): 202-211.

De Pietri, V.L., Scofield, R.P., Zelenkov, N., Boles, W.E. \& T.H. Worthy. 2016. The unexpected survival of an ancient lineage of anseriform birds into the Neogene of Australia: the youngest record of Presbyornithidae. Royal Society Open Science 3(2): 150635.

Del Fueyo, G.M., 1998. Coniferous woods from the Upper Cretaceous of Patagonia, Argentina. Revista Española de Paleontología 13: 43-50.

Del Río, C.J., Camacho, H.H., Aguirre, M., Caramés, A., Cuminsky, G., de Francesco, C., Farinati, E., Gordillo, S., Laprida, C., Miquel, S. \& S. Morton. 2007. Invertebrados del Cenozoico de la Argentina. Ameghiniana, Publicación Especial 11: 221-235.

Dettman, M.E. \& D.M. Jarzen. 1988. Angiosperm pollen from uppermost Cretaceous strata of southeastern Australia and the Antarctic Peninsula. Association of Australasian Palaeontologists, Memoir 5: 217237.

Duckler, G.L. 1997. Parietal depressions in skulls of the extinct saber-toothed felid Smilodon fatalis: evidence of mechanical strain. Journal of Vertebrate Paleontology 17(3): 600-609.

Egerton, V. M., Novas, F. E., Dodson, P. \& Lacovara, K. 2013. The first record of a neonatal ornithopod dinosaur from Gondwana. Gondwana Research 23(1): 268-271.

Ericson, P.G.P. 1997. Systematic relationships of the Palaeogene family Presbyornithidae (Aves: Anseriformes). Zoological Journal of the Linnean Society 121: 429-483.

Fernández, D. 1973. Catálogo de la malacofauna terrestre argentina. Monografías 4, Ed. Comisión de Investigaciones Científicas, La Plata, 197 pp.

Fernández, M.S. \& A. Khosla. 2014. Parataxonomic review of the Upper Cretaceous dinosaur eggshells belonging to the oofamily Megaloolithidae from India and Argentina, Historical Biology: DOI: 10.1080/08912963.2013.871718

Fernández, M.S. 2016. Important contributions of the South American record to the understanding of di- 
nosaur reproduction. In: A. Khosla \& S.G. Lucas, S.G. (eds.), Cretaceous Period: Biotic Diversity and Biogeography. New Mexico Museum of Natural History and Science Bulletin 71: 91-105.

Fernández, M. \& J. Martin. 2009. Description and phylogenetic relationships of Taniwhasaurus antarcticus. Cretaceous Research 30: 717-726.

Fernández, M., Martin, J. \& S. Casadio. 2008. Mosasaurs (Reptilia) from the late Maastrichtian (Late Cretaceous). Journal of South American Earth Sciences 25: 176-186.

Feruglio, E. 1938. El Cretácico superior del lago San Martín (Patagonia) y de las regiones adyacentes. Physis 12: 293-342.

Feruglio, E. 1944. Estudios geologicos y glaciologicos en la region del Lago Argentino (Patagonia). Boletin de la Academia Nacional de Ciencias 37(1-2): 3-255.

Filippi, L.S., García, R.A. \& A.C. Garrido. 2011. A new titanosaur sauropod dinosaur from the Upper Cretaceous of North Patagonia, Argentina. Acta Palaeontologica Polonica 56(3): 505-521.

Forasiepi, A. \& M.F. López Armengol, 1999. Potamolithus windhauseni (Parodiz, 1961) (Gastropoda - Hydrobiidae) in Los Alamitos Formation (Campanian - Maastrichtian) from Río Negro Province, Argentina. VII International Symposium on Mesozoic Terrestrial Ecosystems. Abstract: $25-26$.

Galton, P.M. 1974a. The ornithischian dinosaur Hypsilophodon (Huxley, 1869) from the Wealden of the Isle of Wight. Bulletin of the British Museum (Natural History), Geology 25: 1-152.

Galton, P. M. 1974b. Notes on Thescelosaurus, a conservative ornithopod from the Upper Cretaceous of North America, with comments on ornithopod classification. Journal of Palaeontology 48: 148-167.

Garcia, R.A. \& I.A. Cerda. 2010. Dentition and histology in titanosaurian dinosaur embryos from Upper Cretaceous of Patagonia, Argentina. Palaeontology 53(2): 335-346.

Gasparini, Z., \& M.S. de la Fuente. 2000. Tortugas y plesiosaurios de la Formación La Colonia (Cretácico Superior) de Patagonia. Revista Española de Paleontología 15: 23-35.

Gasparini, Z., Sterli, J., Parras, A., O’Gorman, J. P., Salgado, L., Varela, J. \& D. Pol. (2015). Late Cretaceous reptilian biota of the La Colonia Formation, central Patagonia, Argentina: Occurrences, preservation and paleoenvironments. Cretaceous Research 54: 154-168.

Ghilardi, R.P., Carbonaro, F.A. \& L.R.L. Simone 2011. Physa mezzalirai, a new cretaceous basommatophoran from Adamantina formation, Brazil. Strombus 18(1/2): 1-14.

Godefroit, P., Codrea, V. \& D.B. Weishampel. 2009. Osteology of Zalmoxes shqiperorum (Dinosauria, Ornithopoda), based on new specimens from the Upper Cretaceous of Năălatț-Vad (Romania). Geodiversitas 31(3): 525-554.

Gomez, R.O., Báez, A.M. \& G.W. Rougier. 2008. An anilioid snake from the Upper Cretaceous of northern Patagonia. Cretaceous Research 29: 481-488.
González Abarca, E.J. 2015. Estratigrafía secuencial y sedimentología de la formación Dorotea (maastrichtiano), sector Río de Las Chinas, región de Magallanes y Antártica Chilena (50 $\mathrm{S})$. Tesisa de grado, Universidad de Chile, Facultad de Ciencias Físicas y matemáticas, departamento de Geología. $140 \mathrm{pp}$.

González-Riga, B.G. 1999. Hallazgo de vertebrados fósiles en la Formación Loncoche, Cretácico Superior de la provincia de Mendoza, Argentina. Ameghiniana 36(4): 401-410.

Gonzalez Riga, B.J., Lamanna, M.C., David, L. D.O., Calvo, J.O., \& Coria, J.P. \& R.A. Fariña. 2016. A gigantic new dinosaur from Argentina Giant and bizarres: Body size of some southern the evolution of the sauropod hind foot. Scientific Reports 6: 19165 .

González Riga, B.J., Mannion, P.D., Poropat, S.F., Ortiz David, L.D. \& J.P. Coria. 2018. Osteology of the Late Cretaceous Argentinean sauropod dinosaur Mendozasaurus neguyelap: implications for basal titanosaur relationships. Zoological Journal of the Linnean Society 184(1): 136-181.

Gonzalez Riga, B. J., Lamanna, M. C., Otero, A., David, L.D.O., Kellner, A.W. \& L.M. Ibiricu. 2019. An overview of the appendicular skeletal anatomy of South American Cretaceous titanosaurian sauropods, with definition of a newly recognized clade. Anais da Academia Brasileira de Ciências 91: e20180374.

Grande, L. 2010. An empirical synthetic pattern study of gars (Lepisosteiformes) and closely related species, based mostly on skeletal anatomy. The resurrection of Holostei. Copeia 10(2A): 1-871.

Grande, L. \& W.E. Bemis. 1998. A comprehensive phylogenetic study of amiid fishes (Amiidae) based on comparative skeletal anatomy. An empirical search for interconnected patterns of natural history. Journal of Vertebrate Paleontology 18, Supplement 1, Memoir 4: 1-690.

Griffin, M. \& A.N. Varela, 2012. Systematic palaeontology and taphonomic significance of the mollusc fauna from the Mata Amarilla Formation (lower Upper Cretaceous), southern Patagonia, Argentina. Cretaceous Research 37: 164-176.

Guler, V., Guerstein, G.R. \& S. Casadío, 2005. New dinoflagellate cyst species from the Calafate Formation (Maastrichtian) Austral basin, Argentina. Ameghiniana 42(2): 419-428.

Han, F.-L., Barrett, P.M., Butler, R. J. \& X. Xu. 2012. Postcranial anatomy of Jeholosaurus shangyuanensis (Dinosauria, Ornithischia) from the Lower Cretaceous Yixian Format ion of China. Journal of Vertebrate Paleontology 32(6): 1370-1395.

Henderson, J. 1935. Fossil non-marine Mollusca of North America. Geological Society of America. Special papers 3: 1-313.

Herne, M.C., Tait, A.M., Weisbecker, V., Hall, M., Nair, J.P., Cleeland, M. \& S.W. Salisbury. 2018. A new small-bodied ornithopod (Dinosauria, Ornithischia) from a deep, high-energy Early Cretaceous river of the Australian-Antarctic rift system. PeerJ 5: 
e4113.

Herngreen, G.F.W. \& A.F. Chlonova. 1981. Cretaceous microfloral provinces. Pollen et Spores 23: 441557.

Herngreen, G.F.W., Kedves, M., Rovnina, L.V. \& S.B. Smirnova. 1996. Cretaceous palynofloral provinces: a review. In: J. Jansonius \& D.C. McGregor (Eds.), Palynology: Principles and Applications, pp. 1157-1188, American Association of Stratigraphic Palynologists Foundation, Dallas.

Higgins, J. 1999. Tunel: A case study of avian zooarchaeology and taphonomy. Journal of Archaeological Science. 26: 1449-1457.

Hill, R.S., Macphail, M.K. \& G.J. Jordan. 2001. Macrofossils associated with the fossil fern spore Cyatheacidites annulatus and their significance for Southern hemisphere biogeography. Review of Paleobotany and Palynology 116: 195-202.

Hill, R.S. \& T.J. Brodribb. 1999. Evolution of conifer foliage in the southern hemisphere. IV International Conifer Conference 615: 53-58.

Hocknull, S.A., White, M.A., Tischler, T.R., Cook, A.G., Calleja, N.D., Sloan, T. \& D.A. Elliott. 2009. New Mid-Cretaceous (Latest Albian) Dinosaurs from Winton, Queensland, Australia. PLoS ONE 4: e6190.

Hope, S. 2002. The Mesozoic radiation of neornithes. Mesozoic birds: above the heads of dinosaurs. University of California Press. pp. 339-388.

Horner, J.R. \& R. Makela. 1979. Nest of juveniles provides evidence of family structure among dinosaurs. Nature 282(5736): 296.

Horner, H.R., Weishampel, D. B., \& C.A. Forster. 2004. Hadrosauridae. In: The Dinosauria: Second Edition, pp. 438-463, University of California Press.

Horovitz, I. \& M.R. Sánchez-Villagra. 2003. A morphological analysis of marsupial mammal higher-level phylogenetic relationships. Cladistics 19(3): 181212.

Hornung, J.J. \& M. Reich. 2015. Tylosaurine mosasaurs (Squamata) from the Late Cretaceous of northern Germany. Netherlands Journal of Geosciences 94(1): 55-71.

Hsiou, A.S., Albino, M.A. \& J. Ferigolo. 2010. Reappraisal of the South American Miocene snakes of the genus Colombophis, with description of a new species. Acta Palaeontologica Polonica 55(3): 365-379.

Hu, Y., Meng, J., Wang, Y. \& C. Li. 2005. Large Mesozoic mammals fed on young dinosaurs. Nature 433(7022): 149-152.

Huene, F. von. 1929. Los saurisquios y ornitisquios del Cretáceo Argentino. Anales del Museo de la Plata III: 1-196.

Ibiricu, L.M., Martínez, R.D., Luna, M. \& G.A. Casal. 2014 reappraisal of Notohypsilophodon comodorensis (Ornithischia: Ornithopoda) from the Late Cretaceous of Patagonia, Argentina. Zootaxa 3786(4): 401-422.

Ibiricu, L.M., Casal, G.A., Martínez, R.D., Luna, M., Canale, J.I., Álvarez, B.N. \& B. González Riga.
2019. A new ornithopod dinosaur (Dinosauria: Ornithischia) from the Late Cretaceous of central Patagonia. Cretaceous Research 98: 276-291.

Jain, S.J. 1985. Some new observations on Lepidotes maximus (Holostei: Semionotiformes) from the German Upper Jurassic. Journal of the Palaeontological Society of India 30:18-25.

Jasinoski, S.C., Russell, A.P. \& P.J. Currie. 2006. An integrative phylogenetic and extrapolatory approach to the reconstruction of dromaeosaur (Theropoda: Eumaniraptora) shoulder musculature. Zoological Journal of the Linnean Society 146(3): 301-344.

Jenkins, F.A. \& N.H. Shubin. 1998. Prosalirus bitis and the anuran caudopelvic mechanism. Journal of Vertebrate Paleontology 18(3): 495-510.

Ji, Q., Luo, Z.-X. \& S.-A. Ji. 1999. A Chinese triconodont mammal and mosaic evolution of the mammalian skeleton. Nature 398: 326-330.

Ji, Q., Luo, Z. X., Yuan, C. X., Wible, J.R., Zhang, J.P. \& J.A. Georgi. 2002. The earliest known eutherian mammal. Nature 416(6883): 816-822.

Ji, Q., Luo, Z. X., Yuan, C.X. \& A.R. Tabrum. 2006. A swimming mammaliaform from the Middle Jurassic and ecomorphological diversification of early mammals. Science 311(5764): 1123-1127.

Juarez-Valieri, R., Haro, J., Fiorelli, L. \& J.O. Calvo. 2010. A new hadrosauroid (Dinosauria: Ornithopoda) from the Allen Formation (Late Cretaceous) of Patagonia, Argentina. Revista del Museo Argentino de Ciencias Naturales n. s. 12(2): 217-231.

Jujihara, T., Soto-Acuña, S., Vargas, A., Stinnesbeck, W., Vogt, M., Rubilar-Rogers, D. \& M. Leppe. 2014. The southernmost dinosaurs of South America. 23rd Latin American Colloquium on Earth Sciences, Abstracts: 88.

Katz, H.R. 1963. Revision of Cretaceous stratigraphy in Patagonian Cordillera of Ultima Esperanza, Magallanes Province, Chile. Bulletin of the American Association of Petroleum Geologists 47(3): 506-524

Kielan-Jaworowska, Z. \& P.P. Gambaryan. 1994. Postcranial anatomy and habits of Asian multituberculate mammals. Fossils \& Strata 36: 1-92.

Konishi, T., Lindgren, J., Caldwell, M.W. \& L. Chiappe. 2012. Platecarpus tympaniticus (Squamata, Mosasauridae): osteology of an exceptionally preserved specimen and its insights into the acquisition of a streamlined body shape in mosasaurs. Journal of Vertebrate Paleontology 32(6): 13131327.

Krause, D.W. \& F.A. Jenkins. 1983. The postcranial skeleton of North American multituberculates. Bulletin of the Museum of Comparative Zoology 150(4): 199-246.

Krausel, R. 1924. Beitrage zur Kenntnis der fossilen Flora Sudamerikas. I. Fossile Holzer aus Patagonien und benachbarten Gebieten. Arkiv for Botanik 19: 11-36.

Lacovara, K.J., Ibiricu, L.M., Lamanna, M.C., Poole, J.C., Schroeter, E.R., Ullmann, P.V., Voegele, K.K., Boles, Z.M., Egerton, V.M., Harris, J.D., Martínez, 
R.D. \& F.E. Novas. 2014. A gigantic, exceptionally complete titanosaurian sauropod dinosaur from southern Patagonia, Argentina. Scientific Reports 4: 6196 .

LaDuke, T.C. 1991. The Fossil Snakes of Pit 91, Rancho La Brea, California. Contribution in Science 424:128.

LaDuke, T.C., Krause, D.W., Scanlon, J.D. \& N.J. Kley. 2010. A Late Cretaceous (Maastrichtian) snake assemblage from the Maevarano Formation, Mahajanga basin, Madagascar. Journal of Vertebrate Paleontology 30:109-138.

Langer, M. C., de Oliveira Martins, N., Manzig, P. C., de Souza Ferreira, G., de Almeida Marsola, J. C., Fortes, E., Lima, R., Frediani Sant'ana, L.C., Silva Vidal, L.da, Silva Lorençato, R.H.da \& M.D. Ezcurra. 2019. A new desert-dwelling dinosaur (Theropoda, Noasaurinae) from the Cretaceous of south Brazil. Scientific Reports 9(1): 9379.

Lapparent de Broin, F. \& M.S. de la Fuente. 2001. Oldest world Chelidae (Chelonii, Pleurodira) from the Cretaceous of Patagonia. Comptes Rendus Academie des Sciences 333: 463-470.

Lapparent de Broin, F. 2003. Miocene chelonians from southern Namibia. Memoir of the Geological Survey of Namibia 19:67-102.

Leanza, H. A., Apesteguia, S., Novas, F. E., \& M.S. de la Fuente. 2004. Cretaceous terrestrial beds from the Neuquén Basin (Argentina) and their tetrapod assemblages. Cretaceous Research 25(1): 61-87.

Leppe, M., Mihoc, M., Varela, N., Stinnesbeck, W., Mansilla, H., Bierma, H., Cisterna, K., Frey, E. \& T. Jujihara. 2012. Evolution of the Austral-Antarctic flora during the Cretaceous: New insights from a paleobiogeographic perspective. Revista Chilena de Historia Natural 85(4): 369-392.

Leppe, M, Stinnesbeck, W, Frey, H, Mansilla, H., Vogt, M., Gonzalez, E, Manriquez, L., Cisternas, K, Mihoc, M. \& T. Jujihara. 2014. Late Cretaceous terrestrial biota from Las Chinas-Cerro Guido complex, Magallanes Region, southern Chile: a key area for the Antarctic-South American biogeography. 23rd Latin American Colloquium on Earth Sciences, Abstracts: p. 101.

Lindgren, J. 2005. The first record of Hainosaurus (reptilia: mosasauridae) from Sweden. Journal of Paleontology 79(6): 1157-1165.

Lindgren, J., \& M. Siverson 2002. Tylosaurus ivoensis: a giant mosasaur from the early Campanian of Sweden. Earth and Environmental Science Transactions of the Royal Society of Edinburgh 93(1): 73-93.

Lindgren, J. \& M. Siverson. 2004. The first record of the mosasaur Clidastes from Europe and its palaeogeographical implications. Acta Palaeontologica Polonica 49(2): 219-234.

Longrich, N.R. 2009. An ornithurine-dominated avifauna from the Belly River Group (Campanian, Upper Cretaceous) of Alberta, Canada. Cretaceous Research 30(1): 161-177.

Longrich, N.R., Tokaryk, T. \& D.J. Field. 2011. Mass extinction of birds at the Cretaceous-Paleogene
(K-Pg) boundary. Proceedings of the National Academy of Sciences 108(37): 15253-15257.

Luo, Z.X. \& J.R. Wible. 2005. A Late Jurassic digging mammal and early mammalian diversification. Science 308(5718): 103-107.

Luo, Z. X., Chen, P., Li, G., \& M. Chen. 2007. A new eutriconodont mammal and evolutionary development in early mammals. Nature 446(7133): 288 293.

Macellari, C.E., Barrio, C.A. y M. Manassero. 1989. Upper Cretaceous to Paleocene depositional sequences and sandstone petrography of southwestern Patagonia (Argentina and Chile). Journal of South American Earth Sciences 2(3): 223-239.

Macellari, C.E. 1988. Cretaceous paleogeography and depositional cycles of western South America. Journal of South American Earth Sciences 1(4): $373-418$

Madsen Jr, J.H. 1976. Allosaurus fragilis: a revised osteology. Bulletin of the Utah Geological and Mining Survey 109: 1-163.

Makovicky, P.J., Apesteguía, S. \& F.L. Agnolin. 2005 The earliest dromaeosaurid theropod from South America. Nature 437: 1007-1011.

Malumian, N. \& C. Nanez. 2011. The Late CretaceousCenozoic transgressions in Patagonia and the Fuegian Andes: foraminifera, palaeoecology, and palaeogeography. Biological Journal of the Linnean Society 103(2): 269-288.

Mannion, P.D. \& J.O. Calvo. 2011. Anatomy of the basal titanosaur (Dinosauria, Sauropoda) Andesaurus delgadoi from the mid-Cretaceous (Albian-early Cenomanian) Río Limay Formation, Neuquén Province, Argentina: implications for titanosaur systematics. Zoological Journal of the Linnean Society 163(1): 155-181.

Mannion, P.D. \& A. Otero. 2012. A reappraisal of the Late Cretaceous Argentinean sauropod dinosaur Argyrosaurus superbus, with a description of a new titanosaur genus. Journal of Vertebrate Paleontology 32(3): 614-638.

Mannion, P.D., Upchurch, P., Barnes, R.N. \& Mateus, O. 2013. Osteology of the Late Jurassic Portuguese sauropod dinosaur Lusotitan atalaiensis (Macronaria) and the evolutionary history of basal titanosauriforms. Zoological Journal of the Linnean Society 168(1): 98-206

Manríquez, L. M., Lavina, E.L., Fernández, R.A., Trevisan, C. \& M.A. Leppe. 2019. CampanianMaastrichtian and Eocene stratigraphic architecture, facies analysis, and paleoenvironmental evolution of the northern Magallanes Basin (Chilean Patagonia). Journal of South American Earth Sciences 93: 102-118.

Marenssi, S., Guler, V., Casadío, S., Guerstein, R. \& O. Papú, 2004. Sedimentology and palynology of Calafate Formation (Maastrichtian), Austral Basin, Southern Patagonia, Argentina. Cretaceus Research 25: 907-918.

Martin, J.E. 2006. Biostratigraphy of the Mosasauridae (Reptilia) from the Cretaceous of Antarctica. Geological Society of London, Special Publications 
258(1): 101-108.

Martin, J.E. \& J.A. Crame. 2006. Palaeobiological significance of high-latitude Late Cretaceous vertebrate fossils from the James Ross Basin, Antarctica. Geological Society of London, Special Publications 258(1): 109-124.

Martin, J.E. \& M. Fernández. 2007. The synonymy of the Late Cretaceous mosasaur (Squamata) genus Lakumasaurus from Antarctica with Taniwhasaurus from New Zealand and its bearing upon faunal similarity within the Weddellian Province. Geological Journal 42(2): 203-211.

Martinelli, A.G. \& A.M. Forasiepi. 2004. Late Cretaceous vertebrates from Bajo de Santa Rosa (Allen Formation), Río Negro province, Argentina, with the description of a new sauropod dinosaur (Titanosauridae). Revista del Museo Argentino de Ciencias Naturales n. s. 6: 257-305.

Martinelli, A.G., Garrido, A.C., Forasiepi, A.M., Paz, E.R. \& Y. Gurovich, 2007. Notes on fossil remains from the Early Cretaceous Lohan Cura Formation, Neuquén Province Argentina. Gondwana Research 11:537-552.

Martinelli, A.G., Riff, D. \& R.P. Lopes. 2011. Discussion about the occurrence of the genus Aeolosaurus Powell 1987 (Dinosauria, Titanosauria) in the Upper Cretaceous of Brazil. GAEA, Journal of Geoscience 7(1): 34-40.

Martinelli, A.G., Bogan, S., Agnolin, F.L., Ribeiro, L.C.B., Cavellani, C.L., Ferraz, M.L.F. \& V.P.A. Teixeira. 2013. First fossil record of amiid fishes (Halecomorphi, Amiiformes, Amiidae) from the Late Cretaceous of Uberaba, Minas Gerais, Brazil. Alcheringa 37: 105-113.

Martinelli, A.G., Marinho, T.S., Brisson Egli, F., Hechenleitner, E.M., Iori, F.V., Veiga, F.H., Basilici, G., Soares, M.V.T., Marconato, A. \& L.C.B. Ribeiro. 2019. Noasaurid theropod (Abelisauria) femur from the Upper Cretaceous Bauru Group in Triângulo Mineiro (Southeastern Brazil). Cretaceous Research 104: 104-181.

Martínez, R.D. 1998. Notohypsilophodon comodorensis gen. et sp. nov. Un Hypsilophodontidae (Ornithischia; Ornithopoda) del Cretácico Superior de Chubut, Patagonia central. Acta Geologica Leopoldensia 46(47): 119-135.

Martínez, R.D., Giménez, O., Rodríguez, J., Luna, M. \& M.C. Lamanna. 2004. An articulated specimen of the basal titanosaurian (Dinosauria: Sauropoda) Epachthosaurus sciuttoi from the early Late Cretaceous Bajo Barreal Formation of Chubut province, Argentina. Journal of vertebrate Paleontology 24(1): 107-120.

Mayr, G. \& R. Smith. 2001. Ducks, rails, and limicoline waders (Aves: Anseriformes, Gruiformes, Charadriiformes) from the lowermost Oligocene of Belgium. Geobios 34: 547-562.

McLachlan, S.M., Kaiser, G.W. \& N.R. Longrich. 2017. Maaqwi cascadensis: A large, marine diving bird (Avialae: Ornithurae) from the Upper Cretaceous of British Columbia, Canada. PLoS One 12: e0189473.
Melchor, R.N., Genise, J.F. \& S.E. Miquel. 2002. Ichnology, sedimentology and paleontology of Eocene calcareous paleosols from a palustrine sequence, Argentina. Palaios, 17(1): 16-35.

Méndez, A.H., Novas, F.E. \& F.V. Iori, 2012. First record of Megaraptora (Theropoda, Neovenatoridae) from Brazil. Comptes Rendus Palevol 11: 251-256.

Meng, Q. J., Ji, Q., Zhang, Y.G., Liu, D., Grossnickle, D.M. \& Z.-X. Luo. 2015. An arboreal docodont from the Jurassic and mammaliaform ecological diversification. Science 347(6223): 764-768.

Mezzalira, S. 1974. Contribuição ao conhecimento da estratigrafia e paleontologia do Arenito Bauru. Boletim do Instituto Geográfico e Geológico 51:1163.

Miquel, S.E. 1995. Las especies del género Bostryx Troschel 1847 (Gast. Stylom. Bulimulidae) en la República Argentina (segunda y última parte). Archiv für Molluskenkunde 124 (1/2): 119-127.

Miquel, S.E. 1998. Una nueva especie de Potamolithus de la Patagonia (Gastr. Prosob. Hydrobiidae). Biociências, Porto Alegre 6(1): 145-157.

Miquel, S.E. \& F.F. Brito. In press. New genera and species of fossil continental gastropods of Formación Chorrillo (Maastrichtiano, late Cretacous) from Santa Cruz province, Argentina.

Mikhailov, K.E. 1997. Fossil and recent eggshells in amniotic vertebrates: fine structure, comparative morphology and classification. The palaeontological association. Special papers in Palaeontology 56: $1-80$

Mohabey, D.M., Head, J.J. \& J.A. Wilson. 2011. A new species of the snake Madtsoia from the Upper Cretaceous of India and its paleobiogeographic implications. Journal of Vertebrate Paleontology 31:588-595.

Molnar, R.E. \& P.M. Galton. 1986. Hypsilophodontid dinosaurs from Lightning Ridge, Nueva Gales del Sur, Australia. Geobios 19: 231-239.

Motta, M.J., Aranciaga Rolando, A.M., Rozadilla, S., Agnolín, F.E., Chimento, N.R., Brissón Egli, F., \& F.E. Novas. 2016. New theropod fauna from the Upper Cretaceous (Huincul Formation) of northwestern Patagonia, Argentina. Bulletin of the New Mexico Museum of Natural History and Science 7: 231-253.

Moyano Paz D., Tettamanti, C., Varela, A.N., Cereceda, A. \& D.G. Poiré. 2018. Depositional processes and stratigraphic evolution of the Campanian deltaic system of La Anita Formation, Austral-Magallanes Basin, Patagonia, Argentina. Latin American Journal of Sedimentology and Basin Analysis 25(2): 69-92.

Muizon, C.de, Billet, G., Argot, C., Ladevèze, S. \& F. Goussard. 2015. Alcidedorbignya inopinata, a basal pantodont (Placentalia, Mammalia) from the early Palaeocene of Bolivia: anatomy, phylogeny and palaeobiology. Geodiversitas 37(4): 397-634.

Muzzopappa, P. \& A.M. Báez. 2009. Systematic status of the mid- Tertiary neobatrachian frog Calyptocephalella canqueli from Patagonia (Argentina), with comments on the evolution of the 
genus. Ameghiniana 46: 113-125.

Navarrete, C., Casal, G. \& R. Martínez. 2011. Drusilasaura deseadensis gen. et sp. nov., un nuevo titanosaurio (Dinosauria-Sauropoda), de la Formación Bajo Barreal, Cretácico Superior del norte de Santa Cruz, Argentina. Revista Brasileira de Paleontologia 14(1): 1-14.

Nessov, A., Zhegallo, V.I. \& A.O. Averianov. 1998. A new locality of Late Cretaceous snakes, mammals and other vertebrates in Africa (western Libya). Annales de Paléontologie 84(3-4): 265-274.

Norell, M.A. \& P.J. Makovicky. 1999. Important features of the dromaeosaur skeleton II: information from newly collected specimens of Velociraptor mongoliensis. American Museum Novitates 3282: $1-45$.

Norman, D.B. 2004. Basal Iguanodontia. In: D.B. Weishampel, P. Dodson \& H. Osmólska (eds.), The Dinosauria, Second Edition, pp. 413-437, University of California Press, Berkeley.

Norman, D. B. Sues, H. D. Witmer, L. M. \& R.A. Coria. 2004. Basal Ornithopoda, In: D.B. Weishampel, P. Dodson, H. Osmólska (eds.), The Dinosauria, Second Edition. University of California Press, Berkeley pp. 393-412.

Novas, F.E. 1998. Megaraptor namunhuaiquii gen. et. sp. nov., a large-clawed, Late Cretaceous Theropod from Argentina. Journal of Vertebrate Paleontology 18: 4-9.

Novas, F. E., Fernández, M., de Gasparini, Z. B., Lirio, J.M., Nuñez, H.J. \& P. Puerta. 2002. Lakumasaurus antarcticus, n. gen. et sp., a new mosasaur (Reptilia, Squamata) from the Upper Cretaceous of Antarctica. Ameghiniana 39(2): 245-249.

Novas, F.E. \& D. Pol. 2005. New evidence on deinonychosaurian dinosaurs from the Late Cretaceous of Patagonia. Nature 433(7028): 858-861.

Novas, F.E. \& S. Bandyopadhyay. 2001. Abelisaurid pedal unguals from the Late Cretaceous of India. APA, Special Publication 7: 145-149.

Novas, F.E., Agnolin, F.L. \& S. Bandyopadhyay. 2004. Cretaceous theropods from India: a review of specimens described by Huene and Matley (1933). Revista del Museo Argentino de Ciencias Naturales, nueva serie 6: 67-103.

Novas, F., Cambiaso, A. \& A. Ambrosio. 2004. A new basal iguanodontian (Dinosauria, Ornithischia) from the Upper Cretaceous of Patagonia. Ameghiniana 41: 75-82.

Novas, F.E., Ezcurra, M.D. \& A. Lecuona. 2008. Orkoraptor burkei nov.gen. et sp., a large theropod from the Maastrichtian Pari Aike Formation, Southern Patagonia, Argentina. Cretaceous Research 29: 468-480.

Novas, F.E., Martínez, R.D., De Valais, S. \& A. Ambrosio. 1999. Nuevos registros de Carcharodontosauridae (Dinosauria, Theropoda) en el Cretácico de Patagonia. Ameghiniana 36(4): 17.

Novas, F.E., Agnolin, F.L., Ezcurra, M.D., Porfiri, J. \& J.I. Canale. 2013. Evolution of the carnivorous dinosaurs during the Cretaceous: the evidence from Patagonia. Cretaceous Research 45: 174-215.
Novas, F.E., Pol, D., Canale, J.I., Porfiri, J.D. \& J.O. Calvo. 2009. A bizarre Cretaceous theropod dinosaur from Patagonia and the evolution of Gondwanan dromaeosaurids. Proceedings of the Royal Society B: Biological Sciences 276(1659): 1101-1107.

Nullo, F., Blasco, G., RISSO, C., Combina, A. \& J. Otamendi. 2006. Hoja Geológica 5172-I y 5175- II, El Calafate, provincia de Santa Cruz. Instituto de Geología y Recursos Minerales, Servicio Geológico Minero Argentino, Boletín 396: 86 pp.

Odino Barreto, A.L., Cerecera, A., Gómez-Peral, L.E., Coronel, M.D., Tettamanti, C. \& D.G. Poiré. 2018. Sedimentology of the shallow marine deposits of the Calafate Formation during the Maastrichtian transgression at Lago Argentino, AustralMagallanes Basin, Argentina. Latin American Journal of Sedimentology and Basin Analysis 25(2): 169-191.

Ösi, A., Prondvai, E., Butler, R. \& D.B. Weishampel. 2012. Phylogeny, histology and inferred body size evolution in a new rhabdodontid dinosaur from the Late Cretaceous of Hungary. PLoS One 7(9): e44318.

Ostrom, J.H. 1969. Osteology of Deinonychus antirrhopus, an unusual theropod from the Lower Cretaceous of Montana. Bulletin of the Peabody Museum of Natural History 30(1): e165.

Otero, A. 2010. The appendicular skeleton of Neuquensaurus, a Late Cretaceous saltasaurine sauropod from Patagonia, Argentina. Acta Palaeontologica Polonica 55(3): 399-426.

Otero R.A., Jimenez-Huidobro, P., Soto-Acuña, S. \& R.E. Yury-Yáñez. 2014. Evidence of a giant helmeted frog (Australobatrachia, Calyptocephalellidae) from Eocene levels of the Magallanes Basin, southernmost Chile. Journal of South American Earth Sciences 55: 133-140.

Otero, R.A., Soto-Acuña, S., Rubilar-Rogers, D. \& C.S. Gutstein. 2017. Kaikaifilu hervei gen. et sp. nov., a new large mosasaur (Squamata, Mosasauridae) from the upper Maastrichtian of Antarctica. Cretaceous Research 70: 209-225.

Pan, H.Z. 1977. Mesozoic and Cenozoic fossil Gastropoda from Yunnan. Mesozoic Fossils from Yunnan 2: 83-152.

Parodiz, J.J. 1961. New and little known Physa from the Paleocene of Patagonia. Annals of the Carnegie Museum 36(1): 1-4.

Parodiz, J.J. 1969. The Tertiary Non-marine Mollusca of South America. Annals of the Carnegie Museum 40: $1-242$

Philippe, M. \& M.K. Bamford. 2008. A key to morphogenera used for Mesozoic conifer-like woods. Review of Palaeobotany and Palynology 148(2-4): 184-207.

Philippe, M., Thévenard, F., Nosova, N., Kim, K. \& S. Naugolnykh. 2013. Systematics of a palaeoecologically significant boreal Mesozoic fossil wood genus, Xenoxylon, Gothan. Review of Palaeobotany and Palynology 193: 128-140.

Poole, I., Hunt, R.J. \& D.J. Cantrill. 2001. A fossil wood 
flora from King George Island: ecological implications for an Antarctic Eocene vegetation. Annals of Botany 88: 33-54.

Porfiri, J.D., Juarez Valieri, R.D., Santos, D.D.D. \& M.C. Lamanna. 2018. A new megaraptoran theropod dinosaur from the Upper Cretaceous Bajo de la Carpa Formation of northwestern Patagonia. Cretaceous Research 89: 302-319.

Porfiri, J.D., Novas, F.E., Calvo, J.O., Agnolin, F.L., Ezcurra, M.D. \& I.A. Cerda. 2014. Juvenile specimen of Megaraptor (Dinosauria, Theropoda) sheds light about tyrannosauroid radiation. Cretaceous Research 51: 35-55.

Poropat, S. F., Mannion, P.D., Upchurch, P., Hocknull, S.A., Kear, B.P. \& D.A. Elliott. 2015. Reassessment of the non-Titanosaurian somphospondylan Wintonotitan wattsi (Dinosauria: Sauropoda: Titanosauriformes) from the mid-C retaceous Winton Formation, Queensland, Australia. Papers in Palaeontology 1(1): 59-106.

Poropat, S.F., White, M.A., Vickers-Rich, P. \& T.H. Rich. 2019. New megaraptorid (Dinosauria: Theropoda) remains from the Lower Cretaceous Eumeralla Formation of Cape Otway, Victoria, Australia. Journal of Vertebrate Paleontology e1666273.

Povilauskas, L. 2011. Palinología de la Formación Monte Chico (Cretácico tardío) de la provincia de Santa Cruz, Argentina: esporas. Revista Brasileira de Paleontologia 14(1): 85-94.

Povilauskas, L., 2012. Palinología de la Formación Monte Chico (Cretácico tardío) de la provincia de Santa Cruz, Argentina: gimnospermas. Revista Brasileira de Paleontologia 15(1): 85-94.

Povilauskas, L. 2013. Palinología de angiospermas de la Formación Monte Chico (Cretácico tardío) de la provincia de Santa Cruz, Argentina. Revista Brasileira de Paleontologia 16(1): 115-126.

Povilauskas, L. 2016. Estudio palinológico de la Formación Cerro Cazador (Cretácico tardío) de la provincia de Santa Cruz, Argentina. Revista Brasileira de Paleontologia 19(1): 71-84.

Povilauskas, L. 2017. Palynostratigraphy of the Cretaceous-Paleogene in the Austral Basin, SW Santa Cruz province, Argentina. Revista Brasileira de Paleontologia 20(3): 299-320.

Povilauskas, L., Barreda, V. \& S. Marenssi. 2008. Polen y esporas de la Formación La Irene (Maastrichtiano), sudoeste de la provincia de Santa Cruz, Argentina: primeros resultados. Geobios 41: 819-831.

Powell, J.E. 2003. Revision of South American titanosaurid dinosaurs: palaeobiological, palaeobio-geographical and phylogenetic aspects. Records of the Queen Victoria Museum 111: 1-173.

Previtera, E. \& B.J. González Riga. 2008. Vertebrados cretácicos de la Formación Loncoche en Calmu-Co, Mendoza, Argentina. Ameghiniana 45(2): 349-359.

Pritchard, A. C., McCartney, J.A., Krause, D.W. \& N.J. Kley. 2014. New snakes from the Upper Cretaceous (Maastrichtian) Maevarano Formation, Mahajanga Basin, Madagascar. Journal of Vertebrate Paleontology 34: 1080-1093.

Pujana, R.R. \& D.P. Ruiz. 2017. Podocarpoxylon Gothan reviewed in the light of a new species from the Eocene of Patagonia. IAWA Journal 38: 220-244.

Pujana, R.R., Santillana, S.N. \& S.A. Marenssi. 2014. Conifer fossil woods from the La Meseta Formation (Eocene of Western Antarctica): Evidence of Podocarpaceae-dominated forests. Review of Palaeobotany and Palynology 200: 199-204.

Pujana, R.R., Ruiz, D.P., Martínez, L.C.A. \& Y. Zhang. 2016. Proposals for quantifying two characteristics of tracheid pit arrangement in gymnosperm woods. Revista del Museo Argentino de Ciencias Naturales, nueva serie 18: 117-124.

Quattrocchio, M. \& L. Ruiz. 1999. Paleoambiente de la Formación Pedro Luro (Maastrichtiano?Paleoceno) en base a palinomorfos, cuenca del Colorado, Argentina. Ameghiniana 36(1): 37-47.

Rage, J.C. 1984. Encyclopedia of Paleoherpetology, Part 11, Serpentesx. Gustav Fischer Verlag, Stuttgart, $80 \mathrm{pp}$.

Rage, J.C. 1998. Fossil snakes from the Paleocene of São José de Itaboraí. Brazil. Part I, Madtsoiidae, Aniliidae. Palaeovertebrata 27: 109-144.

Rage, J.C. 2013. Fossil snakes from the Paleocene of São José de Itaboraí. Brazil. Part III. Ungaliophiinae, booids incertae sedis, and caenophidia. Summary, update, and discussion of the snake fauna from the Locality. Palaeovertebrata 36(1-4): 37-73.

Rage J.C. \& C. Werner. 1999. Mid-Cretaceous (Cenomanian) snakes fromWadi Abu Hashim, Sudan: the earliest snake assemblage. Palaeontologia Africana 35: 85-110.

Rauhut, O.W.M. \& Werner, C. 1995. First record of the family Dromaeosauridae (Dinosauria: Theropoda) in the Cretaceous of Gondwana (Wadi Milk Formation, northern Sudan). Paläontologische Zeitschrift 69: 475-489.

Rio J. P. \& P.D. Mannion. 2017. The osteology of the giant snake Gigantophis garstini from the upper Eocene of North Africa and its bearing on the phylogenetic relationships and biogeography of Madtsoiidae. Journal of Vertebrate Paleontology 37(4): e1347179.

Roberts, L. N. R., \& M.A. Kirschbaum. 1995. Paleogeography and the Late Cretaceous of the Western Interior of middle North America; coal distribution and sediment accumulation. U.S. Geological Survey Professional Paper 1561: 1-115.

Rose, K.D., Emry, R.J. \& P.D. Gingerich. 1992. Skeleton of Alocodontulum atopum, an early Eocene epoicotheriid (Mammalia, Palaeanodonta) from the Bighorn basin, Wyoming. Contributions from the Museum of Paleontology, University of Michigan, 28(10): 221-245.

Rose, P. 2007. A new titanosauriform sauropod (Dinosauria: Saurischia) from the Early Cretaceous of Central Texas and its phylogenetic relationships. Palaeontologia Electronica 10: 1-65.

Rougier, G.W.1993.Vincelestesneuquenianus Bonaparte (Mammalia, Theria), un primitivo mamífero del Cretácico inferior de la Cuenca Neuquina. Doctoral dissertation, Universidad Nacional de Buenos Aires. 
Rougier, G.W., Forasiepi, A.M., Hill, R.V. \& Novacek, M. 2009a. New mammalian remains from the Late Cretaceous La Colonia Formation, Patagonia, Argentina. Acta Palaeontologica Polonica 54(2): 195-213.

Rougier, G. W., Chornogubsky, L., Casadio, S., Arango, N.P. \& Giallombardo, A. 2009b. Mammals from the Allen Formation, Late Cretaceous, Argentina. Cretaceous Research 30(1): 223-238.

Rougier, G. W., Apesteguía, S. \& L.C. Gaetano. 2011. Highly specialized mammalian skulls from the Late Cretaceous of South America. Nature 479(7371): 98-102.

Rozadilla, S., Agnolin, F.L. \& F.E. Novas. 2019. Osteology of the Patagonian ornithopod Talenkauen santacrucencis (Dinosauria, Ornithischia). Journal of Systematic Palaeontology 17(24): 2043-2089.

Rozadilla, S., Agnolin, F.L., Novas, F.E., Aranciaga Rolando, A.M., Motta, M.J., Lirio, J.M. \& M.P. Isasi. 2016. A new ornithopod (Dinosauria, Ornithischia) from the Upper Cretaceous of Antarctica and its palaeobiogeographical implicances. Cretaceous Research 57: 311-324.

Salgado, L. 1996. Pellegrinisaurus powelli nov. gen. et sp. (Sauropoda, Titanosauridae) from the Upper Cretaceous of lago Pellegrini, northwestem Patagonia, Argentina. Ameghiniana 33(4): 355365.

Salgado, L. \& C. Azpilicueta. 2000. Un nuevo saltasaurino (Sauropoda, Titanosauridae) de la provincia de Río Negro (Formación Allen, Cretácico Superior), Patagonia, Argentina. Ameghiniana 37(3): 259264.

Salgado, L. \& Carvalho, I. D. 2008. Uberabatitan ribeiroi, a new titanosaur from the Marilia formation (Bauru group, upper Cretaceous), Minas Gerais, Brazil. Palaeontology 51: 881-901.

Salgado, L. \& García, R. 2002. Morphological variation in the sequence of caudal vertebrae of some titanosaur sauropods. Revista Española de Paleontologia 17(2): 21

Salgado, L., Coria, R.A. \& S.E. Heredia. 1997. New materials of Gasparinisaura cincosaltensis (Ornithischia, Ornithopoda) from the Upper Cretaceous of Argentina. Journal of Paleontology 71(5): 933-940.

Salgado, L., Apesteguía, S. \& S.E. Heredia. 2005. A new specimen of Neuquensaurus australis, a Late Cretaceous saltasaurine titanosaur from north Patagonia. Journal of vertebrate Paleontology 25(3): 623-634.

Salgado, L., Garrido, A., Cocca, S.E. \& J.R. Cocca. 2004. Lower Cretaceous rebbachisaurid sauropods from Cerro Aguada del León (Lohan Cura Formation), Neuquén Province, northwestern Patagonia, Argentina. Journal of Vertebrate Paleontology 24(4): 903-912.

Salvador, R.B., Cabrera, F., Martínez, S., Miquel, S.E., Simone, L.R.L. \& C.M. Cunha. 2018. Annotated catalogue of the fossil Hygrophila and Eupulmonata (Mollusca: Gastropoda) from South America (Cretaceous - Neogene). Neues Jahrbuch für Geologie und Paläontologie - Abhandlungen 289(3): 249-280.

Sampson, S.D., Carrano, M.T. \& C.A. Forster. 2001. A theropod dinosaur with bizarre dentition from the Late Cretaceous of Madagascar. Nature 409: 504506.

Santucci, R.M. \& A.C. de Arruda-Campos. 2011. A new sauropod (Macronaria, Titanosauria) from the Adamantina Formation, Bauru Group, Upper Cretaceous of Brazil and the phylogenetic relationships of Aeolosaurini. Zootaxa 3085:1-33.

Scanlon, J.D. 1997. Nanowana gen. nov., small madtsoiid snakes from the Miocene of Riversleigh: sympatric species with divergently specialised dentition. Memoirs of the Queensland Museum 41: 393-412.

Scanlon, J.D. 2006. Skull of the large non-macrostomatan snake Yurlunggur from the Australian OligoMiocene. Nature 439: 839-842.

Schileyko, A.A. 1999. Treatise on recent terrestrial pulmonate mollusks. Ruthenica 2(4): 437-564.

Schulp, A.S., Jagt, J.W. \& F. Fonken. 2004. New material of the mosasaur Carinodens belgicus from the Upper Cretaceous of The Netherlands. Journal of Vertebrate Paleontology 24(3): 744-747.

Sereno, P.C. 1986. Phylogeny of the bird-hipped dinosaurs (Order Ornithischia). National Geographic Research 2: 234-256.

Sereno, P.C. \& S.L. Brusatte. 2008. Basal abelisaurid and carcharodontosaurid theropods from the Lower Cretaceous Elrhaz Formation of Niger. Acta Palaeontologica Polonica 53(1): 15-46.

Sereno, P.C., Martínez, R.N., Wilson, J.A., Varricchio, D.J. \& O.A. Alcober. 2008. Evidence for avian intrathoracic air sacs in a new predatory dinosaur from Argentina. PLoS One 3: e3303.

Sickmann, Z. T., Schwartz, T.M. \& S.A. Graham. 2018. Refining stratigraphy and tectonic history using detrital zircon maximum depositional age: an example from the Cerro Fortaleza Formation, Austral Basin, southern Patagonia. Basin Research 30(4): 708-729.

Silva Junior, J.C.G., Marinho, T.S., Martinelli, A.G. \& M.C. Langer. 2019. Osteology and systematics of Uberabatitan ribeiroi (Dinosauria; Sauropoda): a Late Cretaceous titanosaur from Minas Gerais, Brazil. Zootaxa 4577(3): 401-438

Simón, M.E. 2006. Cáscaras de huevos de dinosaurios de la Formación Allen (Campaniano-Maastrichtiano), en Salitral Moreno, provincia de Río Negro, Argentina. Ameghiniana 43(3): 513-528.

Simone, L.R.L. 2006. Land and Freshwater Molluscs of Brazil. Editorial EGB, Fapesp, São Paulo, 390 pp.

Simone, L.R.L. \& S. Mezzalira. 1994. Fossil Molluscs of Brazil. Boletim do Instituto Geológico 11:1-202.

Simpson, G.G. 1933. A new fossil snake from the Notostylops beds of Patagonia. Bulletin of the American Museum of Natural History 67: 1-22.

Smith, J. B., Lamanna, M.C., Lacovara, K.J., Dodson, P., Smith, J.R., Poole, J.C. \& Attia, Y. 2001. A giant sauropod dinosaur from an Upper Cretaceous mangrove deposit in Egypt. Science 292(5522): 17041706 . 
Solem, A. 1979. Biogeographic Significance of Land Snails, Paleozoic to Recent. In: Historical Biogeography, Plate Tectonics, and the Changing Environment, pp. 277-287, Oregon State University Press, Corvallis.

Solem, A. 1981. Land-Snail Biogeography: A True Snails's Pace of Chage. In: Vicariance Biogeography, pp. 197-237, Columbia University Press, New York.

Soto-Acuña, S. Jujihara, T., Novas, F.E., Leppe, M, González, E., Stinnesbeck, W., Isasi, M.P., RubilarRogers, D. \& A.O. Vargas. 2014. Hadrosaurios (Ornithopoda: Hadrosauridae) en el Cretácico Superior del extremo austral de América del Sur. IV Simposio Paleontología en Chile, Universidad Austral de Chile, Resumenes: 73.

Soto-Acuña, S., Alarcón, J., Guevara, J.P., Fernández, R., González, E. Leppe, M. \& A.O. Vargas. 2016. Nuevos hallazgos de reptiles marinos en la Formación Dorotea (Maastrichtiano) en la Región de Magallanes, extremo austral de Chile. Ameghiniana Supplemento 53(6): R76.

Tambussi, C.P., Degrange, F.J., De Mendoza, R.S., Sferco, E. \& S. Santillana. 2019. A stem anseriform from the early Palaeocene of Antarctica provides new key evidence in the early evolution of waterfowl. Zoological Journal of the Linnean Society 20: $1-28$.

Taylor, D.W. 2003. Introduction to Physidae. Revista de Biología Tropical 51(1): 1-287.

Taylor, M.P. 2009. A re-evaluation of Brachiosaurus altithorax Riggs 1903 (Dinosauria, Sauropoda) and its generic separation from Giraffatitan brancai (Janensch 1914). Journal of Vertebrate Paleontology 29(3): 787-806.

Tennant, J. 2013. Osteology of a near-complete skeleton of Tenontosaurus tilletti (Dinosauria: Ornithopoda) from the Cloverly Formation, Montana, USA. Unpublished MSc thesis, University of Manchester, $195 \mathrm{pp}$.

Tettamanti C., Moyano Paz, D., Varela, A.N., Tineo, D.E., Gómez-Peral, L.E., Poiré, D.G., Cereceda, A. \& A.L. Odino Barreto. 2018. Sedimentology and fluvial styles of the Uppermost Cretaceous Continental Deposits of the Austral-Magallanes Basin, Patagonia, Argentina. Latin American Journal of Sedimentology and Basin Analysis 25(2): 149-168.

Thévenin, A. 1896. Mosasauriens de la Craie Grise de Vaux-Éclusier près Péronne (Somme). Bulletin de la Société Géologique de France, third mémoires série, 24: 900-916.

Tryon, R.M. \& A.F. Tryon. 1982. Ferns and allied plants. With special reference to tropical America. Springer-Verlag, New York, $857 \mathrm{pp}$.

Ullmann, P.V. \& K.J. Lacovara. 2016. Appendicular osteology of Dreadnoughtus schrani, a giant titanosaurian (Sauropoda, Titanosauria) from the Upper Cretaceous of Patagonia, Argentina. Journal of Vertebrate Paleontology 36(6): e1225303.

Upchurch, P., Barrett, P.M. \& P. Dodson. 2004. Sauropoda. En: D.B. Weishampel, P. Dodson \& H.
Osmólska (Eds.), The Dinosauria 2nd edition, p. 259-322, University California Press, Berkeley.

Vajda, V.\& A. Bercovici. 2014. The global vegetation pattern across the Cretaceous-Paleogene mass extinction interval: A template for other extinction events. Global and Planetary Change 122: 29-49.

Varela, A.N., Poiré, D.G., Martin, T., Gerdes, A., Goin, F. J., Gelfo, J. N., \& S. Hoffmann. 2012. U-Pb zircon constraints on the age of the Cretaceous Mata Amarilla Formation, Southern Patagonia, Argentina: its relationship with the evolution of the Austral Basin. Andean Geology 39(3): 359-379.

Vasile, S., Csiki-Sava, Z. \& M. Venczel. 2013. A new madtsoiid snake from the Upper Cretaceous of the Hateg Basin, western Romania. Journal of Vertebrate Paleontology 33: 1100-1119.

Vázquez-Molinero, R., Martin, T., Fischer, M.S. \& R. Frey. 2001. Comparative anatomical investigations of the postcranial skeleton of Henkelotherium guimarotae Krebs, 1991 (Eupantotheria, Mammalia) and their implications for its locomotion. Zoosystematics and Evolution 77(2): 207-216.

Vera, E.I., Perez Loinaze, V.S., Llorens, M. \& M. Passalia. 2019. Fossil woods with coniferalean affinities from the Upper Cretaceous (Campanian?Maastrichtian) Puntudo Chico Formation, Chubut Province, Argentina. Cretaceous Research 99: 321333.

Veroslavsky, G., Aubet, N., Martínez, S.A., Heaman, L.M., Cabrera, F. \& V. Mesa, 2019. Late Cretaceous stratigraphy of the southeastern Chaco - Paraná Basin ("Norte Basin"-Uruguay): the Maastrichtian age of the calcretization process. Geociências 38(2): 427-449.

Vogt, M., Leppe, M., Stinnesbeck, W., Jujihara, T., Mansilla, M., Ortiz, H., Manríquez, L. \& E. González. 2014. Depositional environment of Maastrichtian (Late Cretaceous) dinosaur-bearing deltaic deposits of the Dorotea Formation, Magallanes Basin, southern Chile. 23rd Latin American Colloquium on Earth Sciences, Abstracts: 156.

Volkheimer, W., \& D. Melendi. 1976. Palinomorfos como fósiles guía. Tercera parte: Técnicas de laboratorio palinológico. Revista Minera de Geología y Mineralogía, Sociedad Argentina de Minería, 34: 19-30.

Vuilleumier, F. 1968. Origin of frogs of Patagonian forests. Nature 219: 87-89.

Weishampel, D.B., Jianu, C.M., Csiki, Z. \& D.B. Norman. 2003. Osteology and phylogeny of Zalmoxes (ng), an unusual euornithopod dinosaur from the latest Cretaceous of Romania. Journal of Systematic Palaeontology 1(2): 65-123.

Wilson, J. 2002. Sauropod dinosaur phylogeny: critique and cladistic analysis. Zoological Journal of the Linnean Society 136: 217-276.

Wilson, J. P., Woodruff, D. C., Gardner, J. D., Flora, H. M., Horner, J.R. \& C. L. Organ. 2016. Vertebral adaptations to large body size in theropod dinosaurs. PloS one 11(7): e0158962.

WoRMS Editorial Board, 2019. World Register of Marine Species. Available from http://www.ma- 
rinespecies.org at VLIZ. Accessed 2019-06-21. doi: $10.14284 / 170$

Zaher, H., Apesteguía, S. \& C.A. Scanferla. 2009. The anatomy of the Upper Cretaceous snake Najash rionegrina Apesteguía \& Zaher, 2006, and the evolution of limblessness in snakes. Zoological Journal of the Linnean Society 156: 801-826.

Zhang, S. \& Q. Wang. 1994. Paleocene petrified wood on the west side of Collins Glacier in the King George Island, Antarctica. In: Stratigraphy and Palaeontology of Fildes Peninsula King George Island, Antarctica, pp. 223-238. Science Press, Beijing.

Zilch, A. 1959-60. Gastropoda Euthyneura. Handbuch der Paläozoologie. Borntraeger, Berlin, 834 pp.

Doi: 10.22179/REVMACN.21.655

Recibido: 20-IX-2019

Aceptado: 27-XI-2019 